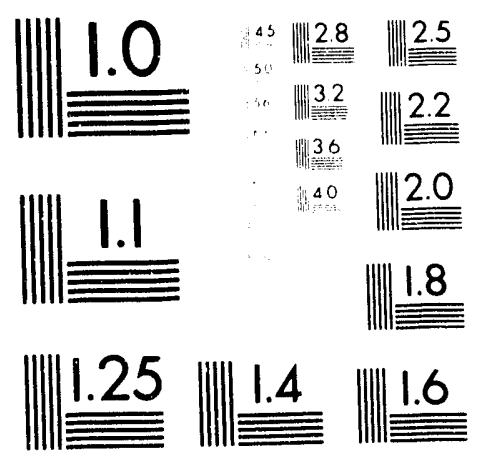



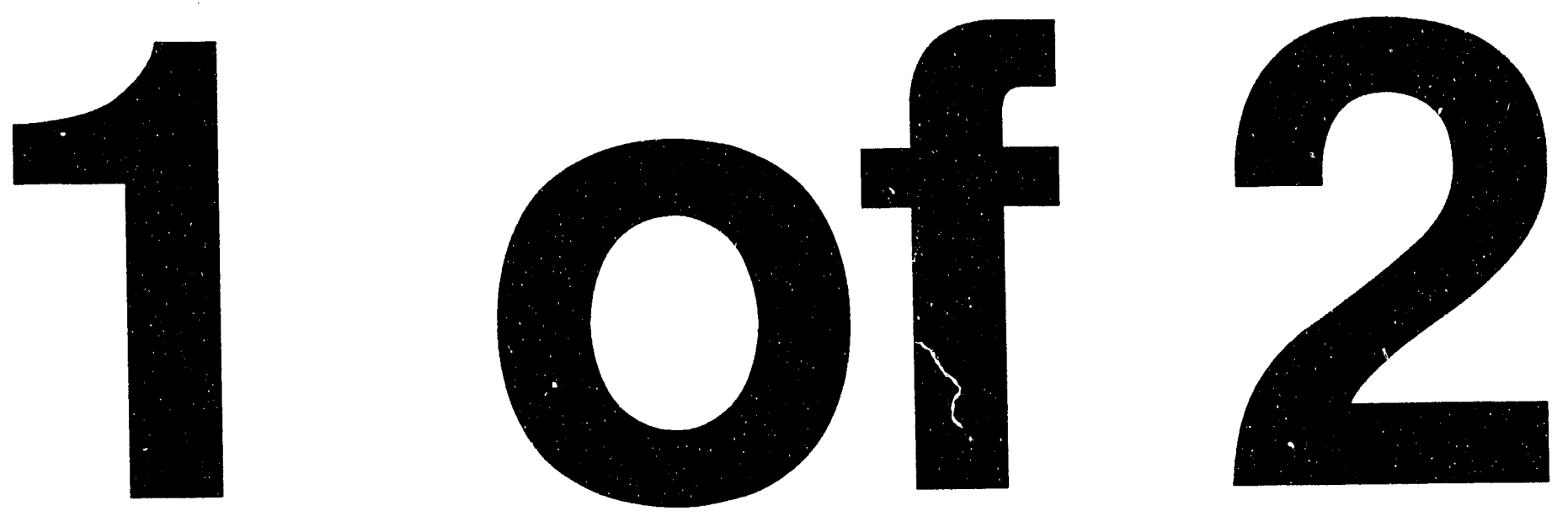


\section{GEOTECHNICAL FIELD DATA \\ AND ANALYSIS REPORT \\ Volume I of II}

July 1991 - june 1992

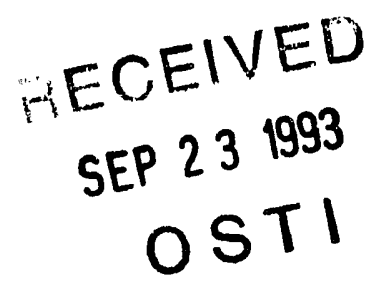

Printed 1993

Any comments or questions regarding this report should be directed to the U.S. Department of Energy WIPP Project Office

P.O. Box 3090

Carlsbad, NM 88221

or to the Manager,

Engineering

Westinghouse Electric Corporation

P.Q. Bux 2078

Carisuad, NM 88221

This document was prepared for the U.S. Department of Energy by the Engineering and Repository Technology Department of the Management and Operating Contractor, Waste Isolation Pilot Plant Project, under Cuntract No. DE-AC04-86AL31950.

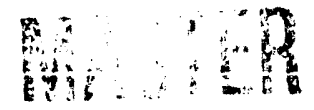




\title{
FOREWORD AND ACKNOWLEDGMENTS
}

This report provides an assessment of the geotechnical status of the Waste Isolation Pilot Plant (WIPP). During the construction of the principal underground access and experimental areas. reporting was on a quarterly basis. Since 1987, reporting has been carried out annually because additional excavations such as the waste storage panel, will take place gradually over an extended period. This report presents and analyzes data collected up to June 30. 1992.

The two-volume format of the Geotechnical Field Data and Analysis Report was selected to meet the needs of several audiences. Volume I focuses on the geotechnical performance of the various underground facilities including the shafts, shaft stations, access drifts, test rooms, and waste storage areas. The results of excavation effects investigations, stratigraphic mapping. and other geologic studies are also included. The report provides an evaluation of the geotechnical aspects of performance in the context of the relevant design criteria. The depth and breadth of the evaluation for the different underground facilities varies according to the types and quantities of data that are available, and the complexity of the resorded geotechnical responses.

Volume II constitutes the principal documentation or data. It also describes the techniques used to acquire the data and the performance history of the instruments. Data files will be made available at nominal cost upon request to the U.S. Department of Energy (DOE) at the following address:

\author{
U.S. Department of Energy \\ WIPP Project Office \\ P.O. Box 3090 \\ Carlsbad. NM 88221 \\ Attention: Arlen Hunt
}

The Geotechnical Field Data and Analysis Report is a multiple-author report that was prepared by Westinghouse Waste Isolation Division and its geotechnical subcontractor, IT Corporation, for the U.S. Department of Energy WIPP Project Office, Carlsbad, New Mexico. 
Section

Foreword and Acknowledgments

\section{Title}

Page

List of Tables

List of Figures

1.0 Introduction

1.1 Background.

1.1.1 Location and Description

1.1.2 Mission

1.1.3 Development Status

1.1.4 Geology

1.2 Purpose and Scope of Geomechanical Monitoring Program

1.3 Comparison of Geomechanical Performance with Design Criteria

2.0 Performance of Excavations

2.1 Analysis of Convergence Data

2.2 E140 Drift

2.3 Performance of Pariel 1 Waste Storage Rooms

2.3.1 Room 1 Supplementary Support System

2.4 Modeling Room Performance

2.4.1 FLAC

2.4.1.1 FLAC Modeling of WIPP Storage Rooms

2.4.1.2 SNL Second Benchmark (BMII) Problem $2-24$

2.4.1.3 Differences Between FLAC \& SNL BMII Guidelines . $2-24$

2.4.1.4 Modeling Parameters $2-26$

2.4.1.5 Results of the Comparison of FLAC to BMII $2-26$

2.4.1.6 Results of FLAC Roof Beam Deformation 2-36

2.4.1.7 Results of FLAC MB139 Behavior $2-36$

2.4.1.8 Results of FLAC Rockbolt Modeling 2-36

2.4 .2 VISCOT $2-38$

2.4.2.1 Munson-Dawson Model. $2-38$

2.4.2.2 Implementation of Munson-Dawson into VISJOINT 2-39

2.4.2.3 Modeling Parameters $2 \cdot 41$

2.4.2.4 VISJOINT Results $2-41$

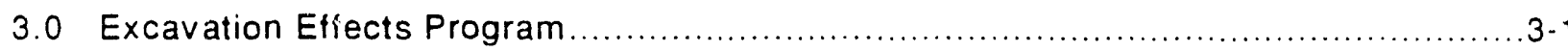

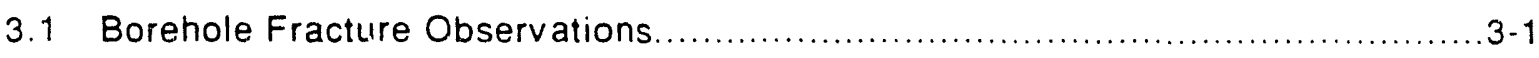

3.1.1 Interpretation of Fracture Observations ..................................... $3-7$

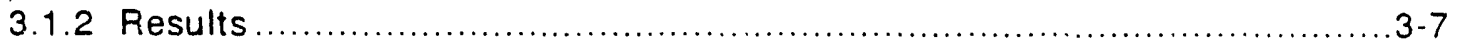


Table of Contents (continued)

Section

$\underline{\text { Title }}$

Page

3.2 Fracture Mapping of Excavation Surfaces ....................................... $3-46$

3.2.1 Waste Shaft Station ........................................................... 3.46

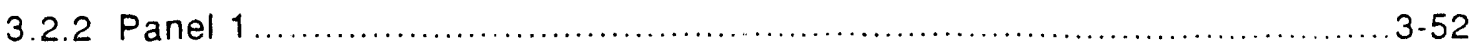

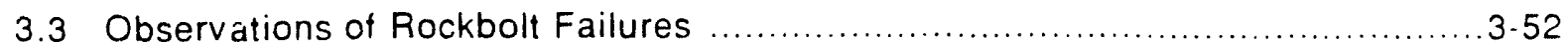

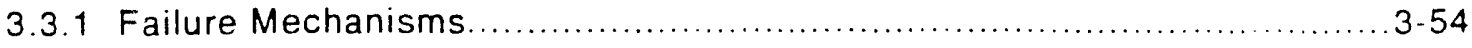

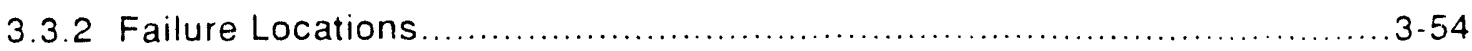

3.4 Summary of Excavation Effects Program ......................................... $3-56$

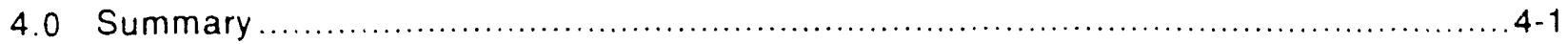

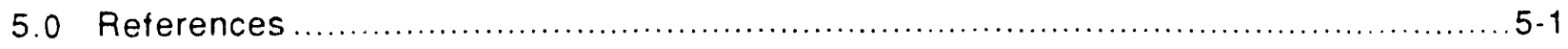

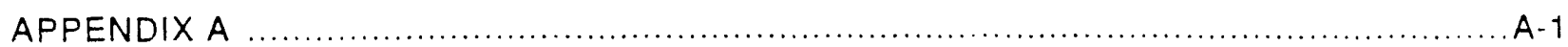


List of Tables

Table

Title

Page

$1-1$

Comparison of Excavation Performance to Design Criteria

$1-10$

$2-1$

Analyses of Underground Closure Rates

2-3

2-2a Mid-Room Roof to Floor Closure Rates

$2 \cdot 4$

2-2b Mid-Room Wall to Wall Closure Rates

$2-6$

2-3a Closure Rates by Time Since Excavation Vertical

Convergence Data

$2 \cdot 10$

2-3b Closure Rates by Time Since Excavation Horizontal

Convergence Data

2-11

3-1

Historical Summary of Excavation Effects

$3-2$

3-2 Cumulative Data from Excavation Effects Program

3-8

iv 
1-1 General Location of the WIPP Facility ....................................... 1-2

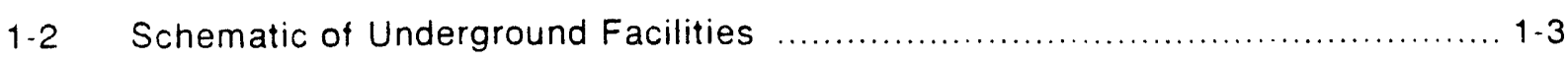

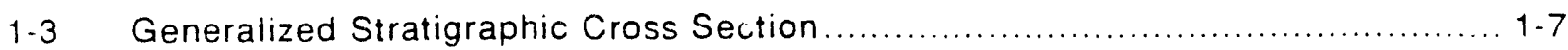

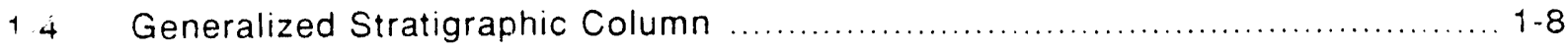

2.1 Schematic View of Room 1. Panel 1. Supplementary Roof Support System ............................................................. 2-13

2-2 Planview of Room 1. Panel 1, Supplementary Roof Support System ............................................................... 2-14

2-3 Roof Expansion Rates Room 1, Panel 1, North Extersomet .i ..................... 2-16

2.4 Roof Expansion Rates Room 1, Panel 1, Center Extenso:neter..................... 2-17

2.5 Roof Expansion Rates Room 1, Panel 1, South Extensometer..................... 2-18

2.6 Room 1 Rockbolt Load Grid .................................................. 2-20

2-7 Finite Difference Mesh for FLAC Storage Room Models.............................. 2-23

2-8 Stratigraphic Details of FLAC and Second Benchmark Problems ................... 2.25

2-9 Revised Vertical Closure Histories ior the Isothermal

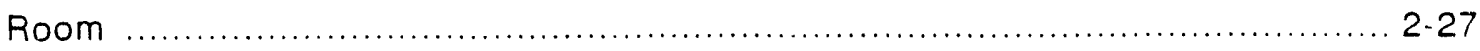

2-10 Revised Midpillar Horizontal Displacement Histories for the

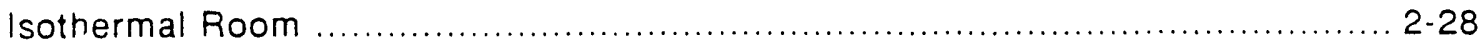

2-11 Revised Relative Slip Across the 650.20 meter Slide Line for the Isothermal Room at 1,2, and 10 Years

2-12 Revised Relative Slip Across the 661.02 meter Slide Line for the Isothermal Room at 1,2. and 10 Years

2-13 Revised Effective Stress Profiles through the Pillar for the Isothermal Room at 10 Years

2-14 Revised Effective Stress Profiles Along the Vertical Centerline of the Isothermal Room for 1, 2, and 10 Years

2-15 Revised Horizontal Stress Profile: Along the Vertical Centerline of the Isothermal Room for 1, 2, and 10 Years.

2-16 Revised Vertical Stress Profiles through the Pillar of the Isothermal Room at 10 Years 2-35

2-17 Comparison of Bolted and Unbolted FLAC Model Results......................... 2-37

2-18 Finite Element Mesh for VISJOINT Models ........................................... 2-40

2-19 Comparison of Model Results to Field Data ....................................... 2.42 


\section{List of Figures (continued)}

Figure

Title

Page

3-1 Borehole Locations for the Excavation Effects Program .......................... 3-6

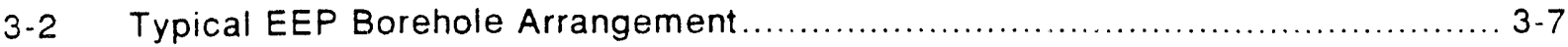

3-3 Excavation Effects Data, Array \#1 Site and Preliminary

Design Validation Room 4, N1175 ............................................ $3-10$

3-4 Excavation Effects Data, Array \#2 Site and Preliminary

Design Validation Room 4, N1264 ........................................... $3-11$

3-5 Excavation Effects Data. Array \#3 Site and Preliminary

Design Validation Room 4, N1361 ........................................... $3-12$

3-6 Excavation Effects Data, Array \#4 Site and Preliminary

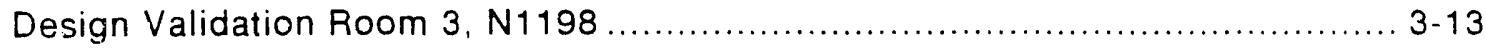

3-7 Excavation Effects Data, Array \#5 Site and Preliminary

Design Validation Room 3, N1243 ................................................... $3-14$

3-8 Excavation Effects Data, Array \#6 Site and Preliminary

Design Validation Room 3. N1312 .......................................... $3-15$

3-9 Excavation Effects Data, Array \#7 Site and Preliminary

Design Validation Roum 2, N1147 .............................................. $3-16$

3-10 Excavation Effects Data. Array \#8 Site and Preliminary

Design Validation Room 2, N1231 ............................................. $3-17$

3-11 Excavation Effects Data, Array \#9 Site and Preliminary

Design Validation Room 1, N1159 ............................................... $3-18$

3-12 Excavation Effects Data, Array \#10 Site and Preliminary

Design Validation Room 1, N1275 ......................................... $3-19$

3-13 Excavation Effects Data, Array \#11 N1100, E0 ...................................... 3-20

3-14 Excavation Effects Data, Array \#12 N1420, E140 ............................... 3-21

3-15 Excavation Effects Data. Array \#13 N1100, E439 ............................... 3-22

3-16 Excavation Effects Data. Array \#14 N1420. E875 ............................. 3-23

3-17 Excavation Effects Data, Array \#15 E0, N626 ....................................... 3-24

3-18 Excavation Effects Data, Array \#16 E140. N305 ...................................... 3-25

3-19 Excavation Effects Data. Array \#17 E0. N28 (Salt Shaft Station) ................... 3-26

3-20 Excavation Effects Data. Array \#18 E0, N24 (Salt Shaft Station) .................... 3-27

3-21 Excavation Effects Data, Array \#19 E0, S56 (Salt Shaft Station) ..................... 3-28

3-22 Excavation Effects Data, Array \#20 E140, S592 ................................... 3-29

3-23 Excavation Effects Data, Array \#21 S700, E66 ................................ 3-30

3-24 Excavation Effects Data, Array \#22 E300, S700 ................................. 3-31 


\section{List of Figures (continued)}

\section{Figure}

Title

Page

3-25 Excavation Effects Data, Array \#23 E300, S1190

3-32

3-26 Excavation Effects Data. Array \#24 E140, S1300

3-27 Excavation Effects Data. Array \#25 E140, S1129

3-34

3-28 Excavation Effects Data. Array \#26 E140, S2205

3.35

3-29 Excavation Effects Data. Array \#27 N1420, E1555

3.30 Excavation Effects Data, Array \#28 N1100, W432

3-31 Excavation Effects Data, Array \#29 E140, S1700

3-38

3-32 Excavation Effects Data, Array \#30 N1100, E1303

3-33 Excavation Effects Data, Array \#31 N1420, E1375.

3-34 Excavation Effects Data, Array \#32 N1420, E1470.

3-35 Excavation Effects Data, Array \#33 N1420, E1110

3-42

3-36 Excavation Effects Data. Array \#34 Panel 1, Room 3-S1862. 3-43

3-37 Excavation Effects Data, Array \#35 Panel 1, Room 3-S1775. 3-44

3-38 Excavation Effects Data, Array \#36 Panel 1, Room 3-S1688 3-45

3-39 Waste Shaft East Brow Face. $3-47$

3-40 Waste Shatt West Brow Face 3-48

3-41 Waste Shaft East Brow Station Back $3-50$

3-42 Waste Shaft West Brow Station Back 3-51

3-43 Plot of Rockbolt Failures in WIPP Underground Facility. $3-53$

3-44 Schematic of Rockbolt Installation 3.55 


\subsection{Introduction}

The Geotechnical Field Data and Analysis Report documents the geotechnical data from the underground excavations at the Waste Isolation Pilot Plant (WIPP) located near Carlsbad. New Mexico. The data are used to characterize conditions, confirm design assumptions, and understand and predict the performance of the underground excavations during operations. The data are obtained as part of a routine monitoring program and do not include data from tests performed by Sandia National Laboratories (SNL), the Scientific Advisor to the project, in support of performance assessment studies.

Geotechnical Field Data Reports have been routinely prepared and made publicly available since 1983. During the Site and Preliminary Design Validation Program, the Architect/Engineer for the project produced the reports on a quarterly basis to document the geomechanical performance during construction of the underground. Since 1987, upon completion of the construction phase of the project, the reports have been prepared annually by the Management and Operating Contractor for the facility. This report includes data collected up to June 30 , 1992, and describes the performance and conditions of selected areas from July 1, 1991, to June 30, 1992.

\subsection{Background}

The location, the mission, and the status of development at the WIPP are discussed below.

\subsubsection{Location and Description}

The WIPP is located in southeastern New Mexico about 30 miles east of Carlsbad (Figure 1-1). The surface facilities have been built on the flat to gently rolling hills that are characteristic of the Los Medanos (sand hills) area. The underground facilities are being excavated approximately 2,150 feet beneath the surface in the Salado Formation, a thick sequence of evaporites which are predominantly halite. A schematic view of the surface and underground facilities at the WIPP site is shown in Figure 1-2.

\subsubsection{Mission}

The WIPP was authorized by Congress in 1979 (Public Law 96-164) to provide "... a research and development facility to demonstrate the safe disposal of radioactive wastes resulting from the defense activities and programs of the United States exempted from regulation by the Nuclear Regulatory Commission". The WIPP is intended to receive, handle, and permanently dispose of transuranic waste. To fulfill this mission, the U.S. Department of Energy (DOE) is 


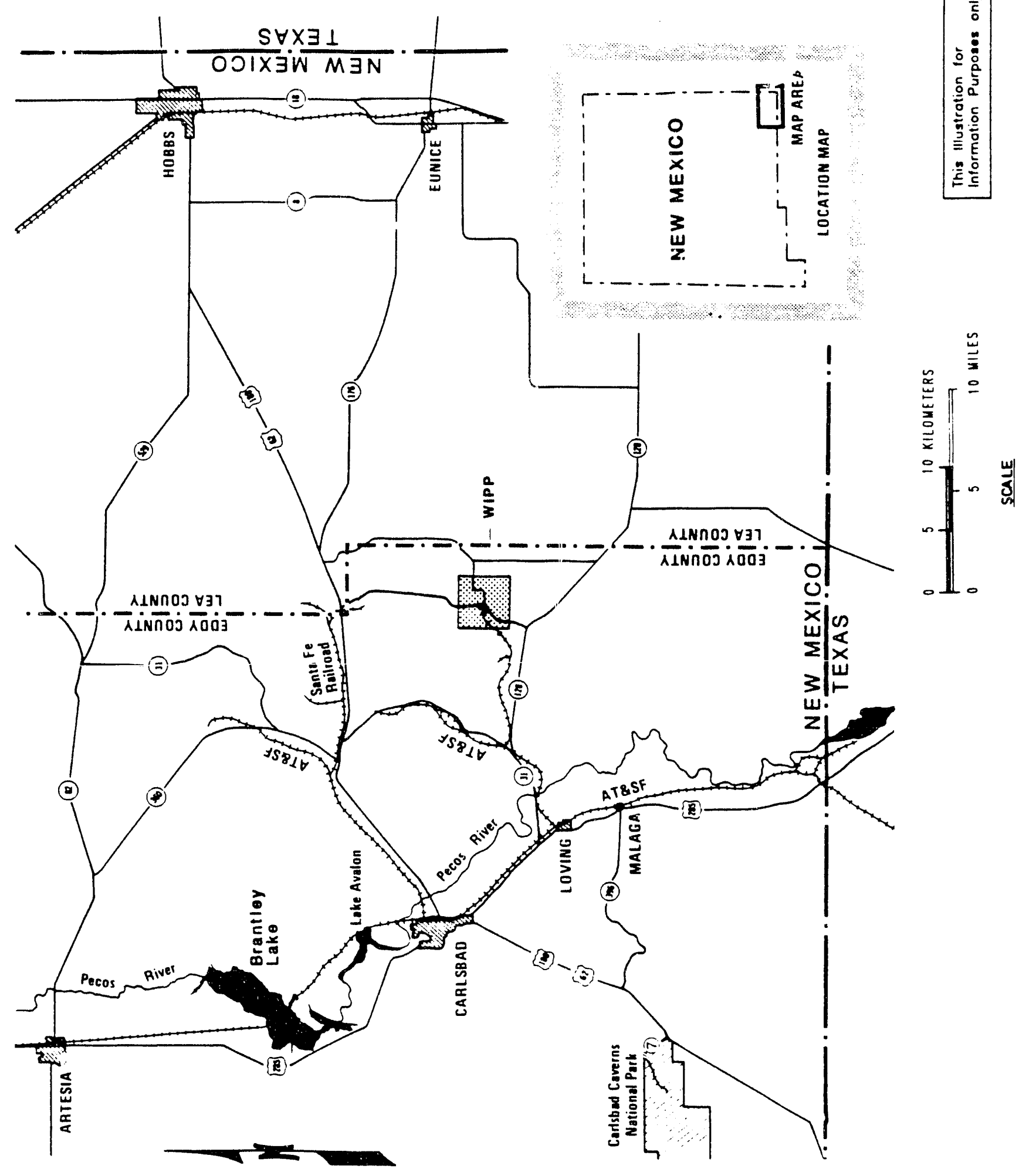

FIGURE 1-1

General Location of the WIPP Facility 


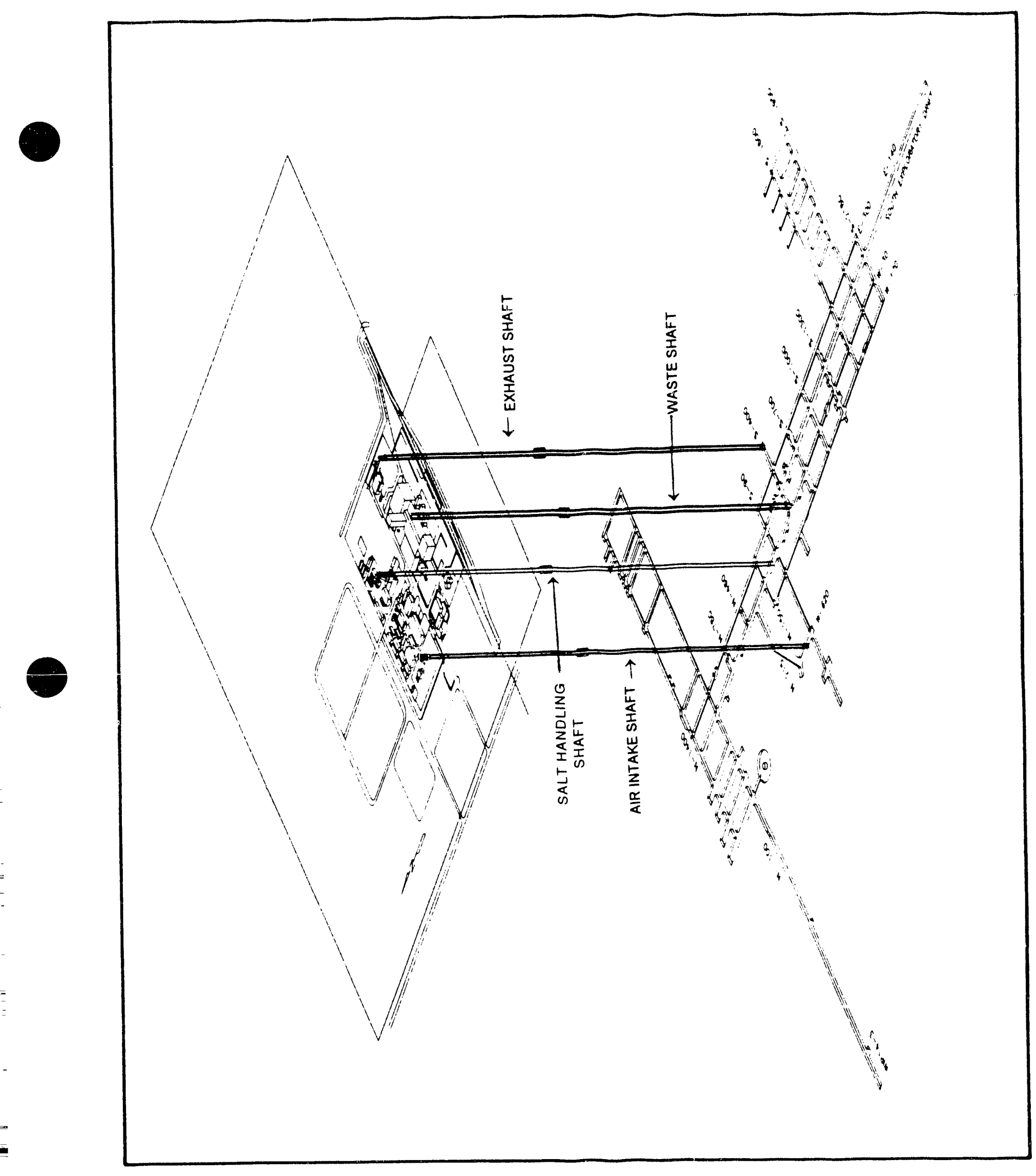

FIGURE 1-2

Schematic of Underground Facilities

WIP 14-3 
constructing a full scale facility to demonstrate both technical and operaticnal principles of the permanent isolation of transuranic waste. Technical aspects are those concerned with the design, construction, and performance of the subsurface structures. Operational aspects refer to the receiving, handling, and emplacement of transuranic waste in salt. The facility is also designed for in situ siudies and experiments in salt. The test phase is includes on-site experiments with mixed transuranic waste. The purpose of the test phase is to continue devel pment of the basis for determining the safety of mixed transiuranic waste disposal.

At the conclusion of the test phase, a decision will be made regarding the suitability of the WIPP facility for disposal of transuranic wastes. The information that will be collected during the :est phase will be used to assure the safe, long-term disposal of radioactive waste in a bedded salt repository. Until the decision is made, waste will be stored in a fully retrievable mode

\subsubsection{Development Status}

To fulfill its missir, the DOE is developing the WiPP in a phased manner. The Site and Preliminary Design Validation phase began in 1980 with the purpose of characterizing the site and obtaining geotechnical data to determine whether site characteristics and design were suitable for a permanent disposal facility. During this phase, an exploratory shaft (now called the Salt Handling Shaft), a ventilation shaft (now called the Waste Shaft), a drift to the southernmost extent of the proposed waste storage area, a four-room test panel, and access drifts were excavated. Surface-based geological and hydrological investigations were also conducted. The data obtained from the Site and Preliminary Design Validation investigations were reported in the WIPP.DOE-161. Summary of the Results of the Evaluation of the WIPP Site and Preliminary Design Validation Program (DOE. 1983).

Based on the favorable results of the Site and Preliminary Design Validation investigations, additional activities were started. These included construction of surface structures, conversion of the Ventilation Shaft for use as the Waste Shaft, excavation of the Exhaust Shaft, development of additional access drifts : 2 !h : waste storage area, and excavation of experimental rooms to support research and development activities. Geotechnical data acquired during this phase were used to evaluate the performance of the excavations in the context of established design criteria (DOE. 1984). Results of these evaluations were reported in Geotechnical Field Data Reports (e.g. DOE, 1985: DOE, 1986a) and were summarized in the Design Validation Final Report (DOE. 1986b) 
The Design Validation Final Report concluded that the facilities including waste storage areas could be developed and operated to fulfill the long-term mission of WIPP. However, some modifications to the reference design were proposed in order to meet the more exacting requirements for the life of openings during an initial demonstration phase when retrievability of the waste remained an option.

The original design for the waste storage rooms at the WIPP provided a limited time in which to mine the salt and emplace waste. Each panel, consisting of seven storage rooms, was scheduled to be mined, filled with waste canisters, and backfilled in less than five years before being sealed. Field studies, as part of the Site and Preliminary Design Validation Program, showed that unsupported openings of a WIPP typical storage room configuration would remain stable and that creep closure would not impact equipment clearances during the five year period following excavation. The information from these studies provided the validation of the design of openings for the permanent disposal of waste under routine operations.

Panel 1 was developed to receive waste for a demonstration and test phase that was scheduled to start in October 1988. This original plan consisted of the storage of drums of contact handled transuranic waste in rooms for a period of five years. During this time and immediately following it, the rooms were to be inaccessible, but the option to reenter was to be maintained so that the waste could be removed, if required. To assist with the possible reentry, ten-foot rockbolts were installed in the rooms in Panel 1 to enhance roof stability.

The demonstration phase was deferred, and the experimental test program was modified to use contact handled transuranic waste in bin scale tests, now planned for Room 1. Panel 1. This program will investigate the potential for gas generation from the different types of waste that will be disposed of in the underground facility. The decision to use Room 1, Panel 1 for these bin scale tests was made in June 1989. when initial waste receipt was anticipated in 1990. The start of the test program has been delayed further, and the new anticipated date for first waste receipt is January 1994. To initiate and conduct the bin scale test, requires an additional seven years of useful life for the test room(s) in Panel 1. Panel 1 test room(s) require essentially uninterrupted accessibility throughout the test phase. This requirement has led to ever more stringent criteria for roof stability.

\subsubsection{Geology}

The underground excavations are located 2.150 feet below the surface in bedded salt of the Permian Salado Formation. A generalized stratigraphy showing the facility horizon is given in 
Figure 1-3. Over 1,000 feet of impermeable evaporite deposits separate the facility horizon from overlying sedimentary formations, and 2,000 feet of evaporites lie below the facility horizon, providing a barrier to Permian limestones and sandstones.

Halite is the most abundant mineral in the Sa!ado Formation and occurs in thick beds intercalated with thinner beds of polyhalite and anhycrite. Salado halite is rarely pure and usually contains trace and minor amounts of clay, anhydrite, and polyhalite. Halite crystal size and morphology vary locally, and various large and small scale sedimentary features are abundant throughout the Salado Formation. A detailed geologic discussion of the Salado Formation can be found in DOE/WIPP 90-051. Geologic Mapping of the Air Intake Shatt at the Waste /solation Pilot Plant (Holt and Powers, 1990).

The facility horizon lies within a 40 foot unit consisting of halite, argillaceous halite, and polyhalitic halite as shown in Figure 1-4. These stratigraphic sequences are laterally continuous.

A 20 to 32-inch thick persistent bed of anhydrite, identified as Marker Bed 139 (MB 139), lies about five feet below the floor throughout most of the underground. Lateral variability in composition and thickness exists within this anhydrite bed at both repository and regional scale. The variability in thickness, up to six inches, has been observed in four inch diameter cores (Holt and Powers, 1990). The bottom of MB 139 is subhorizontal and underlain by Clay E.

Anhydrite "a", located about 13 feet above the roof in most areas of the facility, is underlain by clay $H$, while anhydrite "b", located about 6.5 feet above the roof in most areas of the facility, is underlain by clay $G$. A thin clay layer, clay $F$, is found just below the roof elevation in most excavations.

Marker Bed 139 and the clay layers have a significant impact on the mechanical performance of excavations. The clay layers provide a surface along which slip can occur, whereas MB 139 acts as a brittle unit that does not deform plastically. In addition, the undulating top of the marker bed resists shear movement along the interface with the overlying salt. 
sw

NE

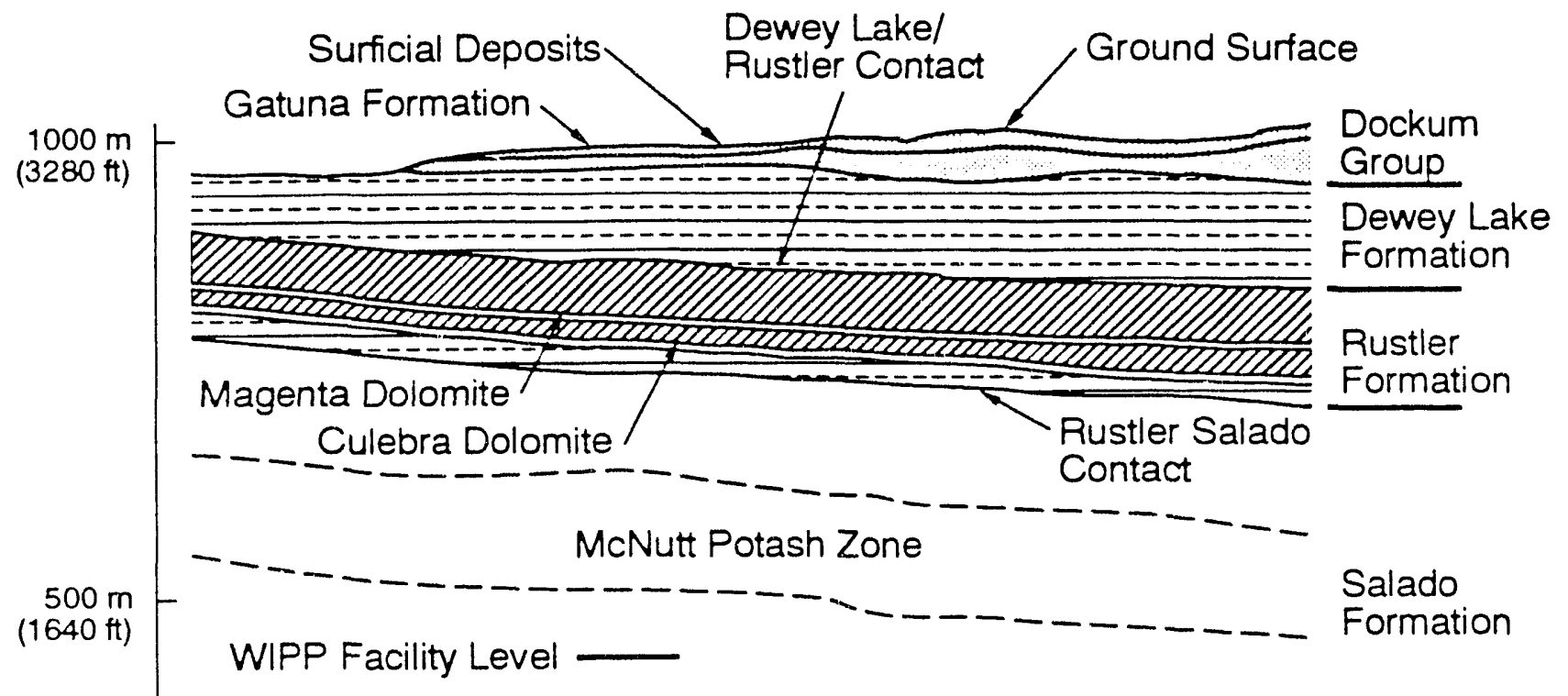

Sea

Level

$-500 \mathrm{~m}$

$(-1640 \mathrm{ft})$
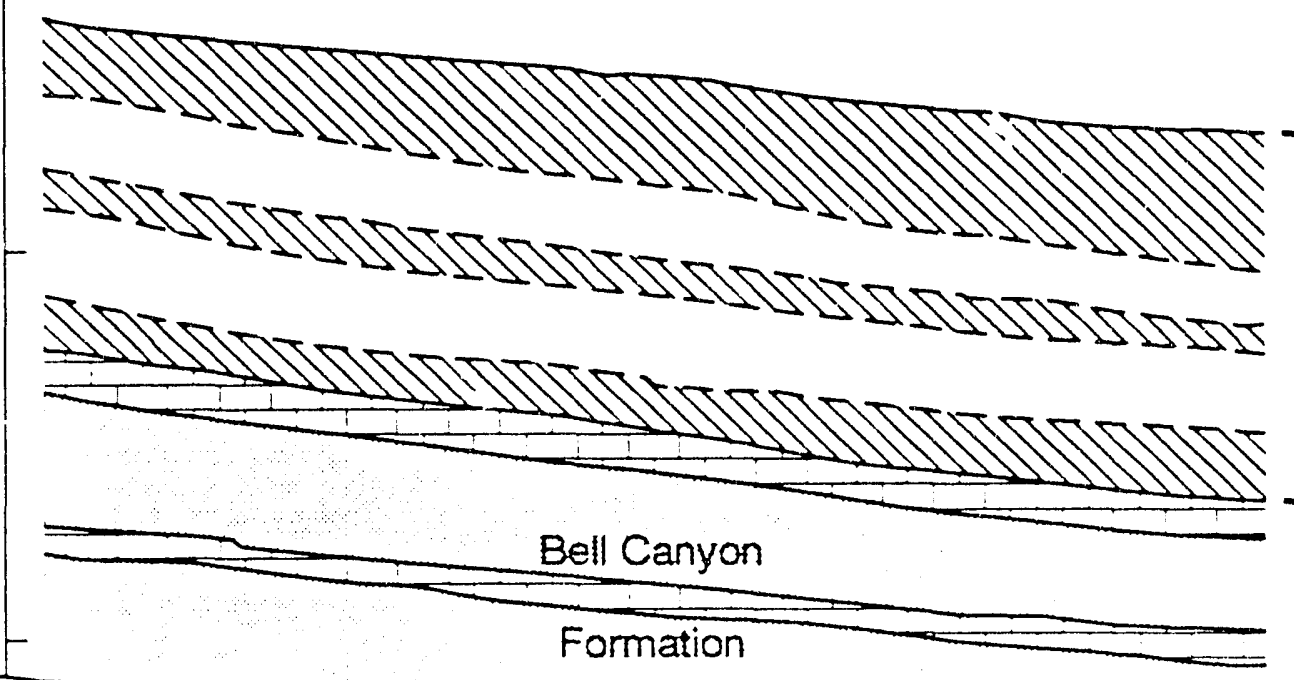

Legend

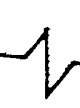

Sand and Sandstone

Mudstone and Siltstone

DIV Anhydrite

$\square$ Halite

Limestone

שIIC Dolomite

FIGURE 1-3

Generalized Stratigraphic Cross Section 
G

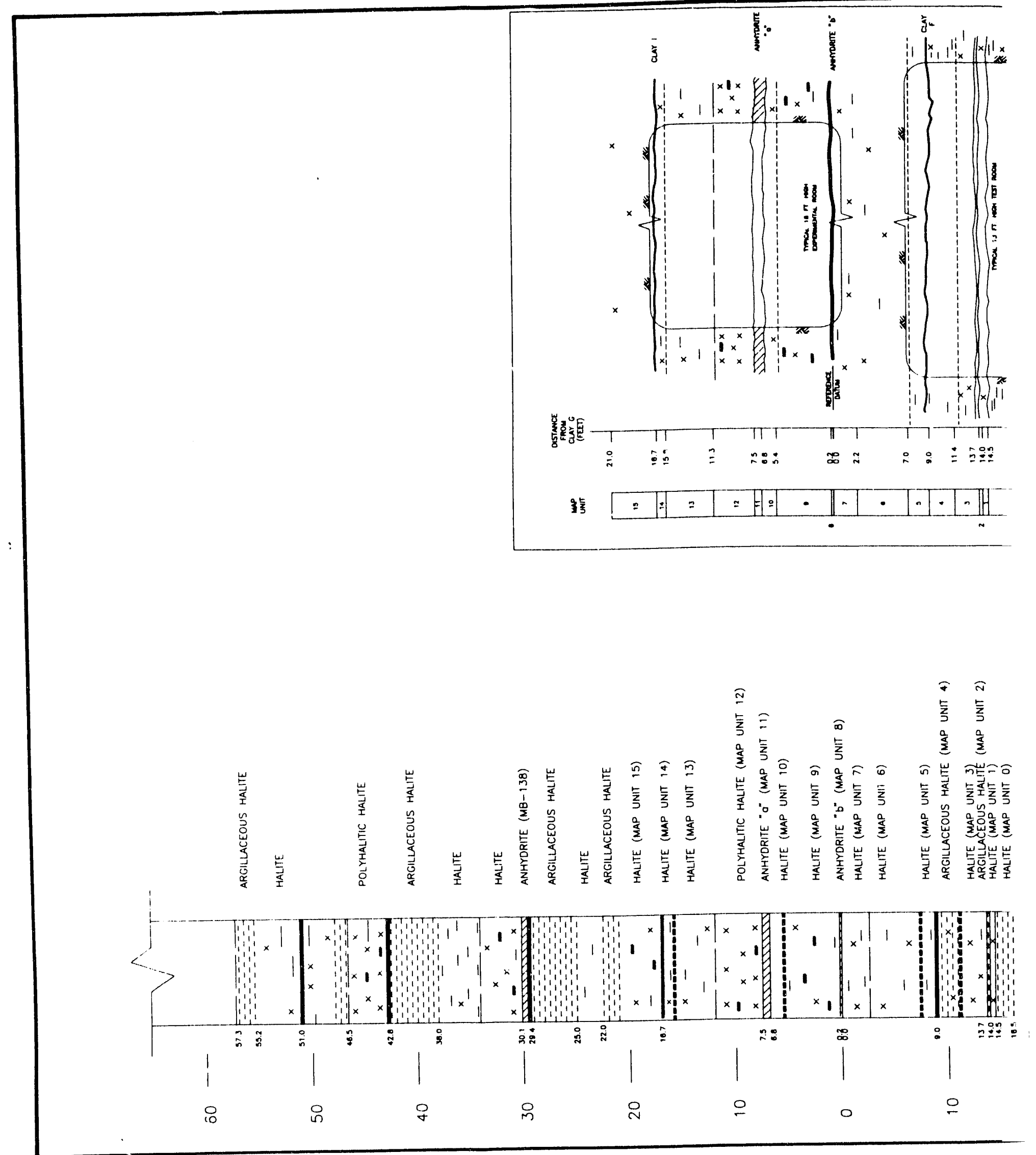

VOLUME 1 


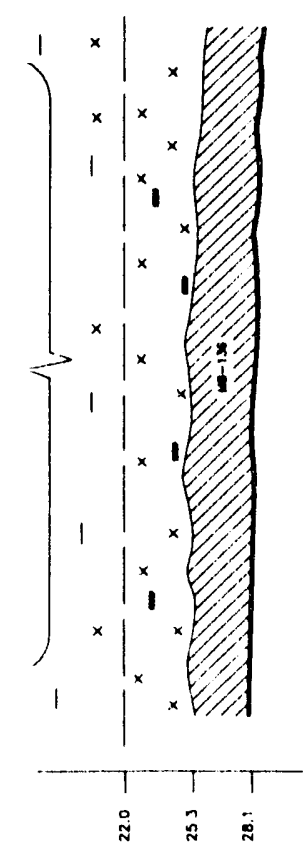

告|
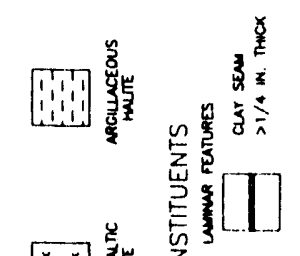

$\left[\begin{array}{ll}x & x \\ x & x\end{array}\right]$ 趁

吕

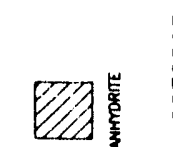

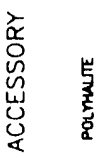

菏
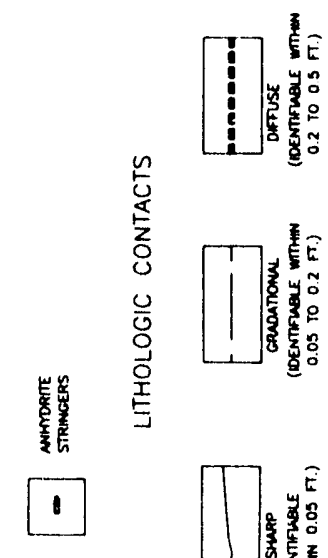

递

$-\square$

$\square$ 亗
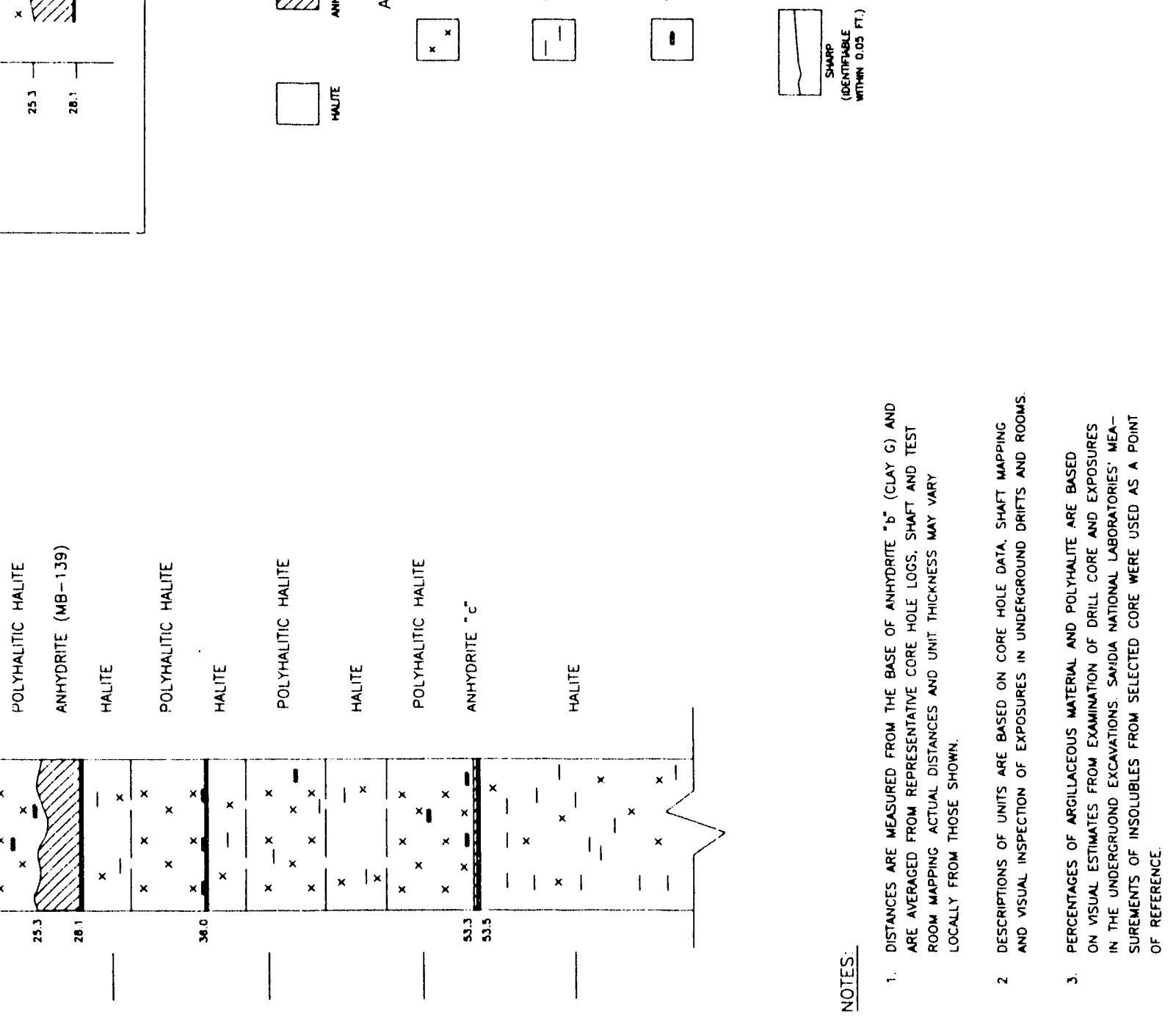

ㅇ

m

온

오

웅 


\subsection{Purpose and Scope of Geomechanical Monitoring Program}

The purpose of the geomechanical monitoring program is to provide in situ data to support continuing assessments of the design for the underground facilities. Specifically, the program provides:

- Early detection of conditions that could compromise operational safety;

- Evaluation of room closure to ensure retrievability of waste;

- Guidance for design modifications and remedial actions; and

- Data for interpreting the actual behavior of underground openings, in comparison with established design criteria.

This Geotechnical Field Data and Analysis Report covers the period July 1, 1991 to June 30. 1992. Volume I provides an interpretation of the field data while Volume II describes and presents the data itself.

\subsection{Comparison of Geomechanical Performance with Design Criteria}

At the start of the project, criteria were developed to follow the requirements that must be addressed in the design of the WIPP. These criteria cover all aspects of the facility and its operation as a pilot plant for the demonstration of technical and operational methods for permanent isolation of contact and remote handled transuranic waste. The criteria are documented in WIPP-DOE-071, Design Criteria. Waste Isolation Pilot Plant (WIPP) Revised Mission Concept-11A (DOE, 1984). This document includes a section specific to the performance of underground excavations. In Table 1-1, these criteria are compared with conditions actually observed in the underground from July 1991 to June 1992 . From the table, it can be seen that the in situ performance of the excavations generally continues to satisfy the appropriate design criteria although specific areas are being identified where deterioration due to aging of the facility must be addressed by maintenance measures. 


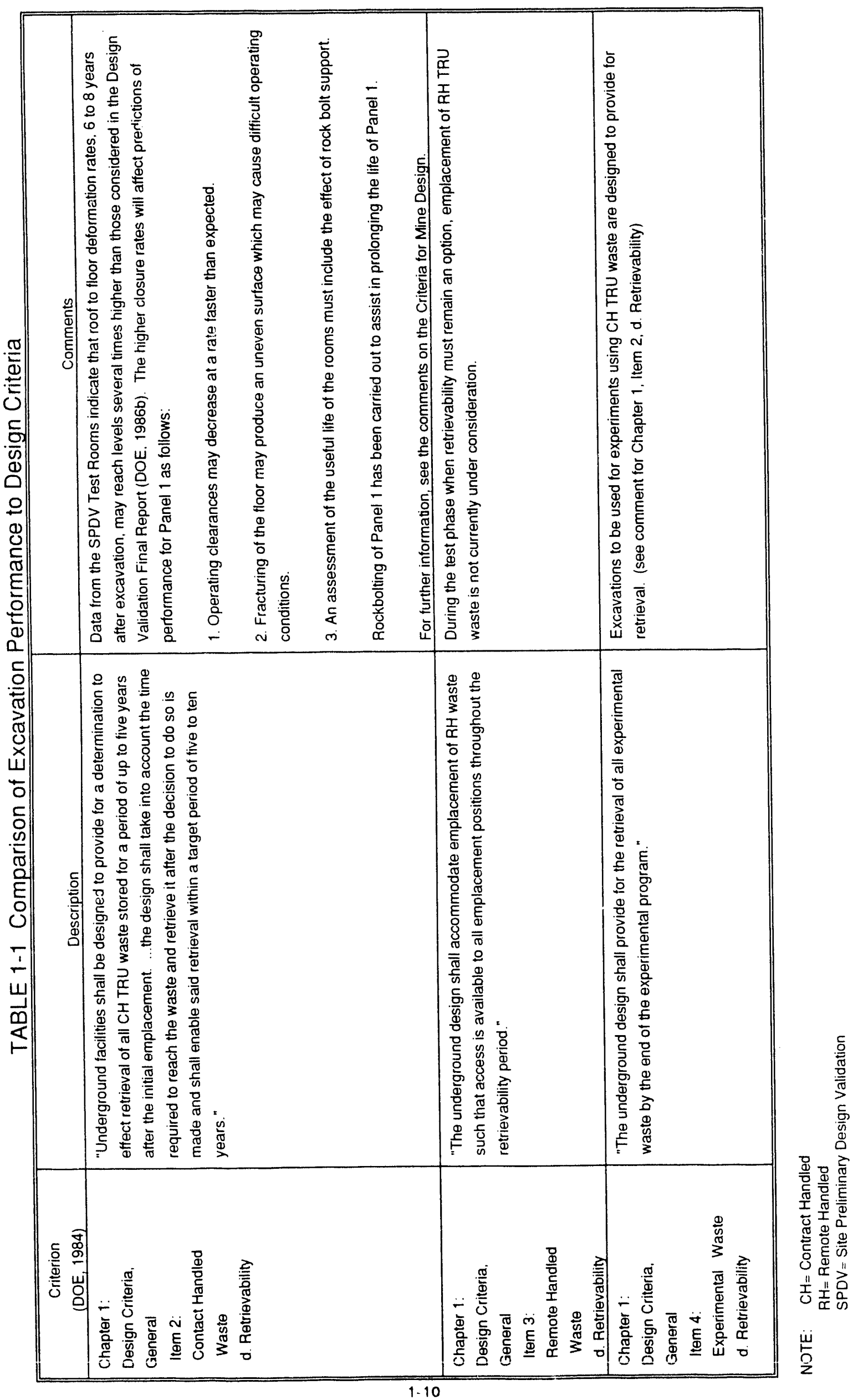




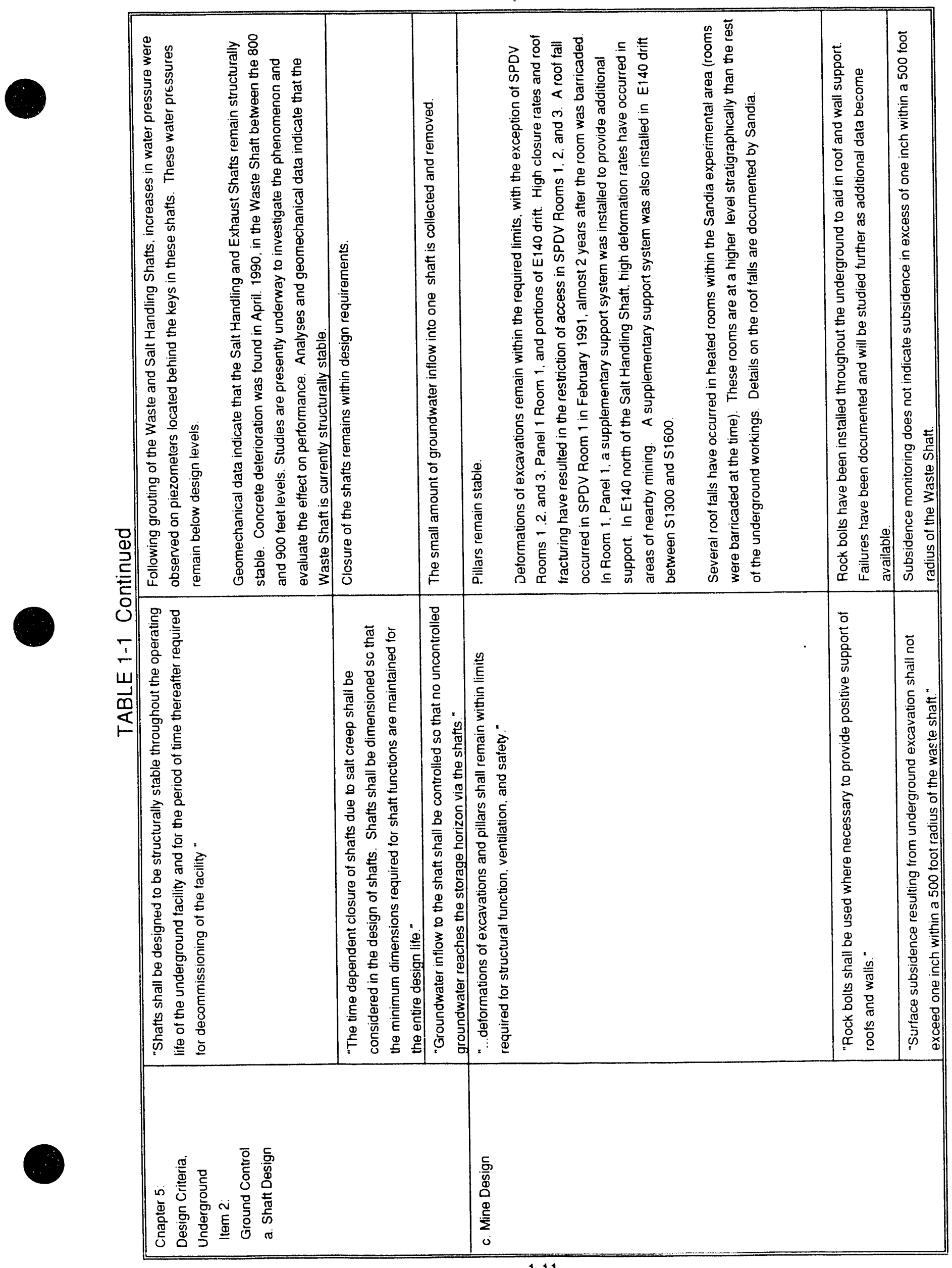




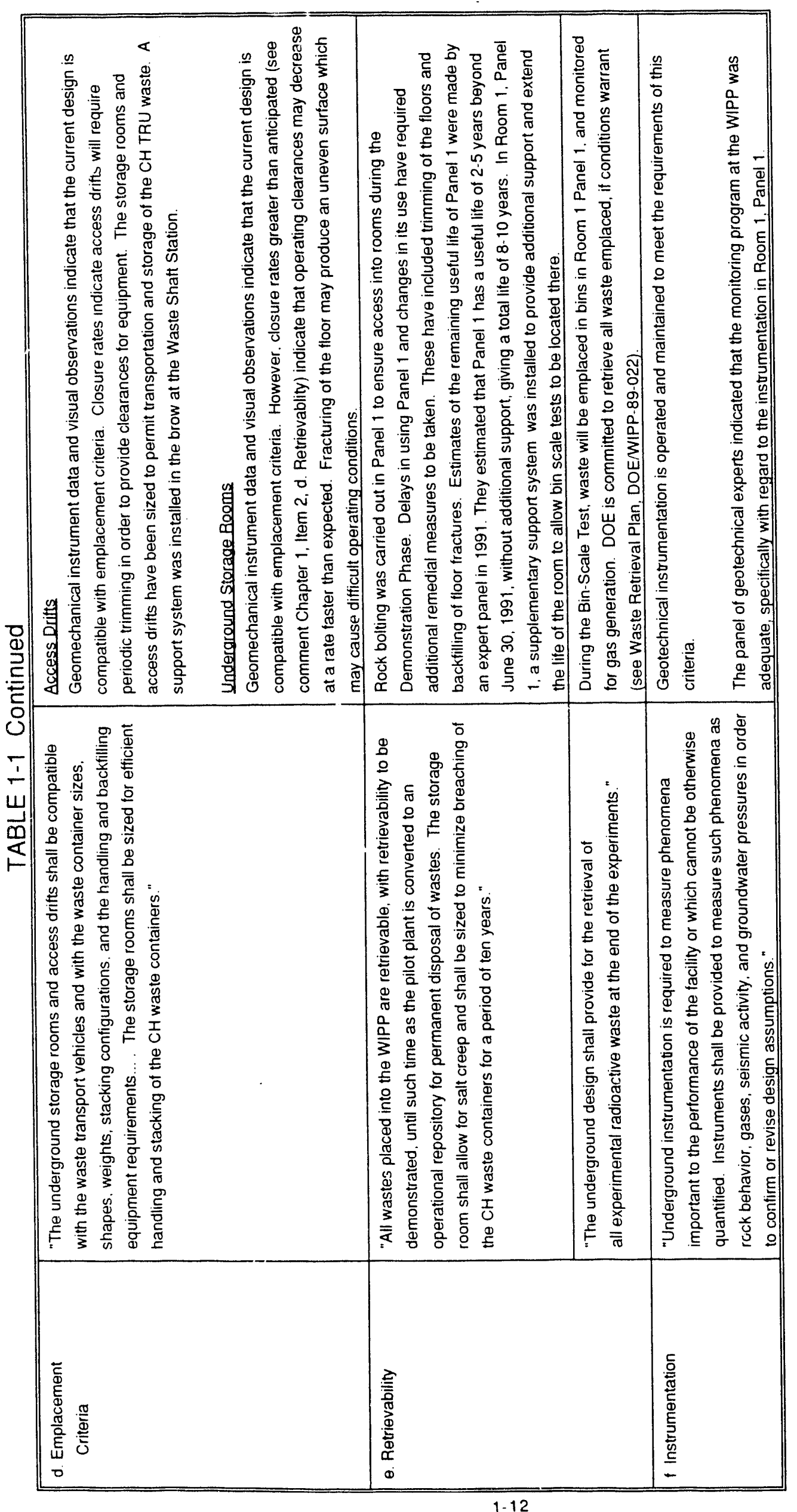




\subsection{Performance of Excavations}

This section describes the in situ geomechanical performance of the underground, interprets underground conditions between July 1, 1991, and June 30,1992, and highlights significant events. Generally, the openings are performing satisfactorily; as the openings age, the effects of deterioration increase. The notable events during this reporting period were installation of supplemental roof support systems in Room 1. Panel 1; E140 drift; and the Waste Shaft Station, as well as the deterioration in the roof in N1420 drift and the continuing increase in closure rates in Site and Preliminary Design Validation (SPDV) Room 2.

Of these events, the most significant was the installation of the supplemental roof support system in Room 1. Panel 1. Opinions presented by a panel of geotechnical experts, whicin convened in April 1991, indicated the need for some type of supplementai roof support system in Room 1, Panel 1, in order to ensure roof stability through the test phase. The individual evaluations of Room 1, Panel 1, by the geotechnical experts are documented in DOE/WIPP 91023. Report of the Geotechnical Panel on the Effective Life of the Rooms in Panel 1 (DOE, 1991a). A supplemental roof support system was subsequently designed with consideration given to both the geomechanical properties of the room and the physical access to the room required during the test phase. The design is documented in DOE/WIPP 91-057, ivaste Isolation Pilot Plant Supplementary Roof Support System. Underground Storage Area Panel 1. Room 1 (DOE, 1991b).

Additional roof support was also installed at the east brow of the Waste Shaft Station to preclude any interference with waste handling operations in the future. Although the geomechanical instrumentation did not indicate increasing instability, the action was prompted due to fracturing observed in the immediate roof beam and bed separation at anhydrite "a".

A slow increase in closure rates was observed in SPDV Room 2 during this reporting period. Convergence data are analyzed on a biweekly basis in an attempt to detect any changes similar to that recorded in SPDV Room 1 prior to failure.

Deterioration in the roof is being observed in the north end of Panel 1, Room 7, and in the S1600 drift. The deterioration consists of low angle shear fracturing along the ribs of Panel 1 , Room 7 and extends west into the $S 1600$ drift. In addition, borehole observations have revealed less than 0.3 centimeter $(1 / 8$ inch) bed separation at anhydrite " $b$ " in this area. Some form of supplementary roof support may eventually be required in this area because the 
anchorage horizon of the presently installed six foot rockbolts is below anhydrite "b", an area known to develop horizontal fractures.

\subsection{Analysis of Convergence Data}

Measurements of room closure are evaluated as a primary means of identifying areas where conditions may be deteriorating. Closure measurements are made throughout the facility, approximately every two months, and are used in conjunction with other observations to assess the geomechanical performance of the excavations. Points that significantly vary from a closure model are monitored more closely to determine the cause of the variance.

Closure and the resulting closure rates are determined by using radial convergence points which measure the reduction in distance between opposing surfaces of the excavations. Radial convergence points are: 1 . accurate. 2. easy to install and read, and 3 . analyzed with simple engineering techniques. Closure rates indicate how an excavation is performing; rates that slow down with time generally indicate stable excavations whereas increasing closure rates, or rates that are higher than anticipated, may indicate potential instability. Previously reported results (DOE, 1990) indicate that closure rates generally decline with time and show cyclic variations that can be attributed to seasonal temperature changes.

Closure rates are plotted against time on a routine basis. In addition, rates are compared to predicted values. The predictions are based on statistical evaluation of selected data from openings of various sizes and ages that provide an empirical relationship between closure rates, room dimensions, and the age of the excavation. The relationship is updated each year as additional data become available. This approach provides an equation for closure rate as a transient function of time and opening dimensions (Table 2-1). Predicted values are assessed as an upper bound, based on the closure rate determined from the statistical analyses of the previous year. A data tolerance of about 1.3 centimeters ( 0.5 inches) per year takes into consideration the variability associated with geologic conditions underground and differences in mining history. Parameters $A, b, c$, and $d$ are determined using nonlinear regression techniques that are in the commercial software package Statgraphics (Version 4.0).

Measured closure rates from July 1, 1991, to June 30, 1992 from locations throughout the underground are compared to the predicted values in Table 2-2a and 2-2b. Actual closure rates are generally in agreement with predicted rates. At locations where predictions have been exceeded, studies were carried out and explanations for the differences are provided in the table. If the cause of high closure rates cannot be adequately explained (i.e., recent mining 
Table 2-1

Analyses of Underground Closure Rates

(From convergence data through June 30, 1992)

\begin{tabular}{||c|c|c|c|c|c|}
\hline \multirow{2}{*}{ CLOSURE } & \multicolumn{5}{|c|}{ Parameter: } \\
\cline { 2 - 6 } & $\mathrm{A}$ & $\mathrm{b}$ & $\mathrm{c}$ & $\mathrm{d}$ & $\mathrm{A}^{2}$ \\
\hline $\begin{array}{c}\text { Roof } \\
\text { to } \\
\text { Floor }\end{array}$ & 0.0030 & 1.018 & 1.119 & -0.184 & 0.817 \\
\hline $\begin{array}{c}\text { Wall } \\
\text { to } \\
\text { Wall }\end{array}$ & 0.0101 & 0.587 & 1.071 & -0.275 & 0.804 \\
\hline
\end{tabular}

Notes:

1. Parameters $A, b, c, d$, are determined using nonlinear regression techniques by means of STATGRAPHICS (Version 4.0).

2. Parameters used in the following relationship:

$$
\begin{array}{lll} 
& C(t)= & A * W^{b *} h^{C *} d \\
\text { Where: } & C(t) & =\text { closure rate } \\
& w & =\text { room width (feet) } \\
& h & =\text { room height (feet) } \\
& t & =\text { age of excavation (years) }
\end{array}
$$

closure rate is in inches/year

3. $R^{2}$ is the coefficient of determination.

The coefficient of determination represents the closeness of fit of the model to the data. Determination with a perfect fit is represented by 1.0 . 


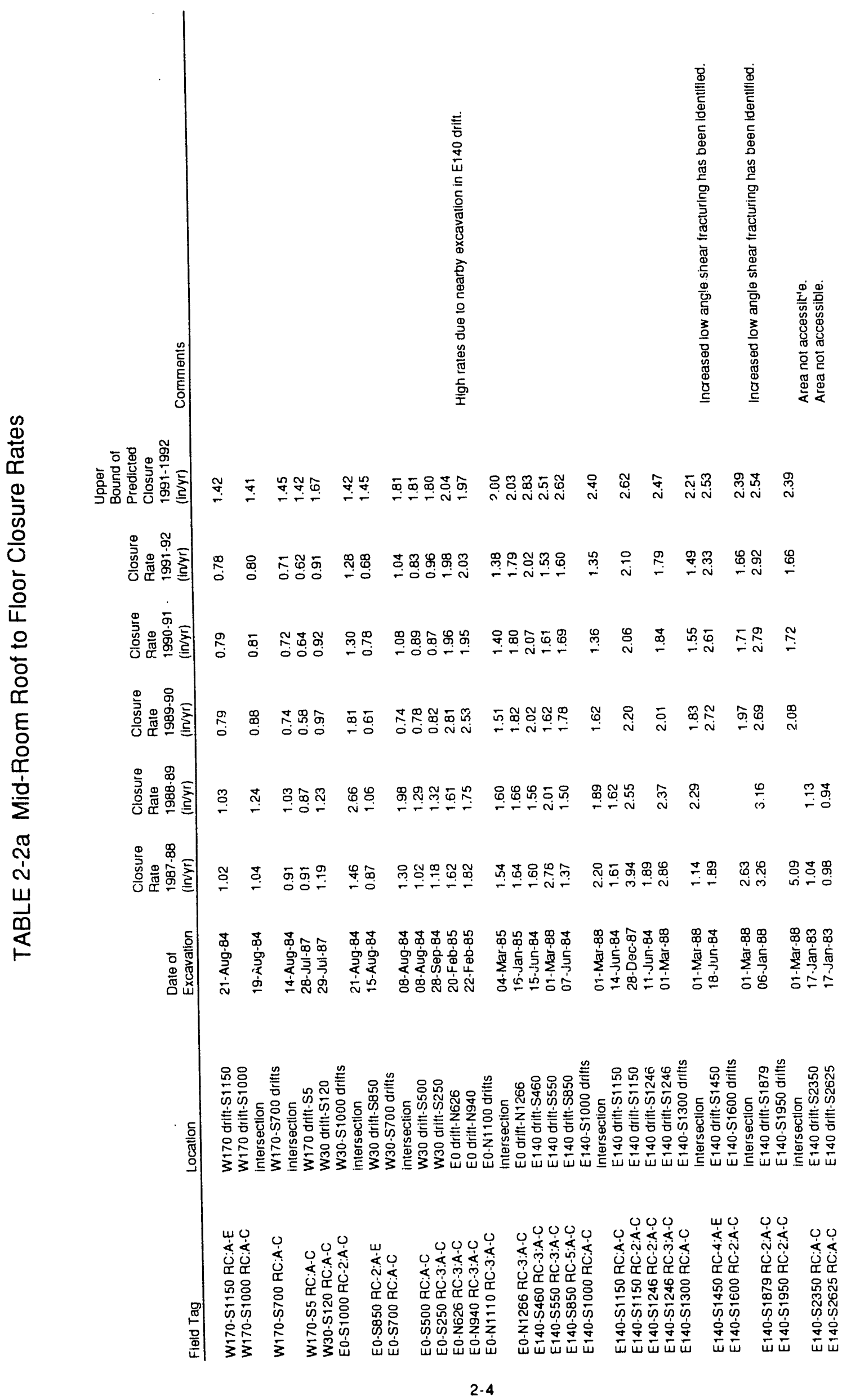




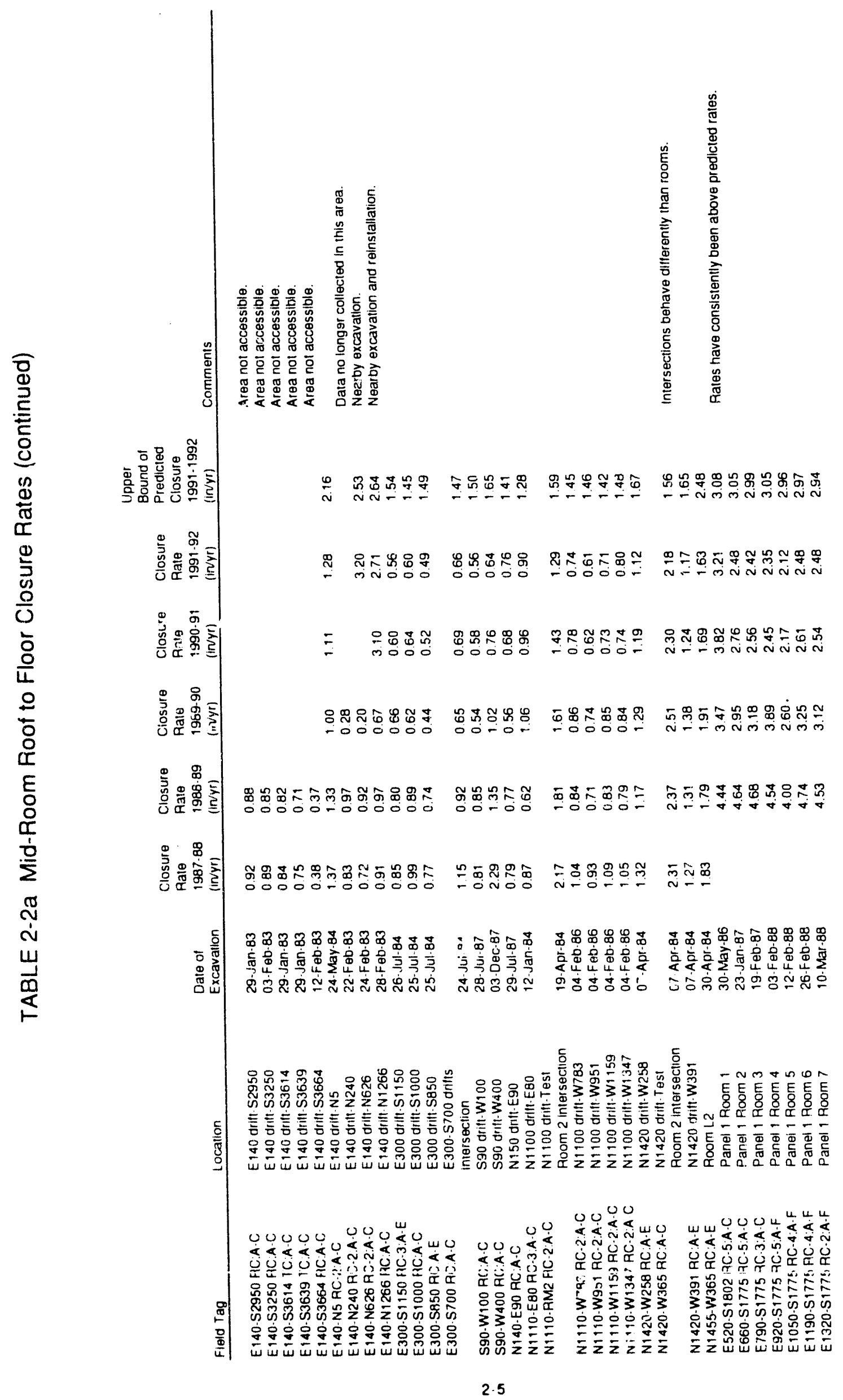




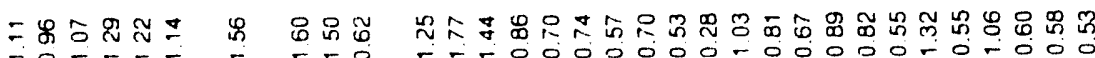

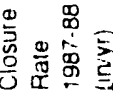

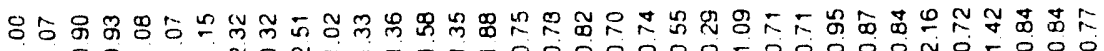

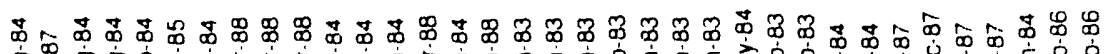

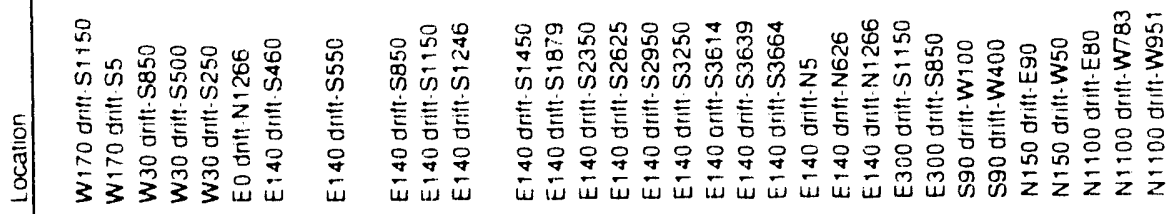

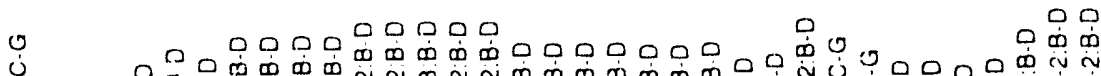
ن்

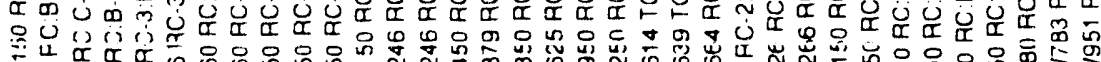

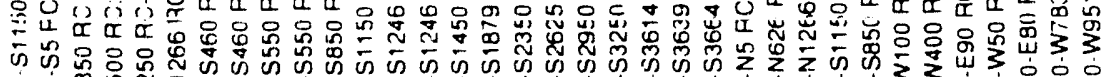

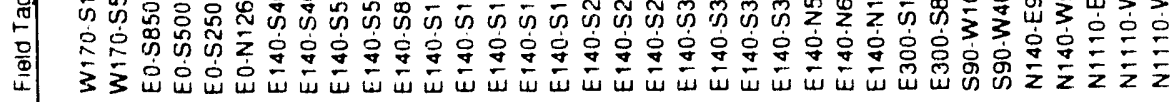




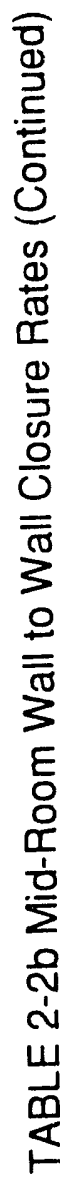

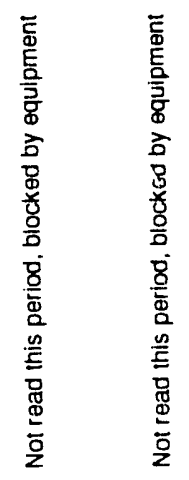

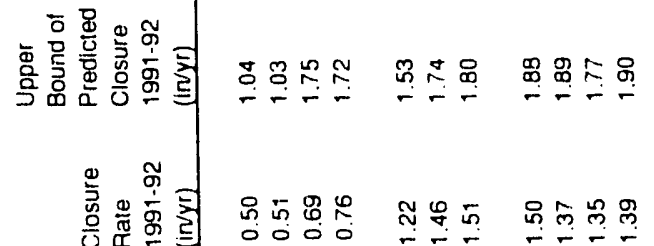

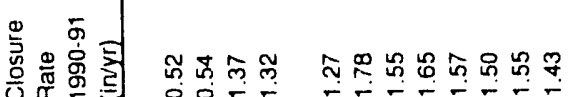

(

ดันก -

$\therefore \quad \stackrel{5}{\bar{\pi}}$

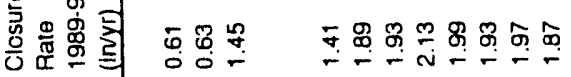

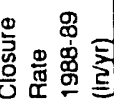

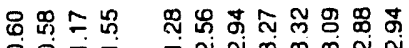

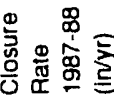

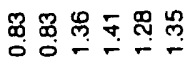

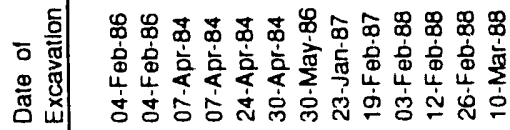

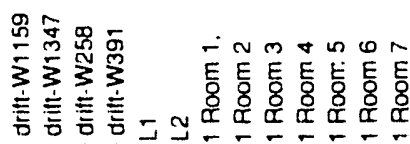

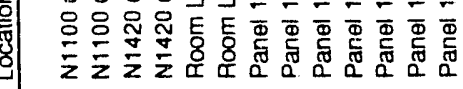

هُ

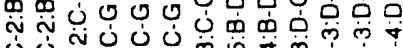

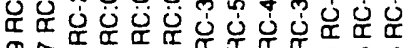

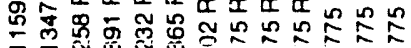

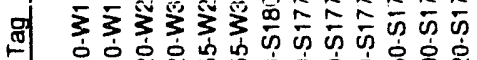

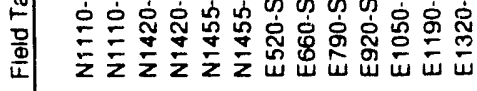


nearby, instrument malfunction, location in an intersection, etc.), the location is monitored more frequently and further field studies may be initiated.

The results of these analyses indicate that the underground is performing within the bounds of the empirical analyses with the exception of the following areas:

- Site and Preliminary Design Validation Roorn 2

- Parts of E140 drift. This drift is the main haulage route to the waste storage area and remedial measures have been taken to increase stability in the affected areas.

- Room 1, Panel 1.

SPDV Rooms 1, 2, and 3 have remained closed throughout this reporting period. The rock fall in SPDV Room 1 destroyed the geotechnical instrumentation in the room, and the uncertainty of present roof conditions prohibits any entry into the room for reinstrumentation or any other purpose. Convergence rates in SPDV Room 2 are closely monitored. This room has been barricaded since 1989 in anticipation of a roof fall or falls in the near future. SPDV Room 3 was closed in June 1990 primarily due to a combination of observed fracturing in the roof and the results of a ground penetrating radar survey of the roof. The radar survey results are documented in Geotechnical Field Data and Analysis Report (DOE, 1991). Because there is no remotely read geotechnical instruments in SPDV Room 3, assessment of the performance of SPDV floom 3 using the empirical analyses is not possible. SPDV Room 4 continues to perform satisfactorily. Closure rates in the room have consistently been below the maximum predicted closure rate for that room size and age of excavation.

\subsection{E140 Drift}

The E140 drift is the main access to the waste storage area, and its stability is essential. Convergence rates in areas of the E140 drift have almost consistently been above the upper bound of the prediction, and fracturing at different stages of development has been identified at these locations. Depending on the degree of deterioration, either remedial ground control measures were taken or geomechanical munitoring activities were intensified in the area, or both.

Roof fracturing, coupled with sporadic rockbolt failures, was observed at two separate areas in the $E 140$ drift between $S 1300$ and $S 1600$. The northernmost area was renovated with rock removal, the installation of wire mesh, and additional rockbolting. Radial convergence arrays 
were installed at the quarter points between the intersections. It was determined that a second area farther south was experiencing vertical closure rates higher than 8 centimeters ( 3 inches) per year. This condition prompted the installation of a supplemental support system at this location consisting of interlaced wire rope and rockbolts. Geotechnical data gathering capabilities were enhanced in this area with the installation of two multipoint borehole extensometers at 30 meter (100 foot) intervals and three observation borehole arrays, spaced 50 feet apart, at the midpoint between the intersections. Data collected from these instruments will be included in the next annual report.

\subsection{Performance of Panel 1 Waste Storage Rooms}

Excavation of the waste storage area began in May 1986 with the mining of entries to Panel 1. Initially, the storage rooms and drifts were developed as pilot drifts that were later excavated to four meters ( 13 feet) high, 10 meters ( 33 feet) wide, and 91 meters ( 300 feet) long. Room 1 was excavated to near full dimensions in August 1986, and pilot drifts for storage rooms 2 and 3 were excavated in January and February of 1987. Rooms 4 through 7 were completed between March and May of 1988.

Convergence points were installed at selected locations immediately following excavation in order to collect early closure data. Tables 2-3a and 2-3b compare the closure rate data for the Panel 1 storage rooms and the SPDV rooms. Although the history of the Panel 1 rooms is shorter than the SPDV rooms, a similar pattern of closure rate change is emerging. The vertical closure rates in Room 1. Panel 1, have shown a slight decrease from the last reporting period. Panel 1 data will continue to be compared with data from the SPDV rooms in order to determine the effect of the supplemental roof support system. Roof to floor convergence data indicate that the closure in the waste storage area is comparable to that of the SPDV rooms at a similar stage of development. The room with the greatest closure rate is Room 1, Panel 1, which was excavated to near full dimensions in 1986.

\subsubsection{Room 1 Supplementary Support System}

This section summarizes the performance of the Room 1. Panel 1, supplementary ground support system. Detailed analyses of system performance, maintenance activities, and procedure development are presented semi-annually in the DOE/WIPP 92-024 and 93-012. WIPP Supplementary Roof Support System. Room 1. Panel 1 Geotechnical Field Data Analysis Reports (DOE, 1992a, 1993). 


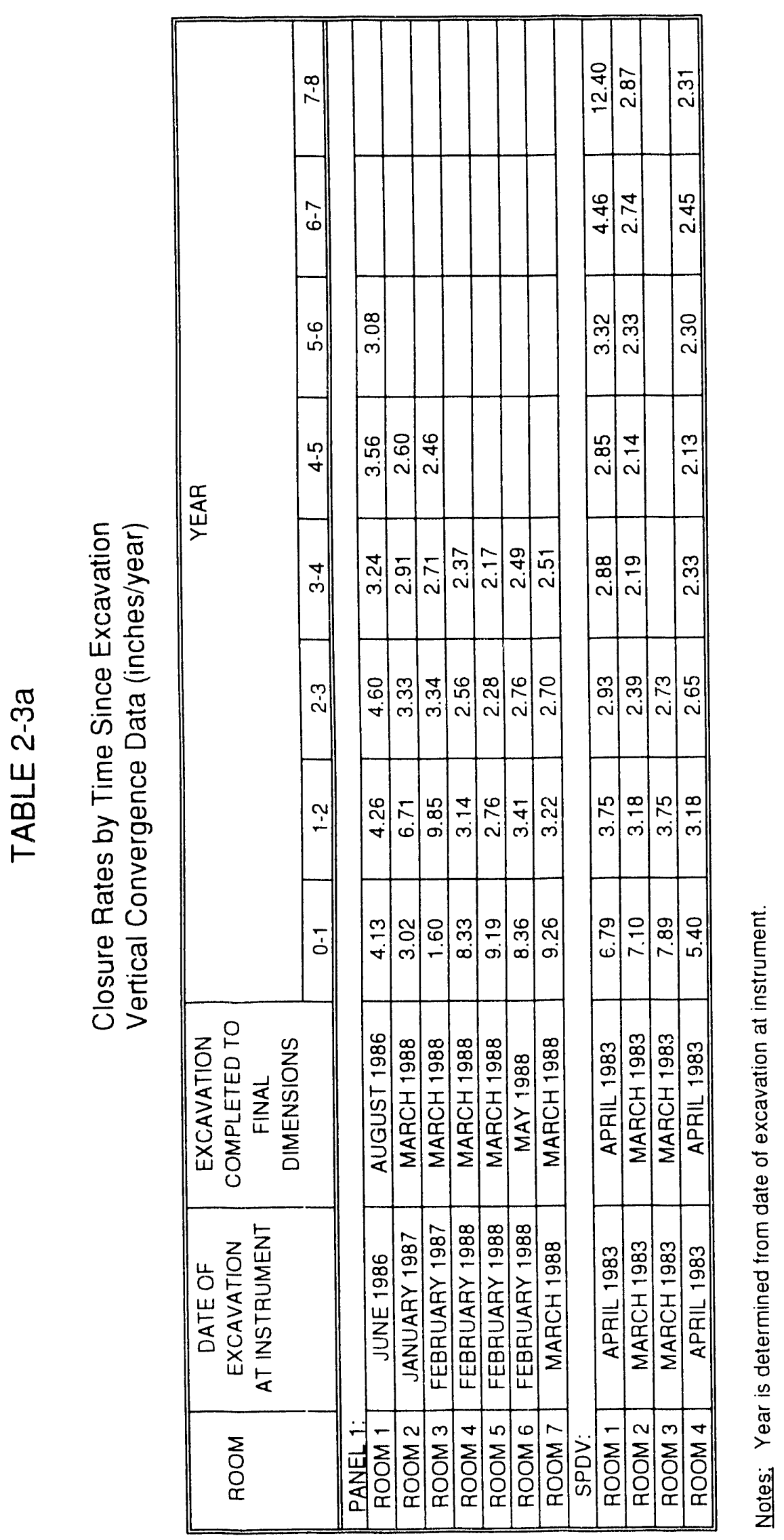




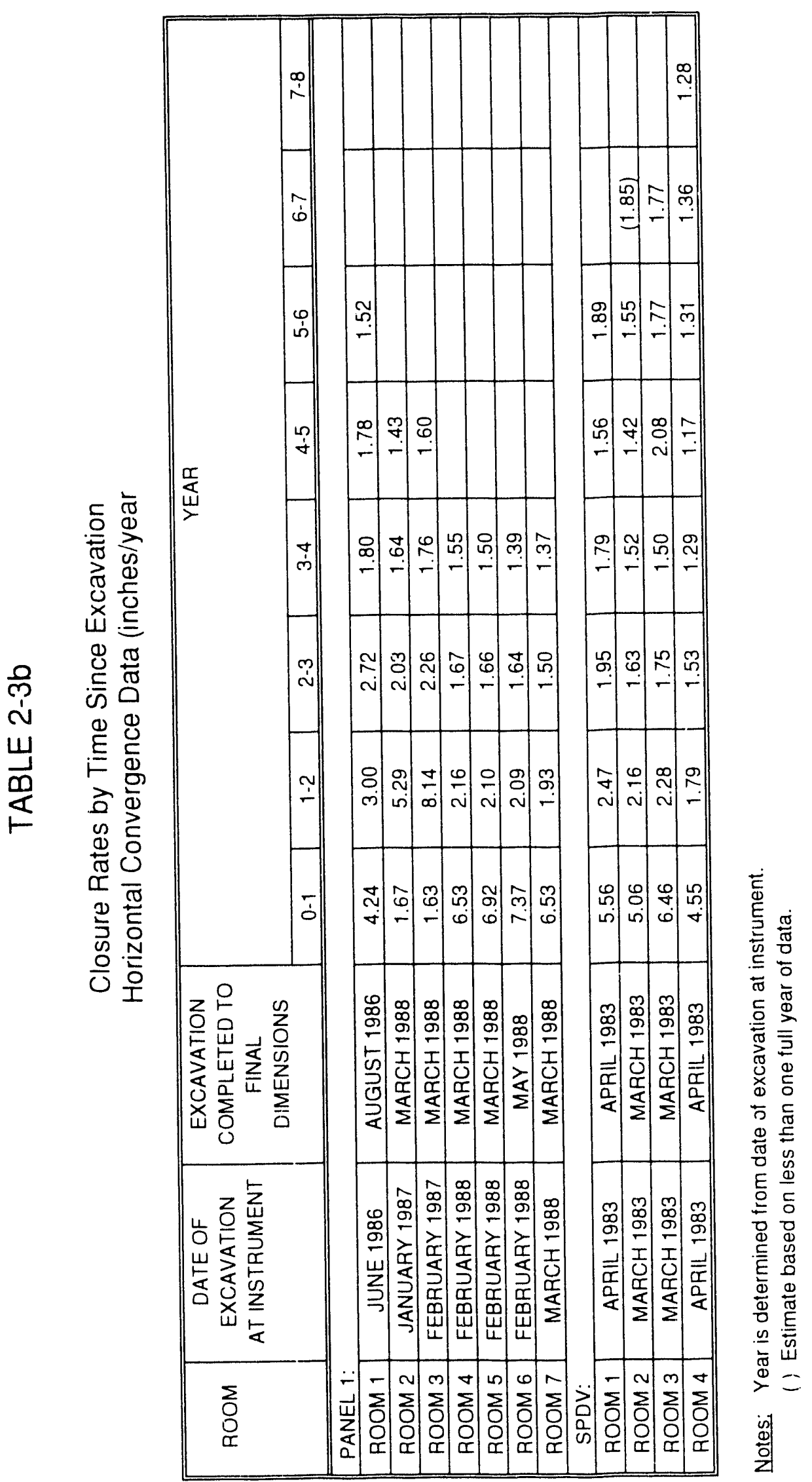


In order to provide a stable roof for the estimated total life required for the Test Phase, a supplemental roof support system was installed. The design was recommended by an independent panel of international experts in salt rock mechanics. To be acceptable, the expert panf 1 recommended that the supplemental roof support system must:

- Be capable of supporting a fully detached root slab such as that observed in SPDV Room 1.

- Be capable of yielding in a manner which accommodates the future closure and deformation of the roof rock.

- Accommodate the bin scale equipment, including forklifts and ancillary equipment.

- Extend the useful life of Room 1, Panel 1 to allow completion of the experiments, for an additional period of at least seven years (from July 1991).

The installation of the support system was completed in December 1991, and bolts were tensioned in February 1992.

The supports consist of 26 rows of eleven bolts on 2.5 to 3.0 meter ( 8 to 10 foot) centers. Each row consists of three 2.7 meter ( 9 foot) long $15 \times 40$ steel channel support sets installed laterally across the room. Eleven 2.5 centimeters (one inch) diameter, 4.0 meter ( 13 feet) long Dywidag threaded rockbolts are installed through the channels. The bolts are resin anchored between the 2.6 and 3.5 meters ( 8.5 to 11.5 feet). Approximately 46 centimeters (18 inches) extends out of the borehole. Each bolt is equipped with a load cell. The area between the channel support sets is covered by a network of steel wire lacing cables underneath a mat of welded steel wire mesh and expanded metal. Figure 2-1 shows a cutaway view of the support system, and Figure 2-2 shows a plan view. The system is designed so that the rockbolts can be continuously monitored by the load cells and adjusted (by loosening the nut) to accommodate roof expansion.

\section{Roof Expansion}

Performance of the roof support system is governed by the magnitude of the vertical and horizontal deformation of the rock between the anchor and the collar of the rockbolts. The criterion for vertical displacement is that the expansion of the rock beiween the anchor and the 
GFDAR

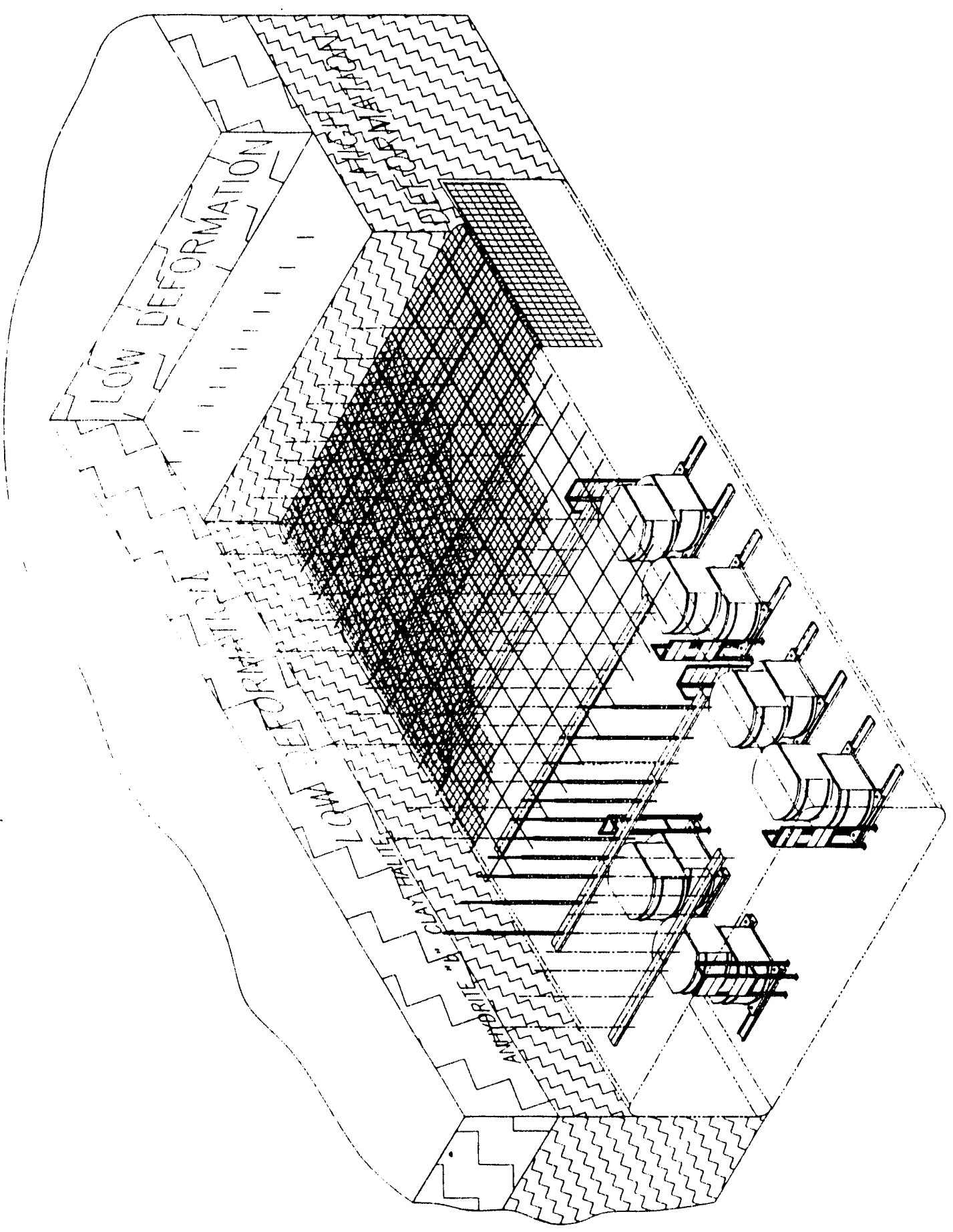

FIGURE 2-1

Schematic View of Room 1, Panel 1 Suppiementaiy Root Suppont System 


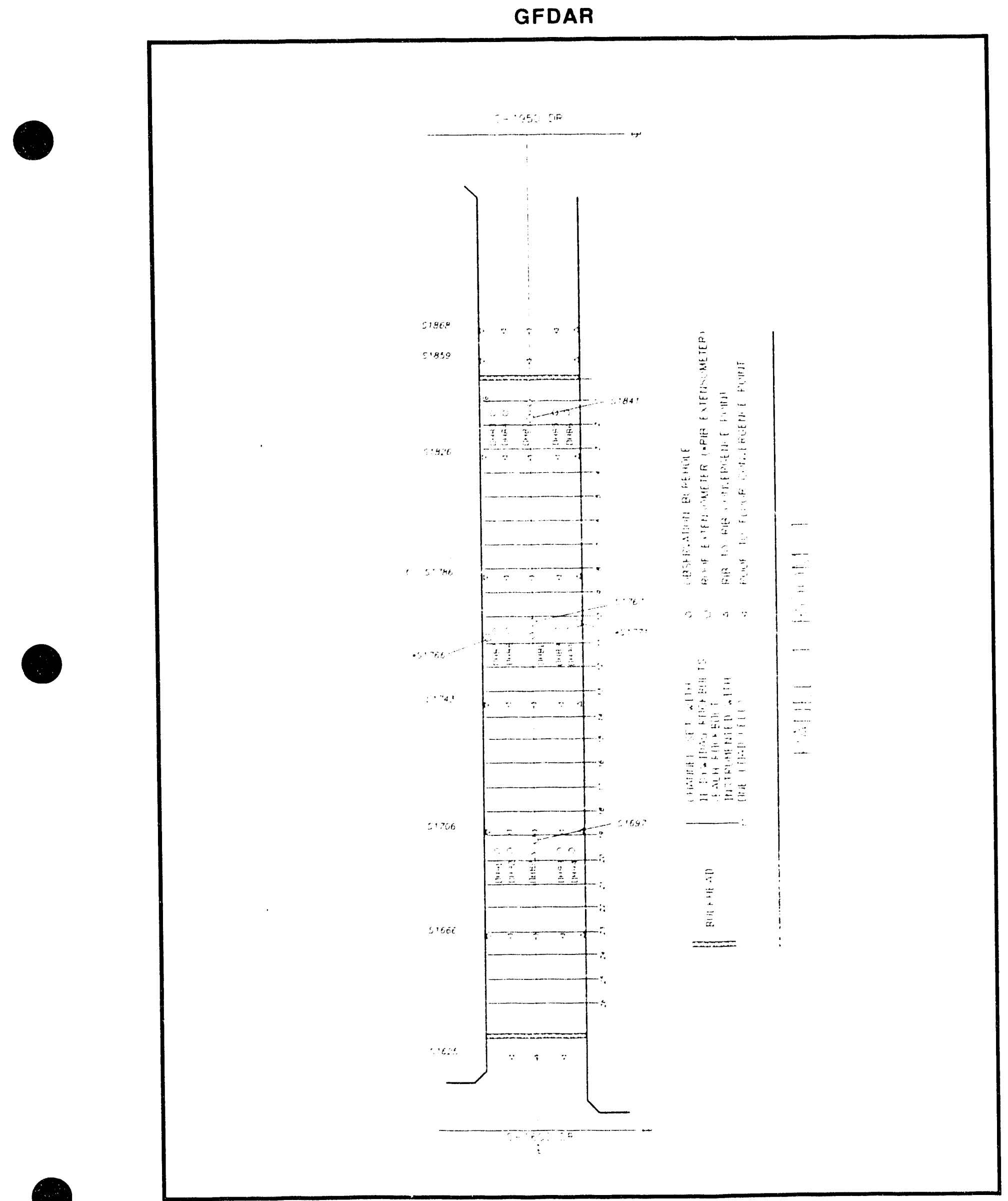

FIGURE 2-2

Planview of Room 1, Panel 1

Supplementary Roof Support System

$2 \cdot 14$ 
collar of the bolts must not exceed 27 centimeters (10.5 inches) or the length of the rockbolt protruding beyond the collar less the thickness of the load cell, nut, plates, etc. The protruding section of the rockbolt is referred to as the "pigtail." Insufficient time has elapsed since installation to directly measure the change in pigtail length. Figures $2-3,2-4$, and $2-5$ show the expansion rate of the first eight feet of the roof as measured by borehole extensometers. Average annual expansion rates vary seasonally from about 1 to 2 centimeters $(0.4$ to 0.8 inches) per year. The criterion gives a total time of 13 to 26 years to reach 27 centimeters (10.5 inches). Movement on the pigtails may be slightly less than that indicated by the extensometers for two reasons. First. the roof expansion as measured by the collar to eight foot bays of the extensometers is probably higher than the expansion over the free length of the rockbolts, because the free length of the bolt is shorter than eight feet. Second, the expansion rate at the bolt locations is probably lower than at locations away from the bolts. In the event that individual bolts run out of pigtail, extension pieces can be attached to the bolts to extend their life.

\section{Horizontal Displacement}

The horizontal displacement criterion for roof bolt performance is determined on the size of the bolt borehole annulus. Initially, there is 5 centimeters (two inches) difference between the diameter of the rockbolt and the diameter of the borehole. After 5 centimeters (two inches) of horizontal offset has occurred in the boreholes, the rockbolt will begin to be pinched by the borehole walls. After some unknown additional horizontal offsetting occurs, the bolts could fail. Should this happen, provisions have been made to reinstall failed bolts. Experience with smaller-diameter (and therefore, weaker) rockbolts has indicated that bolt failures due to horizontal offset occur gradually in an area. Therefore, in the unlikely event that bolts should fail due to offsetting, it will be possible to replace bolts faster than they fail. Fifteen boreholes have been drilled in the roof of Room 1. Panel 1, for measurement of horizontal offset magnitude as well as for monitoring fracture development. These holes were drilled in April 1991 and February 1992. As of June 1992, no measurable offsets were observed in these holes.

\section{Rockbolt Load}

In addition to the deformation criteria discussed above, there is a design load limit of 20,000 pounds per bolt. Each of the bolts in Room 1, Panel 1, is equipped with a load cell. As stated in the design document for the roof support system, when bolt loads approach the design load limit, the bolts will be detensioned by loosening the nut. No bolts have been detensioned as of June 1992. Because bolts will be detensioned individually at different times, the rate of loading 


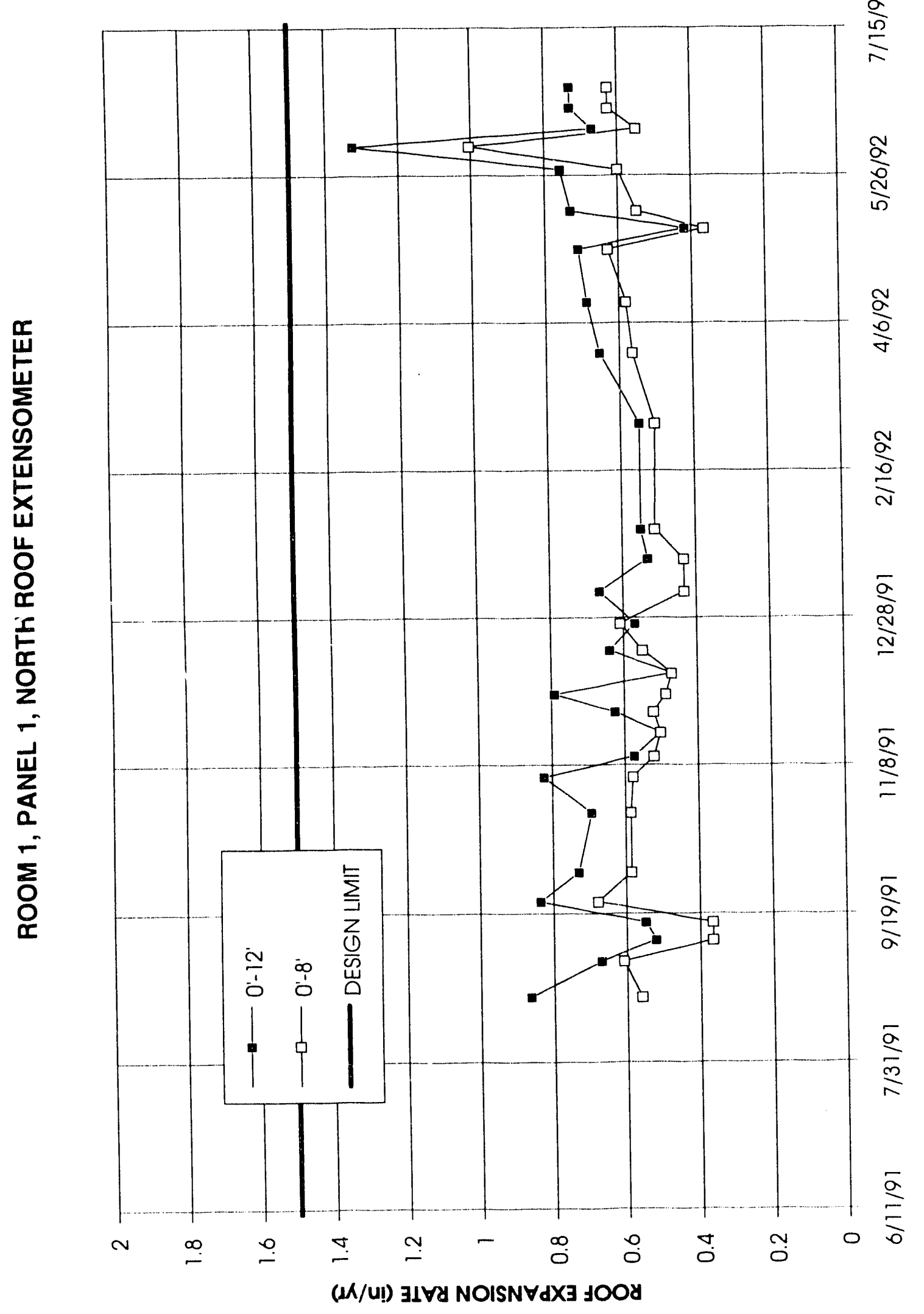

FIGURE 2-3

Roof Expansion Rates

Room 1, Panel 1, North Extensometer 


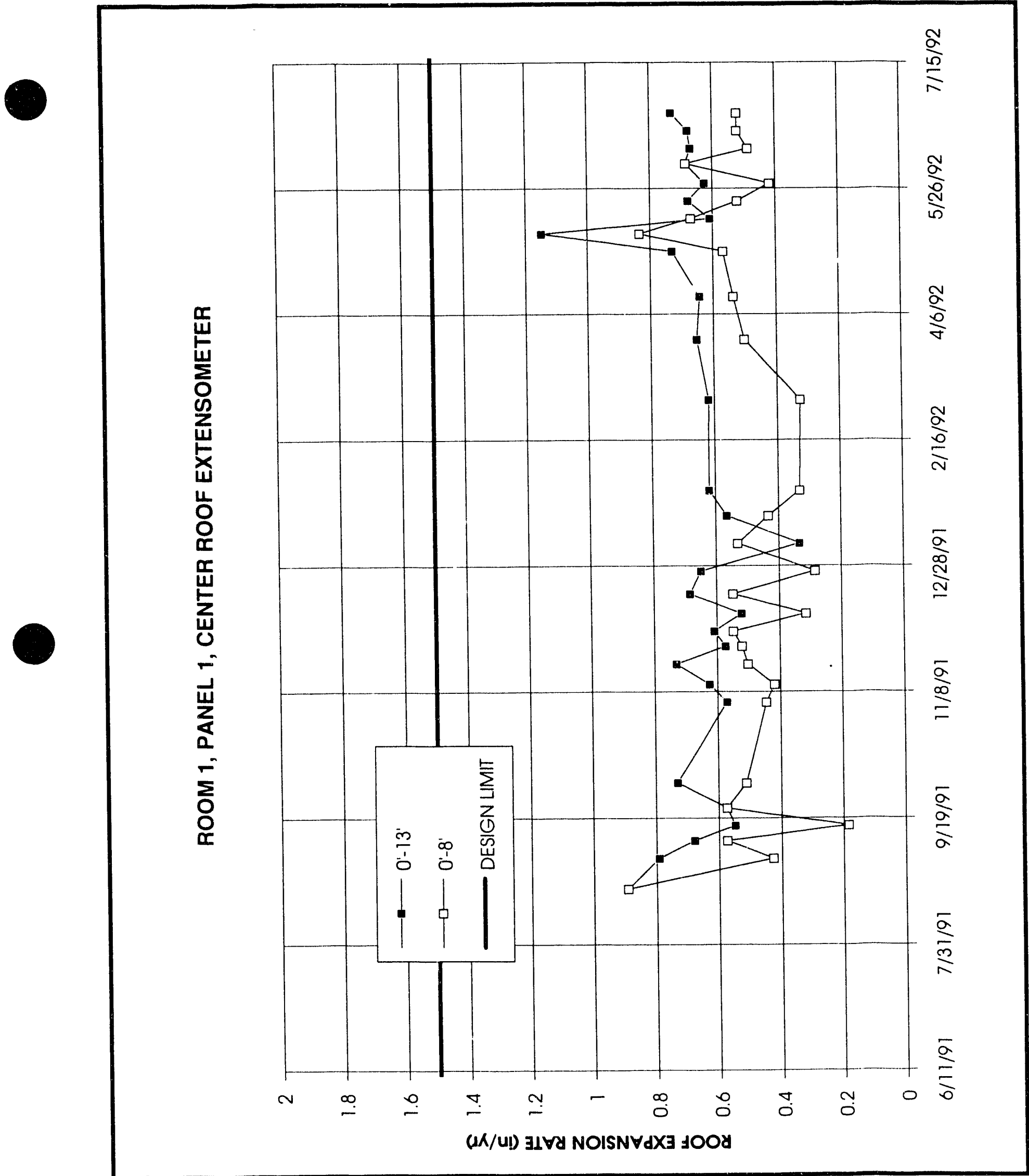

FIGURE 2-4

Roof Expansion Rates

Room 1, Panel 1, Center Extensometer 


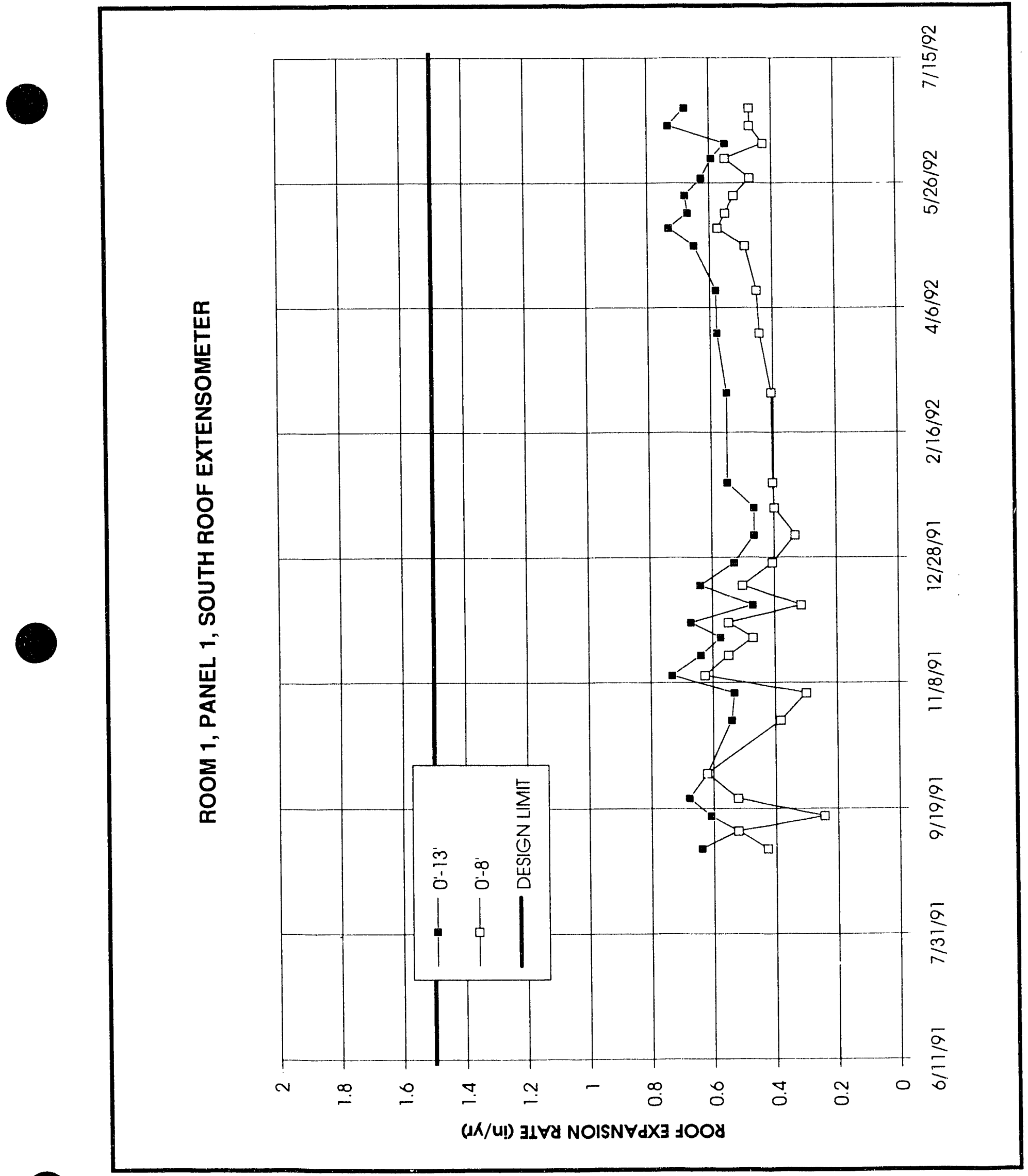

FIGURE 2-5

Roof Expansion Rates

Room 1. Panel 1, South Extensometer 
of individual volts will be as much a function of when a certain bolt and the bolts around it were last detensioned as it is a function of the state of deformation in the rock. Channel bolt loads and individual bolt loading rates are routirely plotted to provide the primary means of load analysis. Periodically a load grid is generat $ə d$ trom the rockbolt load cell data to provide an overall view of bolt loading throughout fire room.

Three load grids from this reporting period are shown in Figure 2-6. The initial tensioning of the boits was completed on February 27, 1992, and the load grid after tensioning is shown in Figure 2.6(a). Twu additional plots from this reporting period are given in Figures 2-6(b) and (c). The primary purpose of this plot format is 'o examine relatively large-scale loading phenomena over extendeo periods of time.

Individual bolt loading rates were generally in the $75-150$ pounds per week range during the first 45 to 60 days aifter initial tensioning. Rates then began to increase to the 200 to 700 pounds per week range. It is believed that the lower initial loading rates are due to the "bedding in" effects of the various components of the roof support system, an anticipated response. The increase in loading rates can be seen by examining the three plots with respect to the overail load amplitude and the time between plots. In view of the dates the data was read, it is obvious that the amplitude increase between (b) and $i c$ ) is larger than the amplitude increase between (a) and (b), indicating an overall increase in loading rate.

\section{Convergence}

Vertical convergence rates in Room 1. Panel 1, have dropped approximately 10 to 20 percent since installation of the supplementary roof support system. Only two vertical convergence gauges have operated continuously from one year before bolt tensioning to June 1992. For the period from February to June 1991, the vertical convergence rate at $S 1717$ (near the center of the support installation) was 9.2 centimeters ( 3.64 inches) per year. Over the same period in 1992 (after bolt tensioning) the rate was 7.5 centimeters ( 2.95 inches) per year, a drop of 19 percent. The convergence rate at $\$ 1853$ (near the south end of the support installation) was 7.3 centimeters (2.88 inches) per year in 1991 compared to 6.6 centimeters ( 2.61 inches) per year in 1992. a drop of nine percent. It is too early to make any assertions as to the cause of the closure rate decrease, although it is possible that the roof support system may have influenced the change

In summary, as reported in the semi-annual assessments, the roof support system is performing within the design limits. Based on roof deformation rates, it appears at this time that the 


$$
11
$$


要

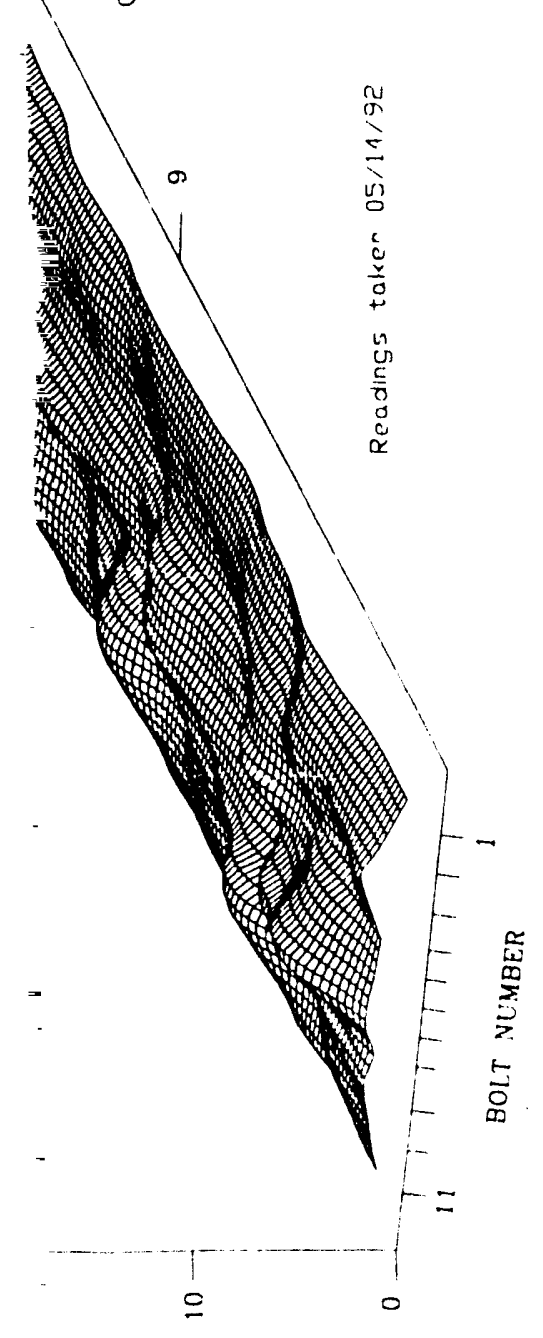

(sdir) dYOT

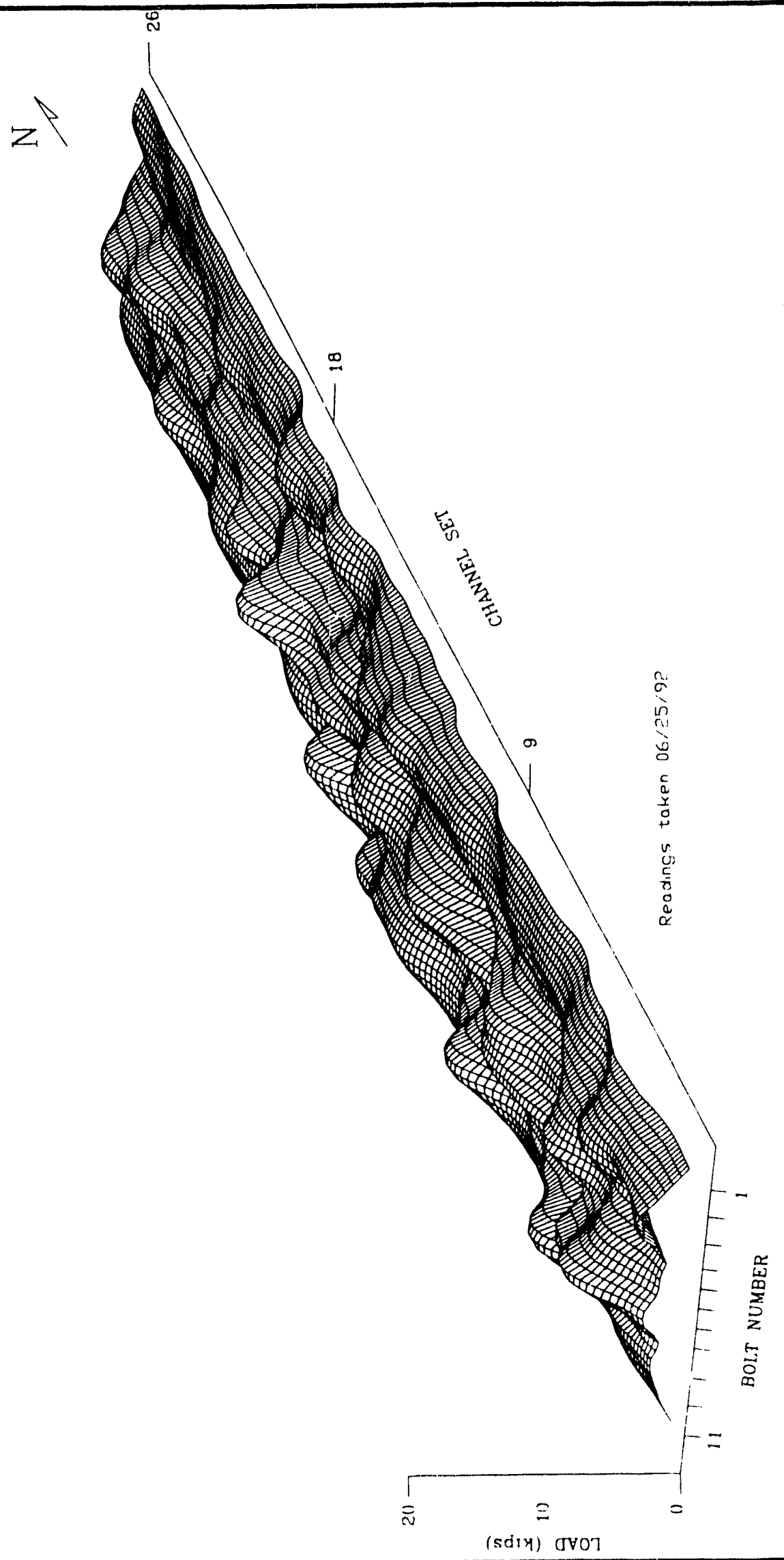

FIGURE 2-6

Room 1 Rockbolt Load Grid 
effective life of the system could be significantly greater than the minimum of seven years after installation specified in the design documents.

\subsection{Modeling Room Performance}

During and after excavation, stresses are redistributed in the surrounding salt. The stress distribution depends on the constitutive properties of the salt mass. clay seams and anhydrite beds. and the geometry of the excavation. In rock salt, the excavation responds initially by elastic deformation due to the stress redistribution, and subsequently by inelastic, timedependent deformation due to deviatoric stress. These changes in deviatoric stress, and the deformation of salt under gravity loading will result in clay seam sliding and separation and an increase in closure rates. Computer modeling is a standard method for preaicting the reaction of the surrounding rock to excavation, as well as for predicting how the rock mass will respond to different room configurations, material properties. and support designs. Two computer programs. FLAC and VISCOT, were used to study different constitutive models and modeling inethods for WIPP. These results were also compared with other models used by other WIPP participants.

\subsubsection{FLAC}

Fast Lagrangian Analysis of Continua (FLAC) is a two-dimensional, explicit, finitedifference code that simulates the behavior of structures built of soil, rock, or other materials that may undergo plastic flow when their yield point is reached. Materials are represented by zones that form a mesh that is adjusted by the user to fit the shape of the object to be modeled. Each zone behaves according to a prescribed linear or non-linear stress/strain law in response to the applied forces and boundary conditions. Under certain stress conditions, the material will yield and flow, and the mesh will deform and move with the material that is represented.

FLAC was developed by Peter Cundall in 1986 specifically to perform engineering analyses on IBM-compatible personal computers and can handle relatively large problems at relatively high speeds (Itasca, 1991). Itasca Consulting Group now markets FLAC in an executable-only form and has incorporated the 1983 SNL Reference Creep Law (Krieg. 1984).

FLAC is primarily intended for geotechnical engineering applications. FLAC has seven built-in material models, an interface model, three structural models. and can simulate groundwater flow problems. Three creep and thermal models are available as 
enhancements. FLAC is capable of solving plane strain, plane stress, and axisymmetric problems. All the FLAC models discussed here used the plane strain case.

\subsubsection{FLAC Modeling of WIPP Storage Rooms}

Six FLAC models were created to model the WIPP storage rooms, particularly Room 1. Panel 1, to evaluate the effect of rockbolting on the mechanical performance of the rooms. In addition, the models were compared to the results from the SNL Second Benchmark Problem (Morgan et al., 1981). All the models used the same mesh and boundary and initial conditions, but used different material properties or rockbolt layouts. The six FLAC models are summarized below:

SRO - Standard WIPP stratigraphy, including clay seams.

Calculations include primary creep.

SR1 - Same mesh as SRO. except it was assumed that the stratigraphy is composed of homogeneous halite interbedded with clay seams.

SR2 - Same as SRO, without primary creep.

SR3 - Same as SRO. but using larger units (megapascals and years rather than pascals and seconds).

SBO - Same as SRO to five years creep time, then 3.5 meter (11.5 foot) long grout-anchored rockbolts were installed.

SB1 - Same as SBO to two years creep time, then three meter (10 foot) long mechanical rockbolts installed on a diagonal pattern with 3.5 meter $(11.5$ fcot) grout anchored bolts installed after five years.

The mesh for all six models consisted of 3857 nodes and 3696 elements (Figure 2-7). 
GFDAR

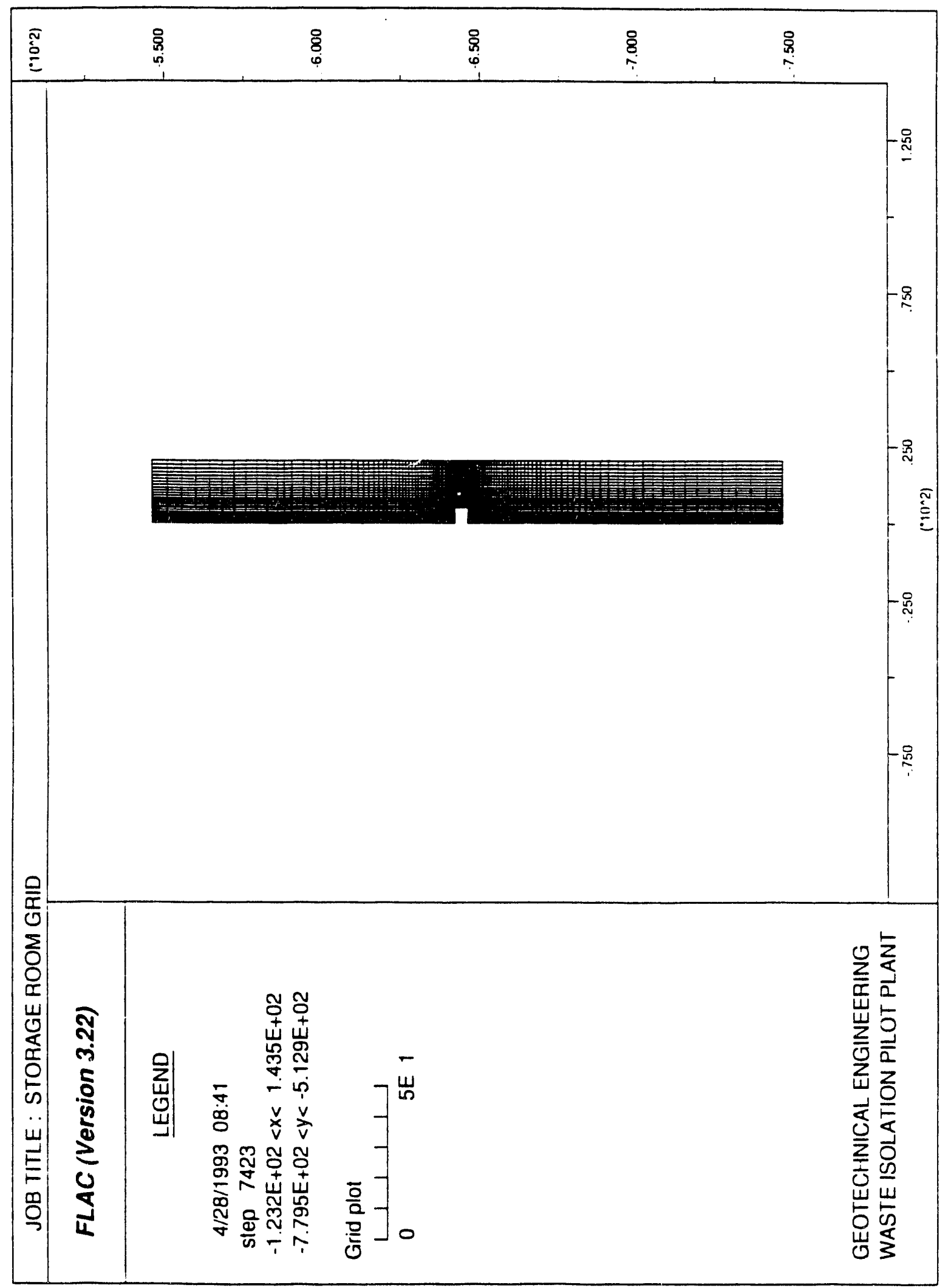

FIGURE 2-7

Finite Difference Mesh for FLAC

Storage Room Models 


\subsubsection{SNL Second Benchmark (BMII) Problem}

The Second Benchmark (BMII) Problem was formulated in late 1980 (Krieg et al., 1980), and the results were published in late 1981 (Morgan et al., 1981). The BMII problem involved calculating the mechanical response of an excavation in salt. using nine computer codes by several WIPP participants. The BMII problem examined two drift contigurations. an isothermal (unheated) drift, and a heated drift. The isothermal room was placed at approximately the same stratigraphic horizon as the current WIPP storage rooms. In 1988 . Itasca reproduced the Second Benchmark problem using FLAC (Itasca, 1988). Itasca's results compared favorably with the results of the nine codes used in BMII.

\subsubsection{Differences Between FLAC and SNL BMII Guidelines}

Although the six models created for FLAC are very similar to the isothermal case in the SNL Second Benchmark Problem, they do not meet the exact specifications of that analysis. The following are notable differences:

- Size of the Model: The FLAC model is approximately 100 meters ( $328 \mathrm{ft}$ ) longer vertically than the BMII models. This difference provides FLAC models with more accurate results, because boundary effects would be less than those of the BMII models. In addition. FLAC has many more zones and gridpoints than the BMII models: this tends to increase the accuracy of the FLAC results.

- Stratigraphy: The FLAC model corrects the elevation of the room with respect to $M B 139$ and clays $G$ and $H$ to reflect the field observations in Room 1. Panel 1, more accurately (Figure 2-8). Overall elevation of the room and stratigraphy was decreased by approximately 12 meters (39 feet) to coincide with earlier WIPP modeling efforts (DOE, 1989). The BMll models ignore clay $G$ which exerts significant influence on the behavior of the roof of the storage rooms. The FLAC model included slidelines for clay $G$ and clay $H$ in the roof and clay $E$ in the floor of the excavations.

- Material Properties: Material properties for the FLAC models were taken from the Reterence Stratigraphy (Krieg, 1984) rather than the BMII guidelines. In addition, the value for the friction angle of the clay seams used in the FLAC models is larger than in BMII. The larger friction angle slightly increases the resistance to slip in the FLAC models. However, after clay seam separation occurs in the FLAC models, the friction angle is effectively zero. 

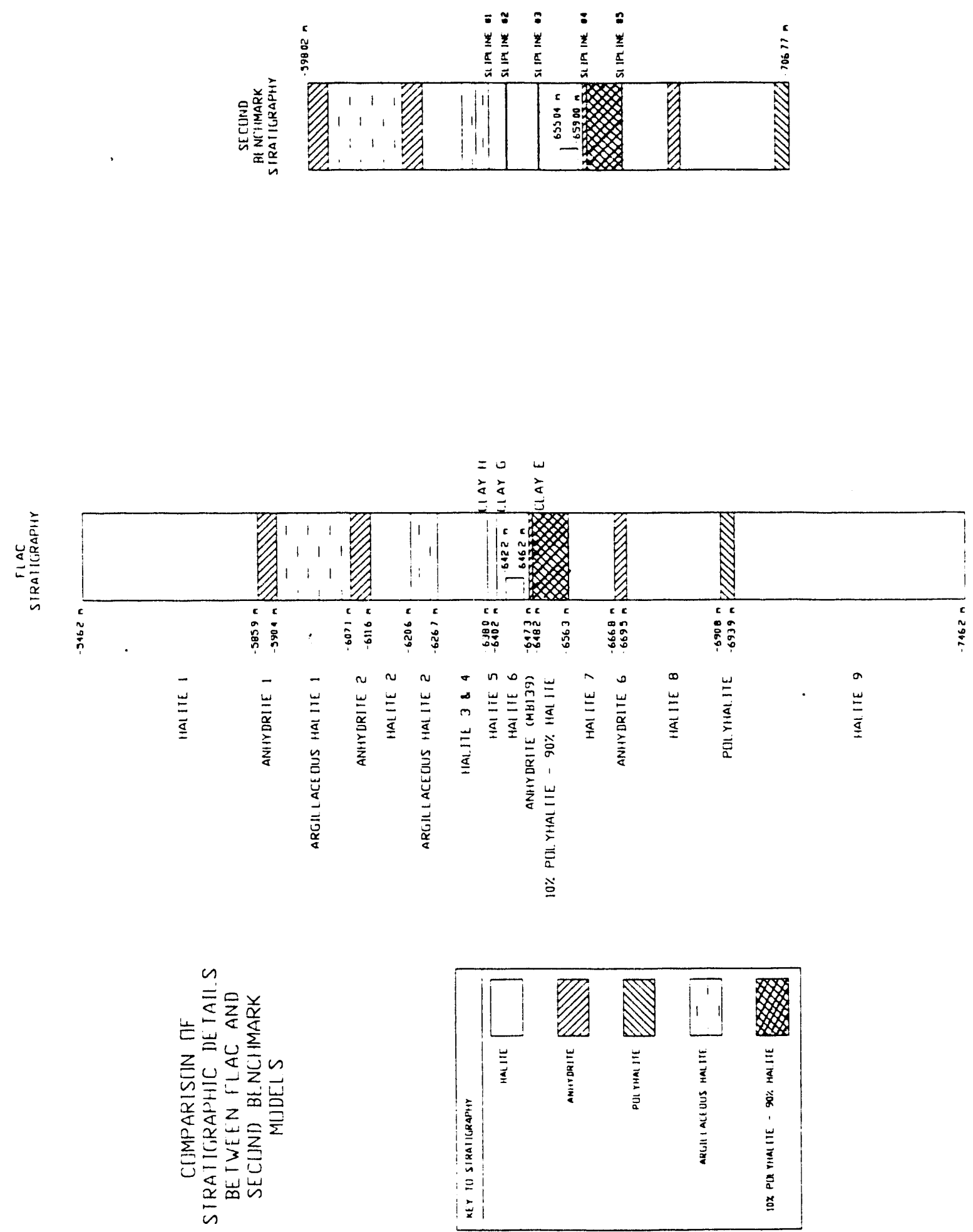

FIGURE 2.8

Siratigrapitic Details of FLAC and

Second Benchmark Problems 


\subsubsection{Modeling Parameters}

Vertical boundaries for all cases are at the center of the room and in the center of pillars. because they represent lines of symmetry and are constrained to move in the horizontal direction. The boundary condition at the top is uniform stress, and the boundary condition at the bottom was constrained vertical displacement.

The initial conditions applied to the models were in situ stresses. The initial stresses were lithostatic and equivalent to the overburden stress.

Excavation dimensions were four meters by ten meters ( 13 feet by 33 feet), and the surrounding rock was modeled from a depth of 746 meters (2448 teet) to a depth of 546 meters (1792 feet).

The material properties for the rockbolts are based on manufacturer's statements and field tests. The FLAC calculations consider bolt cross-sectional area. stiffness, and strength and grout bond stiffness and bond strength. Rockbolt properties were scaled to account for the difference between the actual three-dimensional rockbolt pattern and the two-dimensional representation by FLAC.

The creeping rock types were modeled using the WIPP reference creep law. The anhydrites and polyhalites were considered Mohr-Coulomb materials. All zones with the exception of the excavation and the interfaces were modeled as isotropic thermal materials.

\subsubsection{Results of the Comparison of FLAC to BMII}

The results of the FLAC SR2 model are compared to the SNL BMII results and a limited discussion is presented of some aspects because not all six models are applicable to the BMII results.

The vertical and horizontal closure histories for the FLAC model fit well within the bounds of the BMII results. Figure 2-9 shows the overlay of the mid-span vertical closure histories from BMIl and FLAC. For vertical closure, the FLAC model is in the upper half of the main group of BMII models. The horizontal closure history (Figure 2-10) for the FLAC model is in the upper half of the main group. The FLAC model gives slightly higher than average horizontal and vertical closure. The results indicate that the FLAC model predicts displacements as well as the other BMII models. 


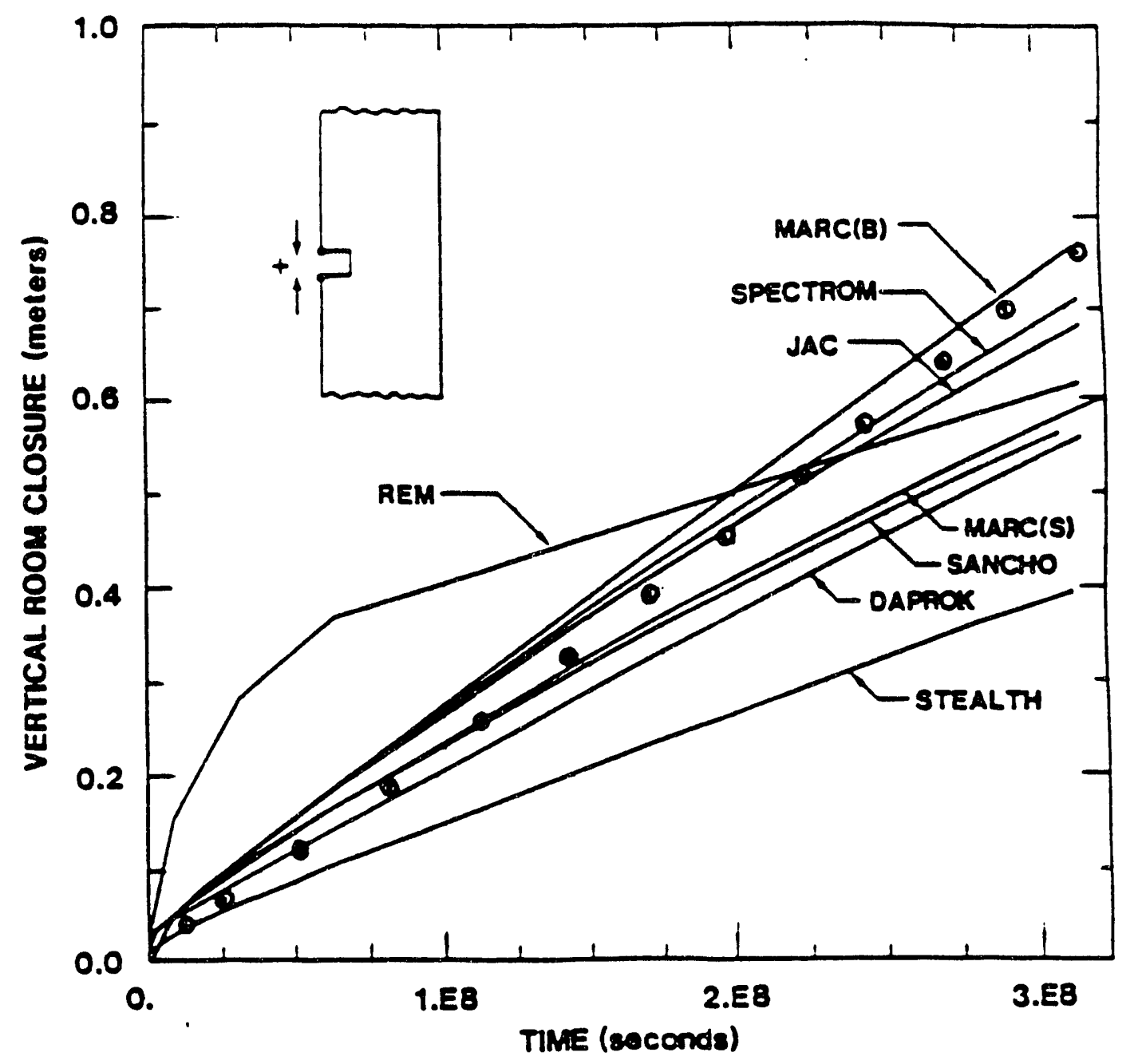

$\odot-$ FLAC 


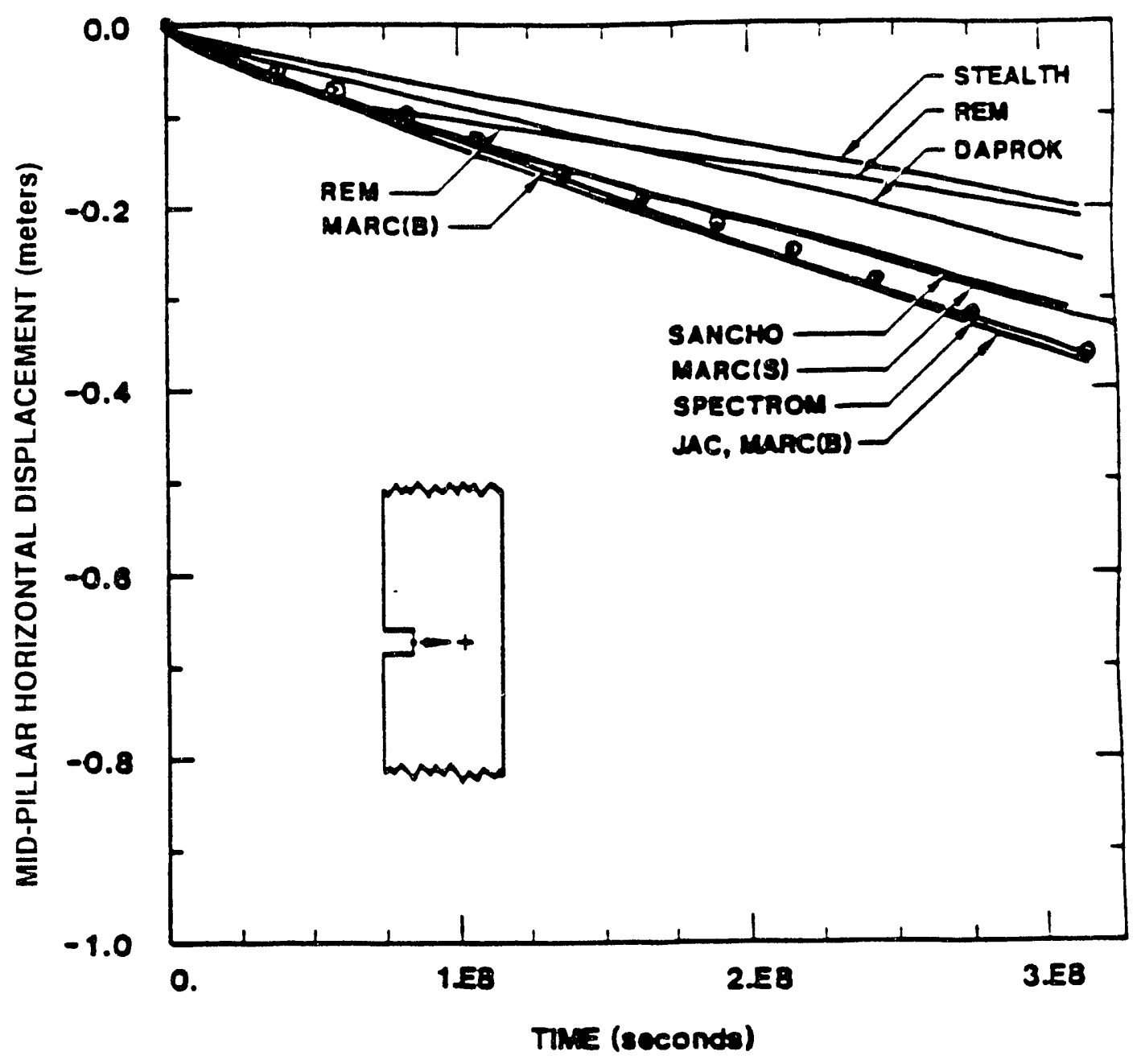

$\odot-$ FLAC 
The results of clay seam relative vertical displacements were difficult to compare because the location of the slidelines and the thicknesses of the salt beams between slidelines is different between the FLAC and BMII models. Because the friction angle of five degrees used for FLAC clay seams was higher than the zero degrees used in the BMII models and because FLAC models allow complete separation of unlimited magnitude at the clay seams. the overlays of the relative vertical displacement profile plots from BMII were not included in the comparison.

Figure 2-11 shows the clay seam relative horizontal displacement profile (shear or ride) comparison. The clay $H$ and clay $G$ interfaces in FLAC were overlain on the first slideline over the BMII excavation because this slideline was closest in elevation to clay $H$ and $G$ The clay $E$ interface in FLAC was overlain on the first slideline under the BMII excavation for the same reason (Figure 2-12).

The FLAC clay $\mathrm{H}$ interface showed shear displacements slightly less than those of the BMII models (Figure 2-11). This is reasonable considering that the BMII slideline has no other slidelines between it and the excavation. The FLAC clay G interface gives shear displacements that are essentially the same as those of the BMII models over the excavation, but are about $50 \%$ of the BMII models over the pillar. The FLAC clay E interface compared most favorably with the BMII models (Figure 2-12). This result was not surprising because the model itself is essentially the same as the BMII models in this area. However, the FLAC model does not show the negative shear displacement of clay $E$ under the pillar. Overall, the FLAC interfaces compared reasonably well with the BMII slidelines.

The differences between the FLAC model and the BMII models again made it difficult to compare the stress profiles along the vertical centerline. The horizontal profiles were much more suitable for comparison.

Effective stress through the pillar compared well to the BMll models (Figure 2-13). FLAC produced the same shape profile, but was slightly higher near the center of the pillar especially for the first few years after excavation when compared to BMII models. This may be due to the differences in stratigraphy in the models. Effective stress along the vertical centerline also compared well (Figure 2-14). The FLAC model produced stress at nearly the same level except near the anhydrites in the roof of the BMII model which are absent in the FLAC models. Overall, the effective stresses in the FLAC models compared favorably with the BMII model results. 
GFDAR

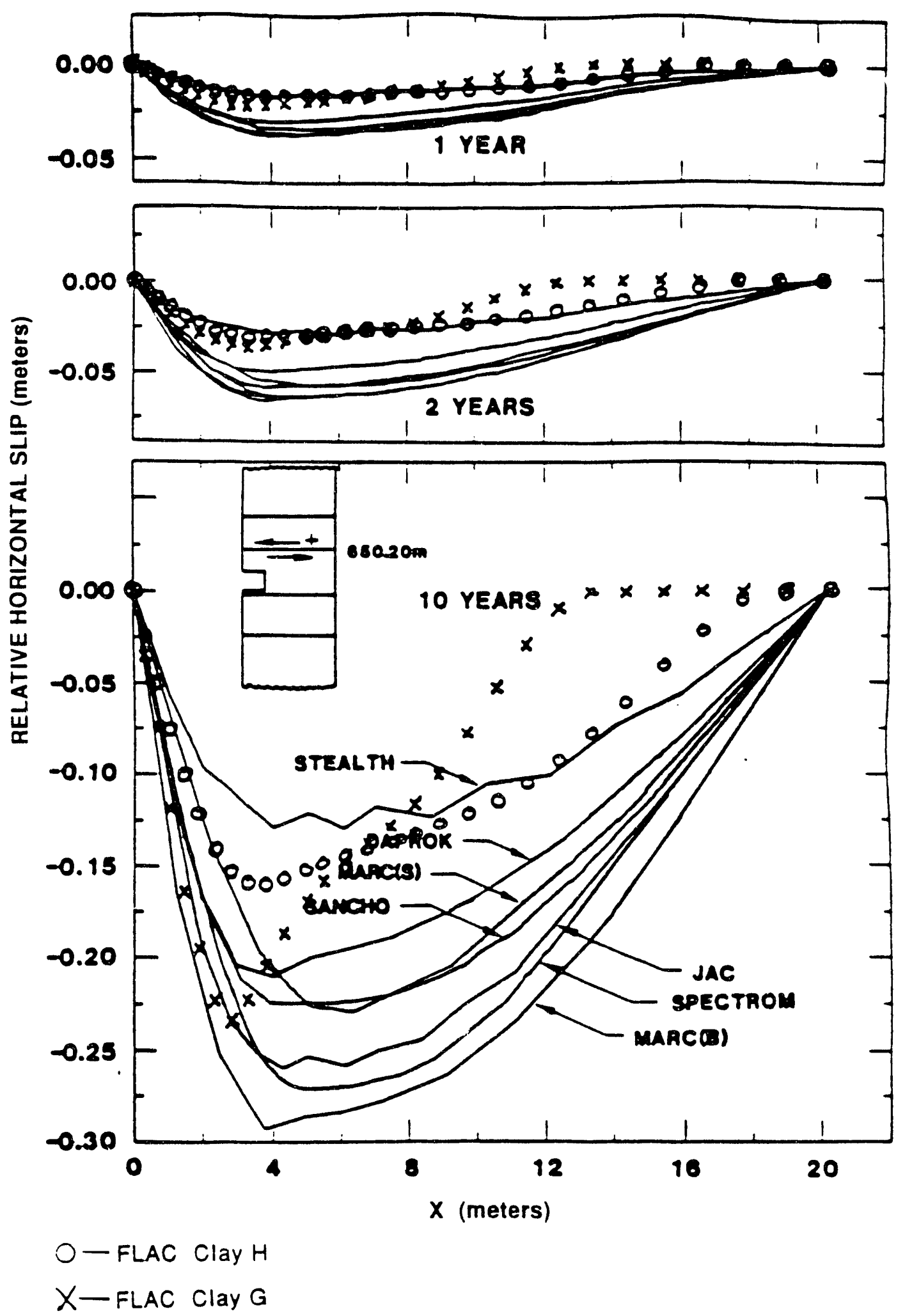

FIGURE 2.11

Revised Relative Slip Across the 650.20 meter Slide Line for the Isothermal Room at 1,2, and 10 Years (Atter Morgan et. al.. 1981) 
GFDAR
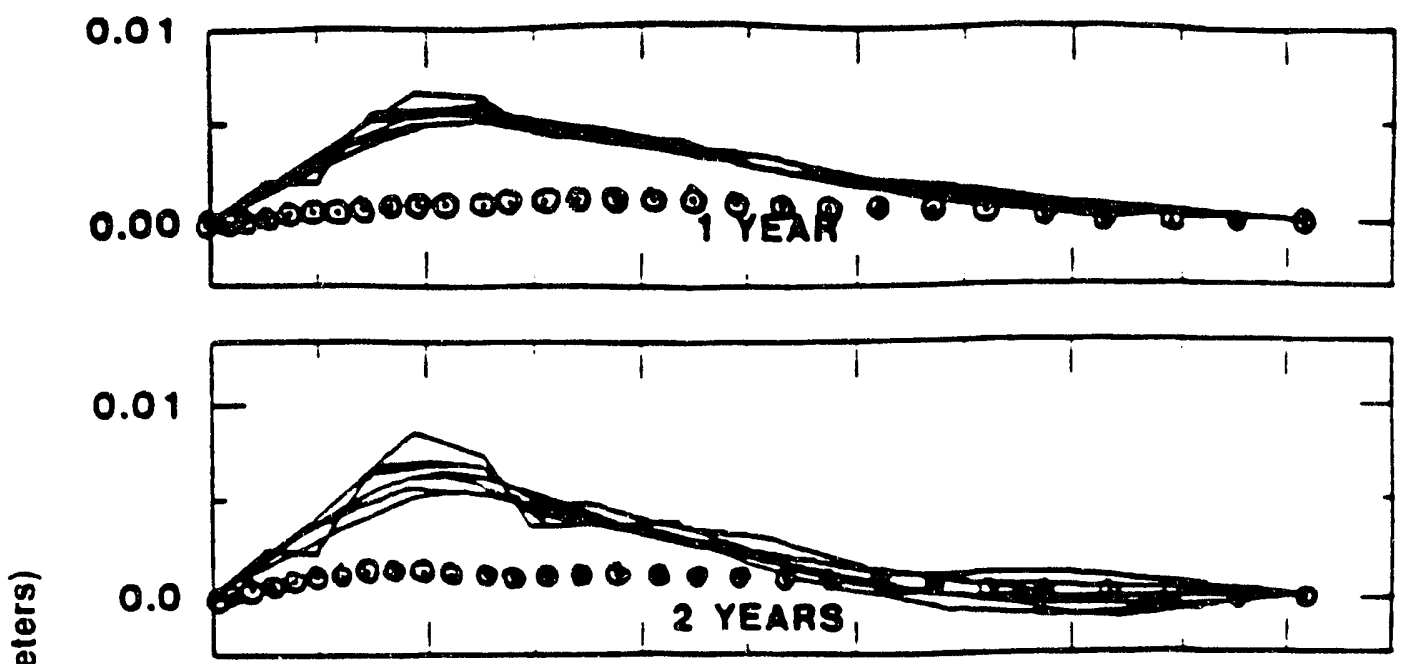

ज

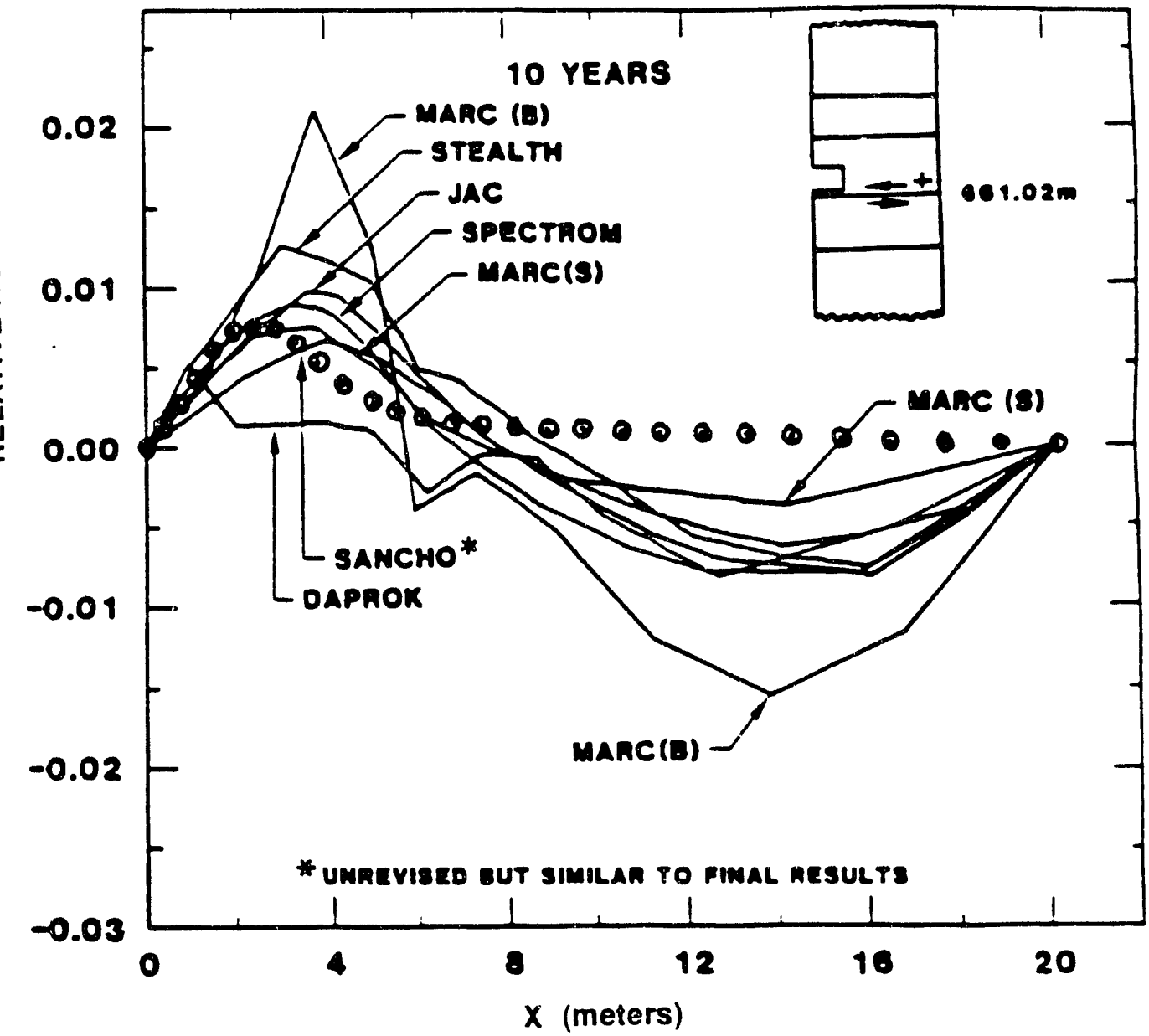

$\odot$ - FLAC Clay E 


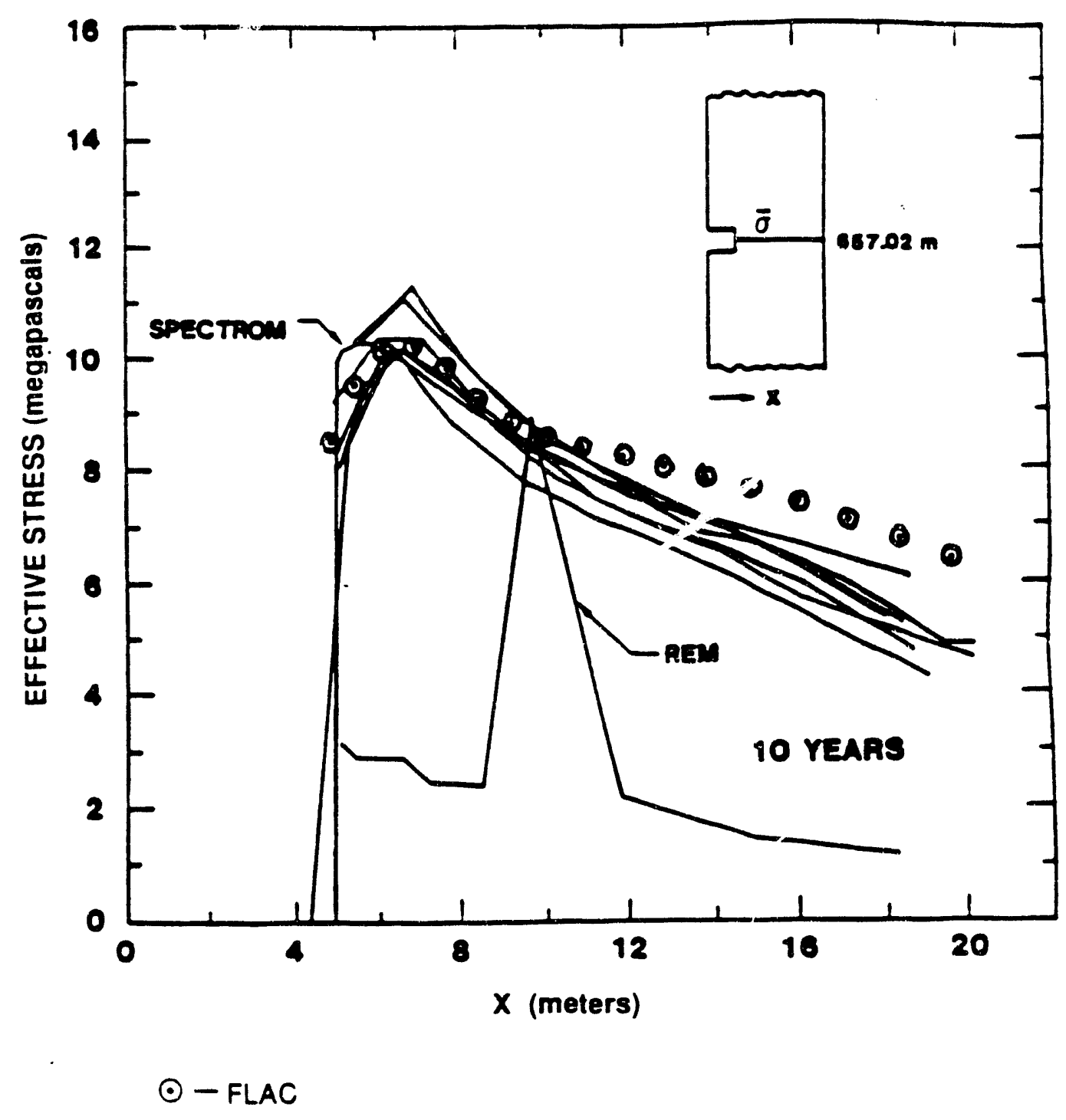

FIGURE 2.13

Revised Effective Stress Profiles through the Pillar of the Isothermal Room at 10

Years (After Morgan et. al., 1981) 


\section{GFDAR}
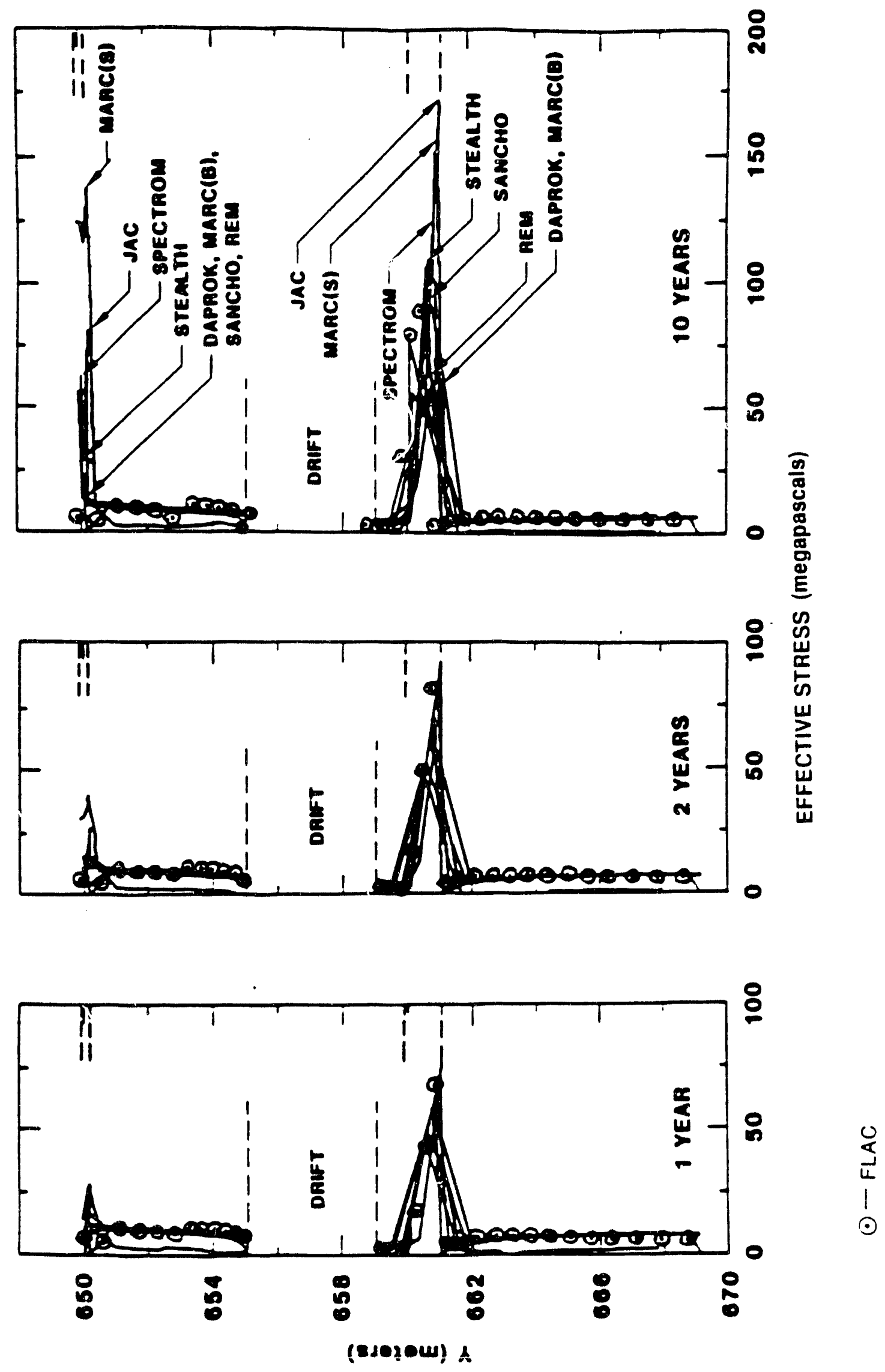

FIGURE 2.14

Revised Effective Stress Profiles Along the Vertical Centerline of the Isothermal Room for 1. 2, ard 10 Years (After Morgan et. al., 1981) 

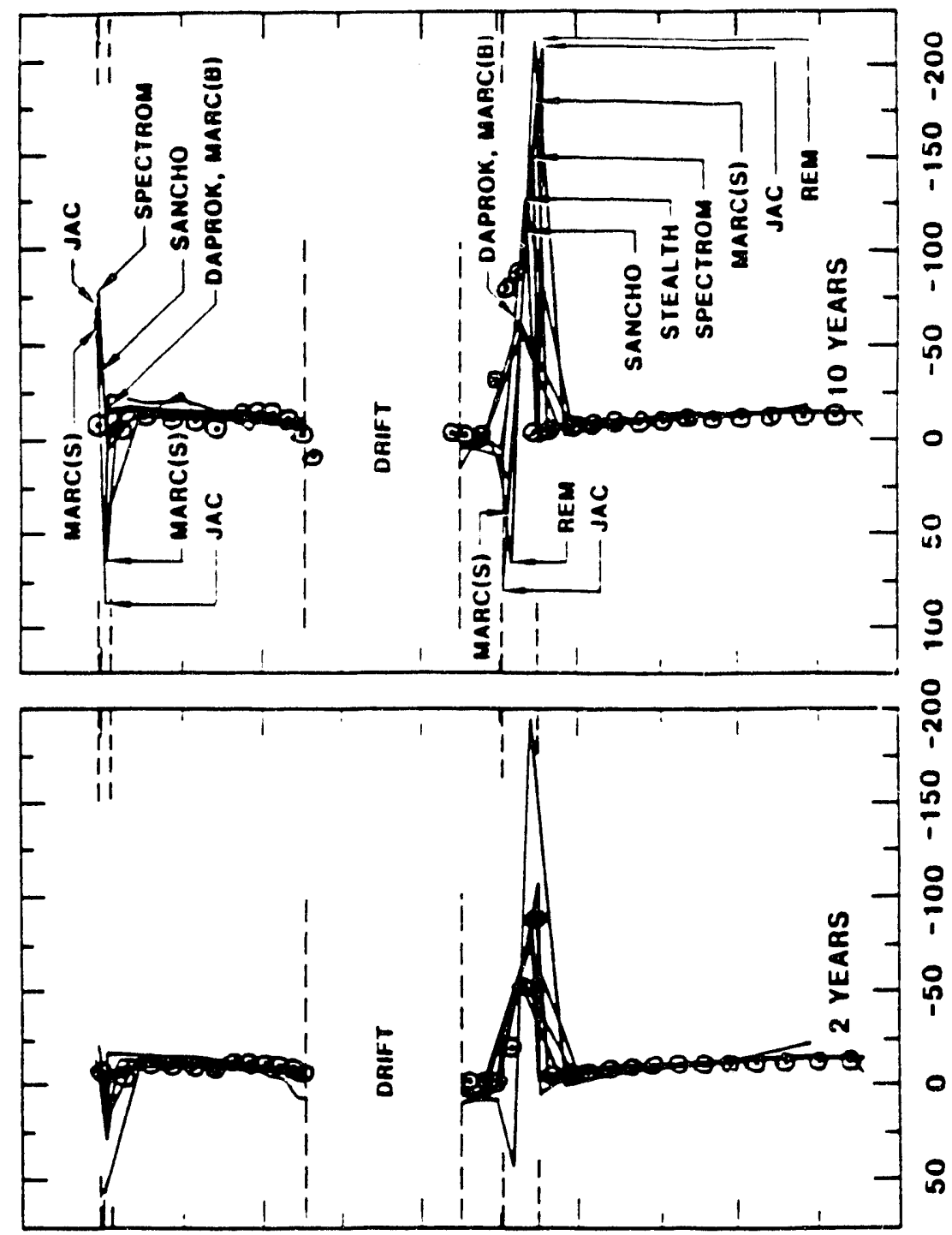

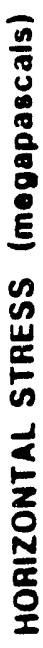

西

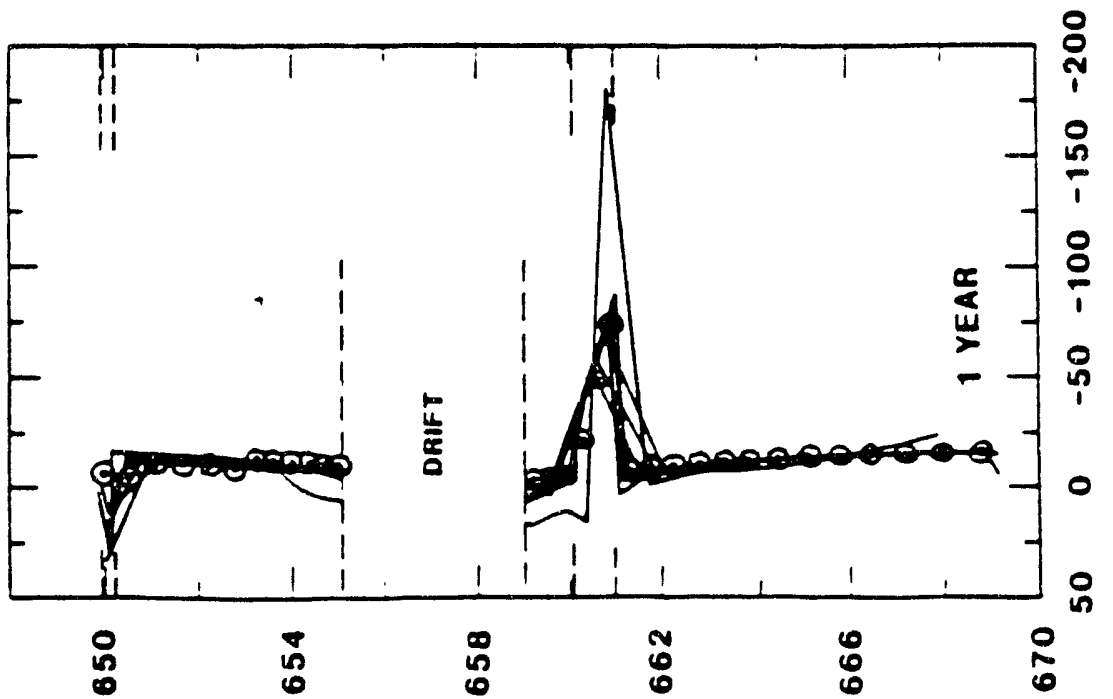

(ะseรou) $\lambda$

FIGURE 2-15

Revised Horizontal Stress Profiles Along the Vertical Centerline of the Isothermal Room for 1.2, and 10 Years (After Morgan et. al., 1981) 


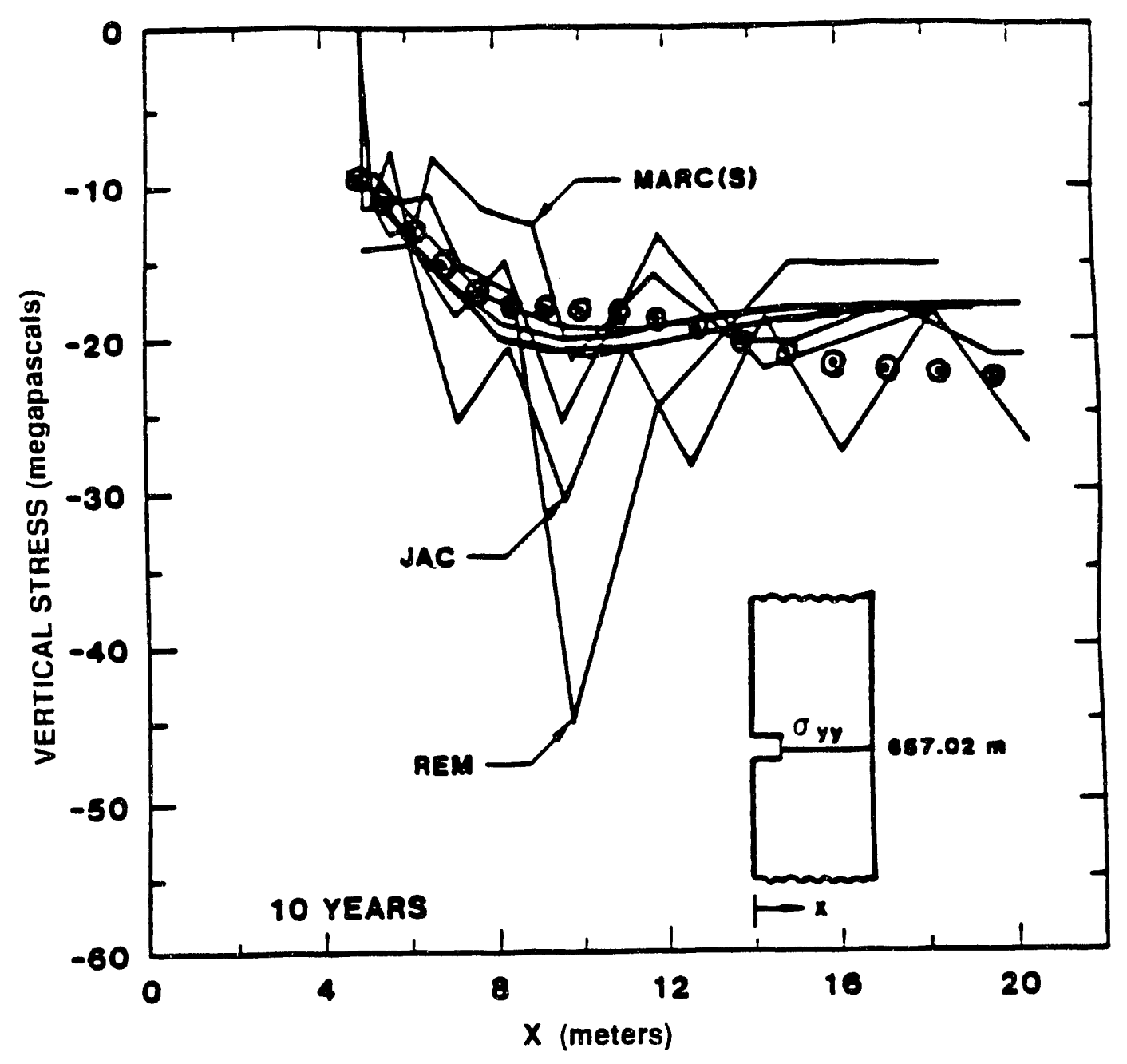

$\odot-F L A C$ 
The horizontal and vertical stress protiles from FLAC also compared well to the BMII models (Figures 2-15 and 2-16). The differences between the models are similar to those for effective stress. For vertical stress through the pillar, the FLAC model showed slightly lower stress near the center of the pillar where for effective stress it showed slightly higher stress than the BMII models in that location. Overall, the FLAC models produced stress distributions that are within the range of the BMII results.

\subsubsection{Results of FLAC Roof Beam Deformation}

The six FLAC models produce very little variation in the response of the two roof beams over the excavation. Figure 2-17 shows the deformed mesh around the excavation for two FLAC models. All the unbolted models produced a uniform sag over the length of the roof beam with varying separations at clay $G$. The SR1 model (all salt stratigraphy) produced the largest separation at clay $G$, about twice that of the other models. This was expected because the absence of the stiffer stratigraphic units in SR1 model would tend to increase the deformation around the excavation. The bolted models showed less beam sag and almost no separation at clay $G$. This is most likely due to the reinforcement provided by the rockbolts.

\subsubsection{Results of FLAC MB139 Behavior}

The material properties used for MB139 in the FLAC and BMII models make this unit excessively strong but in reality there are pre-existing tractures that weaken it. This is backed up by field observations that indicate that MB139 is essentially unable to support load due to intense, excavation-induced fractures after approximately 18 months. Therefore, the large stress buildup in the anhydrite shown by FLAC and BMII models probably does not really exist.

\subsubsection{Results of FLAC Rockbolt Modeling}

FLAC models SBO and SB1 include the installation of rockbolts two and tive years after excavation of the drift. The mesh plots (Figure 2-17) best show the effect of the rockbolts on the performance of the excavation. The SB models were the same as the SRO model except that 2.5 centimeter (one inch) diameter, 3.5 meter ( 11.5 foot) long grout anchored bolts were installed after five years in SBO. SB1 had two centimeter (3/4-inch) diameter three meter (ten foot) long point anchored bolts installed after two years in addition to the 3.5 meters $(11.5 \mathrm{ft})$ bolts after five years. The effect of installing bolts after five years was to reduce both the beam bending and the separation at clay $G$. However, the SBO model 


\section{GFDAR}

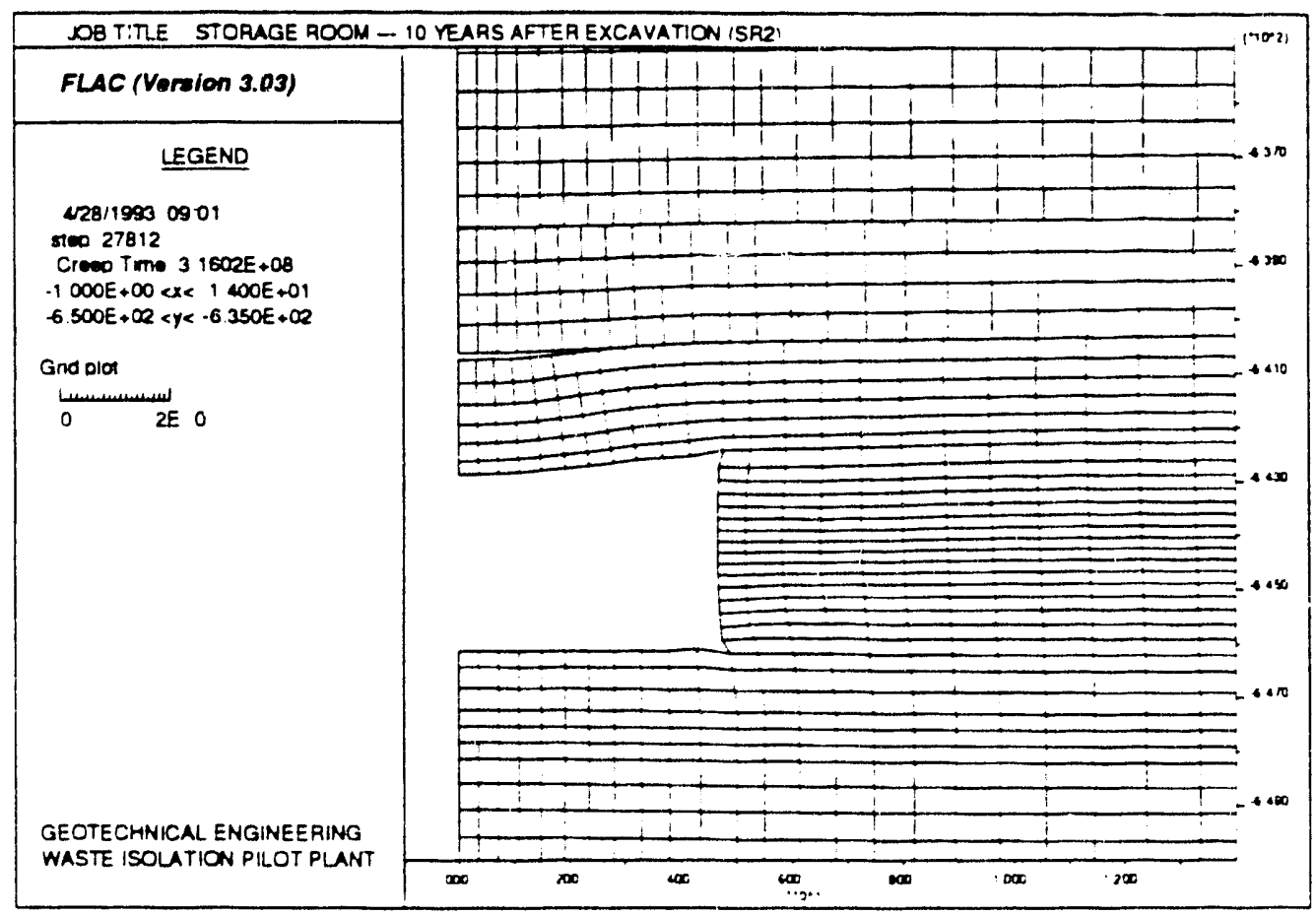

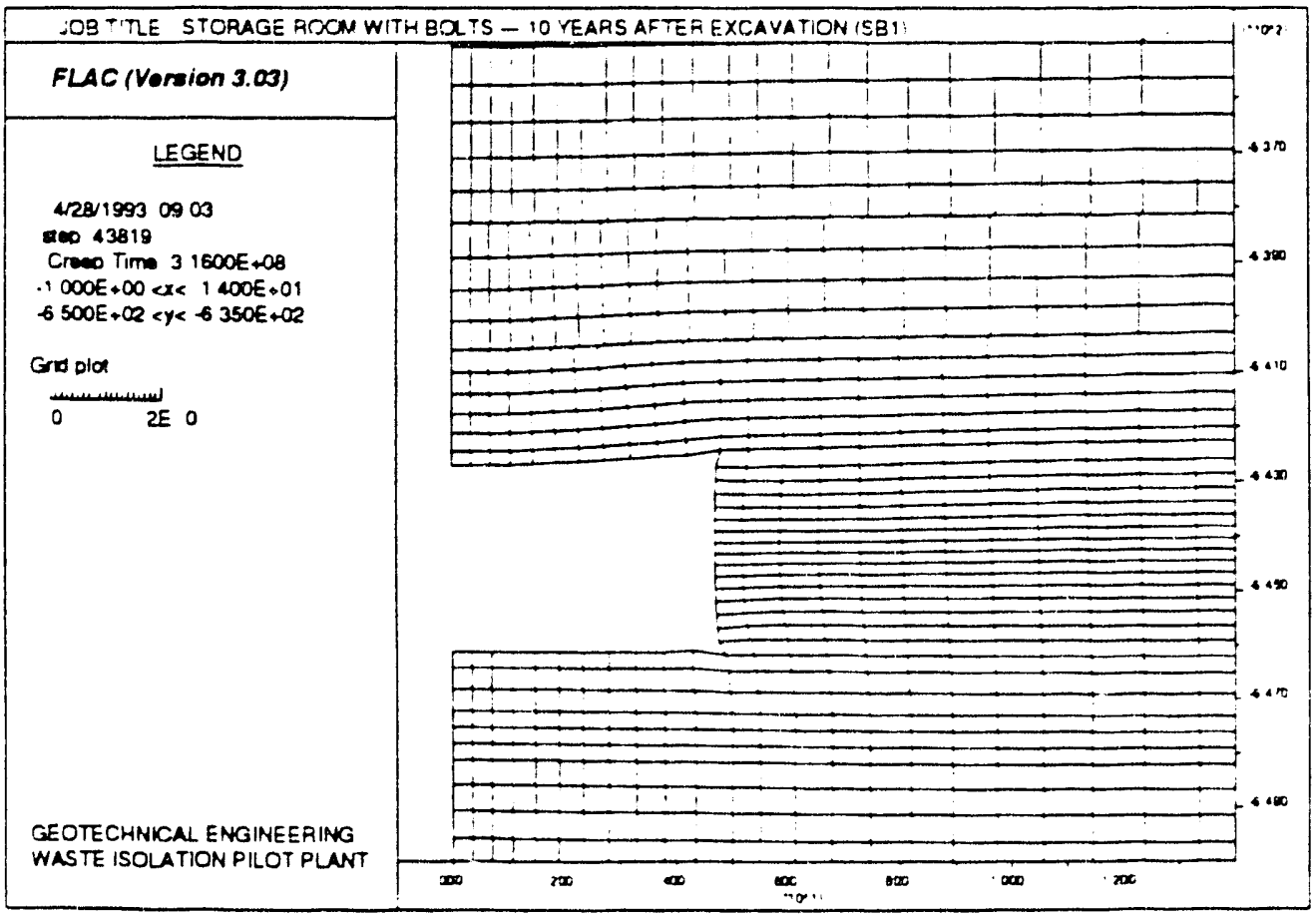

FIGUAE 2.17

Comparison of Botted and Unbolted FLAC Model Results 
showed slightly greater separation at clay $\mathrm{H}$. The effect of both sets of bolts in model SB1 was to slightly reduce the beam bending and nearly eliminate the separation at the clay seams. The FLAC model results indicated that the bolts do provide some reinforcement to the roof beams and probably reduce the onset and extent of fracturing. The bolts also reduce vertical closure in the FLAC models by about $18 \%$ over ten years, a significant amount over the life of the facility.

\subsubsection{VISCOT}

VISCOT is a computer program used to model the salt creep around excavations at WIPP. The VISCOT computer code solves two-dimensional or axisymmetric nonlinear transient thermo-viscoelastic or thermo-viscoplastic structural problems by the finite element method (INTERA, 1983). Originally, the VISCOT code was used to solve thermomechanical problems for salt creep for the high-level nuclear waste program. Currently, WIPP Engineering uses the code in interpreting underground movements for the repository.

VISCOT, in its original form, did not have the capability of modeling clay seams and separations along the salt bedding. Therefore a joint element with a constitutive relation for normal and shear deformation was added to enhance the VISCOT capabilities. The addition of the joint element has resulted in a revised program called VISJOINT.

\subsubsection{Munson-Dawson Model}

In 1985 SNL presented the results of a comparison between calculations using the 1983 reference creep law and measured closure data which showed that measured vertical closures and closure rates were at least three times larger than calculated closures and closure rates. The new Munson-Dawson constitutive creep law was developed in an attempt to resolve this discrepancy between measured and calculated room closure rates (Munson et al., 1989). The new model provides a more accurate representation of the transient strain curve using a quadratic function that replaces the earlier linear function. Although the steady-state portion of the model formulation remains as initially presented by Munson and Dawson, minor improvements have been added. Furthermore, the model now uses a Tresca creep flow potential in place of the previously used von Mises flow potential. Munson et al. (1989) simulated Room $D$ using the new constitutive model. Munson et al. (1989) used a modified stratigraphy, based on a re-evaluation of underground conditions, and modeled the clean salt and argillaceous salt layers and clay seams. They did not include the anhydrite and polyhalite layers in their analysis, assuming that the layers would have an insignificant effect on the result. The comparison between calculated and 
measured in situ Room $D$ closures showed a good correlation. A description of the formulation of the new Munson-Dawson model is provided in Appendix A.

Callahan and DeVries (1991) used the new Munson-Dawson constitutive creep law for analysis of WIPP backfilled disposal rooms. Because the backfill initially has high porosity. it does not provide any initial resistance to the ronm creep closure. Therefore, the closure history of the backfilled room should be very similar to that of an open drift at early times (Sjaardema and Krieg, 1987).

For purposes of this report. the analysis of a WIPF storage room using VISJOINT with the 1983 SNL Reference Creep Law (Krieg, 1984) will be referenced as Case A which allows opening of the joints. The result of the analysis of a WIPP storage room by Callahan and DeVries will be referenced as Case $B$

The 1983 SNL Reference Creep Law (Case A) and the Callahan and DeVries (Case B) both indicate a reasonably good agreement between prediction and measurement of room closure in SPDV Rooms 1, 2, and 4. Note that Case A uses the 1983 reterence creep law and employs the joint element that allows for opening to occur along clays $G$ and $H$. whereas Case $B$ uses the new Munson-Dawson model and does not simulate the opening along bedding planes or joints.

\subsubsection{Implementation of the Munson-Dawson Model into VISJOINT}

The new Munson-Dawson constitutive creep law was implemented into the VISJOINT code to predict the behavior of the WIPP rooms and to provide additional comparisons.

Three different finite element meshes (Figure 2-18) were prepared for a four meter by ten meter ( 13 foot by 33 foot) room to examine the effect of modeling clays $G$ and $H$. The three meshes are:

Case 1: Uses the new Munson-Dawson constitutive creep law and allows for shearing and opening of joints. The mesh consists of 405 nodes and 357 elements.

Case 2: Uses the new Munson-Dawson constitutive creep law and has a mesh with joints that can shear but cannot open. The mesh consists of 405 nodes and 357 elements. 

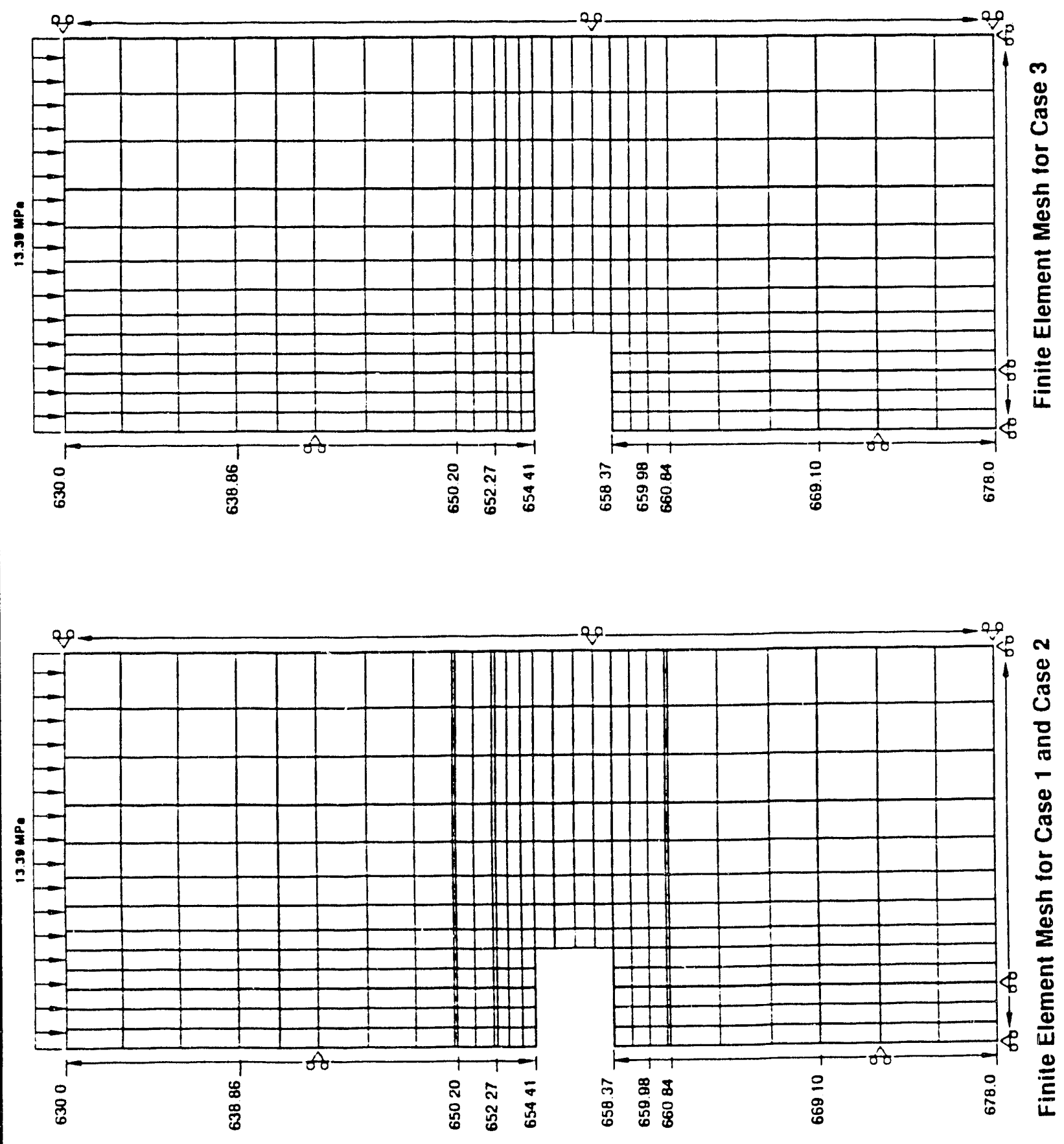

FIGURE 2-18

Finite Element Mesh for VISJOINT Mode!s 
Case 3: Uses the new Munson-Dawson constitutive creep law and has a mesh without joints containing 363 nodes and 318 elements.

\subsubsection{Modeling Parameters}

Vertical boundaries for all cases are in the center of the room and in the center of pillars. since they represent lines of symmetry and are constrained against movement in the horizontal direction. The boundary condition at the top is uniform stress. and the boundary condition at the bottom is constrained displacement. In order to compare the results with those of Case B (Callahan and DeVries, 1991), it was assumed that the rooms are located in a homogeneous layer of bedded salt. Because of the memory limitation of the program. only the surrounding rock from a depth of 678 meters (2224 feet) to a depth of 630 meters (2067 feet) was modeled. Joint elements were used tc model clay $\mathrm{H}$ at a depth of 650 meters (2133 feet), clay $G$ at a depth of 652 meters (2140 feet) and clay $E$ at the bottom of MB139 at a depth of 661 meters (2168 feet). In situ stress was assumed to be hydrostatic.

\subsubsection{VISJOINT Results}

The Munson Dawson constitutive creep law was implemented into the VISJOINT code and validated by comparing the results of Case 3 (Munson-Dawson Constitutive Creep Law without joints) with those of Case B (Callahan and DeVries. 1991).

Case A, 1983 WIPP reference creep law allowing the opening of joints, and Case 3. Munson-Dawson constitutive creep law without joints, showed good agreement with actual WIPP closure data over a period of eight years. However, Case 3 ignores the opening along bedding planes and is therefore not physically realistic.

Case 1 using Munson-Dawson constitutive creep law allowing the opening of joints, and Case 2 using Munson-Dawson constitutive creep law with joints that can shear but not open. showed a much higher convergence, about 200 to 400 percent of measured convergence. From the comparison. Case 1 and Case 2 do not seem appropriate for modeling the behavior of storage rooms.

Cases $A, B$, and 3 provided good results when compared to actual measured convergence from SPDV Rooms 1.2, and 4 (Figure 2-19). 
GFDAR

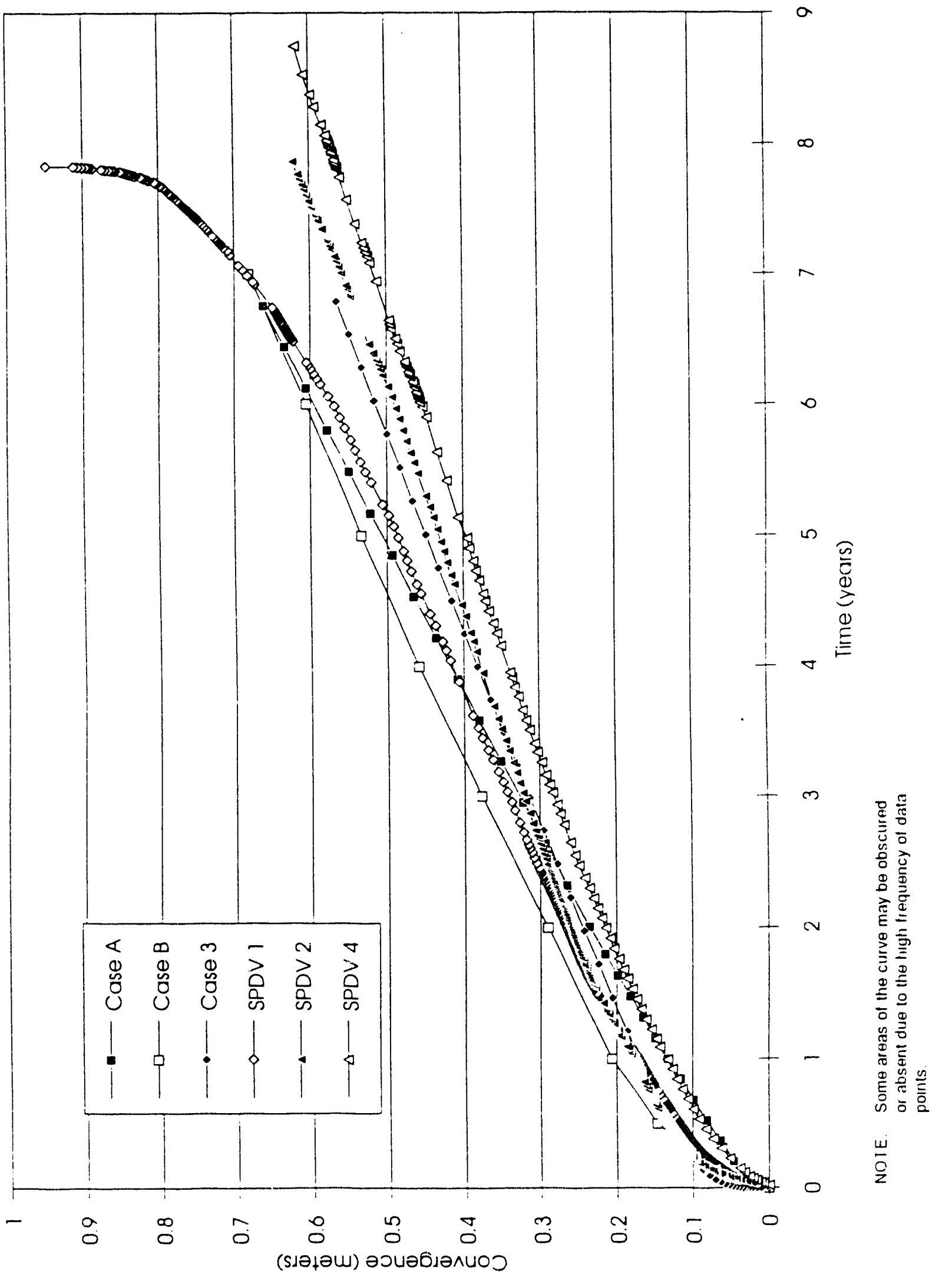

FIGURE 2-19

Comparison of Model Results to Field Data 


\subsection{Excavation Effects Program}

Excavation effects, which are the structural responses of the rock mass to excavation, have been observed and monitored since mining of the underground facility began at WIPP. A historical summary of excavation effects is presented in Table 3-1. During this reporting period. observations of excavation effects have included:

1.) observations of subsurface fractures in boreholes;

2.) mapping of fractures on excavation surfaces:

3.) observations of rockbolt failures.

These observations detect, quantify, and assist in the interpretation of fractures and bed separations that result from the excavation of salt in the underground. The magnitudes of fracture apertures or of bedding plane separations are recorded as the value at the excavation surface in which such features are found. When possible, indirect measurement or visual estimates are made of the distance a fracture or separation continues into the rock. Spalls are localized areas of rock that have a plane of separation subparallel to and very near an excavation surface, and are usually scaled off or controlled with combinations of rockholts and wire mesh.

\subsection{Borehole Fracture Observations}

Systematic borehole observations were started in mid-1986 to study fracturing and separations in the roof and the floor of the repository. This program consists of an annual inspection of boreholes, 2 to 4 meters ( 6 to 12 feet) deep, that are arranged in arrays located throughout the underground as shown in Figure 3-1. A typical array is shown in Figure 3-2. These observations are subjective and have been conducted by more than one individual in past inspections. Variations in the field data and in its subsequent interpretation must be taken into consideration when evaluating the results presented here.

The original 161 boreholes (30 arrays) were drilled in 1986. Eighteen additional boreholes ( 6 arrays) were drilled in 1991 . Only 78 of the original 161 boreholes were available for inspection during this reporting period. The other holes, primarily floor holes. were destroyed by mining activities or were otherwise inaccessible. No new arrays were drilled during this reporting period. 


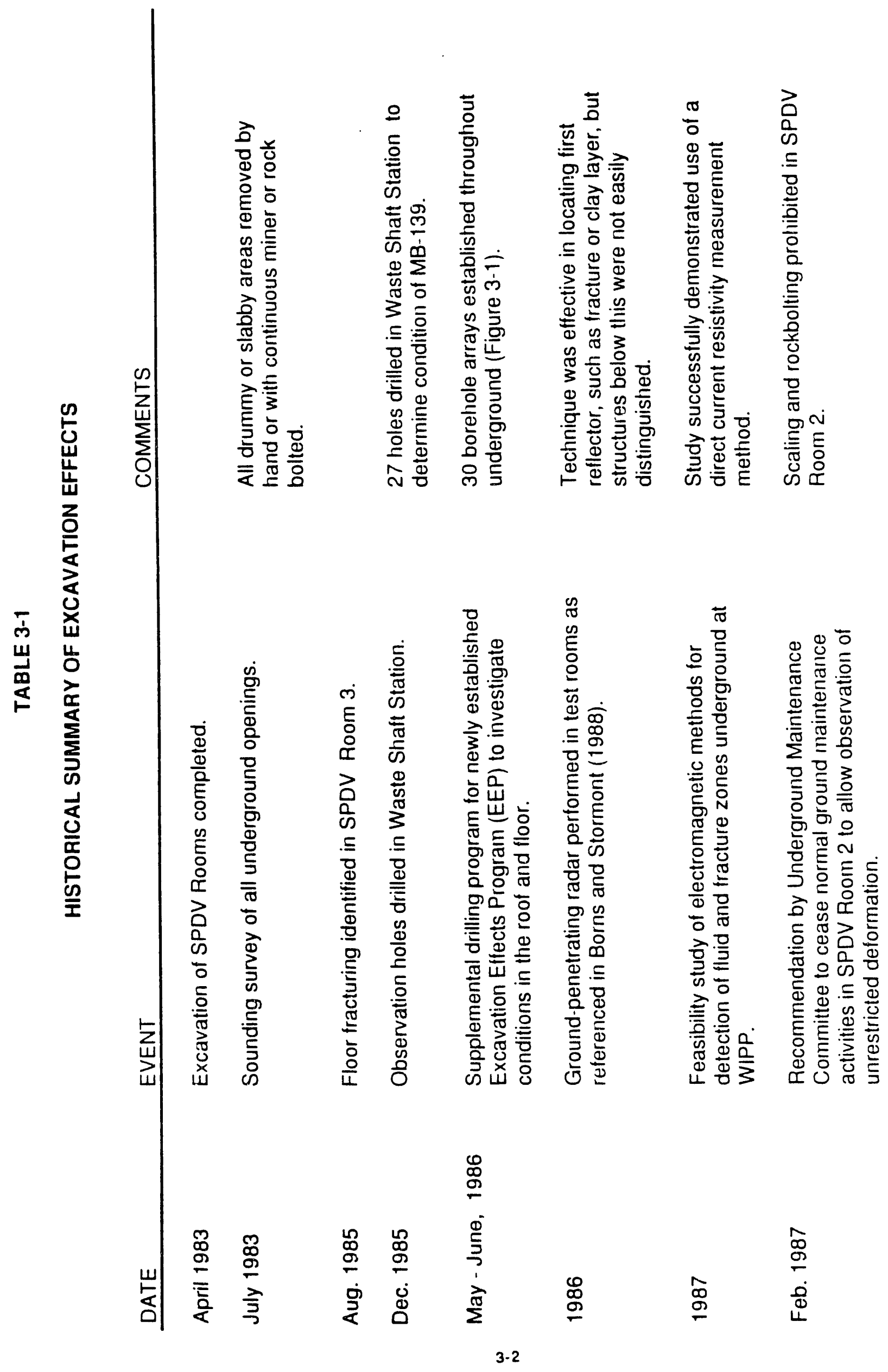




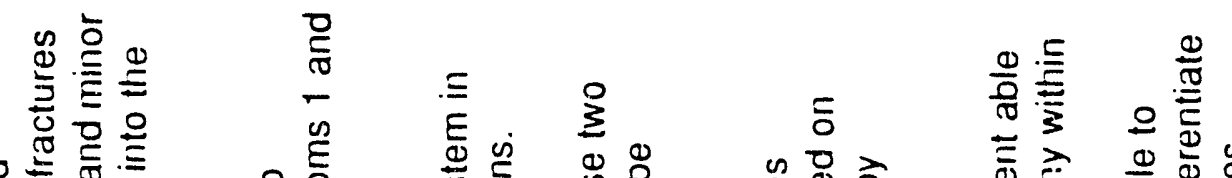

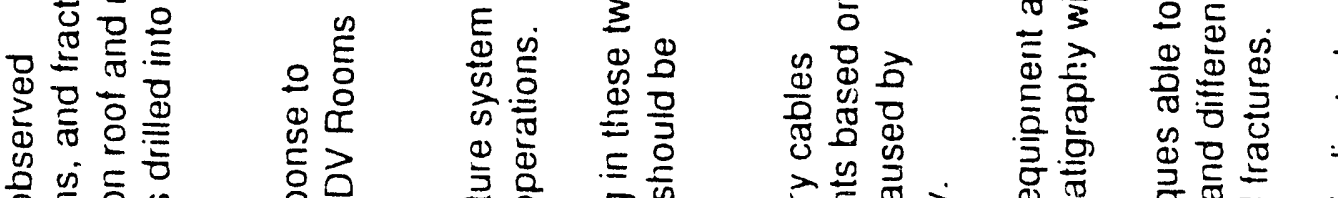

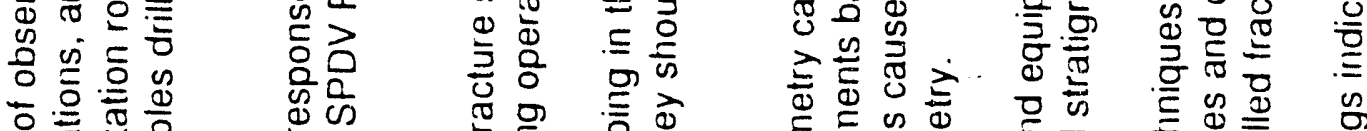

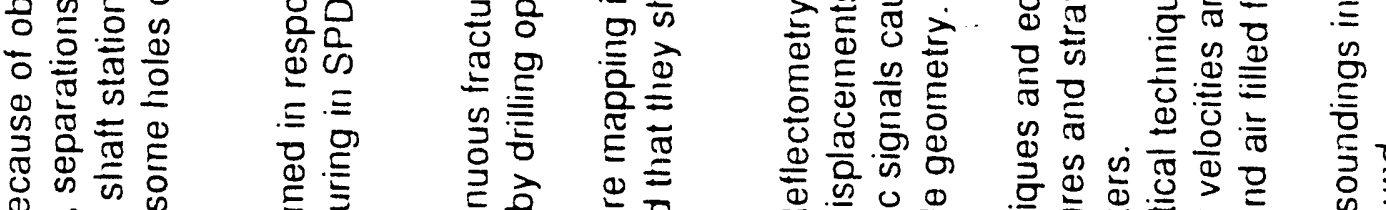

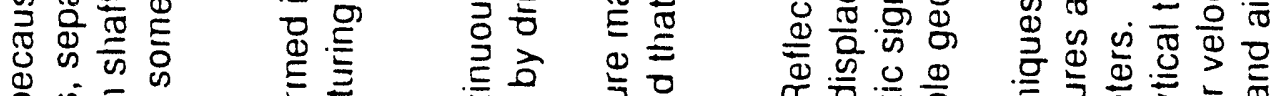

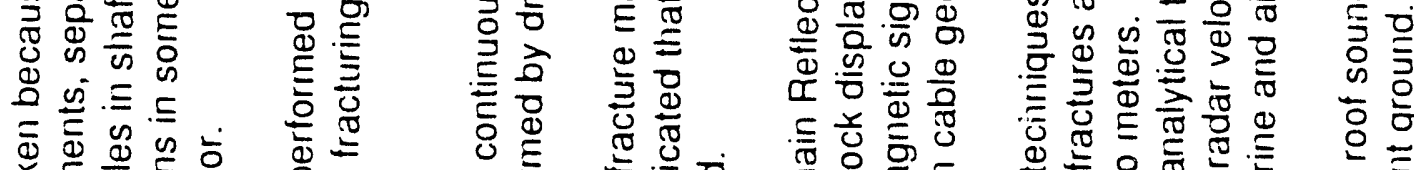

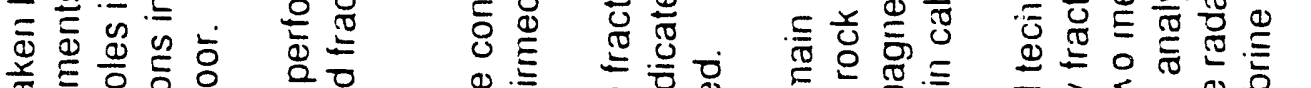

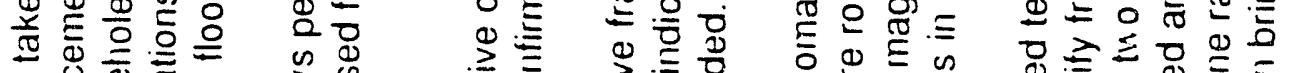

出

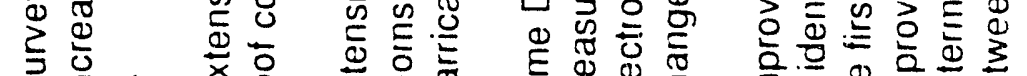

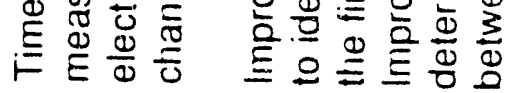

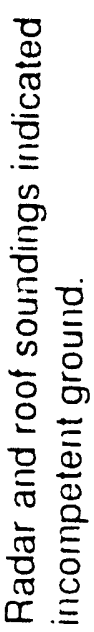

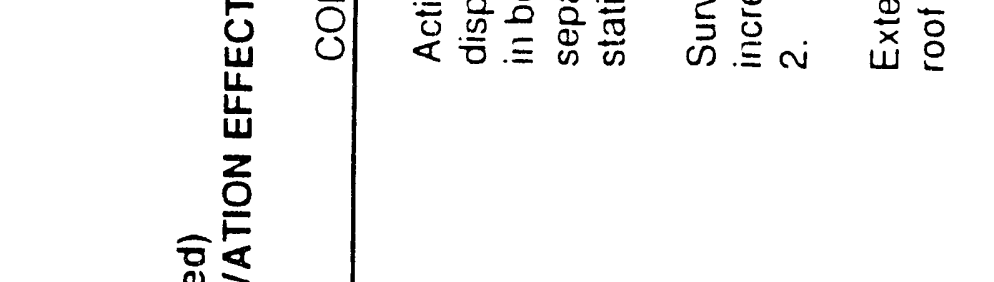

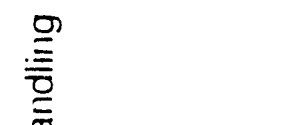

$\frac{\mathrm{S}}{\alpha}$

옴

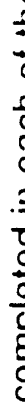

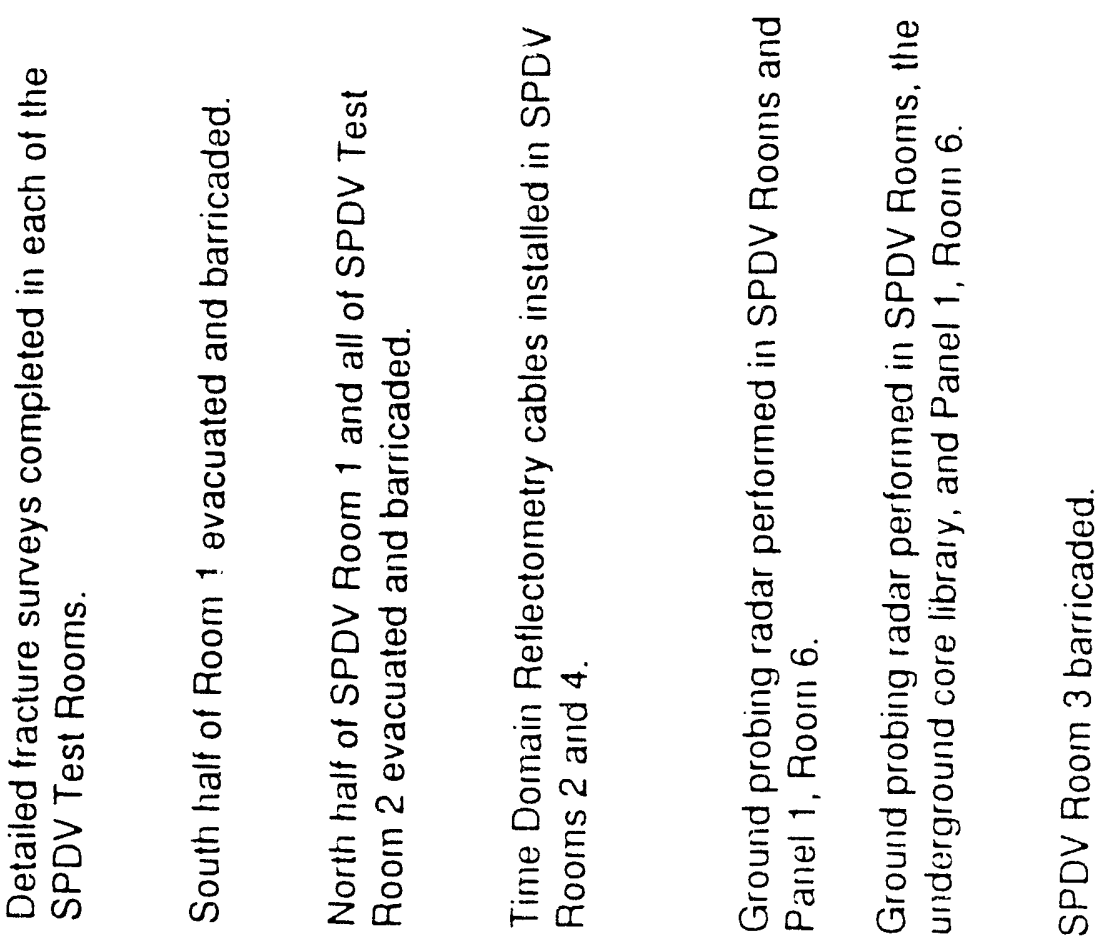

으

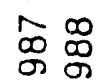

-

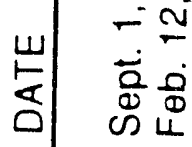

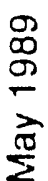

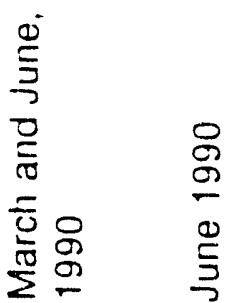




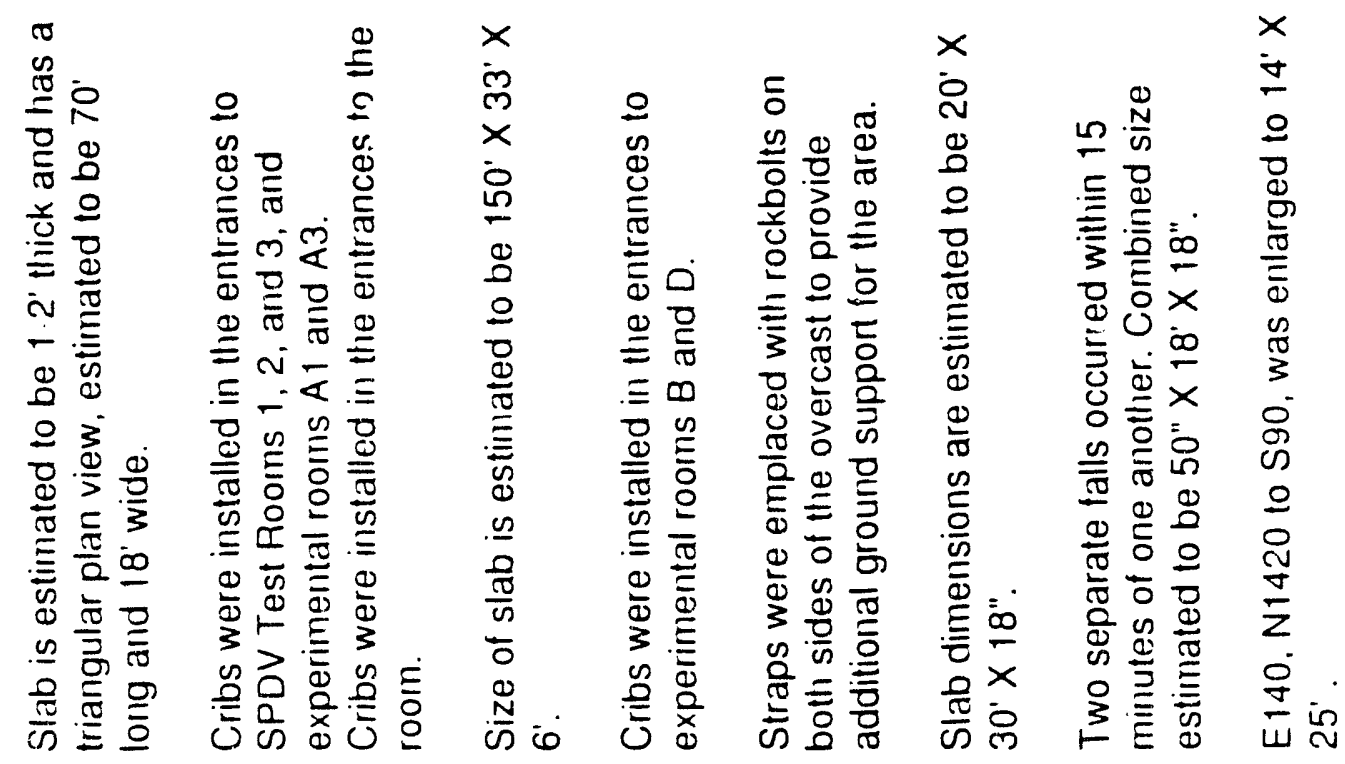

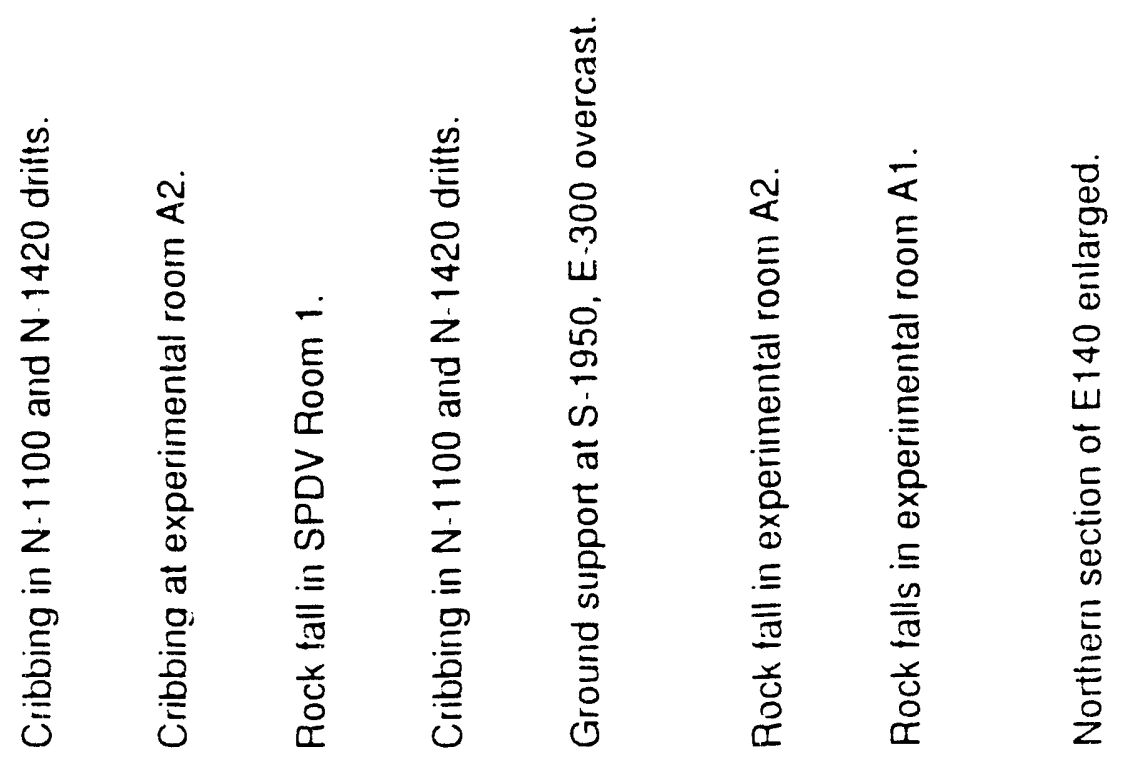

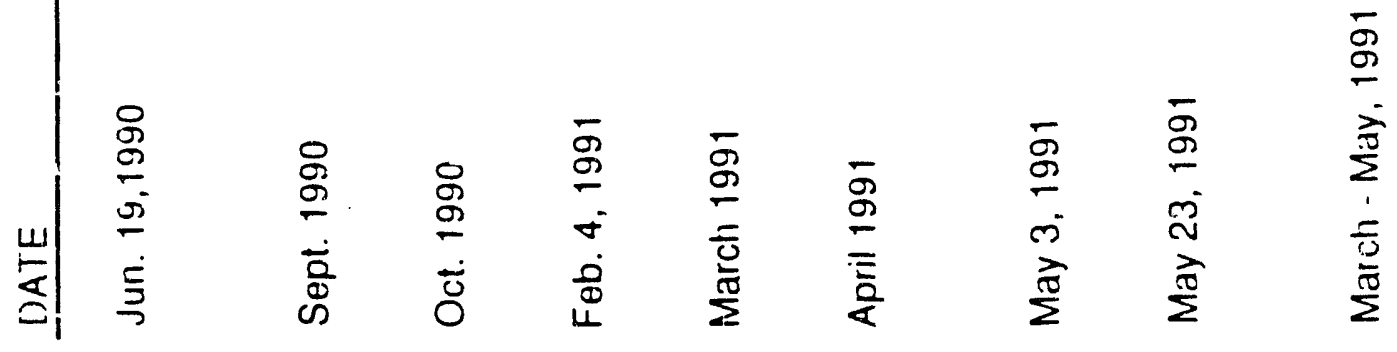




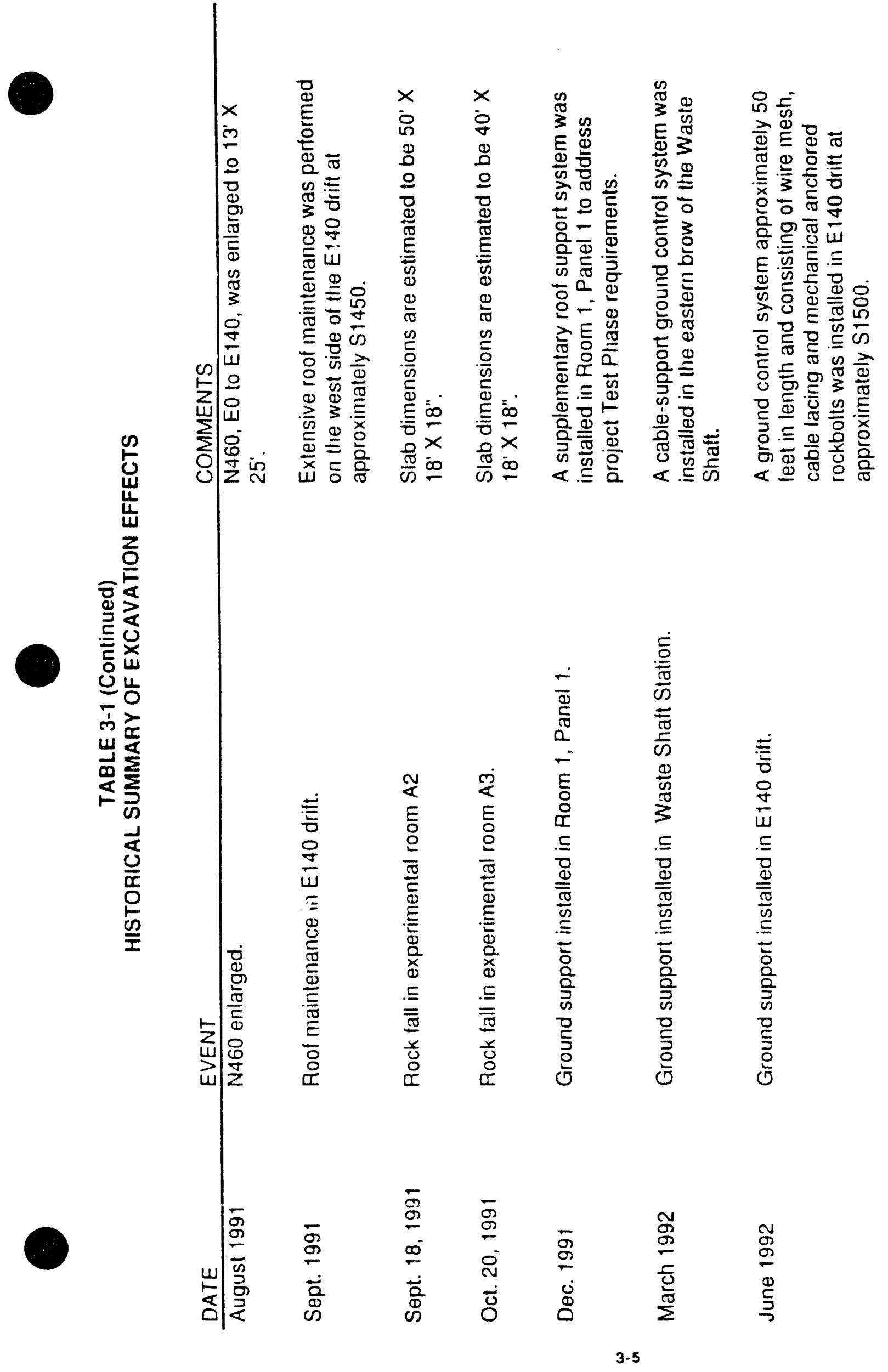




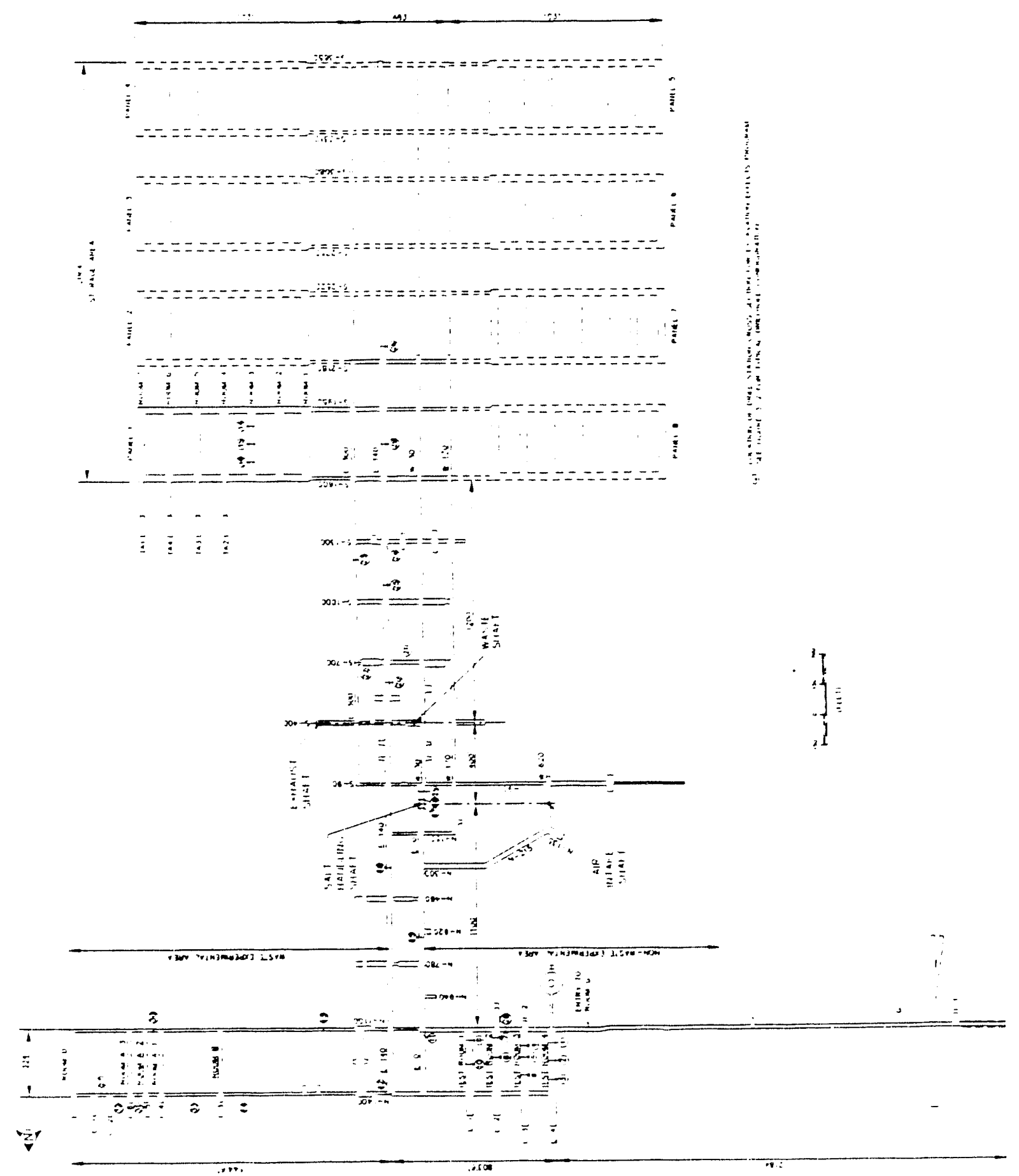

FIGURE $3-1$

Borehole Locations for the Excavation Effects Program 


\subsubsection{Interpretation of}

\section{Fracture Observations}

The results of the 1992 survey are compared with the results of previous surveys in Table 3-2. The data for each array are presented in Figures 3-3 to 3-38. The fractures and their distribution in roof and floor boreholes are interpreted.

The main conclusions that can be drawn from the data are that as the excavations age:

- fractures and horizontal offsets increase

- width of fractures and separations increases

- relative displacement at horizontal offsets increases

Horizontal offsets in the roof usually occur within the first few inches of the back as shallow spalls or at clay seams. The majority of these offsets are

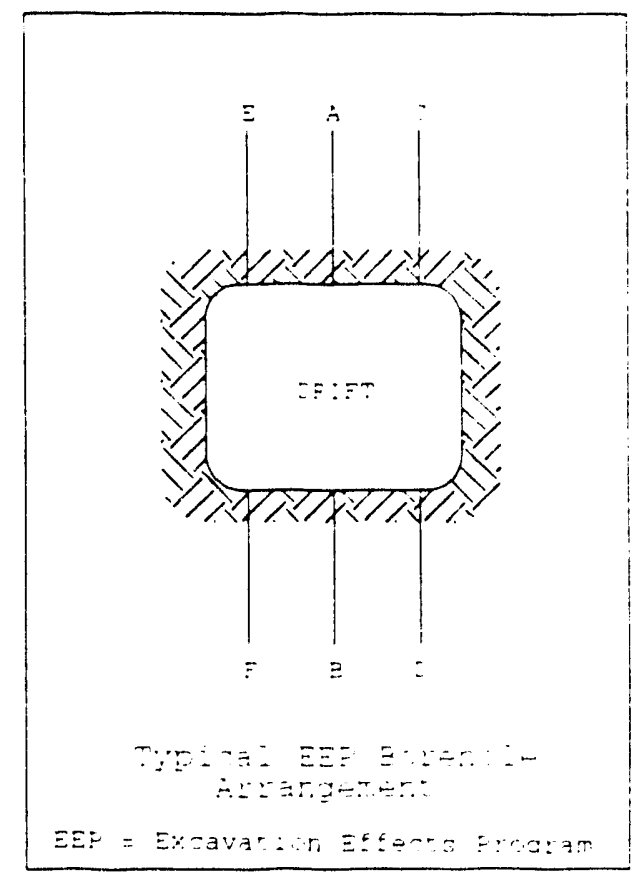

Figure 3-2 observed near the ribs, with the portion of the borehole from the collar to the offset moving towards the center of the excavation.

Floor fractures tend to occur with similar frequencies near ribs and at mid-span. Horizontal offsets in the floor are generally associated with fractures that define large. shallow, dish-shaped slabs. Access into many of the floor holes has been lost due to horizontal offsetting or infilling with salt debris.

Fourteen percent of all fractures recorded in this year were open wider than 0.3 centimeters ( $1 / 8$ inch). The largest of the fractures are located within the first foot of the excavations, as shallow spalls.

\subsubsection{Results}

Fractures and separations below the surface of excavations may be present before inspection boreholes are drilled; however, offsets do not manifest themselves until some time has passed after drilling. Results from the survey are presented in two groups to separate offset information for boreholes drilled at different times. Arrays 1 through 30 (original EEP system) were drilled in 1986, and offsets were first recorded for many of 
Table 3-2

Cumulative Data from Excavation Effects Program

\begin{tabular}{|c|c|c|c|c|c|c|c|c|c|}
\hline $\begin{array}{l}\text { Percent of } \\
\text { Holes with: }\end{array}$ & $\begin{array}{c}\text { Hole } \\
E \\
(\%)\end{array}$ & $\begin{array}{c}\text { Hole } \\
\text { A } \\
(\%)\end{array}$ & $\begin{array}{c}\text { Hole } \\
C \\
(\%)\end{array}$ & $\begin{array}{c}\text { Hole } \\
F \\
(\%)\end{array}$ & $\begin{array}{c}\text { Holf } F_{i} \\
\text { B } \\
(\%)\end{array}$ & $\begin{array}{c}\text { Hole } \\
D \\
(\%)\end{array}$ & $\begin{array}{c}\text { All } \\
\text { Roof } \\
\text { Holes } \\
(\%)\end{array}$ & $\begin{array}{l}\text { All } \\
\text { Floor } \\
\text { Holes } \\
(\%)\end{array}$ & $\begin{array}{c}\text { All } \\
\text { Holes } \\
(\%)\end{array}$ \\
\hline $\begin{array}{c}\text { Fracturing } \\
1986 \\
\end{array}$ & 22 & 28 & 22 & 29 & 46 & 36 & 24 & 37 & 30 \\
\hline $\begin{array}{c}\text { Fracturing } \\
1987 \\
\end{array}$ & 41 & 52 & 41 & 46 & 62 & 64 & 44 & 57 & 51 \\
\hline $\begin{array}{c}\text { Fracturing } \\
1988 \\
\end{array}$ & 52 & 64 & 52 & 54 & 65 & 71 & 56 & 63 & 60 \\
\hline $\begin{array}{c}\text { Fracturing } \\
1989\end{array}$ & 63 & 80 & 67 & 61 & 69 & 71 & 70 & 67 & 68 \\
\hline $\begin{array}{c}\text { Fracturing } \\
1990 \\
\end{array}$ & 78 & 88 & 78 & 71 & 77 & 79 & 81 & 76 & 78 \\
\hline $\begin{array}{c}\text { Fracturing } \\
1991 \\
\end{array}$ & 81 & 88 & 78 & 71 & 77 & 79 & 82 & 76 & 79 \\
\hline $\begin{array}{c}\text { Fracturing } \\
1992 \\
\end{array}$ & 81 & 92 & 89 & 79 & 77 & 79 & 87 & 76 & 81 \\
\hline $\begin{array}{c}\text { Horizontal Offsetting } \\
1987 \\
\end{array}$ & 63 & 32 & 63 & 21 & 35 & 21 & 53 & 26 & 39 \\
\hline $\begin{array}{c}\text { Horizontal Offsetting } \\
1988 \\
\end{array}$ & 78 & 44 & 85 & 32 & 46 & 43 & 70 & 40 & 55 \\
\hline $\begin{array}{c}\text { Horizontal Offsetting } \\
1989 \\
\end{array}$ & 85 & 60 & 89 & 46 & 54 & 46 & 78 & 49 & 63 \\
\hline $\begin{array}{c}\text { Horizontal Offsetting } \\
1990 \\
\end{array}$ & 89 & 64 & 93 & 54 & 58 & 54 & 82 & 55 & 68 \\
\hline $\begin{array}{c}\text { Horizontal Offsetting } \\
1991 \\
\end{array}$ & 89 & 80 & 93 & 54 & 62 & 54 & 87 & 56 & 71 \\
\hline $\begin{array}{c}\text { Horizontal Offsetting } \\
1992 \\
\end{array}$ & 93 & 80 & 93 & 57 & 62 & 54 & 89 & 57 & 73 \\
\hline
\end{tabular}

Notes

1. Section locations and typical hole configurations are shown on Figure 3-1.

2. Observabons were made using a probe consisong of a nail attached perpendicular to the end of a rod.

3. Observadons from previous surveys were used for inaccessible holes.

4. Percentages for 1991 and 1992 do not reflect data obtaned from arrays 31 through 36 . 
these holes in 1987. Arrays 31 through 36, drilled in 1991, consist of rootholes only. Offsets were first recorded in these arrays in 1992. Arrays 31,32 and 33 are located in the eastern section of the N1420 drift. Arrays 34, 35 and 36 are located in Room 3. Panel 1.

\section{Arrays 1-30}

Fractures have been recorded in 87 percent of all roofholes in the original 30 arrays. During this reporting period, fractures were recorded in 75 percent of rootholes available for inspection. Ninety-four percent of these fractures had a width of 0.3 centimeters ( $1 / 8$ inch) or less; 1.3 centimeters (1/2 inch) was the maximum recorded width. Twenty percent of the fractures recorded in 1992 occur at clay seams.

Horizontal offsets were found in 89 percent of all roofholes, with increases in lateral displacements up to 1.3 centimeters ( $1 / 2$ inch) recorded during this reporting periud.

In general, floor fractures in 1992 are not wider than 0.6 centimeters ( $1 / 4$ inch) and are often associated with MB 139. The widest opening 12 centimeters ( 4.8 inches) found in this inspection was in the floor of SPDV Room 4. Openings wider than six inches have been observed in the floor near the ribs in the SPDV rooms in past inspections. They are associated with shallow, dishshaped slabs.

Horizontal offsets were observed in 57 percent of floorholes. A maximum annual relative displacement of at least 2.6 centimeters ( $1 \frac{1}{8}$ inches) was reported from one floor hole, located near an excavation that was widened in 1990.

\section{Arrays $31-36$}

Seventy-two percent of the boreholes in arrays 31 through 36 contained fractures. Maximum openings of up to one inch were found within the first foot and were associated with small roofbolted spalls. Fourteen percent of recorded fractures were located at clay seams.

Horizontal offsets were observed in four of the nine boretioles in Arrays 31, 32 and 33 in N1420. with maximum relative displacements of 0.6 centimeters (1/4 inch). Seven of the nine boreholes in Arrays 34, 35 and 36 (Room 3. Panel 1) contain offsets. Maximum relative displacements were 0.9 centimeters ( $3 / 8$ inch). 


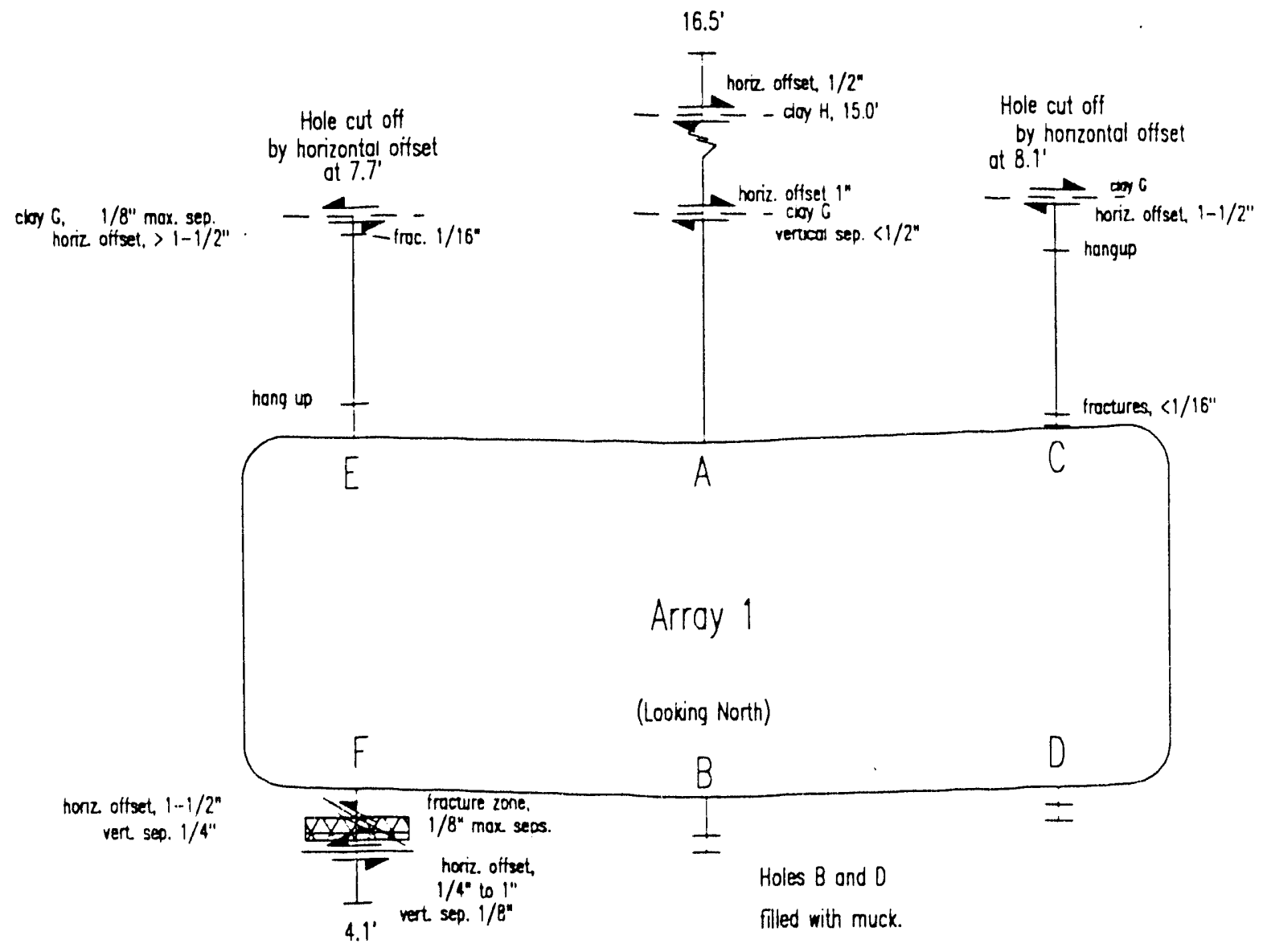

\begin{tabular}{|c|c|c|c|c|c|}
\hline \multirow{3}{*}{$\begin{array}{l}-10 \\
-8 \\
- \\
-6 \\
-4 \\
- \\
-2 \\
-0\end{array}$} & \multicolumn{5}{|c|}{ Legeno: } \\
\hline & $\infty$ & $\operatorname{lnotan}_{\text {home }} \propto$ & $\begin{array}{c}\text { trotarn } \\
\text { tome }\end{array}$ & 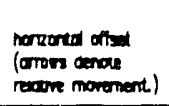 & $\begin{array}{l}\text { end of hole } \\
\text { mith deoth } \\
\text { of hole }\end{array}$ \\
\hline & 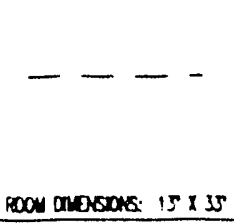 & $t$ & $\frac{1}{8 \times 80}$ & $\frac{1}{11}$ & $\frac{1}{9.4^{\prime}}$ \\
\hline
\end{tabular}

Figure 3-3

Excavation Effects Data, Array \#1

Site and Preiiminary Design Validation Foom A, Ni175 


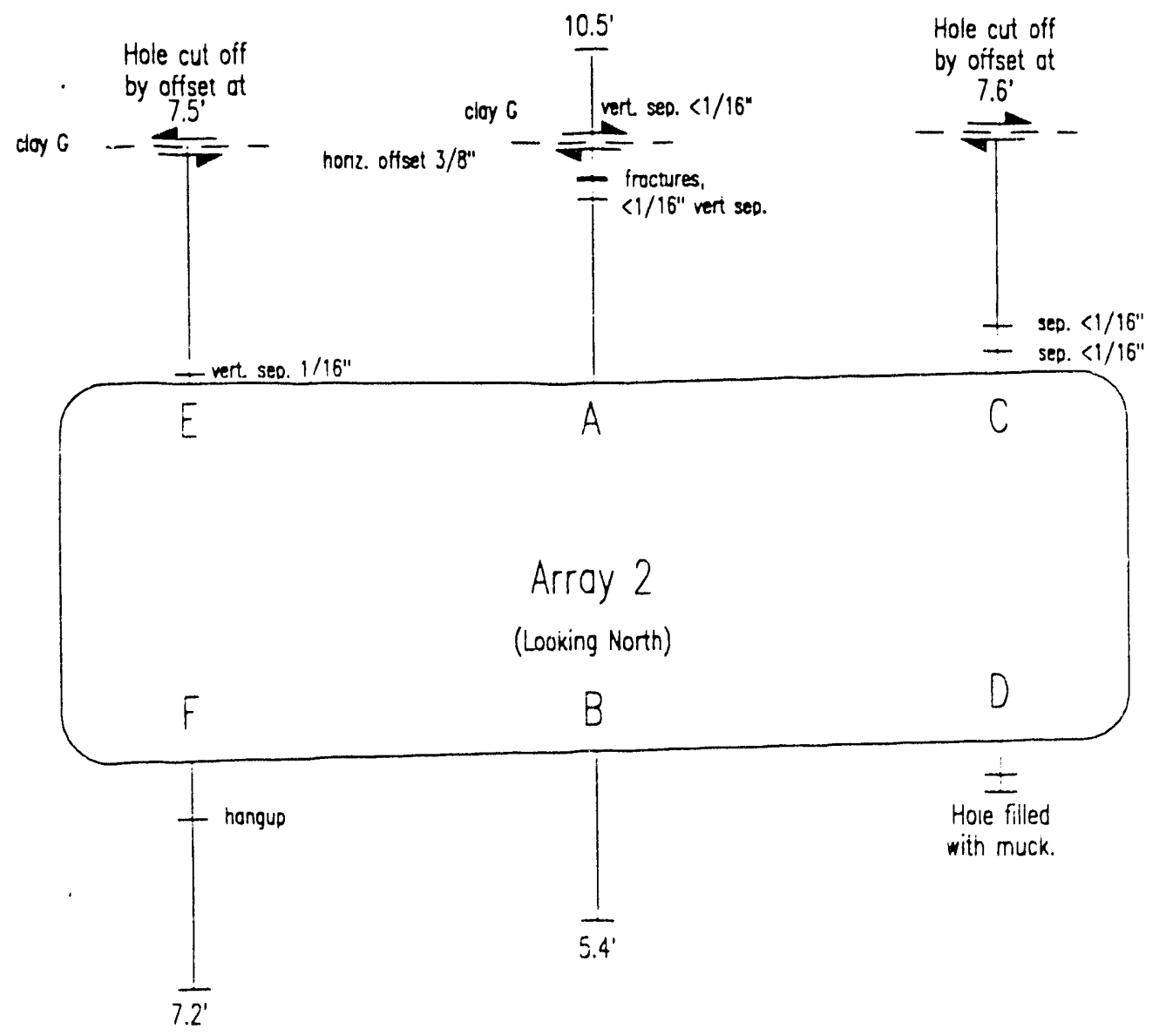

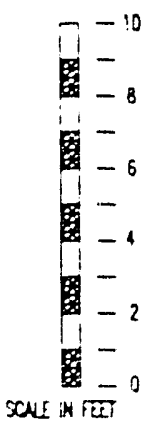

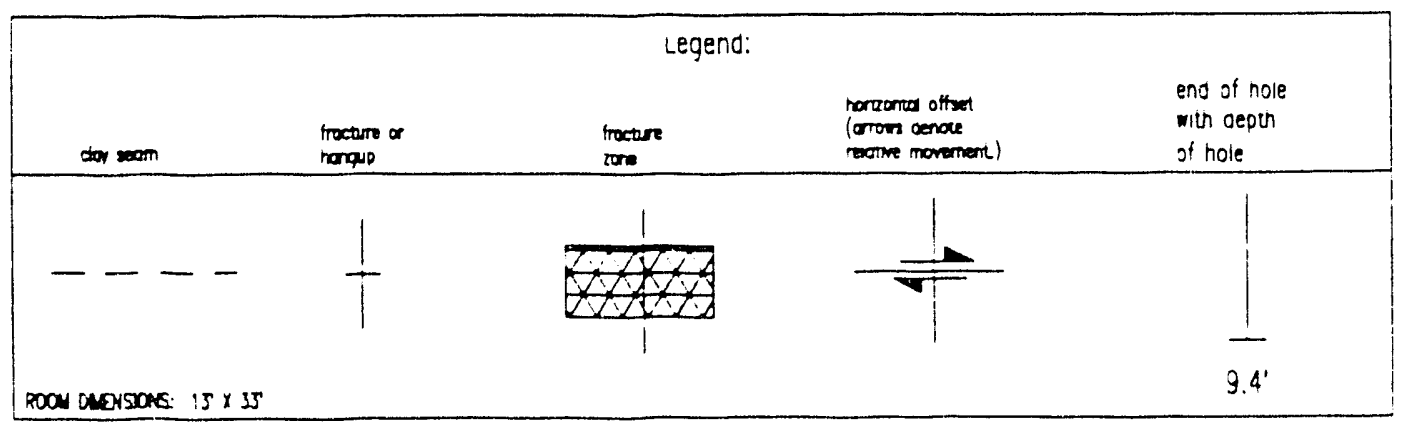

Figure 3-4

Excavation Effects Data, Array \$2

Site and Preliminary Design Validation Room 4, N1264 

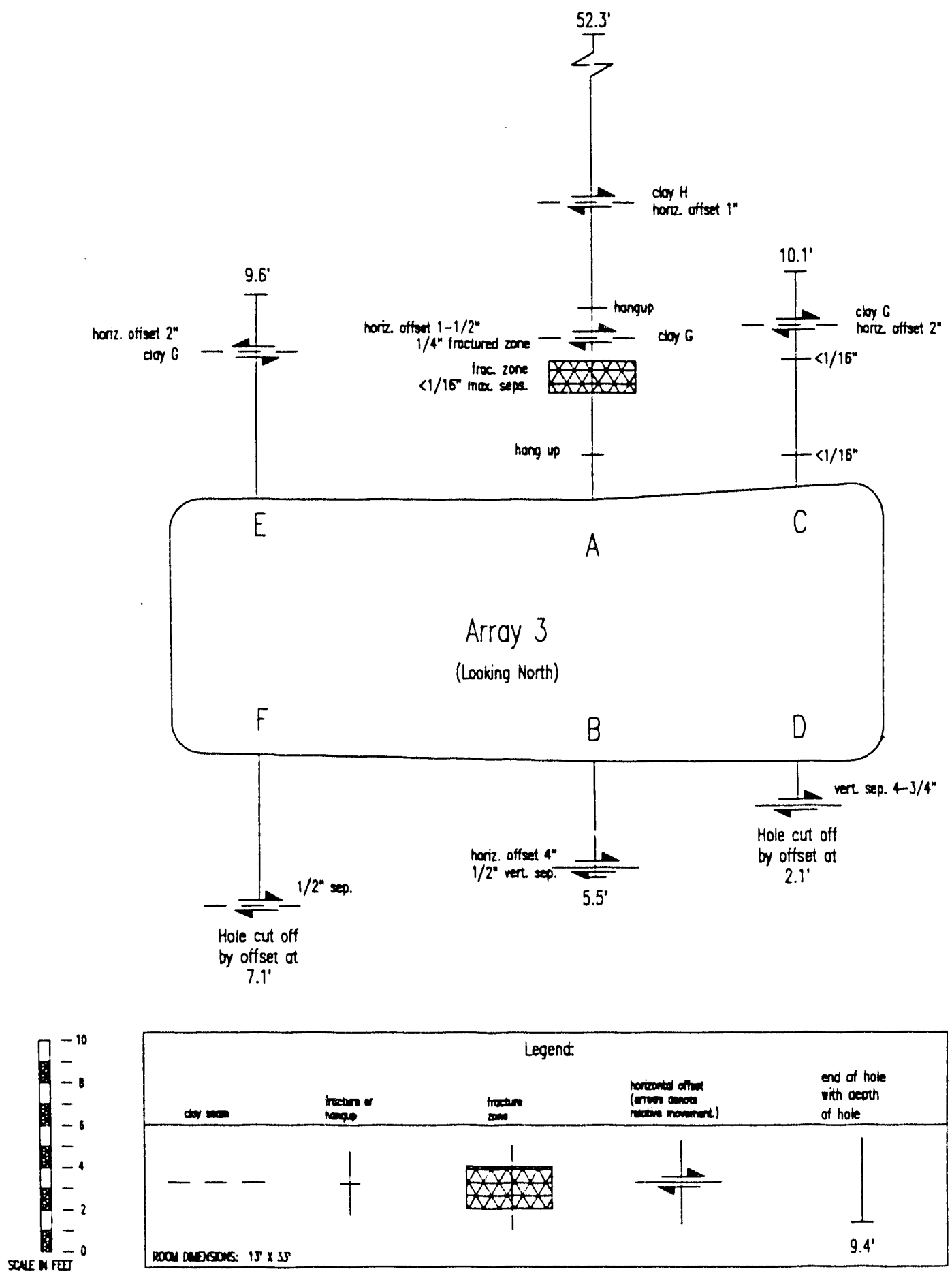

Figure 3-5

Excavation Effects Data, Array $\# 3$

Site and Preliminary Design Validation Room 4, N1361 


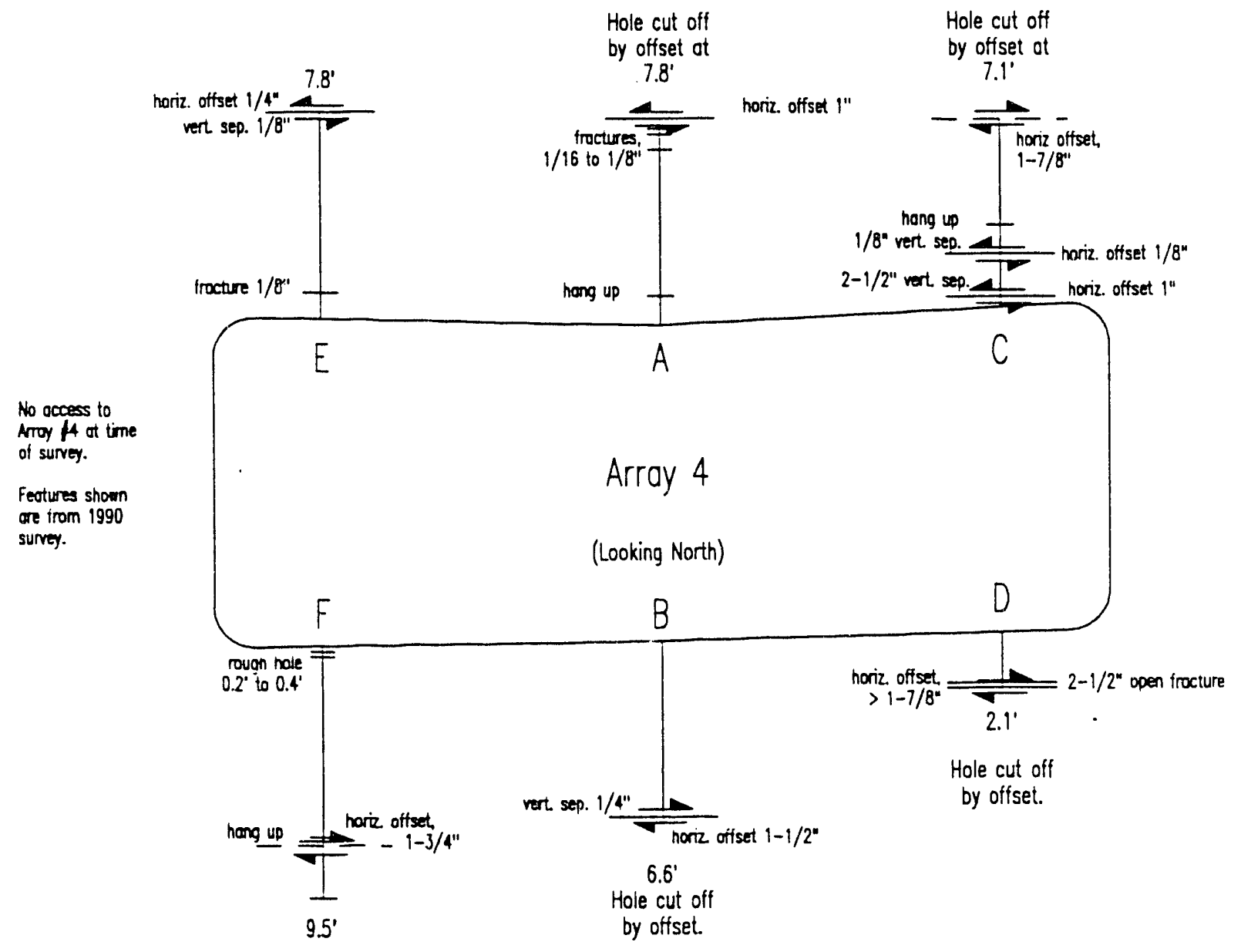

-10
-8
-6
-4
-2
-2
-0

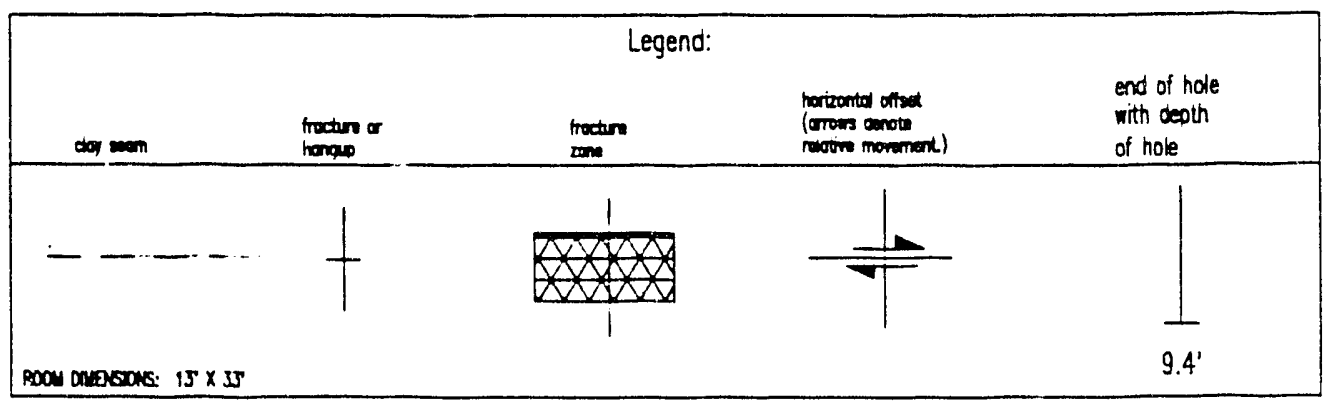

Figure 3-6

Excavation Effects Data, Array \#4

Site and Preliminary Design Validation Room 3, N1198 


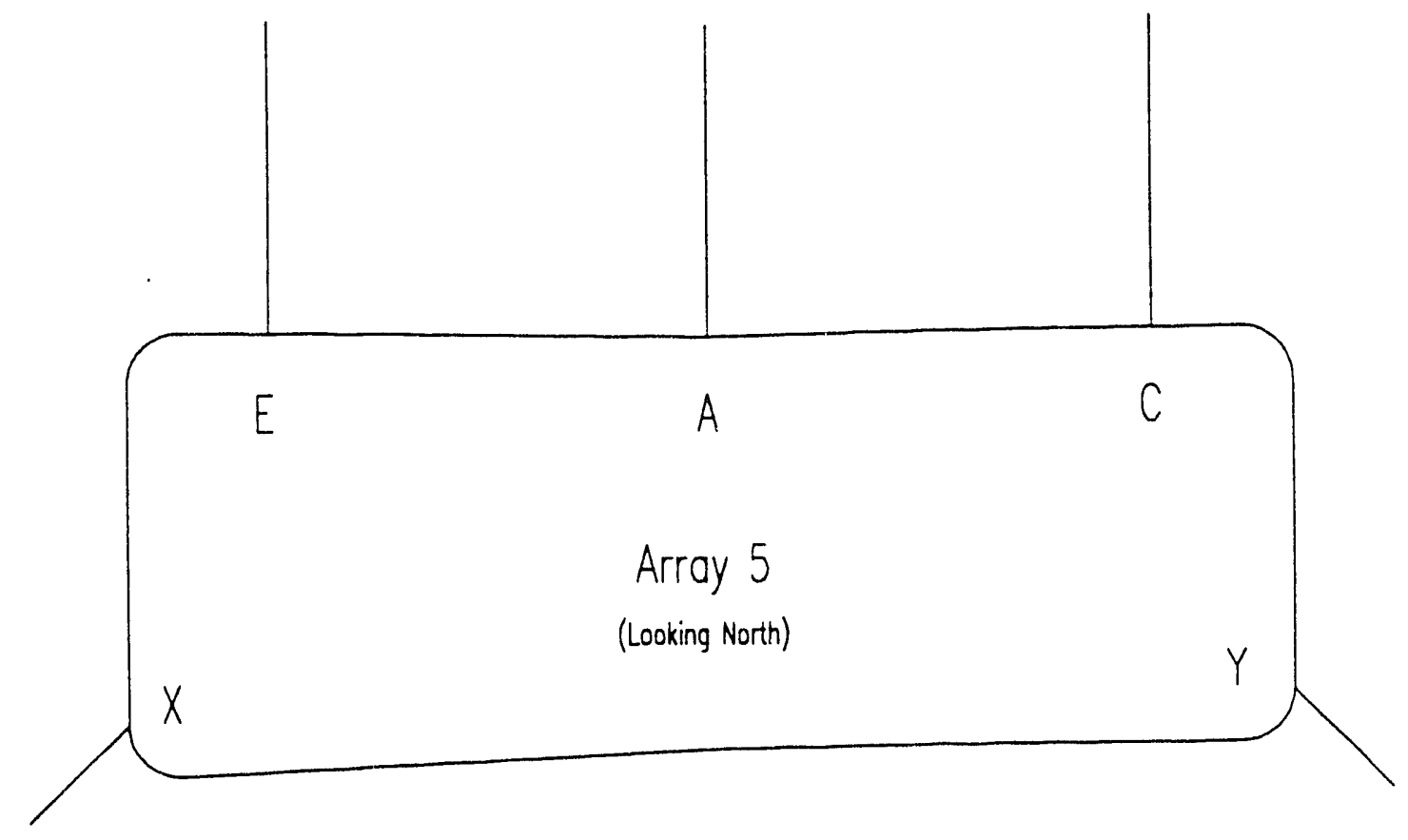

Entire array blocked by

SNL experiment.

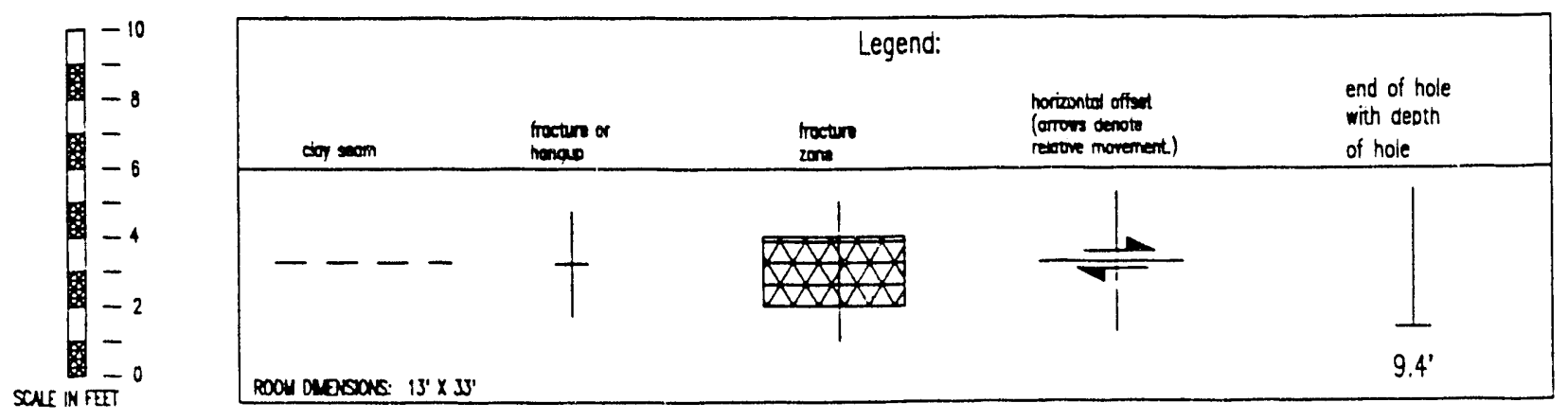

Figure 3-7

Excavation Effects Data, Array $\$ 5$

Site and Preliminary Design Validation Room 3, N1243 


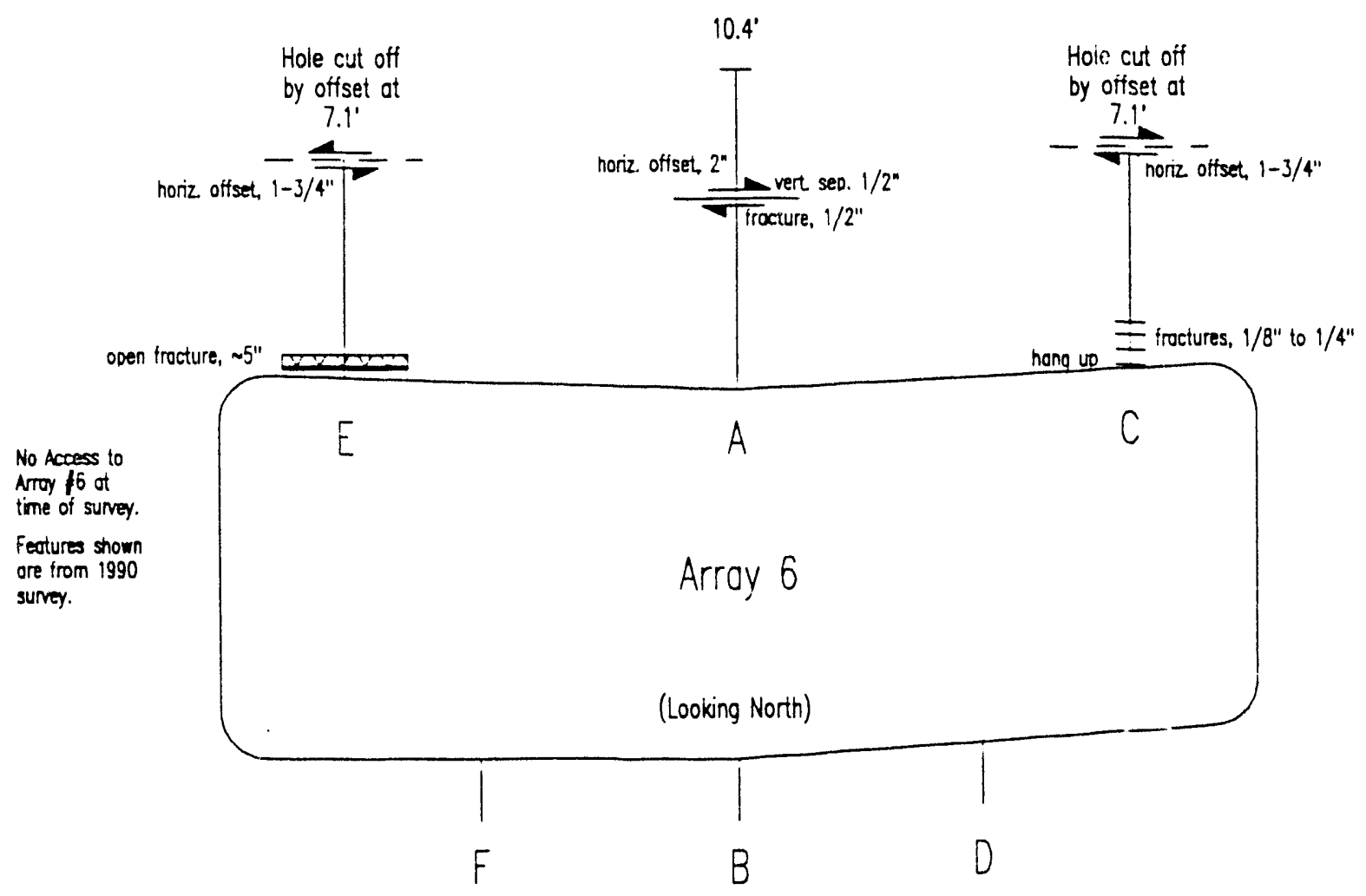

Holes $F, B$, and $D$

blocked by SNL installation.

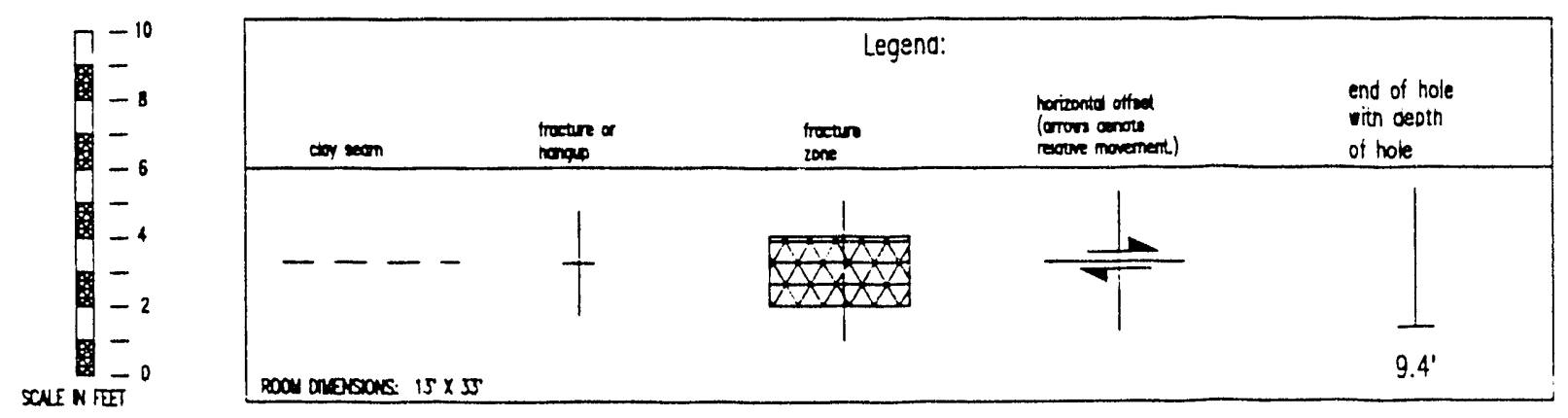

Figure 3-8

Excavation Effects Data, Array $\$ 6$

Site and Preliminary Design Validation Room 3, N1312 


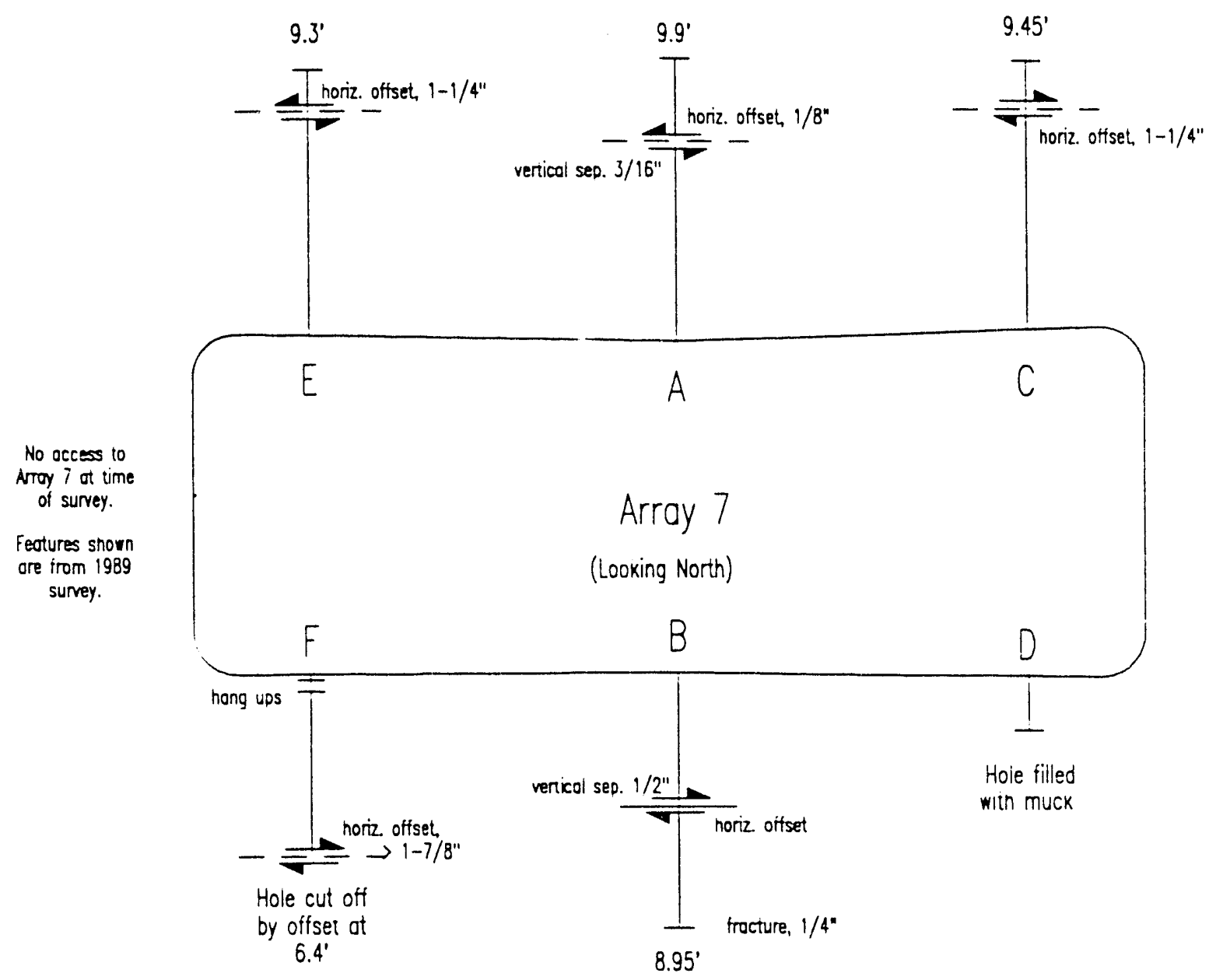

\begin{tabular}{|c|c|c|c|c|c|}
\hline \multirow{3}{*}{$\begin{array}{l}7^{-10} \\
-8 \\
=-8 \\
= \\
=- \\
=-2 \\
=0\end{array}$} & \multicolumn{5}{|c|}{ Legena: } \\
\hline & dor stom & $\begin{array}{l}\text { trative ox } \\
\text { nongete }\end{array}$ & $\begin{array}{l}\text { thecoun } \\
\text { zone }\end{array}$ & 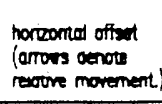 & $\begin{array}{l}\text { end of hole } \\
\text { with oeoth } \\
\text { of hoie }\end{array}$ \\
\hline & 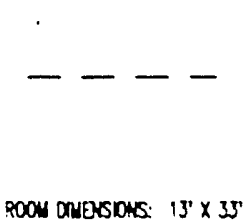 & 1 & $\frac{1}{x}$ & 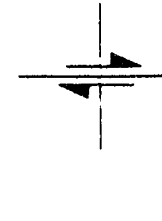 & $\frac{1}{9.4}$ \\
\hline
\end{tabular}

Figure 3-9

Excavation Effects Data, Array \#7

Site and Preliminary Design Validation Room 2, N1147 


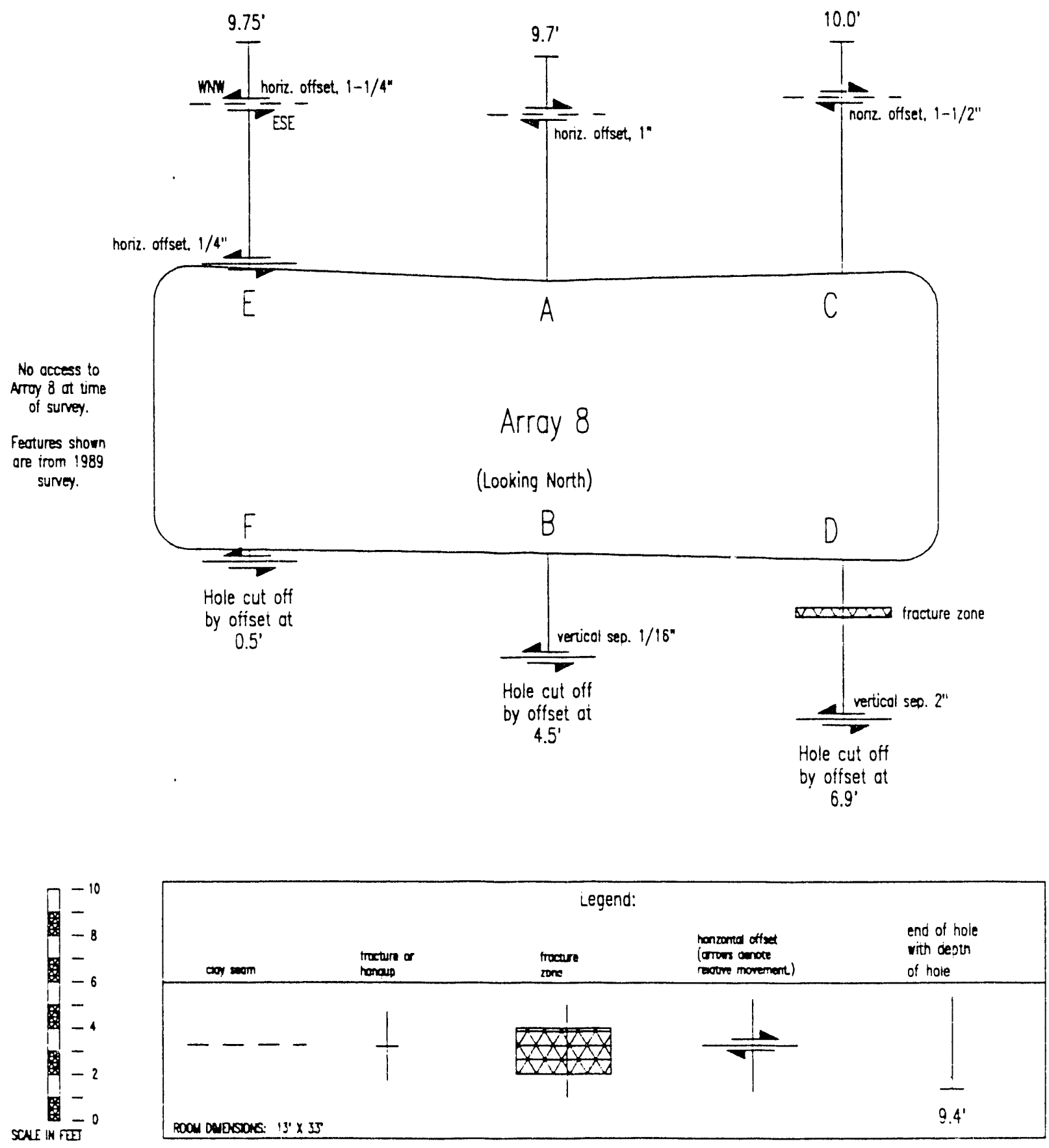

Figure $3-10$

Excavation Effects Data, Array \#8

Site and Preliminary Design Validation Room 2, N1231 


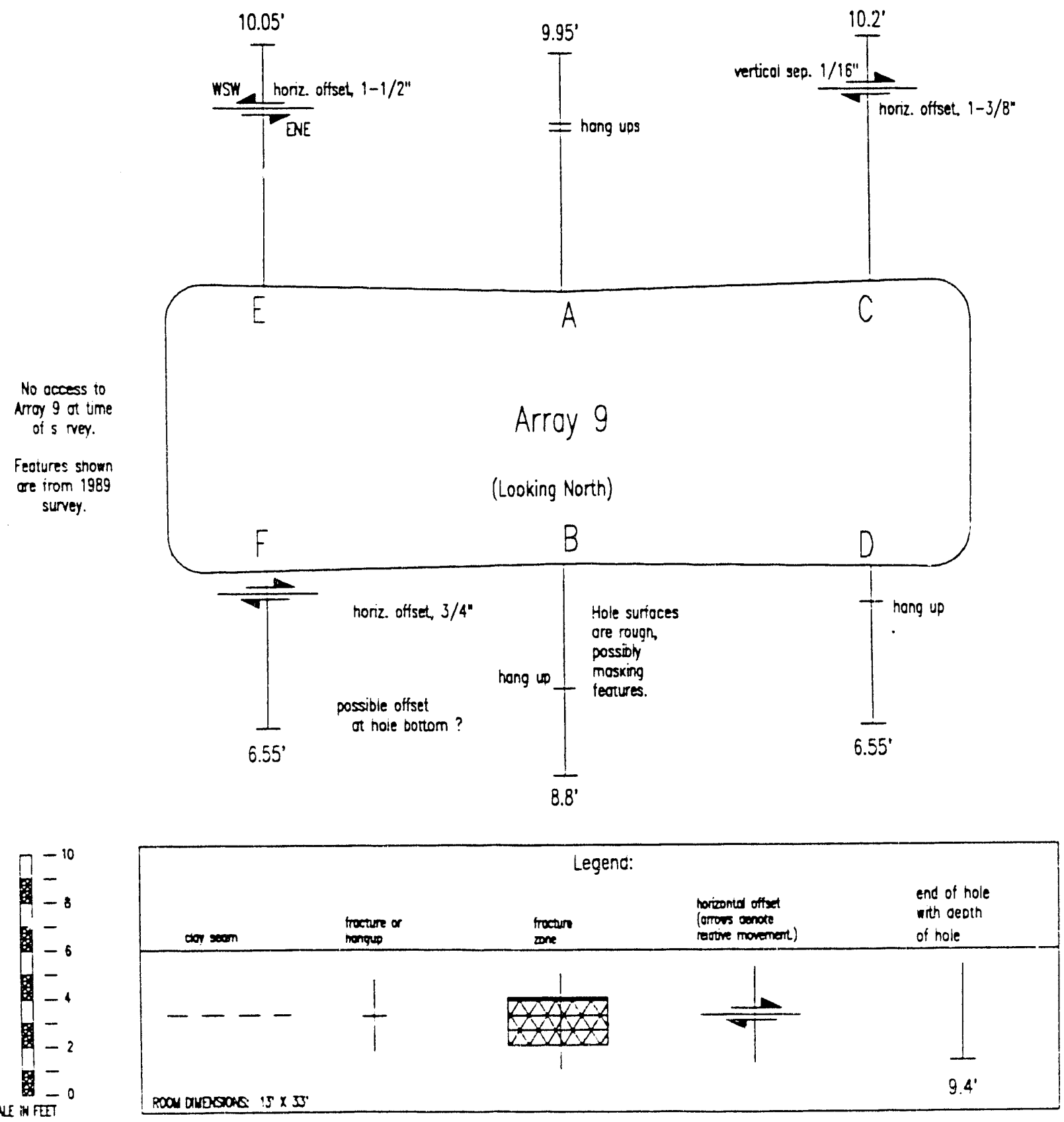

Figure 3-81

Excavation Effects Data, Array $\#$

Site and Preliminary Design Validation Room 1, N1159 


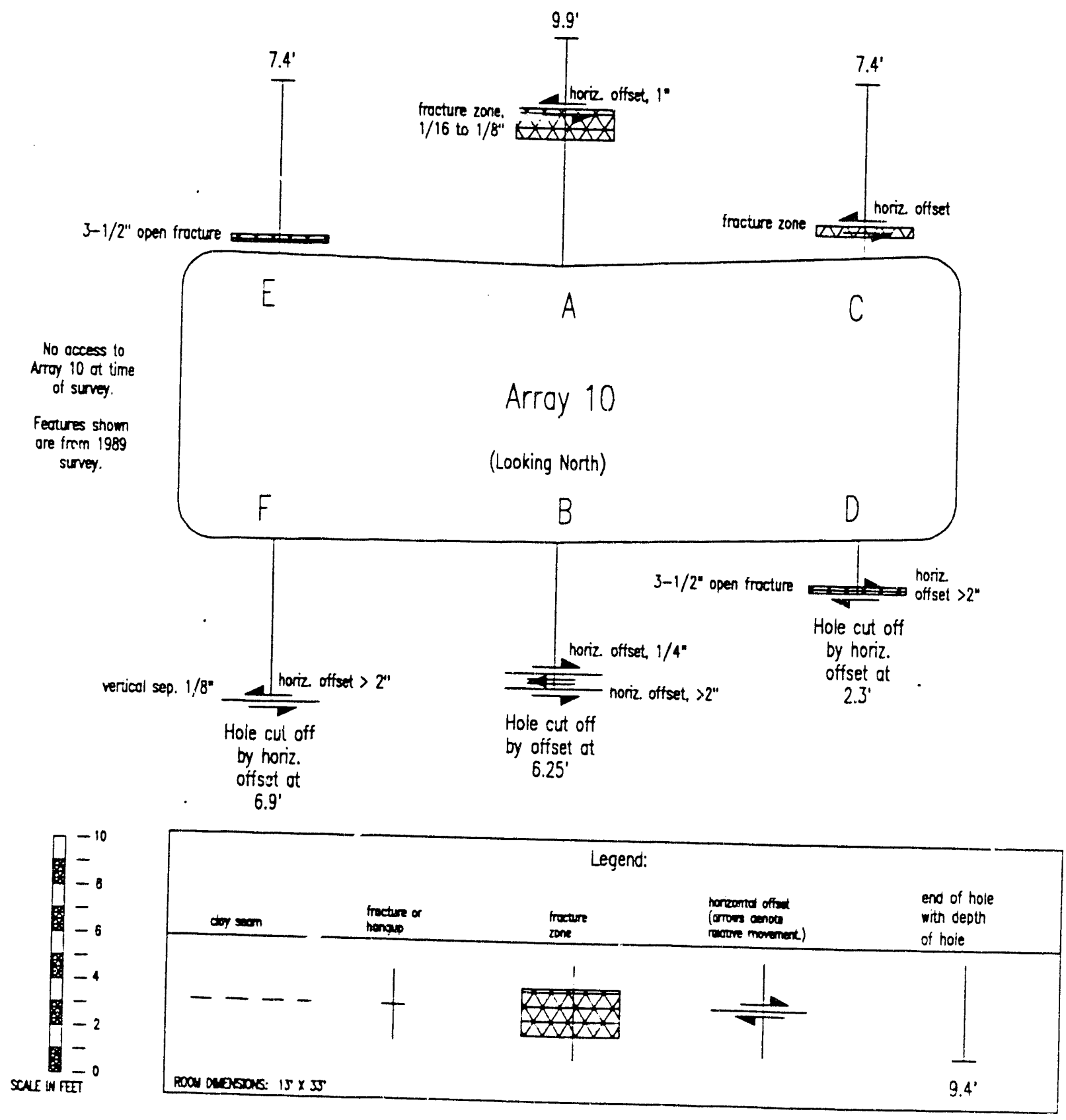

Figure 3-12

Excavation Effects Data, Array $\# 10$

Site and Preliminary Design Validation Room 1, N1275 


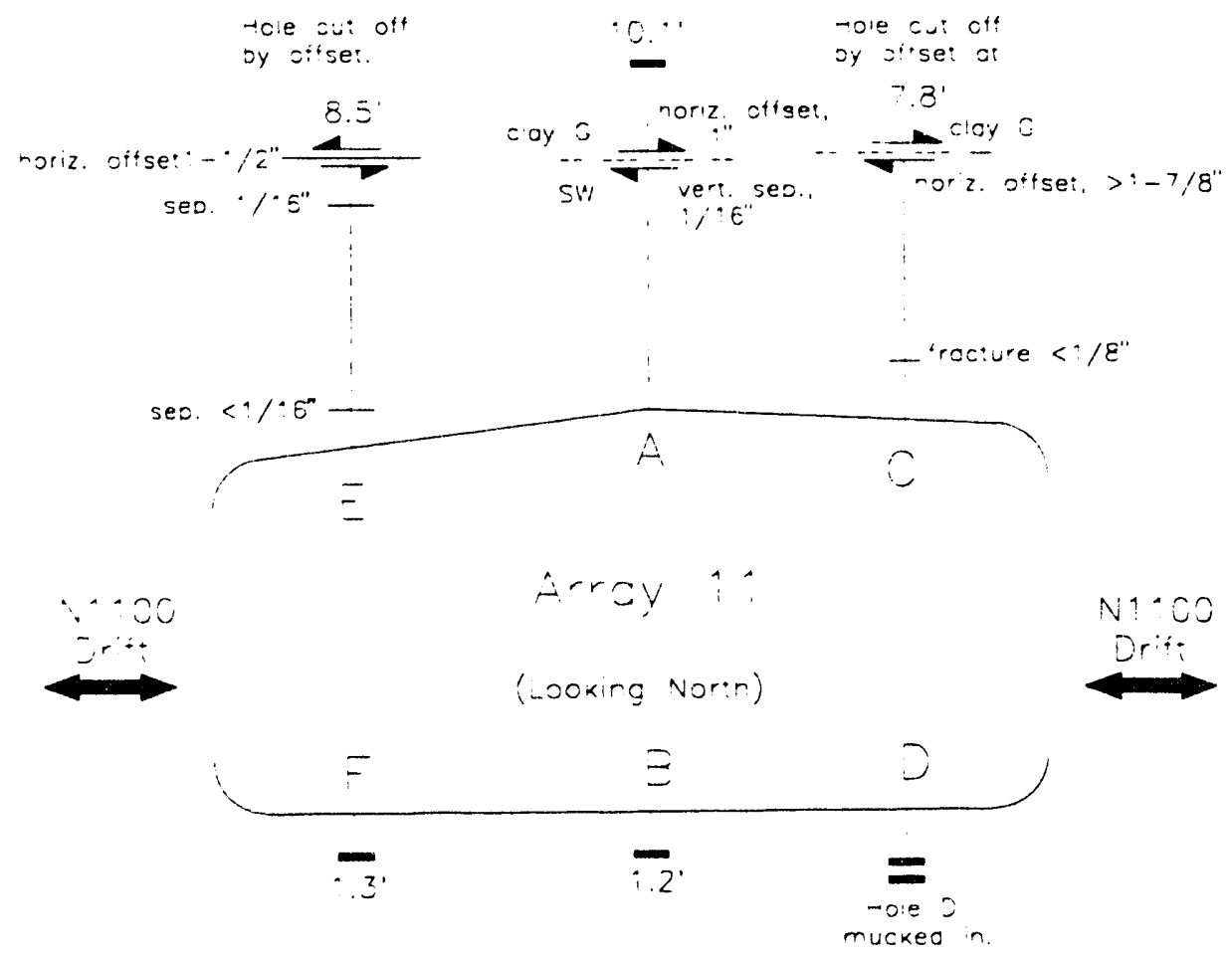

Holes $F$ and $B$ cre muckeo in to the aed:n noicoiec.
Sides of nole $F$ are rough.

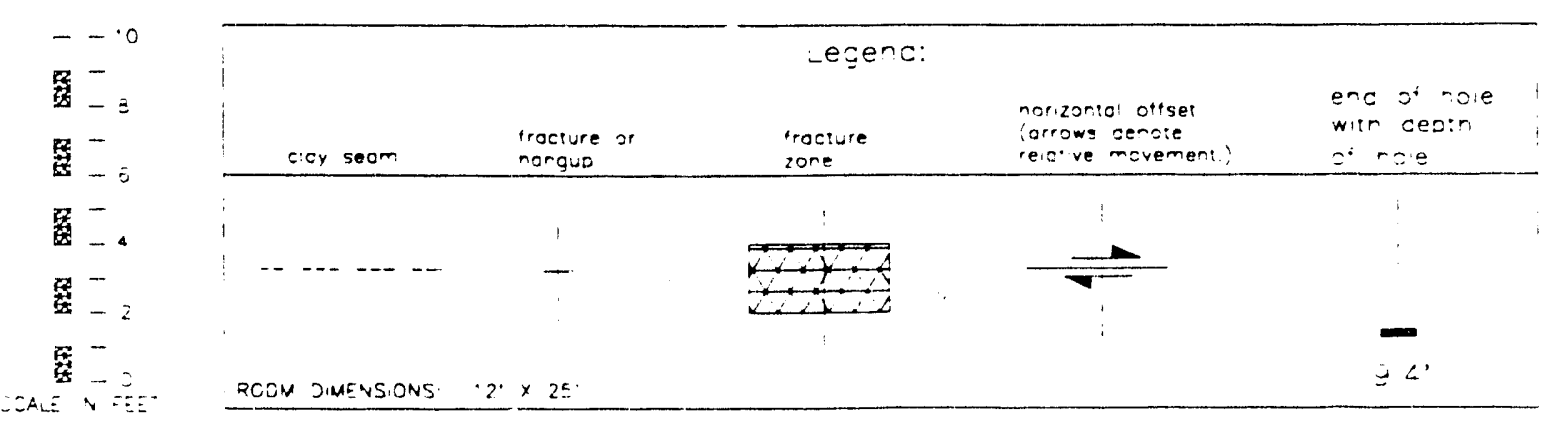

Figure 3-13

Excavation Effects Data, Array \#11

N1100, EO 


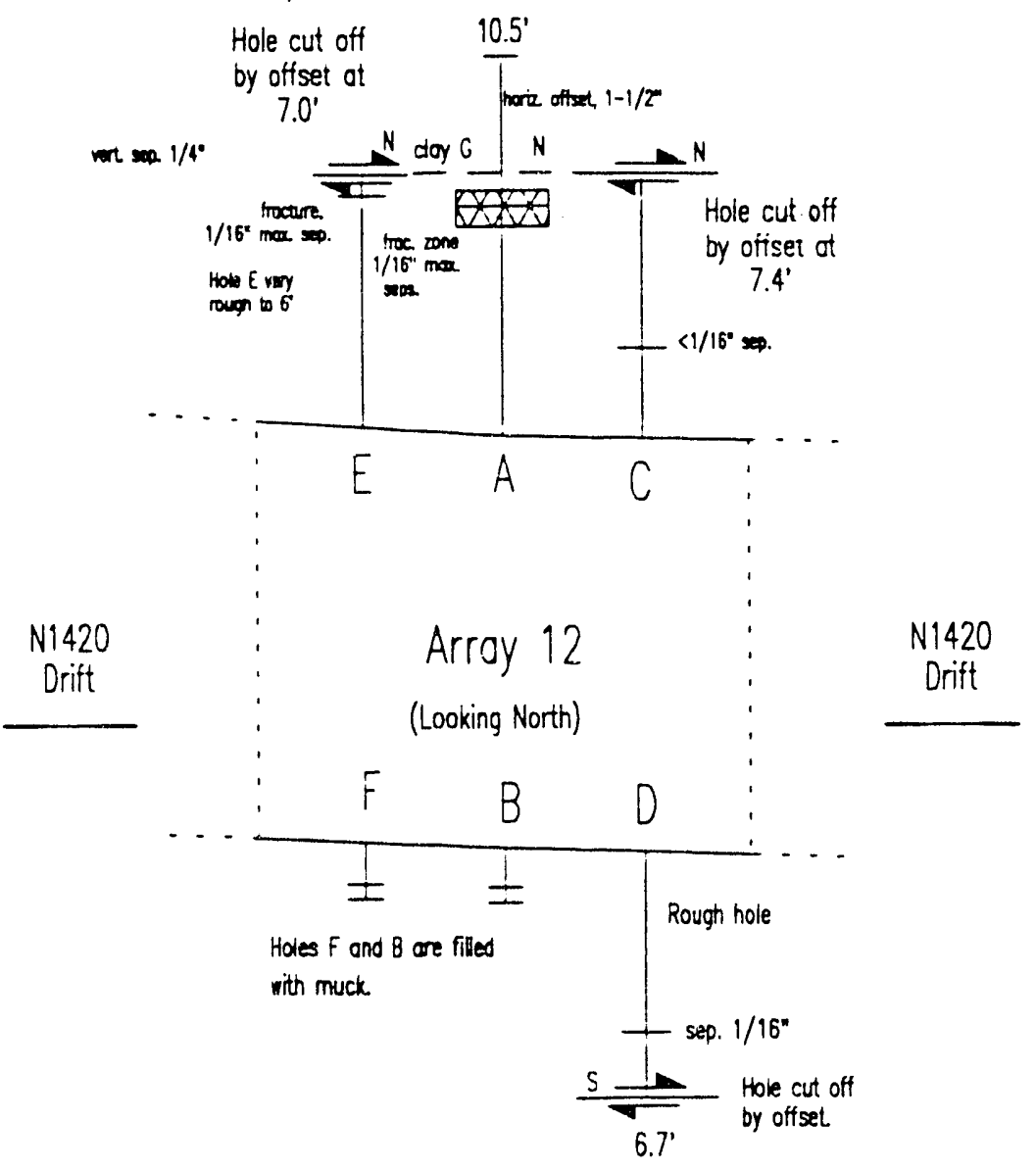

Hole $C$ is rough from $5.0^{\prime}$ to $7.4^{\prime}$.

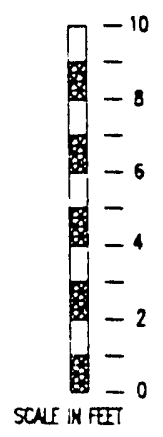

\begin{tabular}{|c|c|c|c|c|}
\hline cho & $\begin{array}{l}\text { trocturs I } \\
\text { noneque }\end{array}$ & trocture & 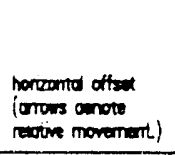 & $\begin{array}{l}\text { end of hole } \\
\text { with dedth } \\
\text { of hole }\end{array}$ \\
\hline 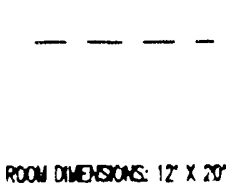 & 1 & $\frac{x}{4}$ & $\frac{1}{1}$ & $\frac{1}{9.4^{\prime}}$ \\
\hline
\end{tabular}

Figure 3-14

Excavation Effects Data, Array $\# 12$

N1420, E140 


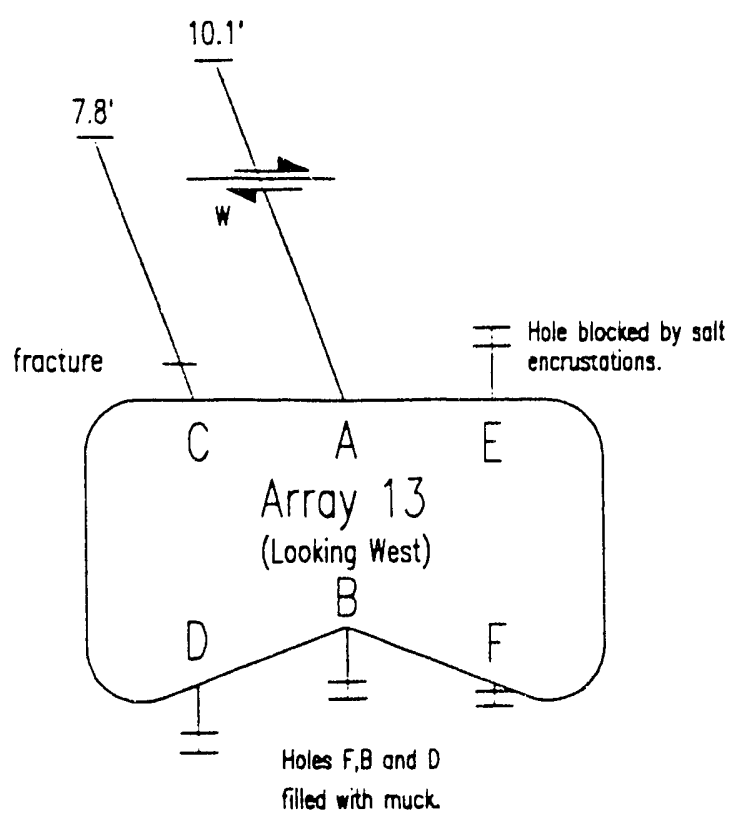

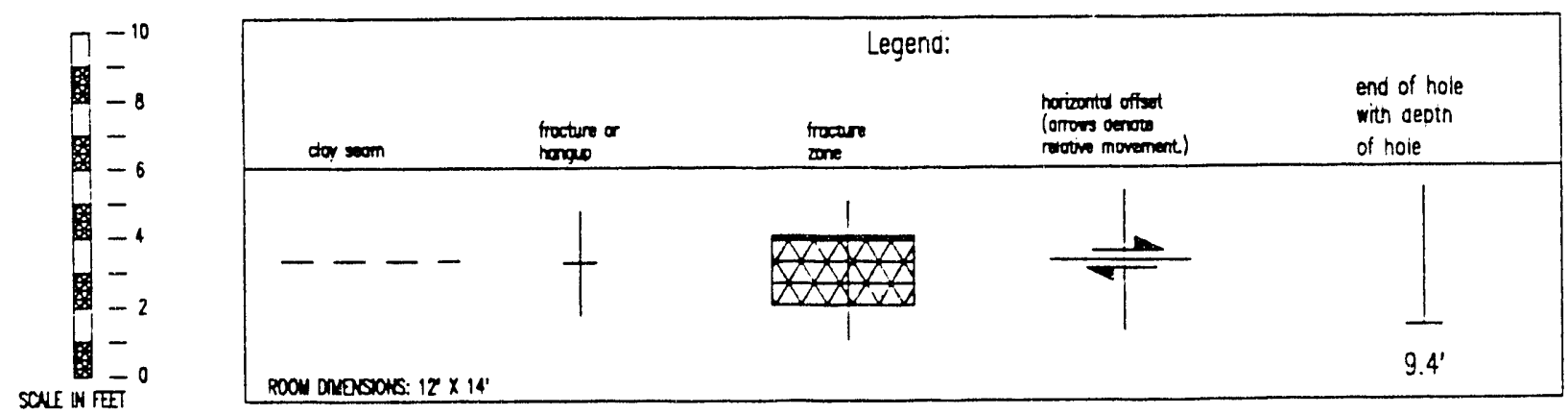

Figure 3-15

Excavation Effects Data, Array $\# 13$

N1100, E439 

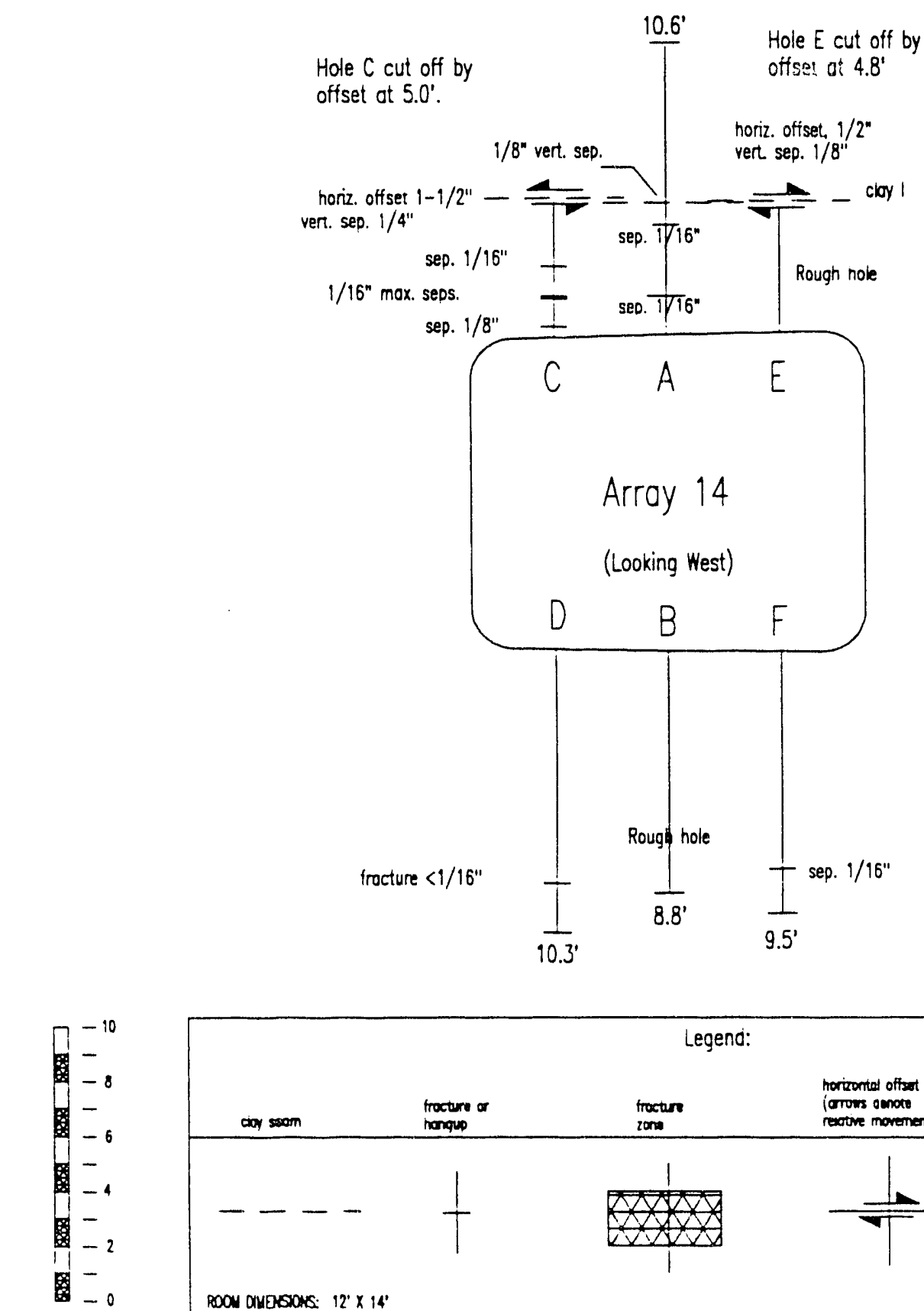

SCNE IN FET

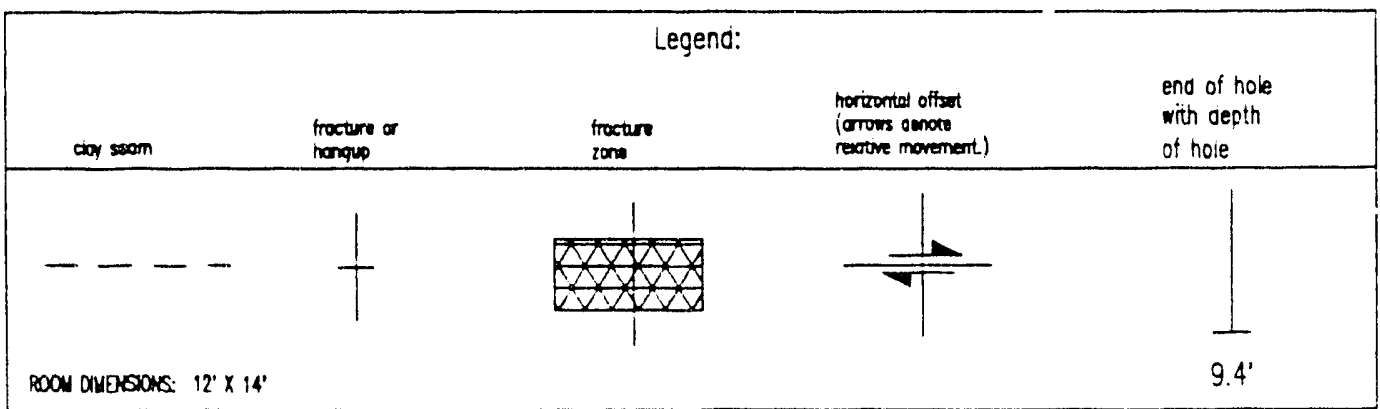

Figure 3-16

Excavation Effects Data, Array \#14

Ni 420, EBT5 

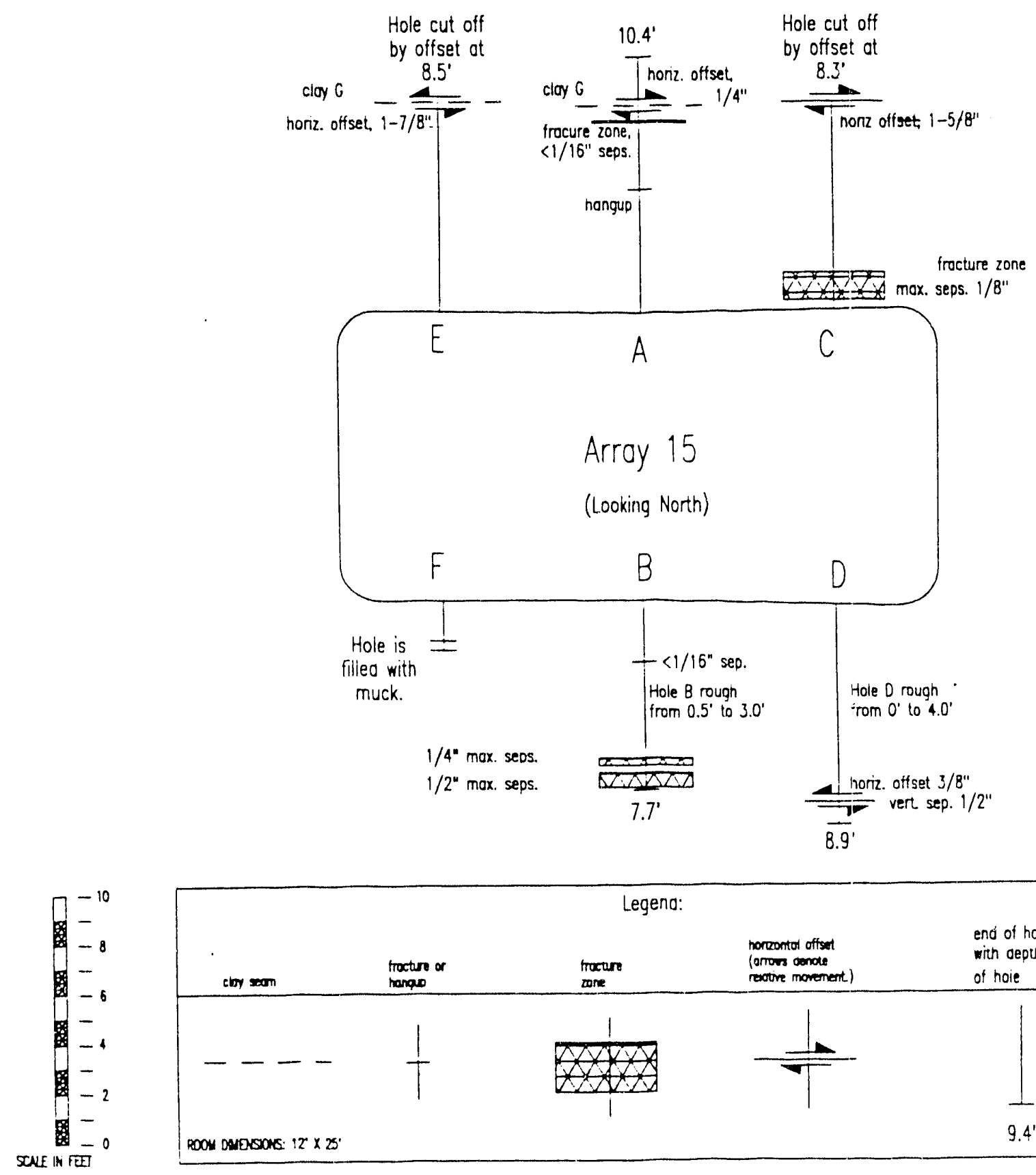

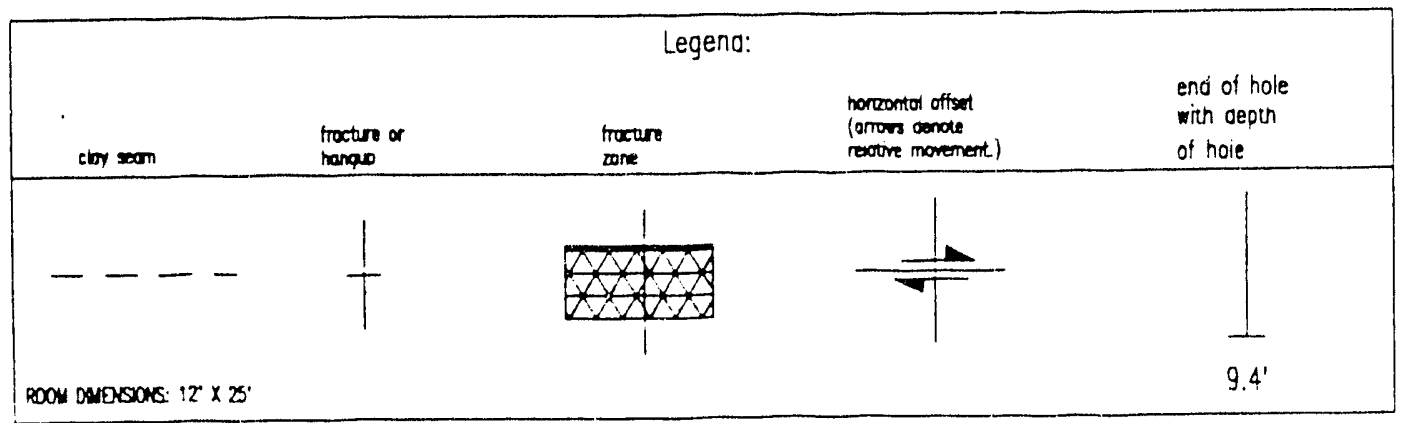

Figure 3-17

Excavation Effects Data, Array \#15

E0, N626 
Holes no longer occessible.

Feotures shown ore irom 1989 survey.
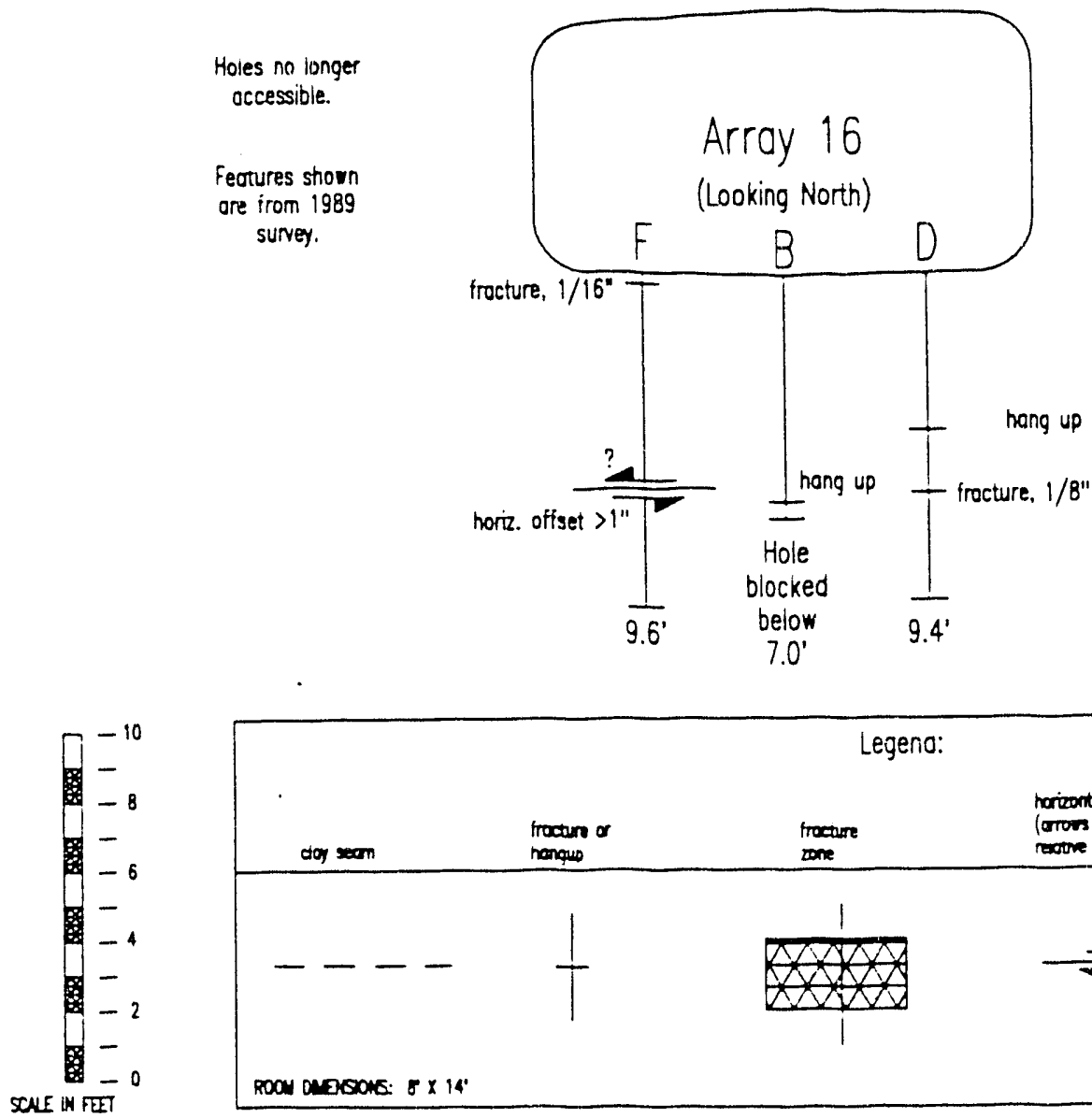

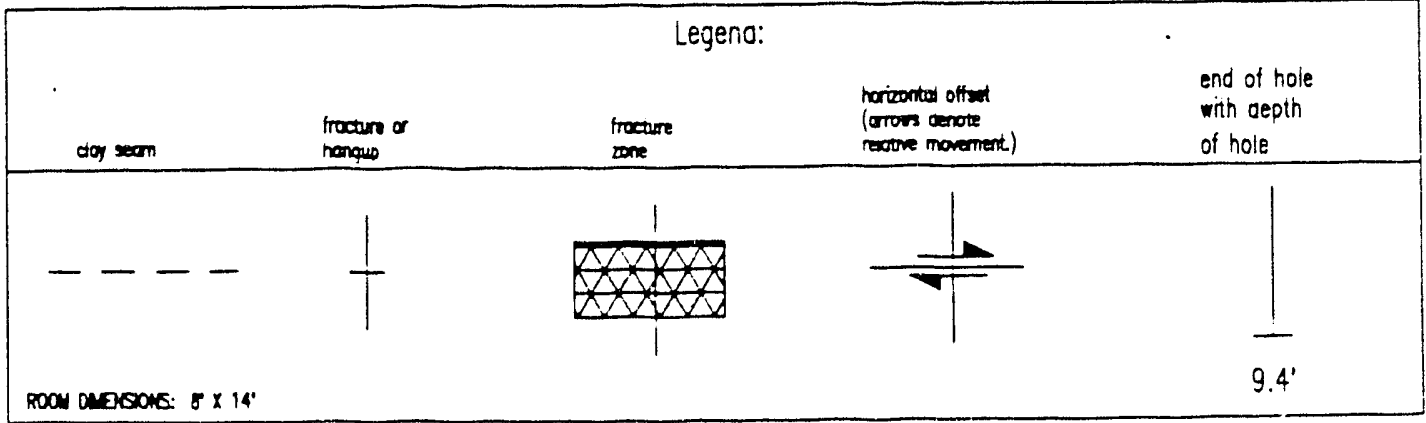

Figure 3-18

Excavation Effects Data, Array \#16

E140, N.3n5 

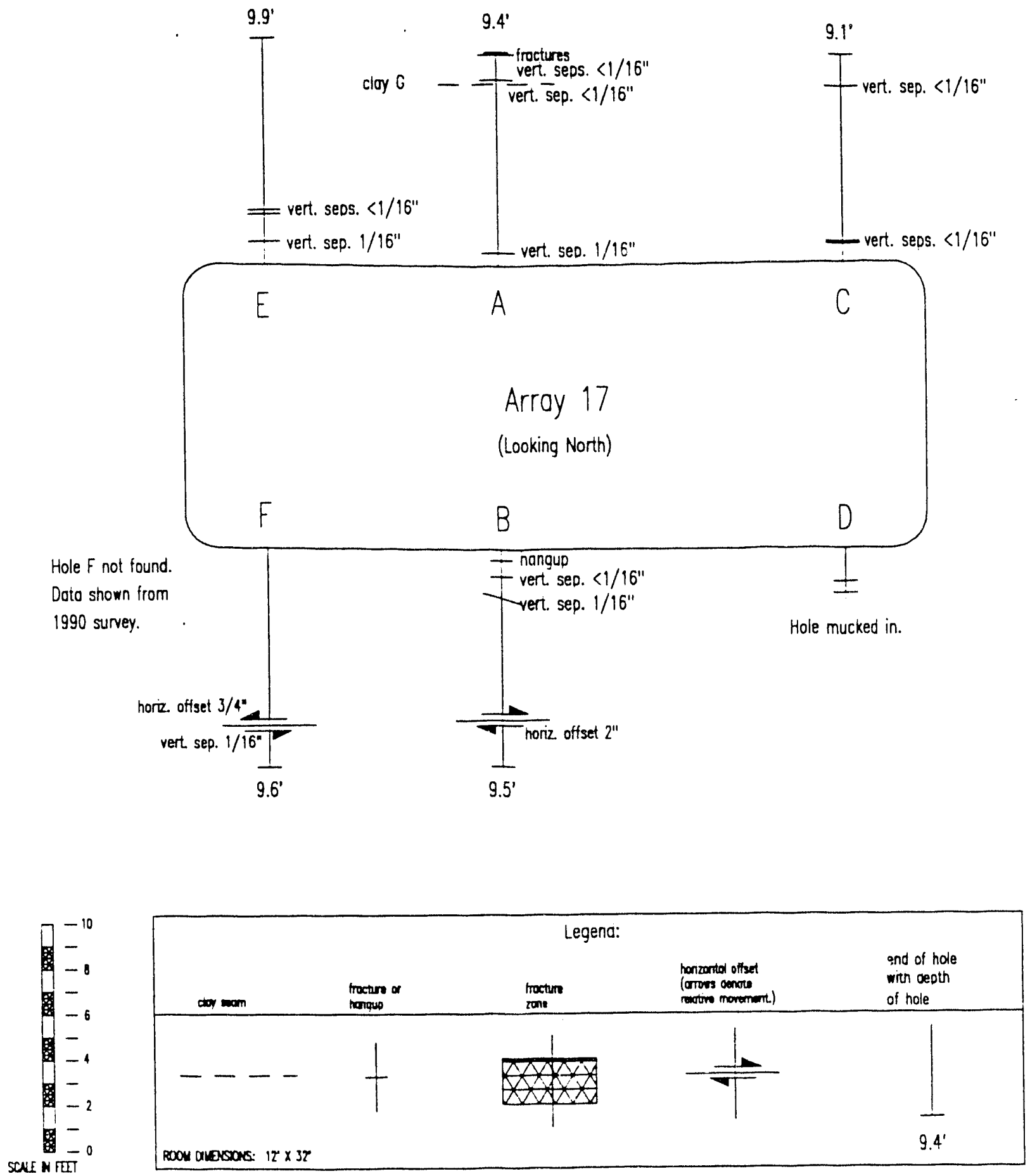

Figure 3-19

Excavation Effects Data, Array \#17

E0, N28 (Salt Shaft Station) 


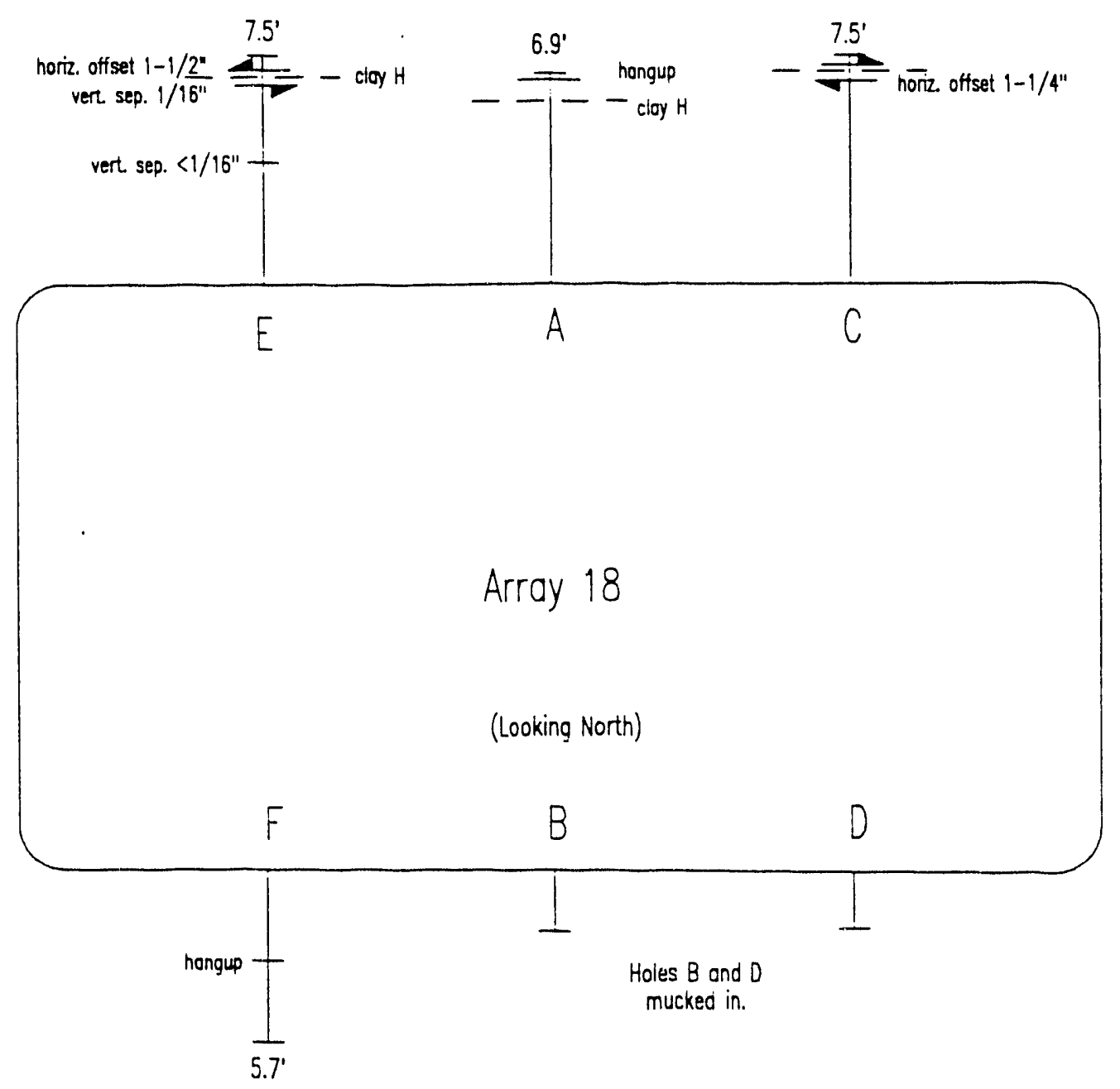

-10
-8
-6
-6
-4
-2
$\operatorname{sen} 2 \pi$

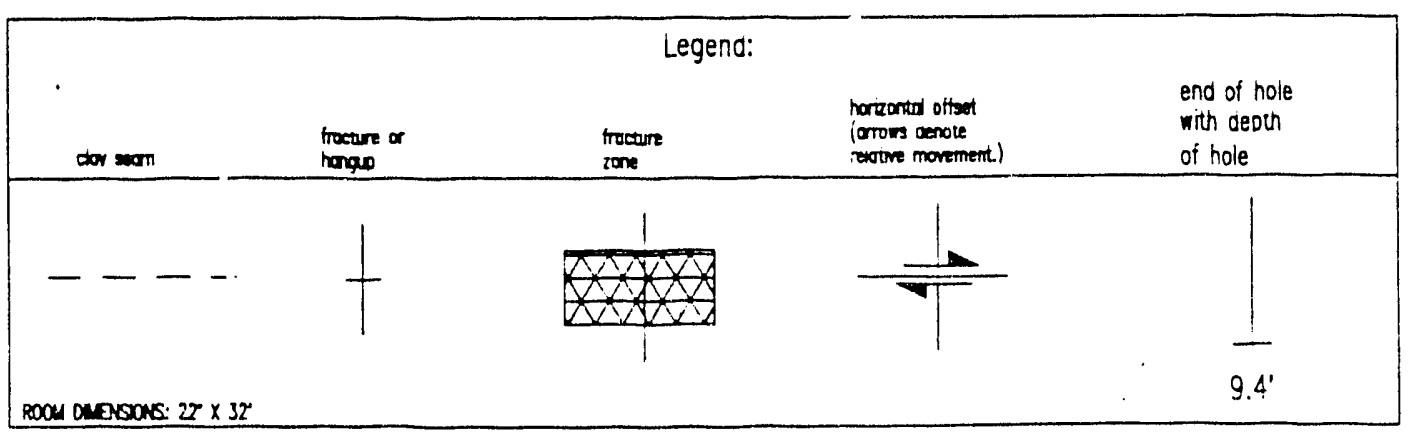

Figure 3-20

Excavation Effects Data, Array \#18

E0, iN24 (Salt Shaft Station) 


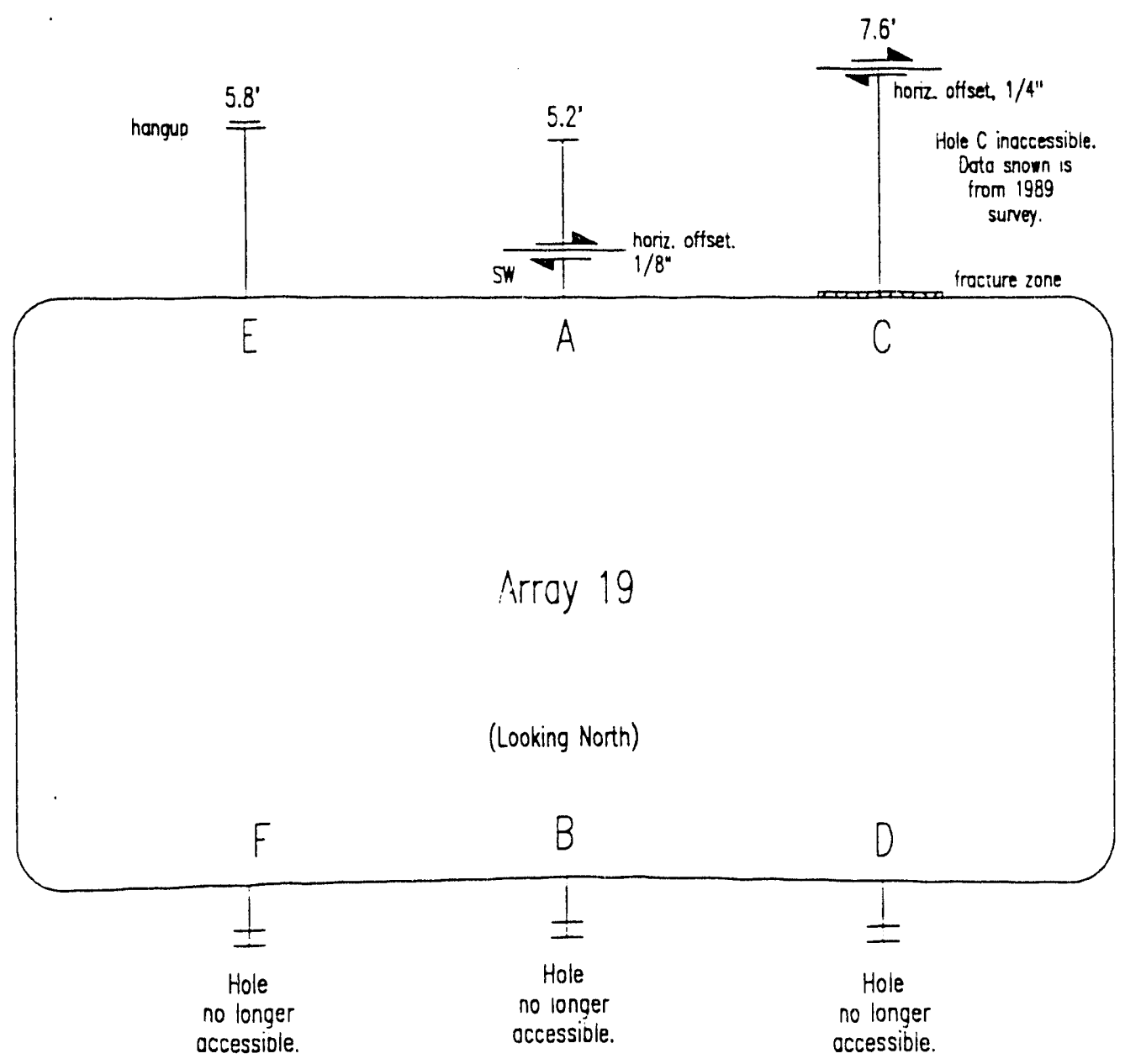

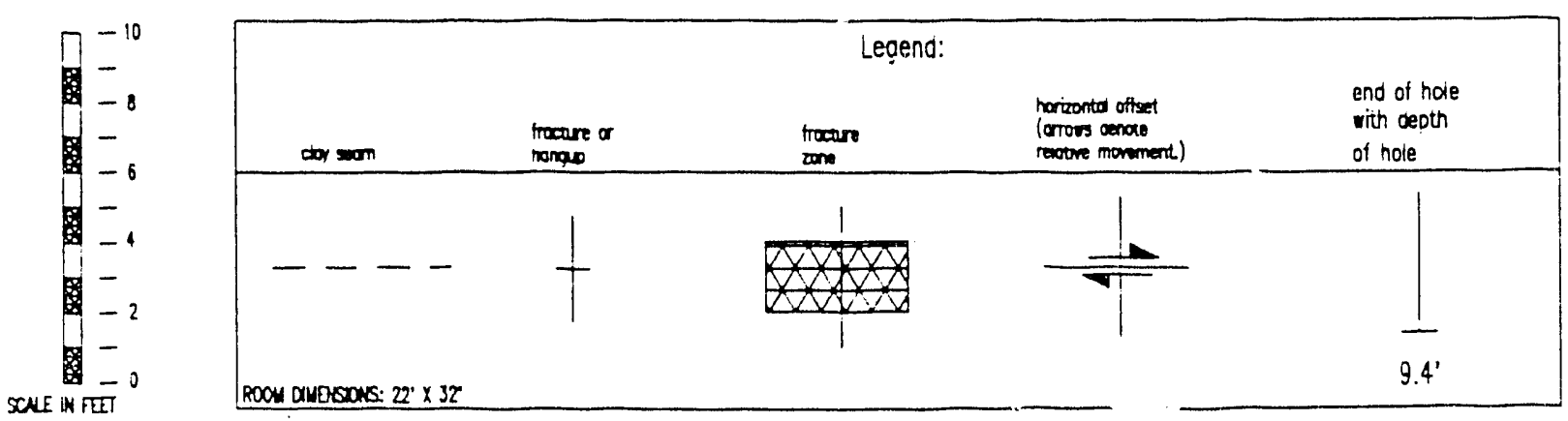

Figure 3-21

Excavation Effects Data, Array \#19

E0, S56 (Salt Shaft Station) 

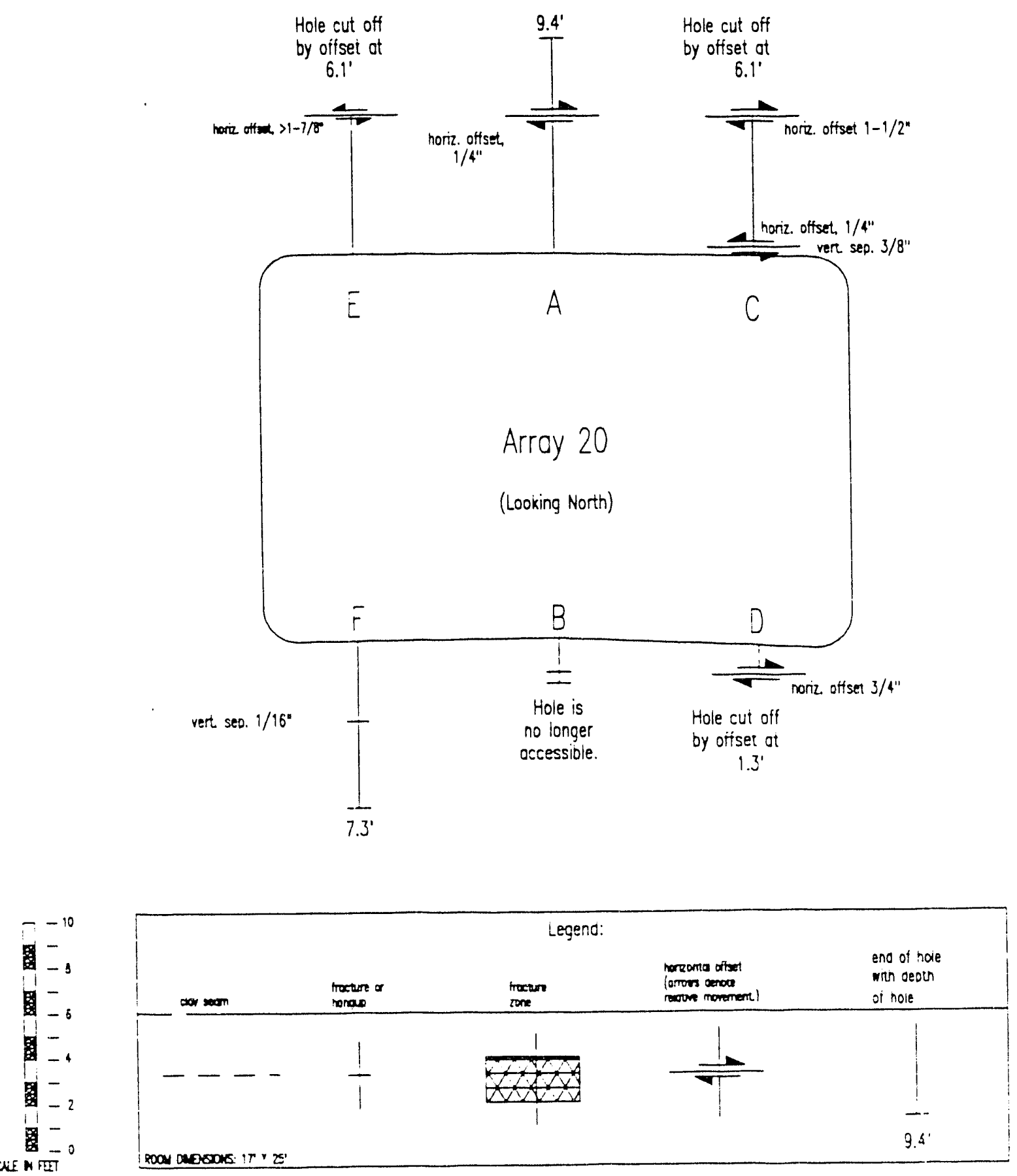

Figure 3-22

Excavation Effects Data, Array $\$ 20$

E140, S592 

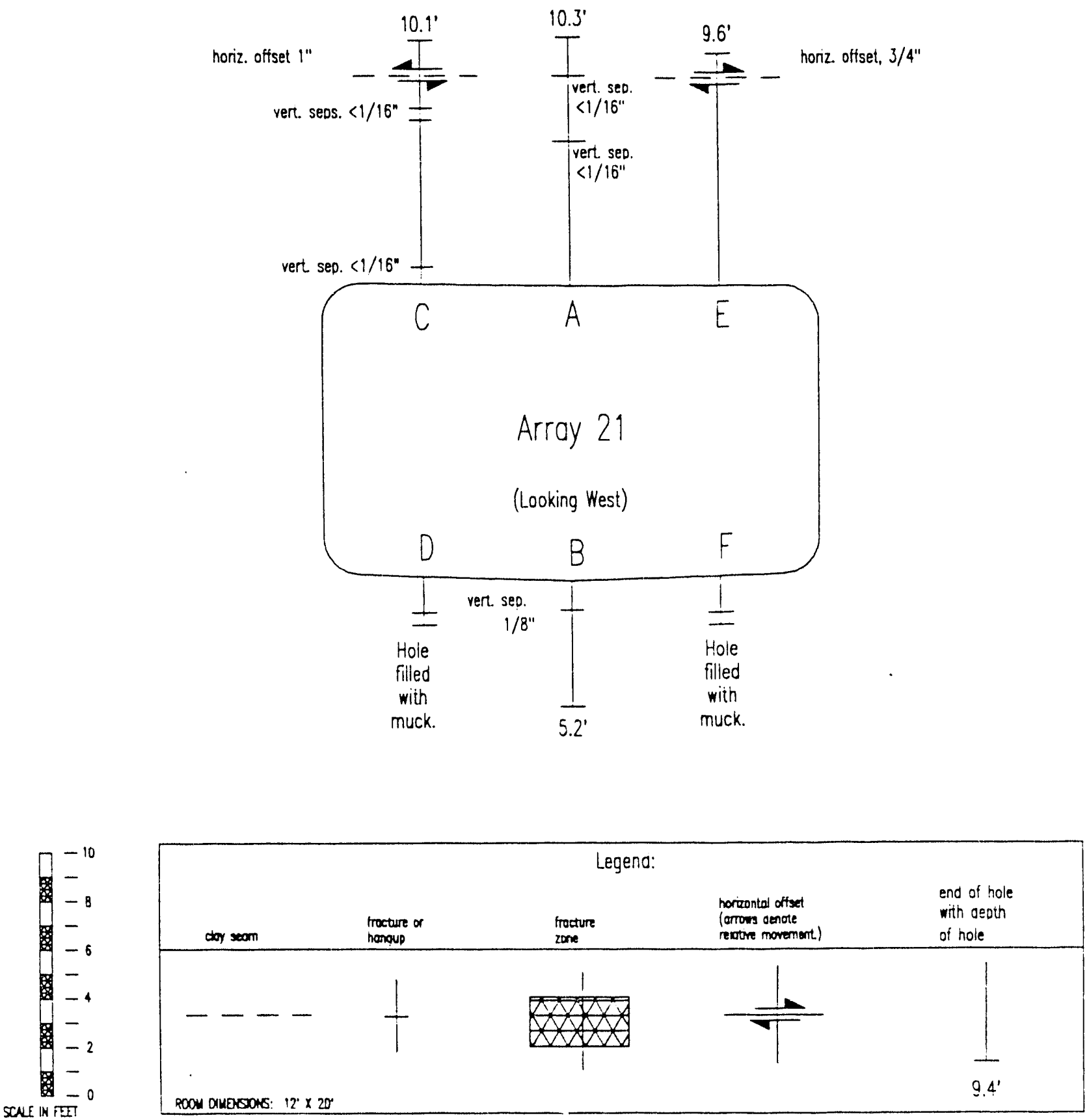

Figure 3-23

Excavation Effects Data, Array \#21

S700, E66 

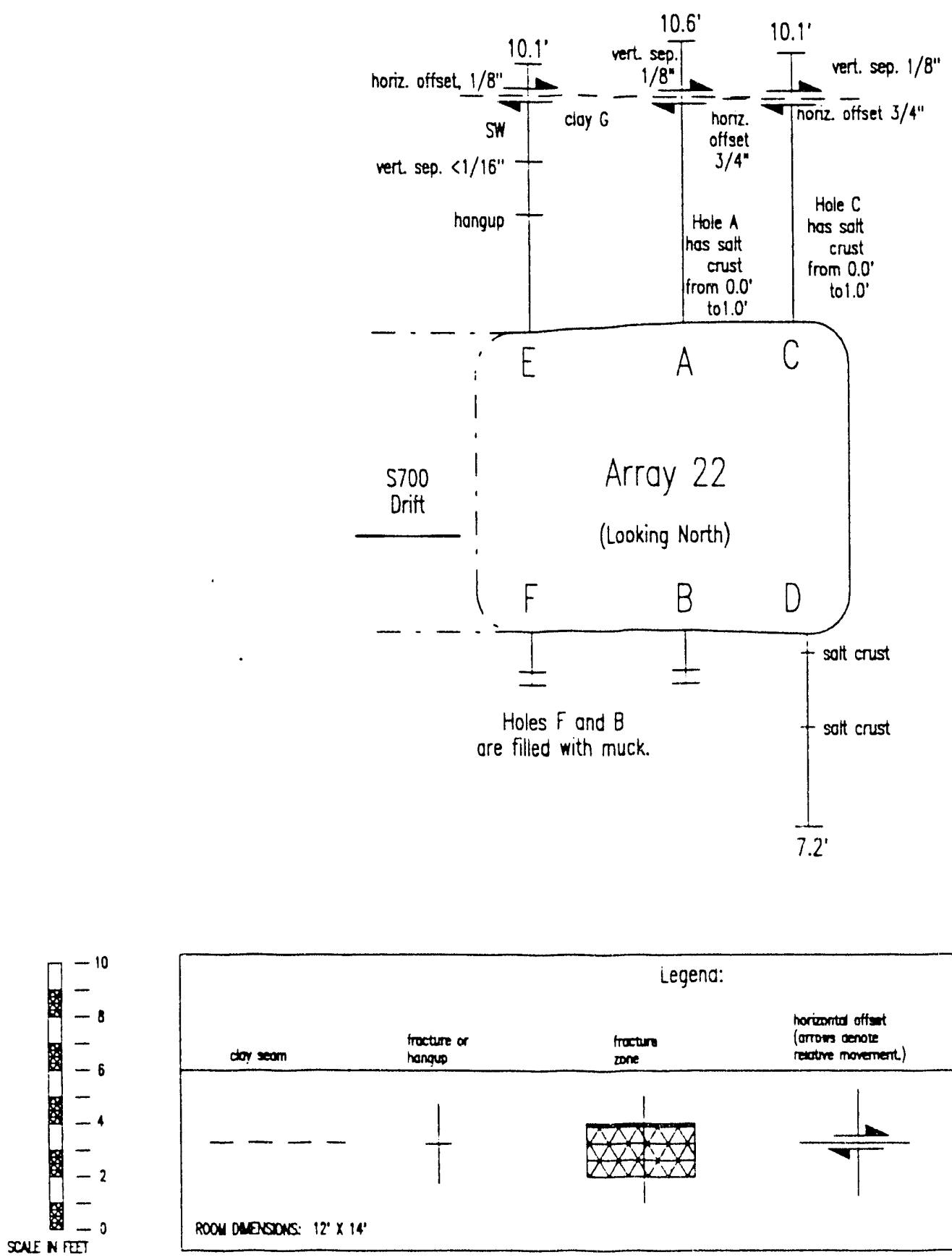

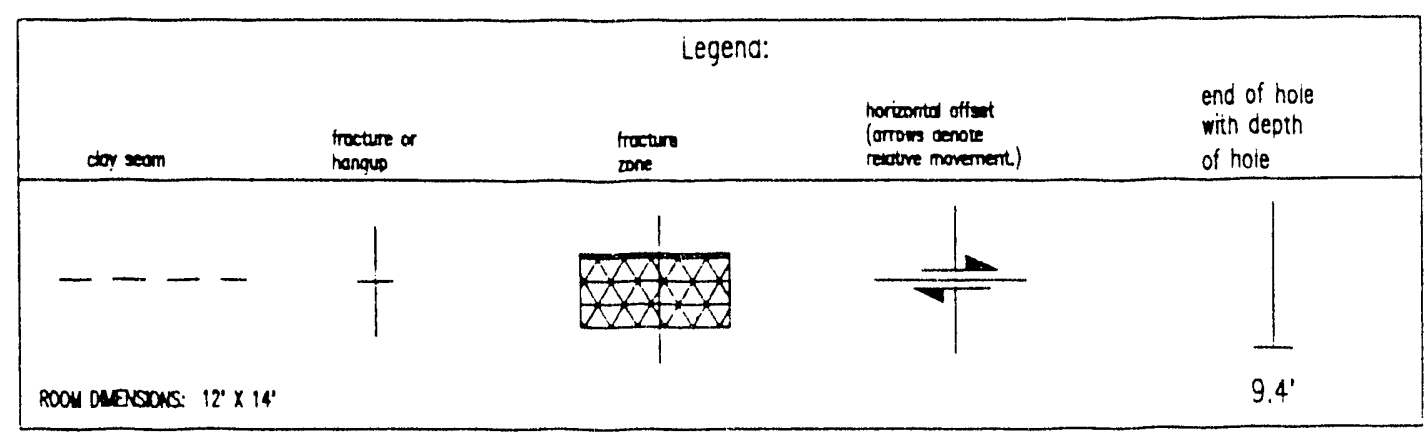

Figure 3-24

Excavation Effects Data, Array \#22

E300, 5700 


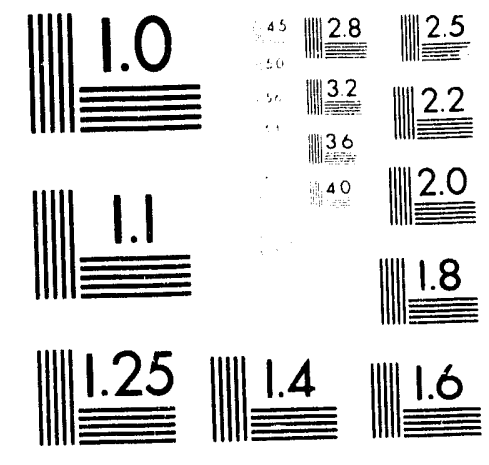



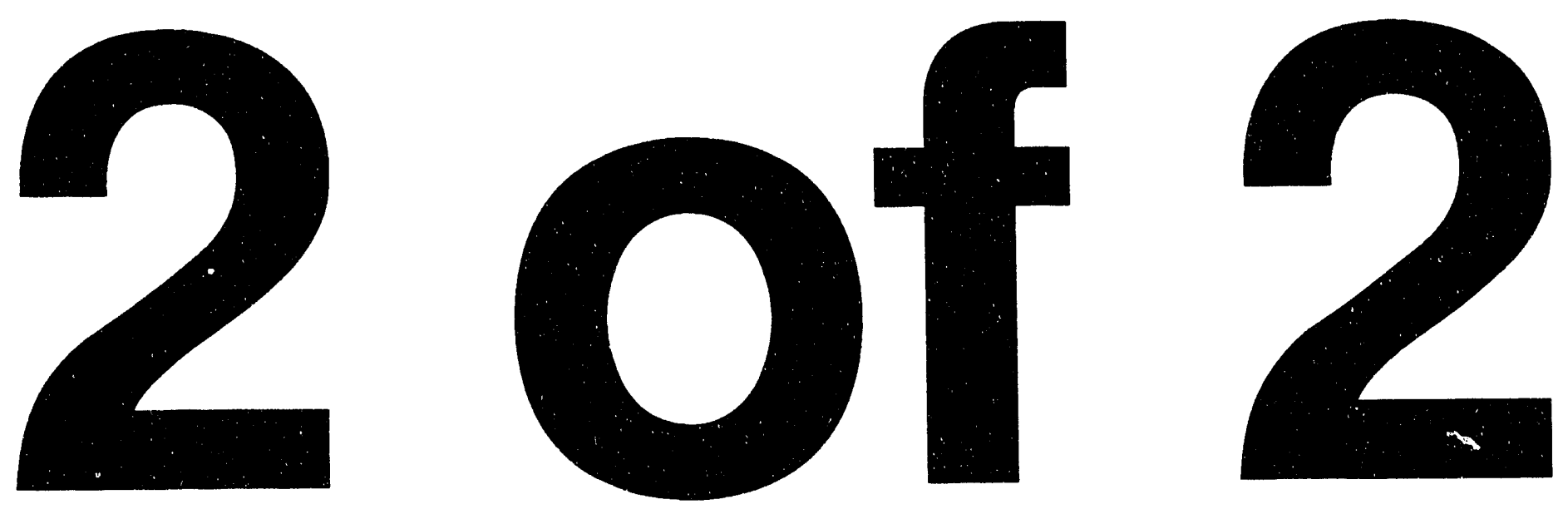

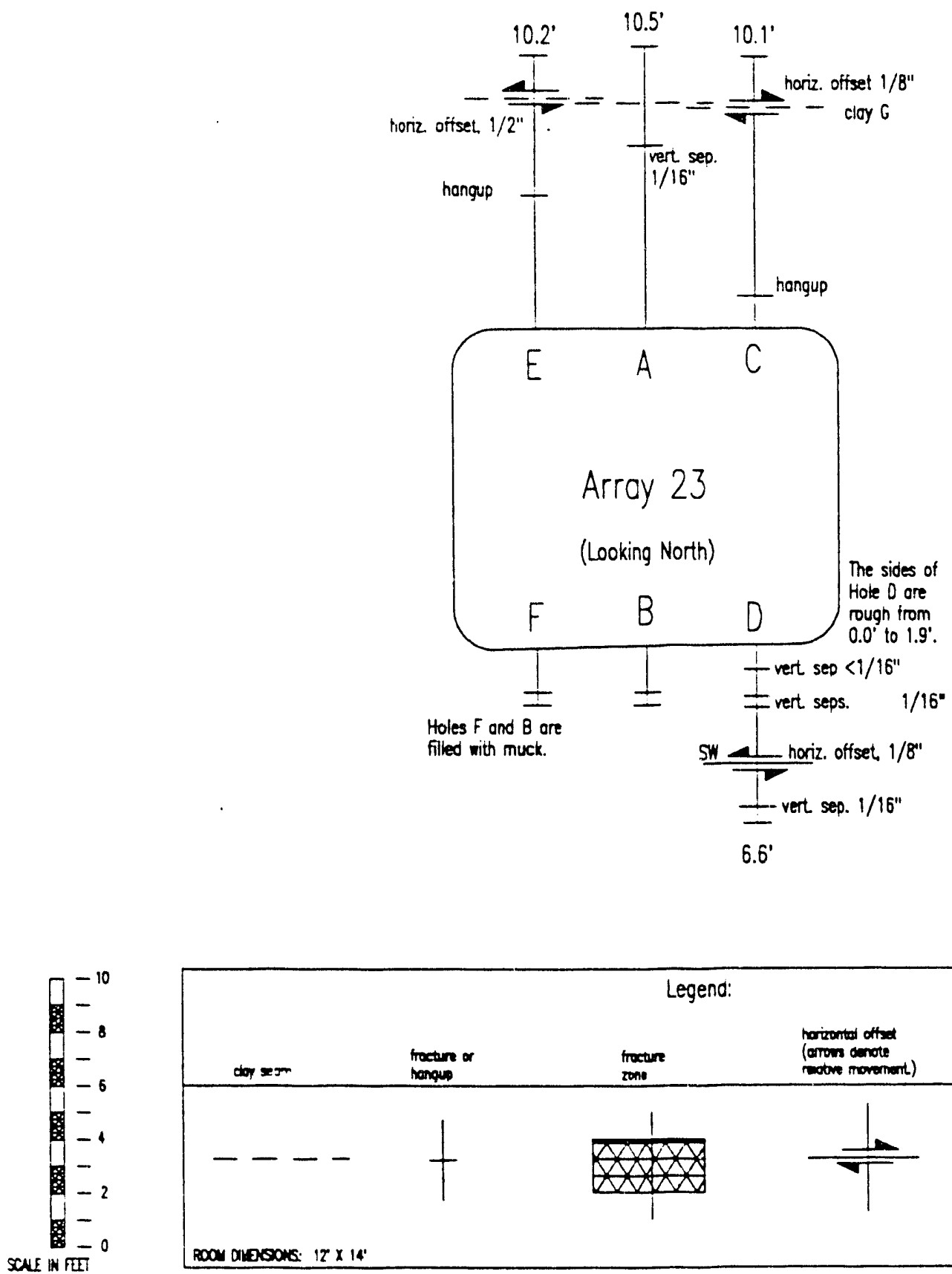

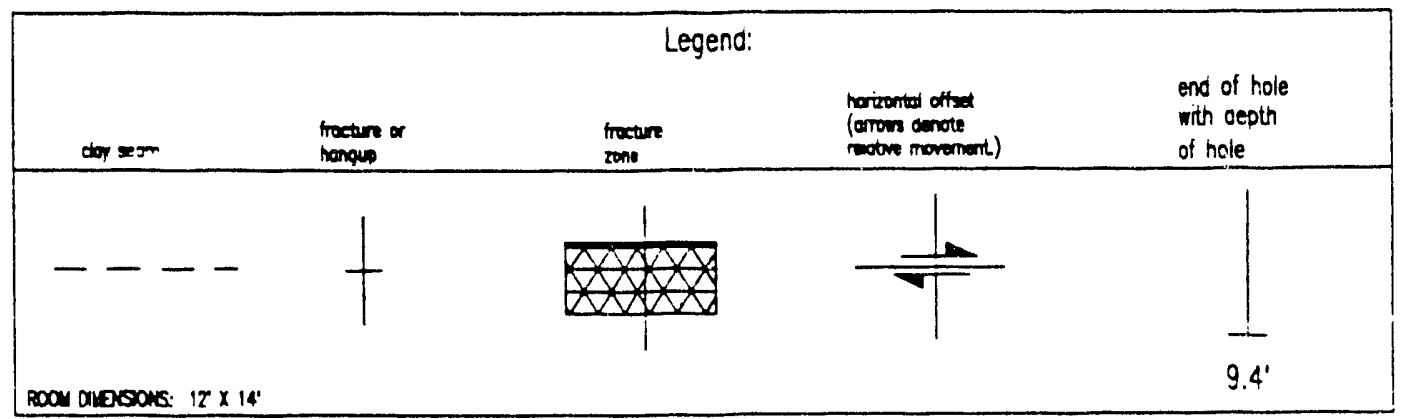

Figure 3-25

Excavation Effects Data, Array \#23

$E 300, S 1190$ 

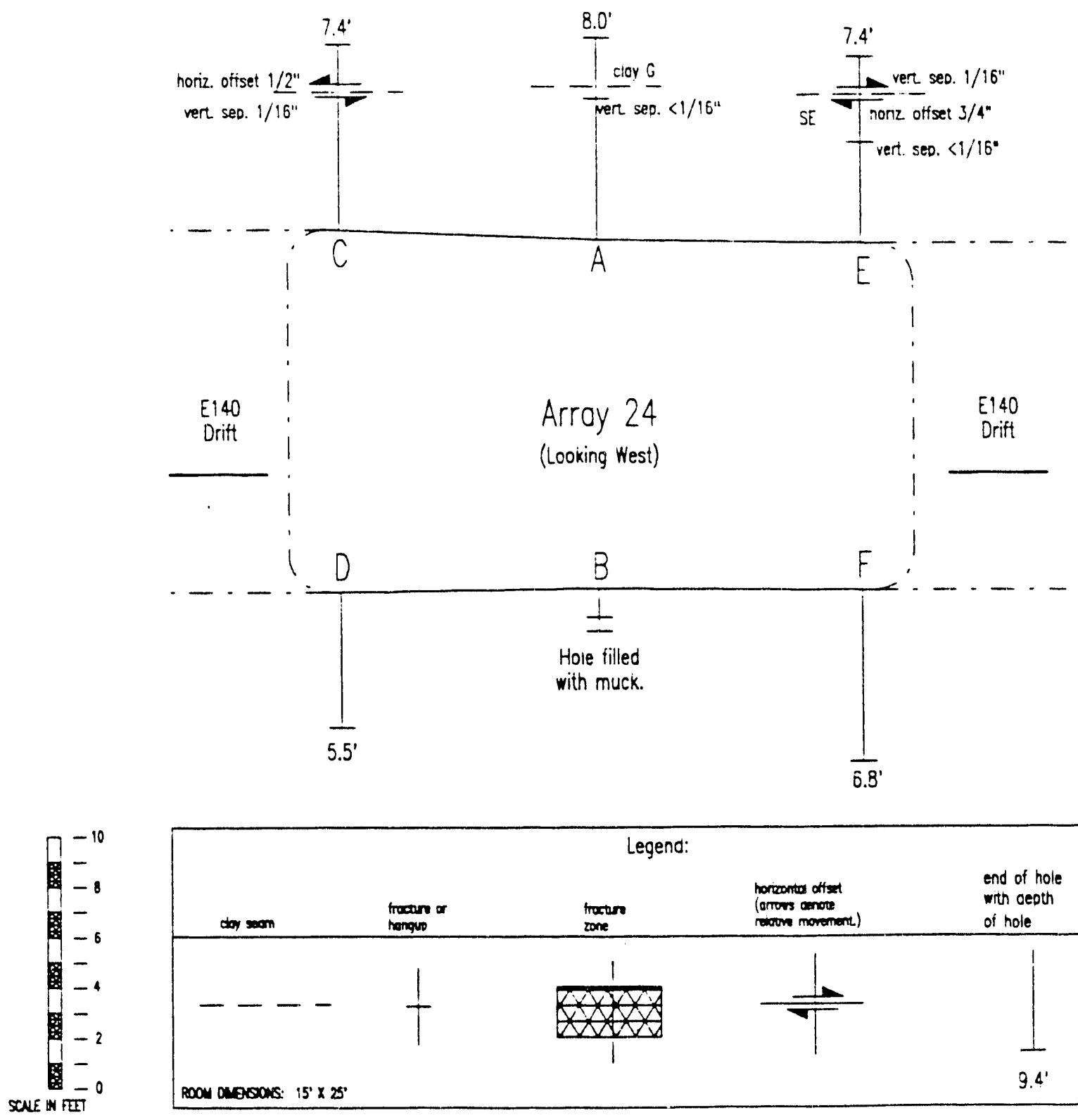

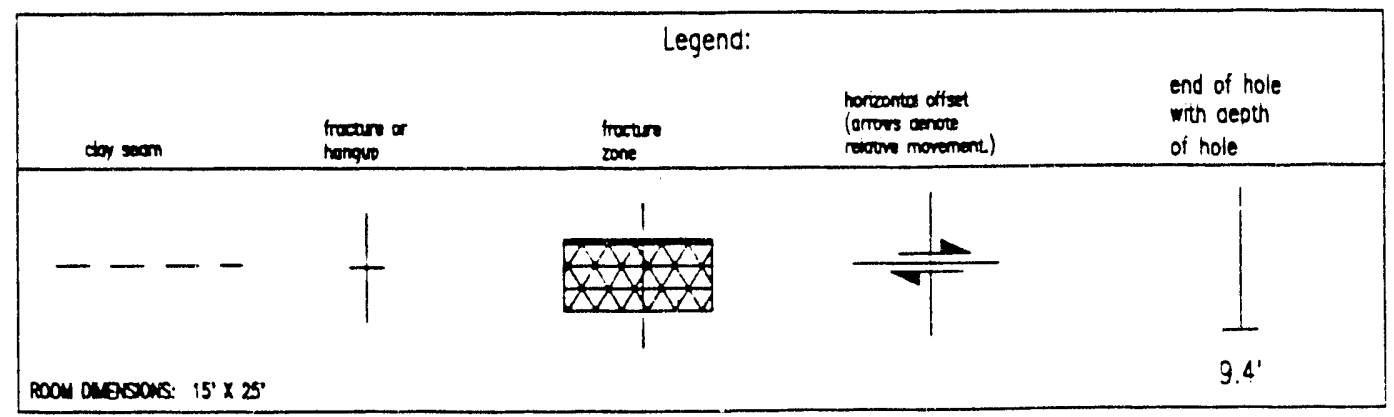

Figure 3-26

Excavation Effects Data, Array $\$ 24$

$E 140,51300$ 


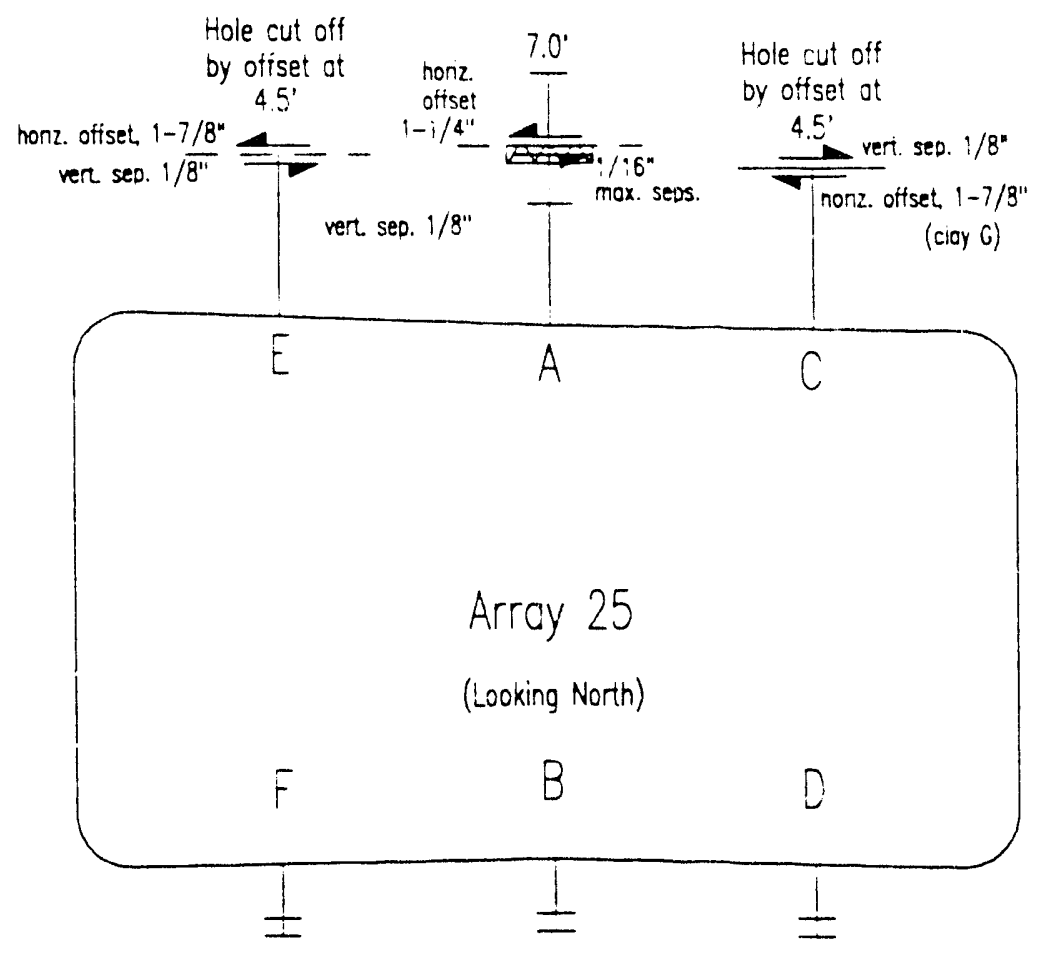

Four holes filled with muck.

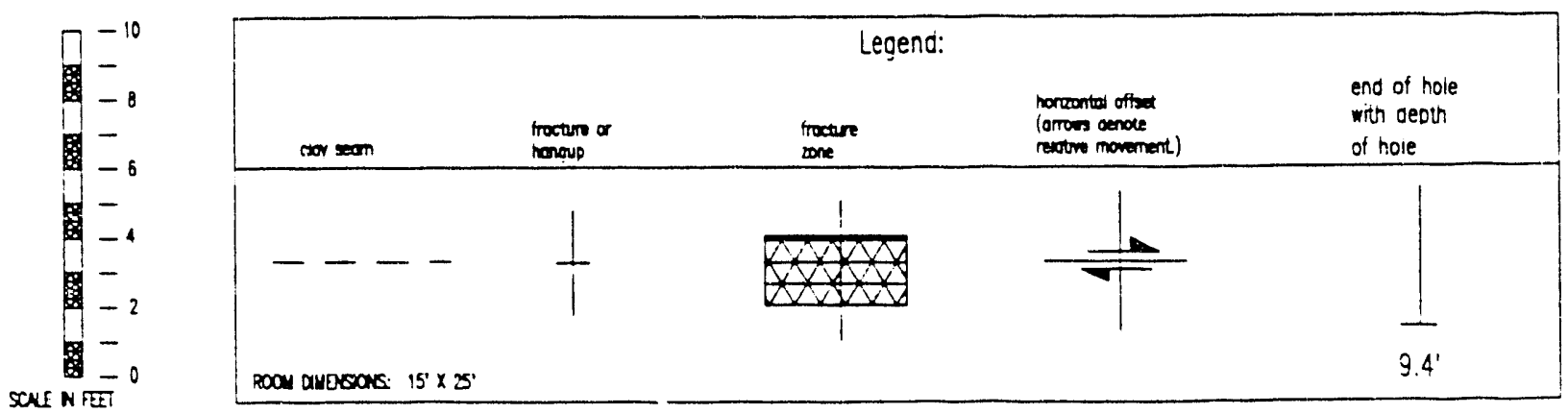

Figure 3-27

Excavation Effects Data, Array $\# 25$

E140, S1129 
Hoies not accessible this reporting period.

Figure shows ooto from 1988 survey.
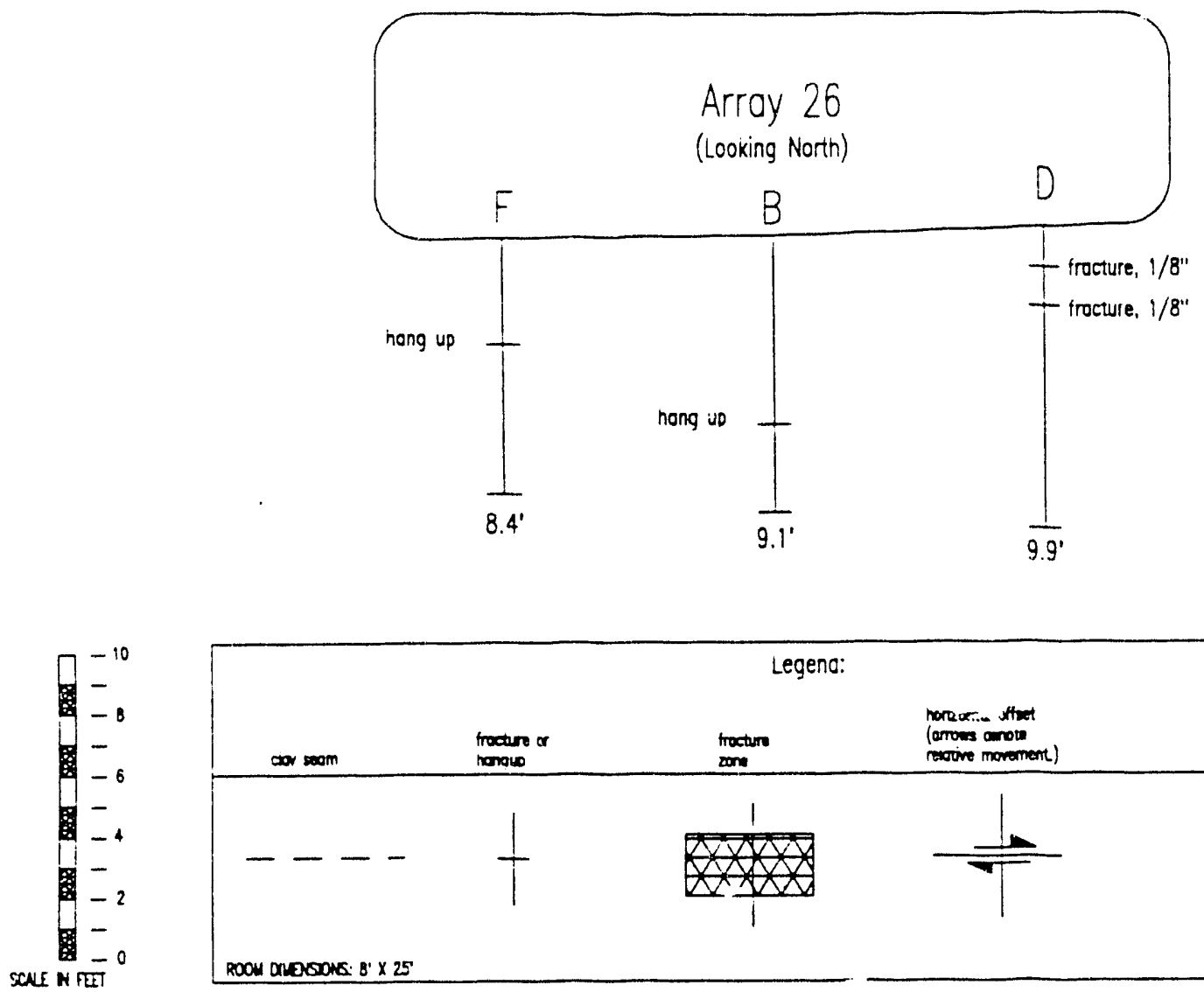

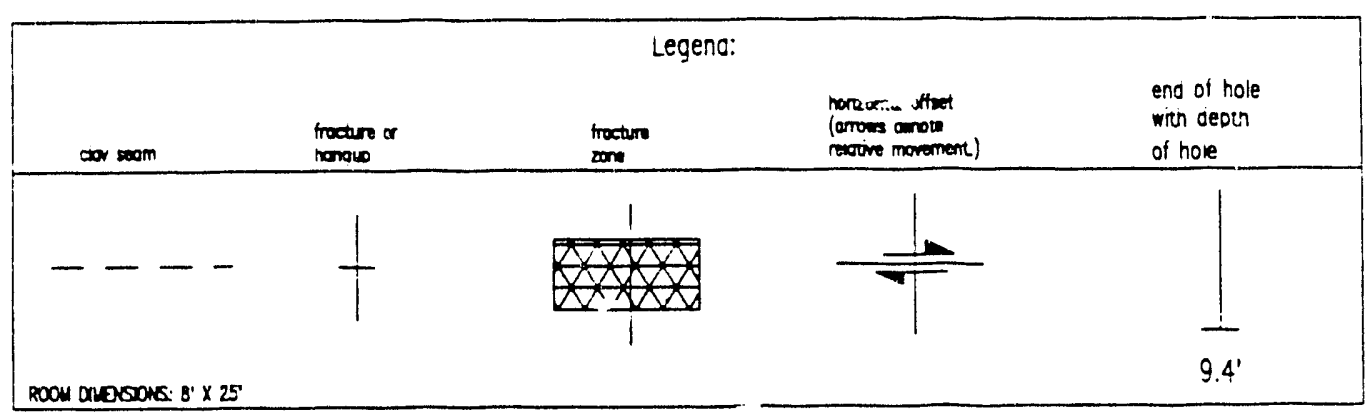

Figure 3-28

Excavation Effects Data, Array $\$ 26$

E140, S2205 


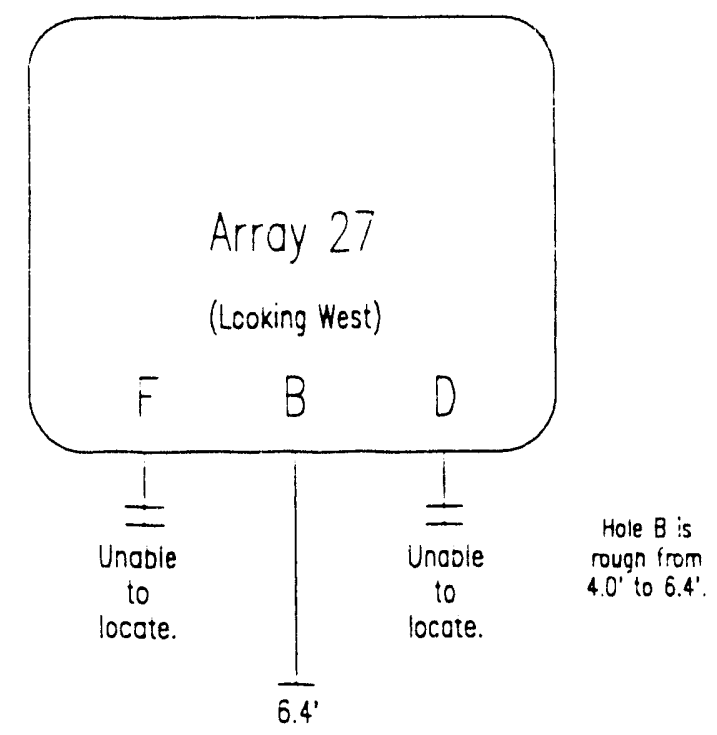

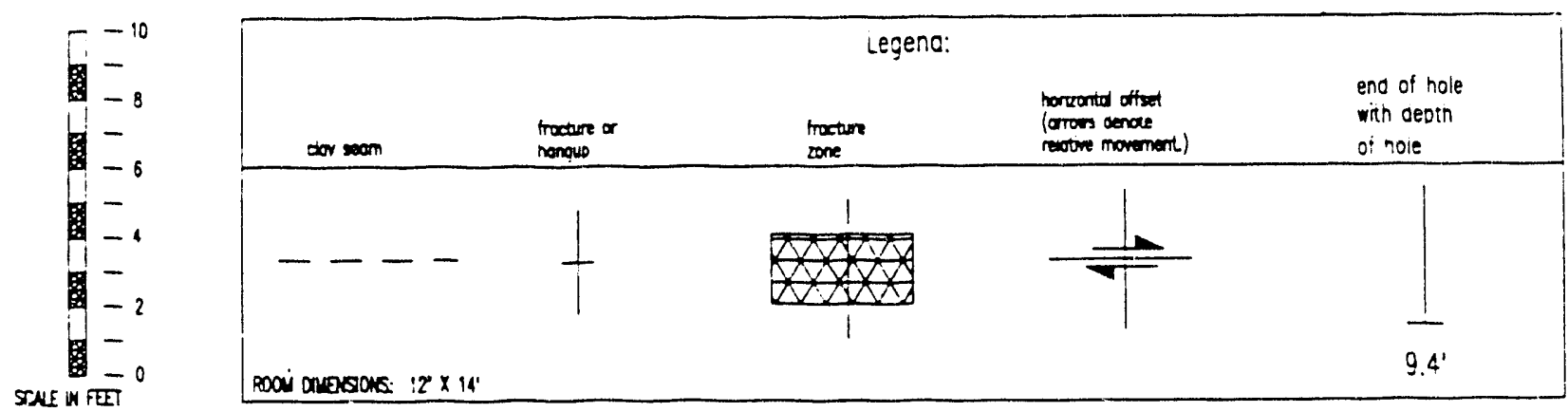

Figure 3-29

Excavation Effects Data, Array $\$ 27$

N1420, E1555 

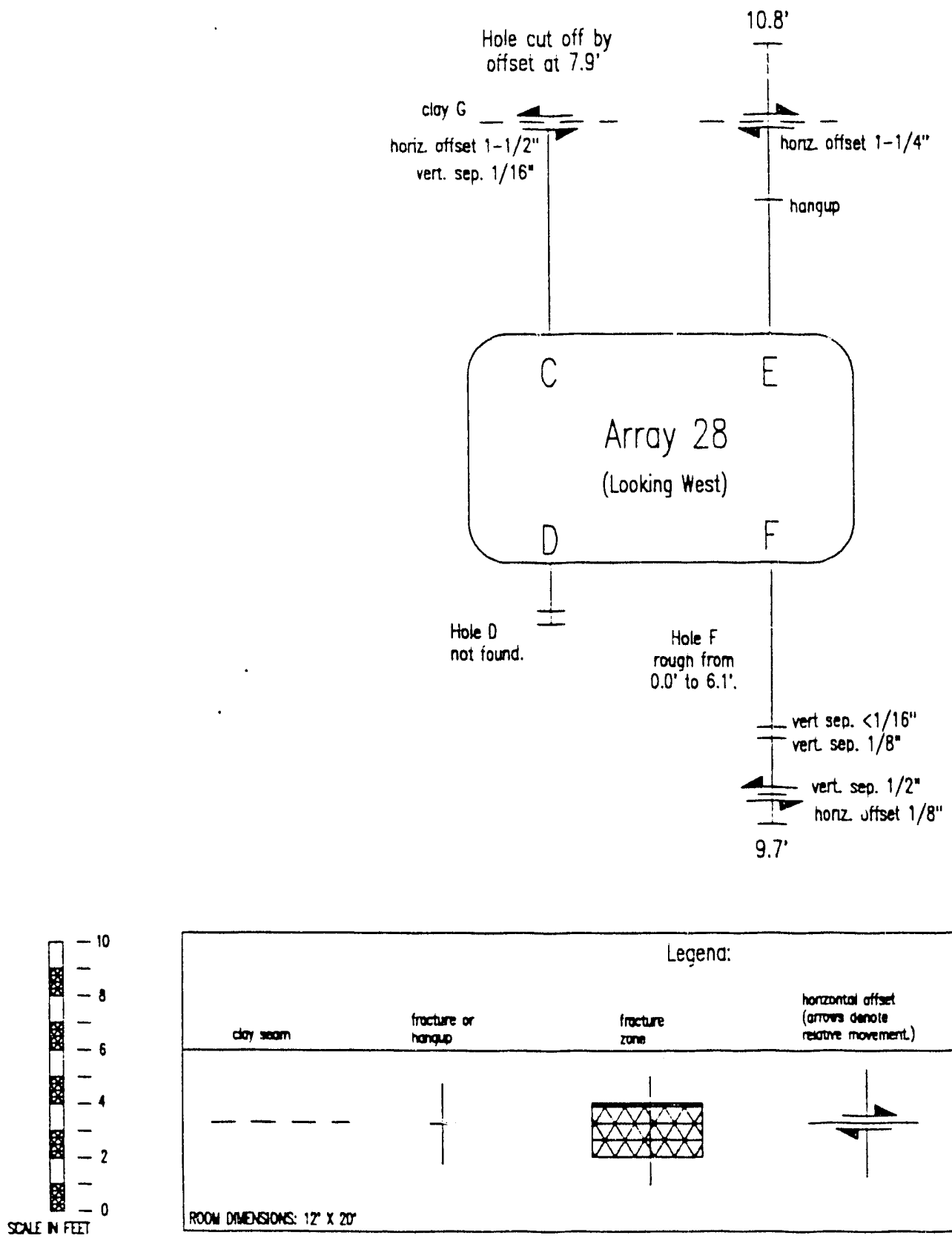

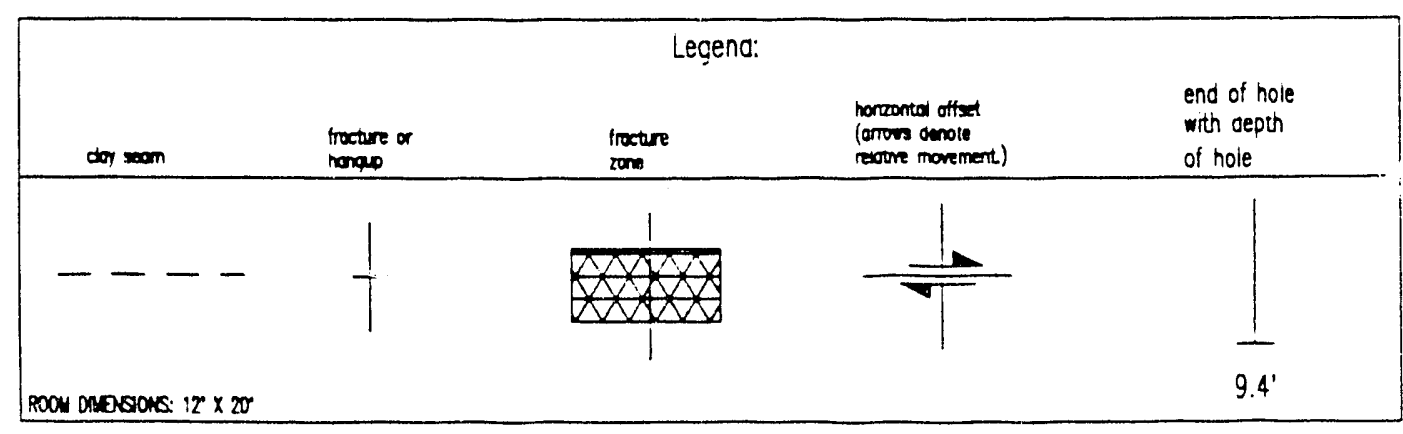

Figure 3-30

Excavation Effects Data, Array $\$ 28$

N1100, W432 

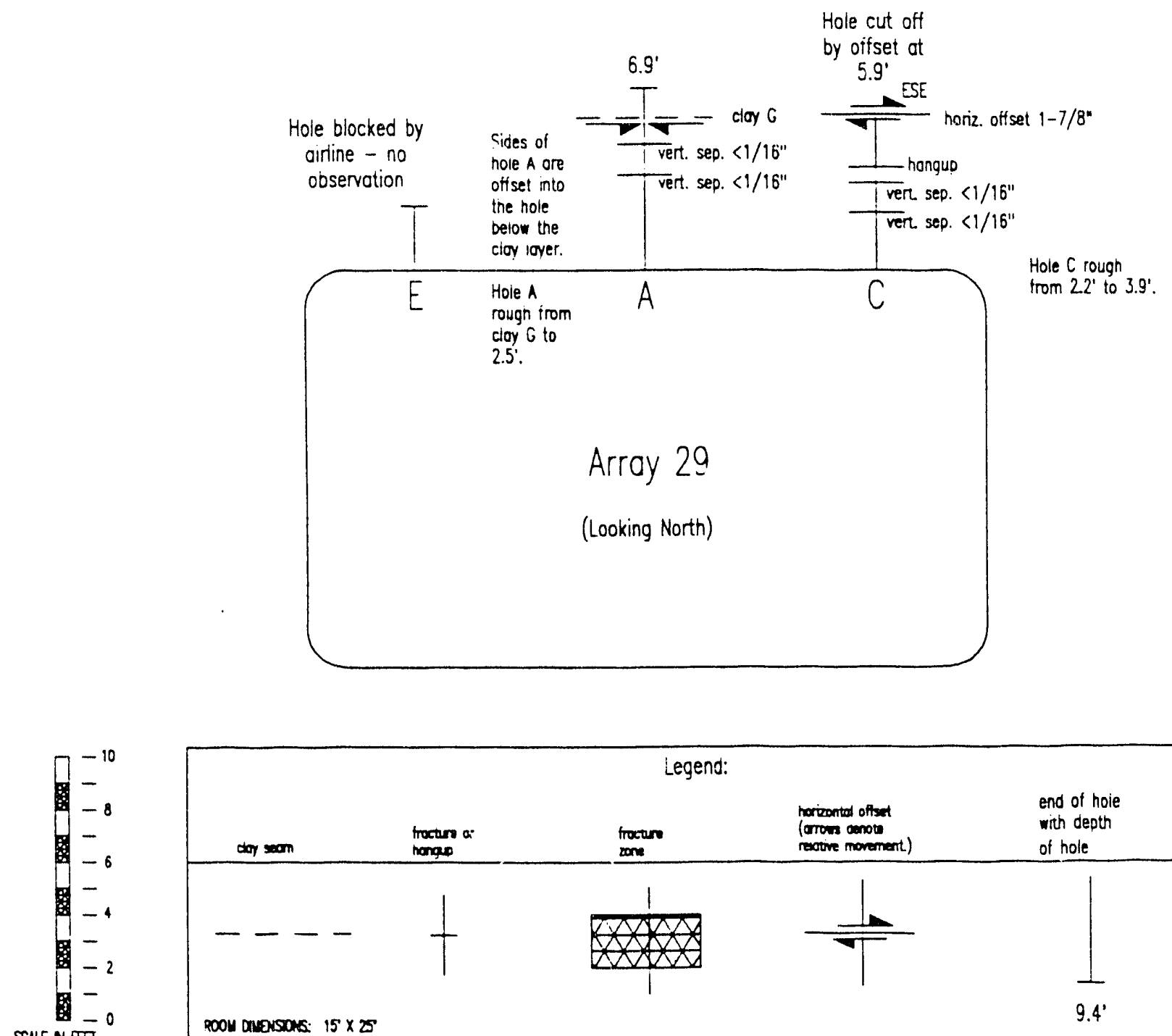

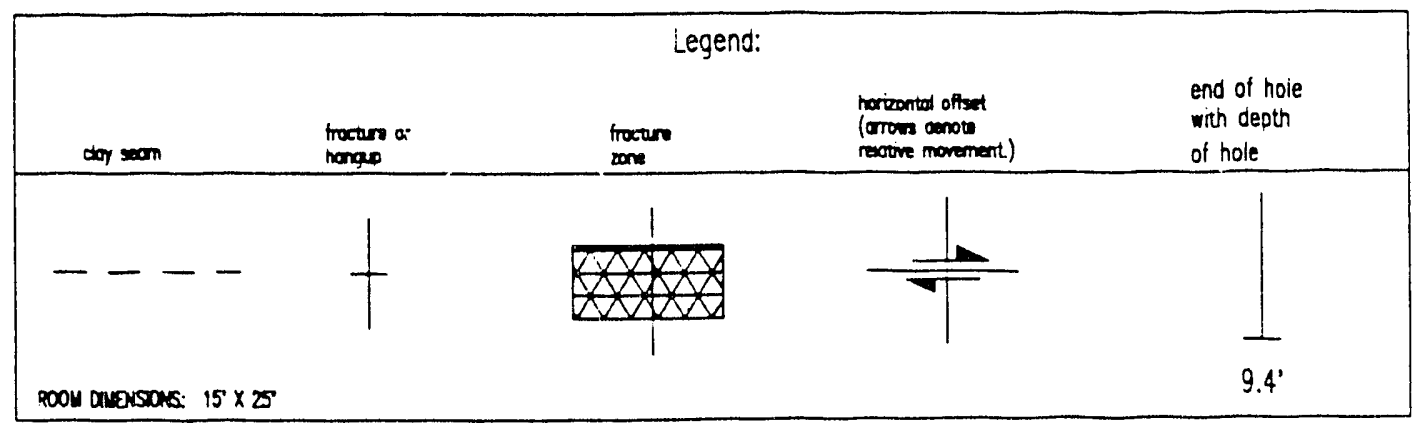

Figure 3-31

Excavation Effects Data, Array $\# 29$

E140, S1700 


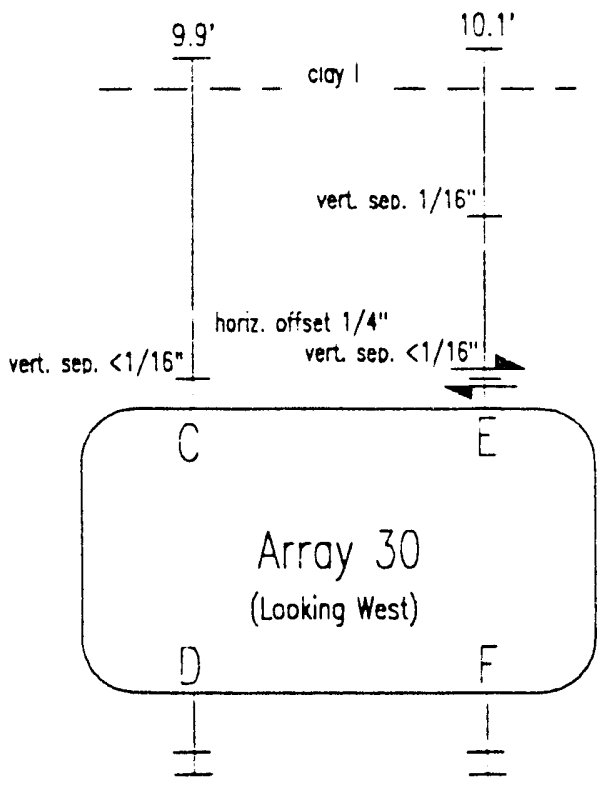

Floor holes not found this reporing penod.

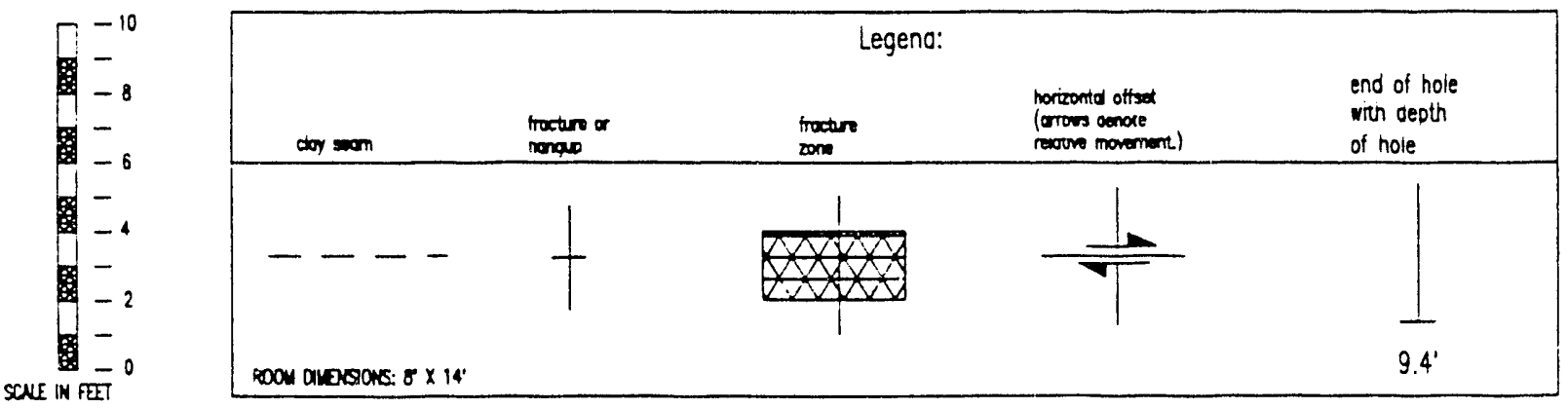

Figure 3-32

Excavation Effects Data, Array $\$ 30$

N1100, E1303 


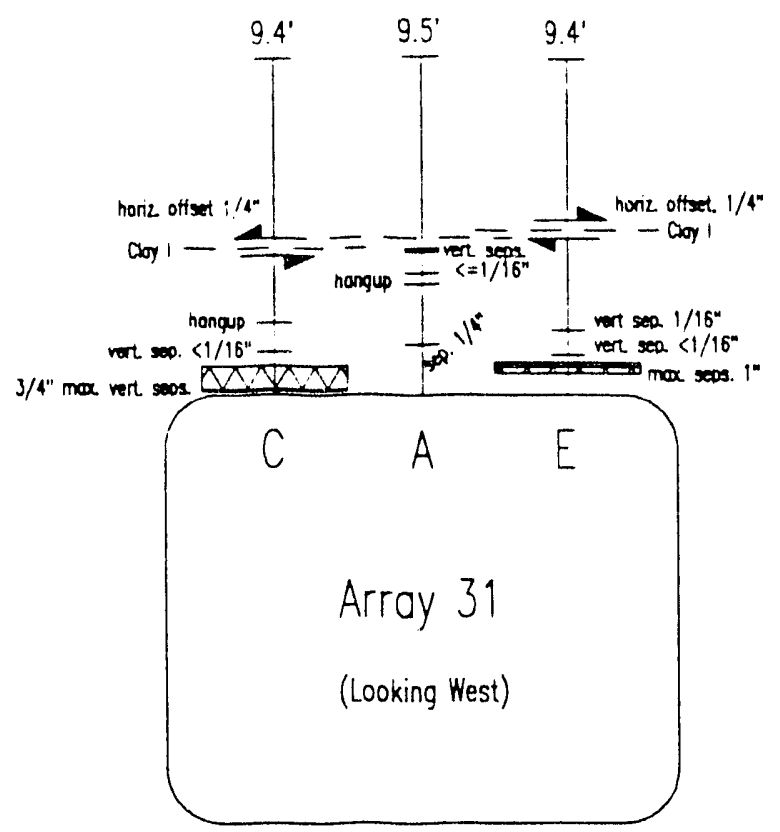

-10
-8
-6
-1
-2
-2
-0

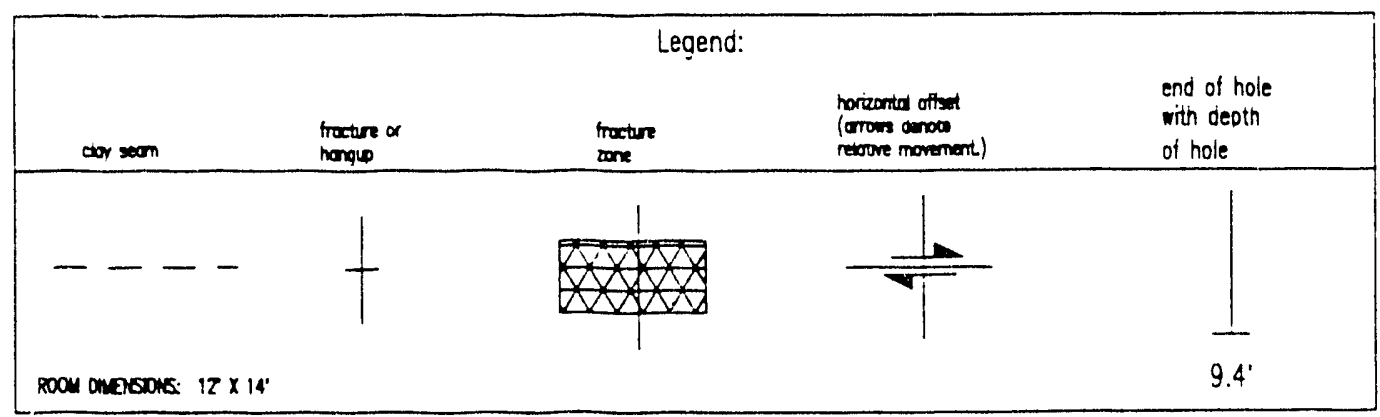

Figure 3-33

Excavation Effects Data, Array \#31

N1420, E1375 


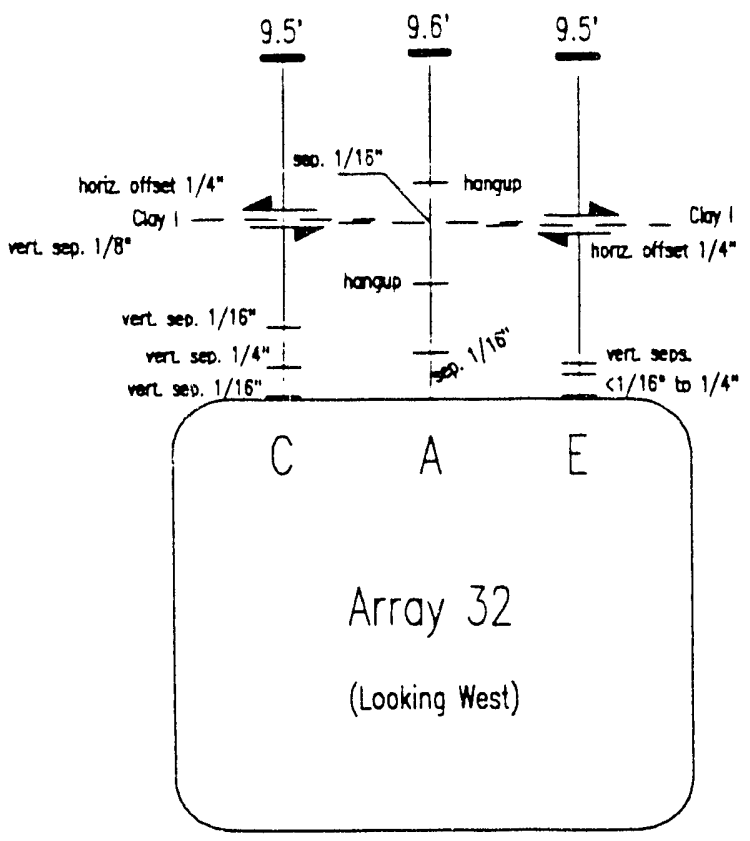

\begin{tabular}{|c|c|c|c|c|c|}
\hline $\begin{array}{l}-10 \\
-8\end{array}$ & cory & $\begin{array}{l}\text { Trecture ox } \\
\text { hongup }\end{array}$ & $\begin{array}{l}\text { Legen } \\
\text { trocture } \\
\text { zone }\end{array}$ & 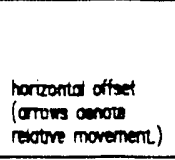 & $\begin{array}{l}\text { end of hole } \\
\text { with depth } \\
\text { of noie }\end{array}$ \\
\hline $\begin{array}{l}- \\
-4 \\
-2 \\
-0\end{array}$ & $\begin{array}{l}---- \\
\text { Roou duensons: } 12 \times 14\end{array}$ & $\frac{1}{1}$ & $\frac{1}{\Delta x}$ & $\stackrel{\omega}{\sigma}$ & $\frac{1}{9.4^{\prime}}$ \\
\hline
\end{tabular}

Figure 3-34

Excavation Effects Data, Array $\$ 32$

N1420, E1470 

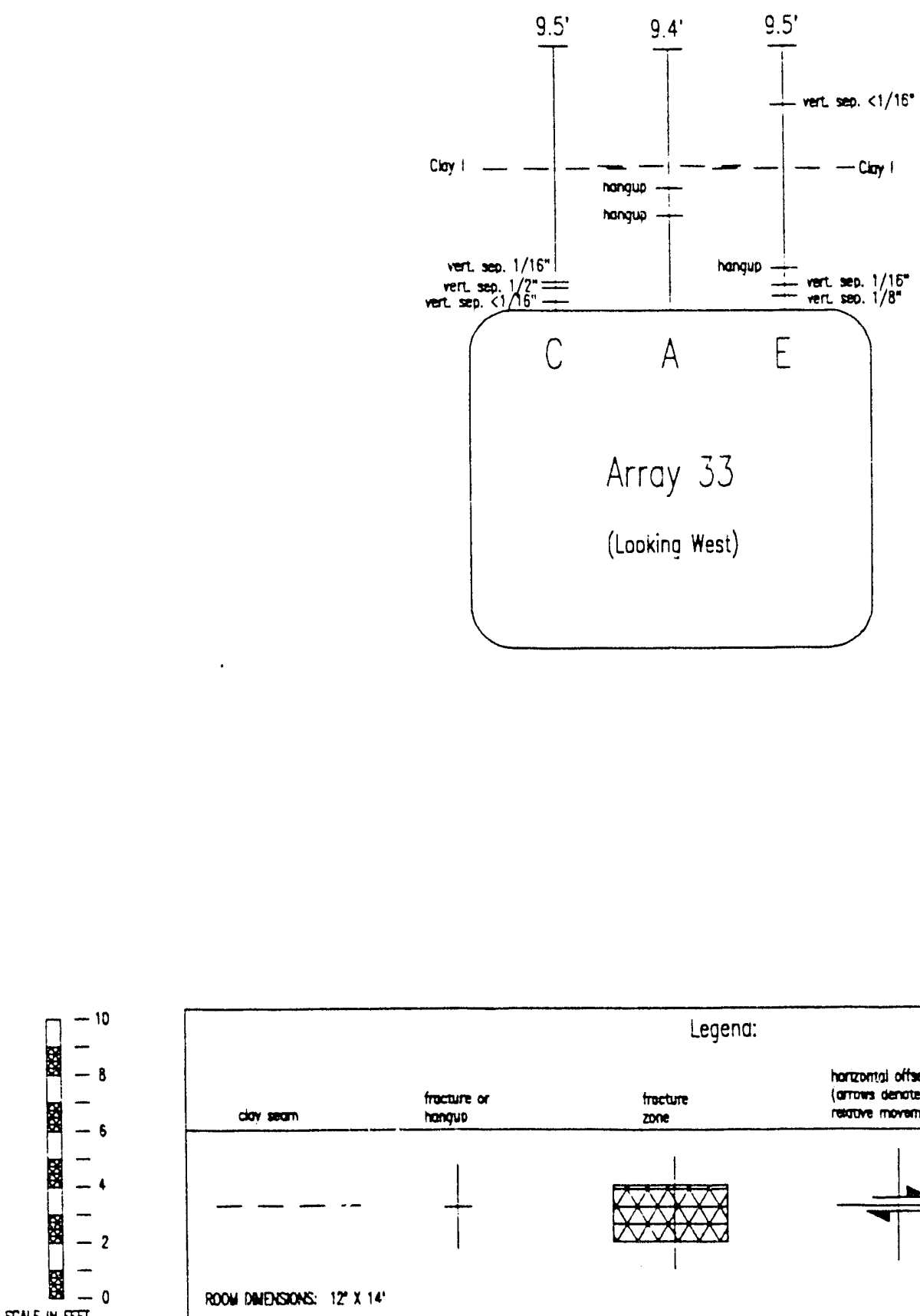

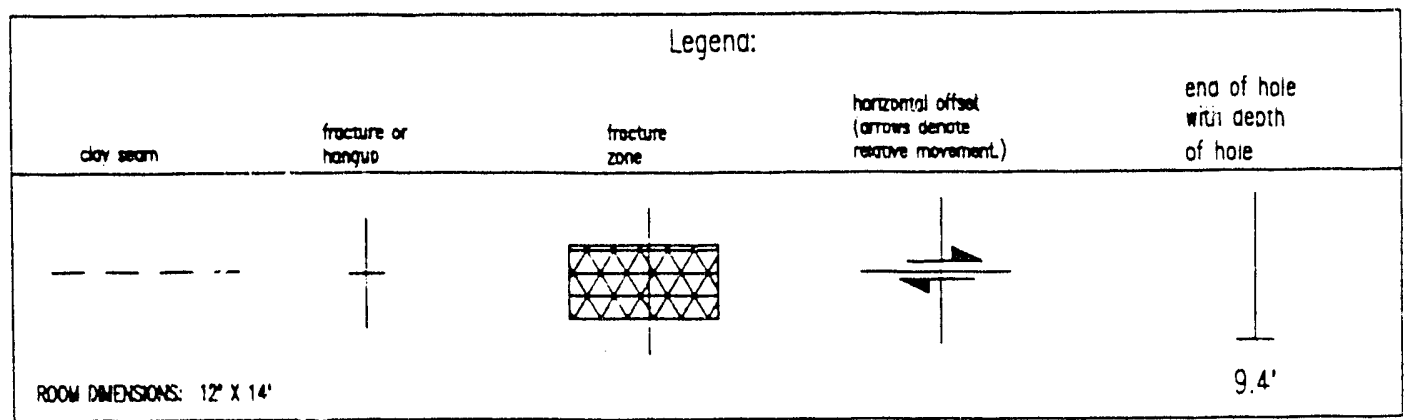

Figure 3-35

Excavation Effects Data, Array \#33

N1420, E1110 

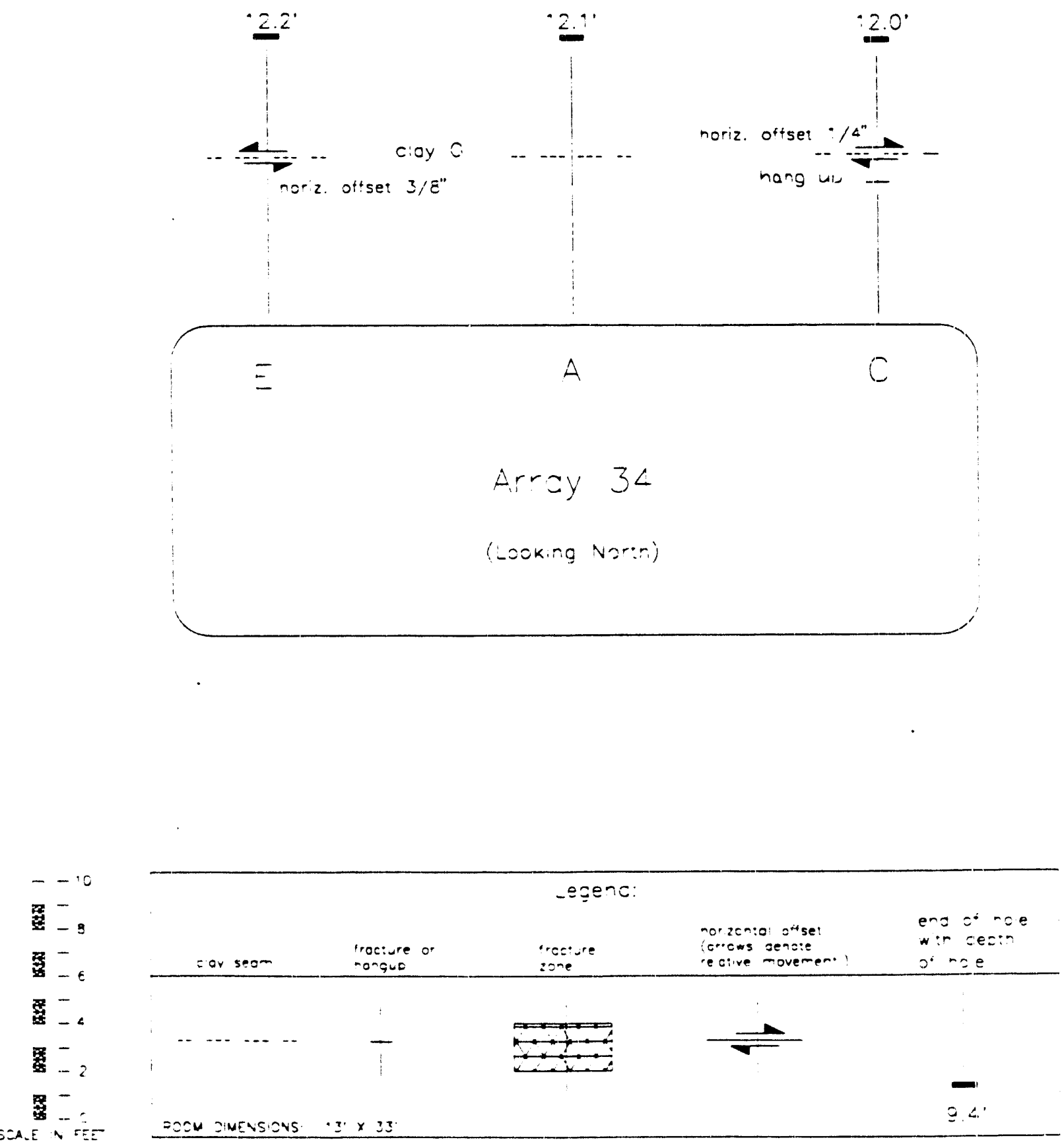

Figure 3-36

Excavation Effects Data. Array 34

Panel 1, Room 3 - S1862 


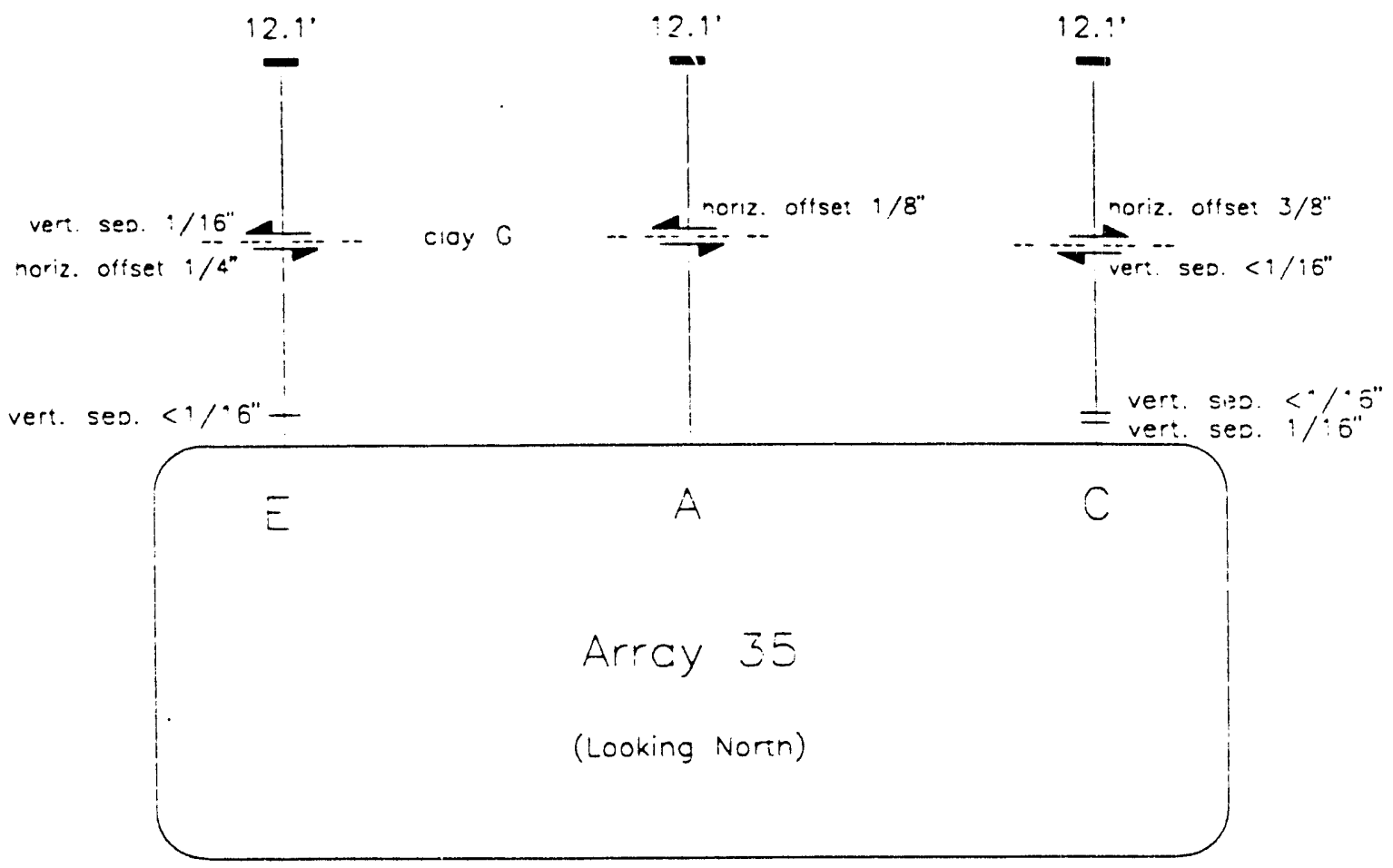

Figure 3-37

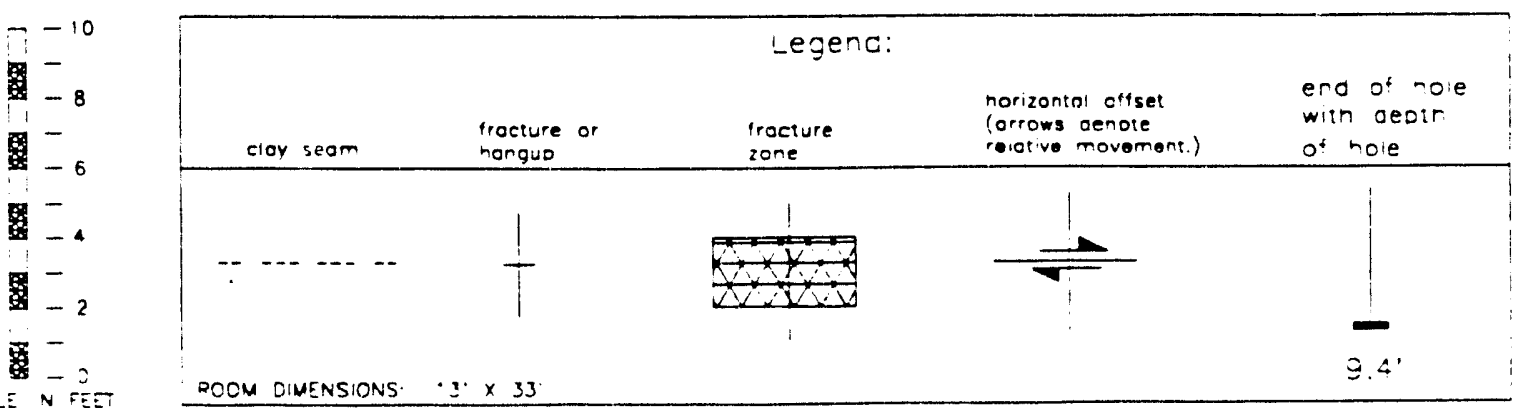

Excavation Effects Data, Array $\$ 35$

Panel 1, Room 3 - S1775 


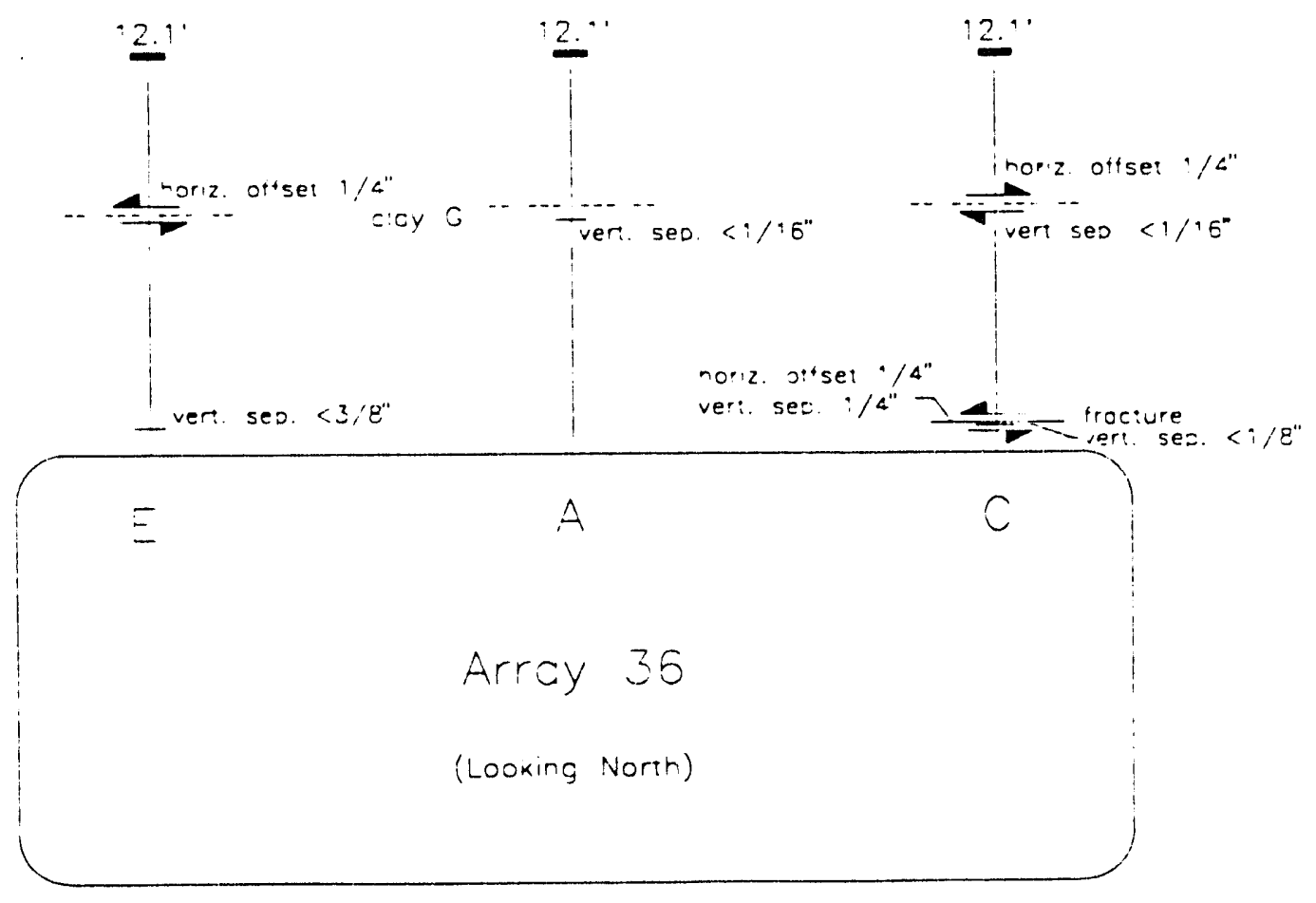

\begin{tabular}{|c|c|c|c|c|c|}
\hline$r^{-10}$ & & & Legenc & & \\
\hline $\begin{array}{l}- \\
-8 \\
-8 \\
-6\end{array}$ & Elor seam & $\begin{array}{l}\text { rocture of } \\
\text { rorguo }\end{array}$ & $\begin{array}{l}\text { 'rocture } \\
\text { zone }\end{array}$ & $\begin{array}{l}\text { Zorizonict of'set } \\
\text { (crows genole } \\
\text { elotive mavemen: ) }\end{array}$ & $\begin{array}{l}\text { eno o* nole } \\
\text { witn oesth } \\
0^{+} \text {-ole }\end{array}$ \\
\hline $0^{-}$ & & & 1 & $!$ & 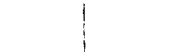 \\
\hline 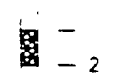 & - & $\frac{1}{1}$ & $\frac{6+4}{4+2}$ & 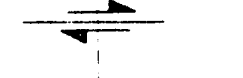 & 1 \\
\hline $\operatorname{lin}_{n=0}^{-}=0$ & POCM DIMENSIONS & $3.3 \times 3$ & 1 & & 5. \\
\hline
\end{tabular}

Figure 3-38

Excavation Effects Data, Array $\$ 36$

Panel 1, Room 3 - S1688 


\subsection{Fracture Mapping of Excavation Surfaces}

Distribution of excavation surface fractures is shown on fracture maps created for areas of the WIPP underground facility as required. During this reporting period, fracture maps were produced to assist in ground stability assessments for the collowing areas:

- Waste Shaft Brows

- Room 7, Panel 1 Back

- Room 1, Panel 1 Floor

\subsubsection{Waste Shaft Station}

The fractures of the shaft brows of the Waste Shait Station were mapped in November, 1991. Fractures were mapped for the following areas:

- East Brow Face (within the shaft)

- West Brow Face (within the shaft)

- East Brow Underside (station back)

- West Brow Underside (station back)

\section{East Brow Face}

Fractures in the shaft are shown in Figure 3-39. Vertical extent of mapping is from the base of the brow to approximately eighteen feet up into the shaft. No visible horizontal fractures were found in the halite unit above anhydrite "a" (approximately 4 meters (13 feet) up into the shaft); however, some subvertical spalling was found. The contact between the halite and the top of anhydrite "a" contained discontinuous fractures with openings up to 0.2 centimeters ( $1 / 16$ inch) wide.

There is a separation spanning from rib to rib at the contact of anhydrite "a" with the underlying halite unit. Width of this separation varied from tight to 1.3 centimeters ( $1 / 2$ inch). The depth of this separation into the rock could not be determined. A discontinuous horizontal fracture was observed in the halite unit between anhydrite "a" and anhydrite "b" (approximately 1.5 meters (5 feet) up into the shaft), with openings up to 0.9 centimeters $(3 / 8$ inches) wide. The depth of this fracture into the rock could not be determined, and no horizontal displacement (offset' was noted.

The halite below anhydrite " $b$ " is offset along the contact toward the shaft by one to three inches: opening widths of up to one inch were observed along the contact. There are several horizontal fractures in this section of halite. A discontinuous fracture 0.6 centimeter ( $1 / 4$ inch) wide. occurs about 1.2 meters ( 4 feet) above the base of the brow and appears to span the width of the brow 
GFDAR

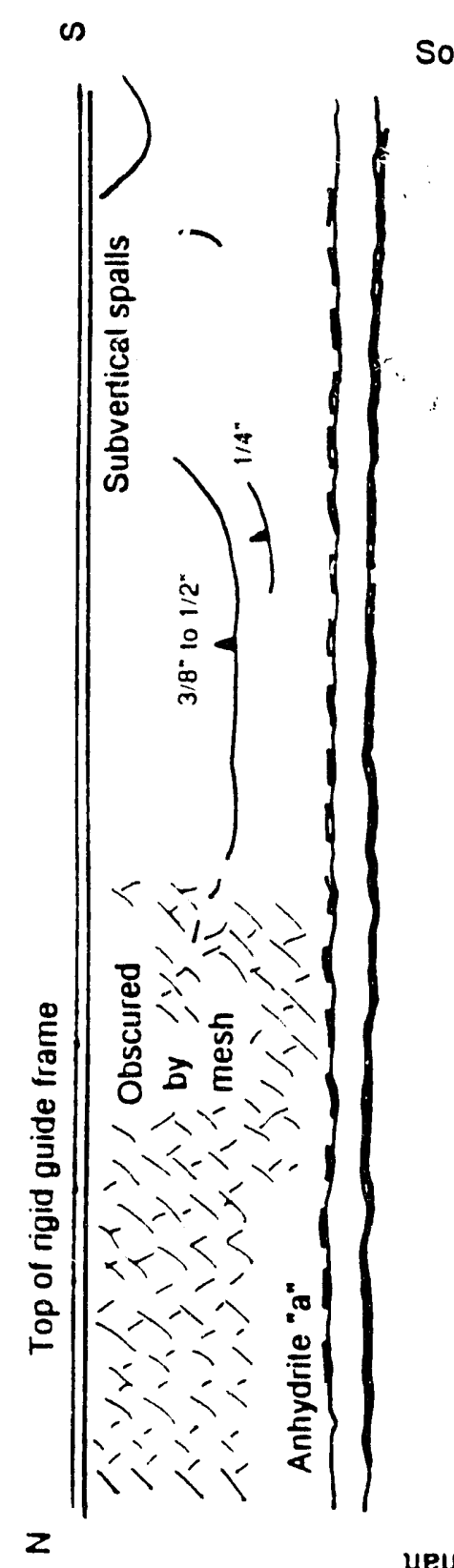

South Wall of Shaft
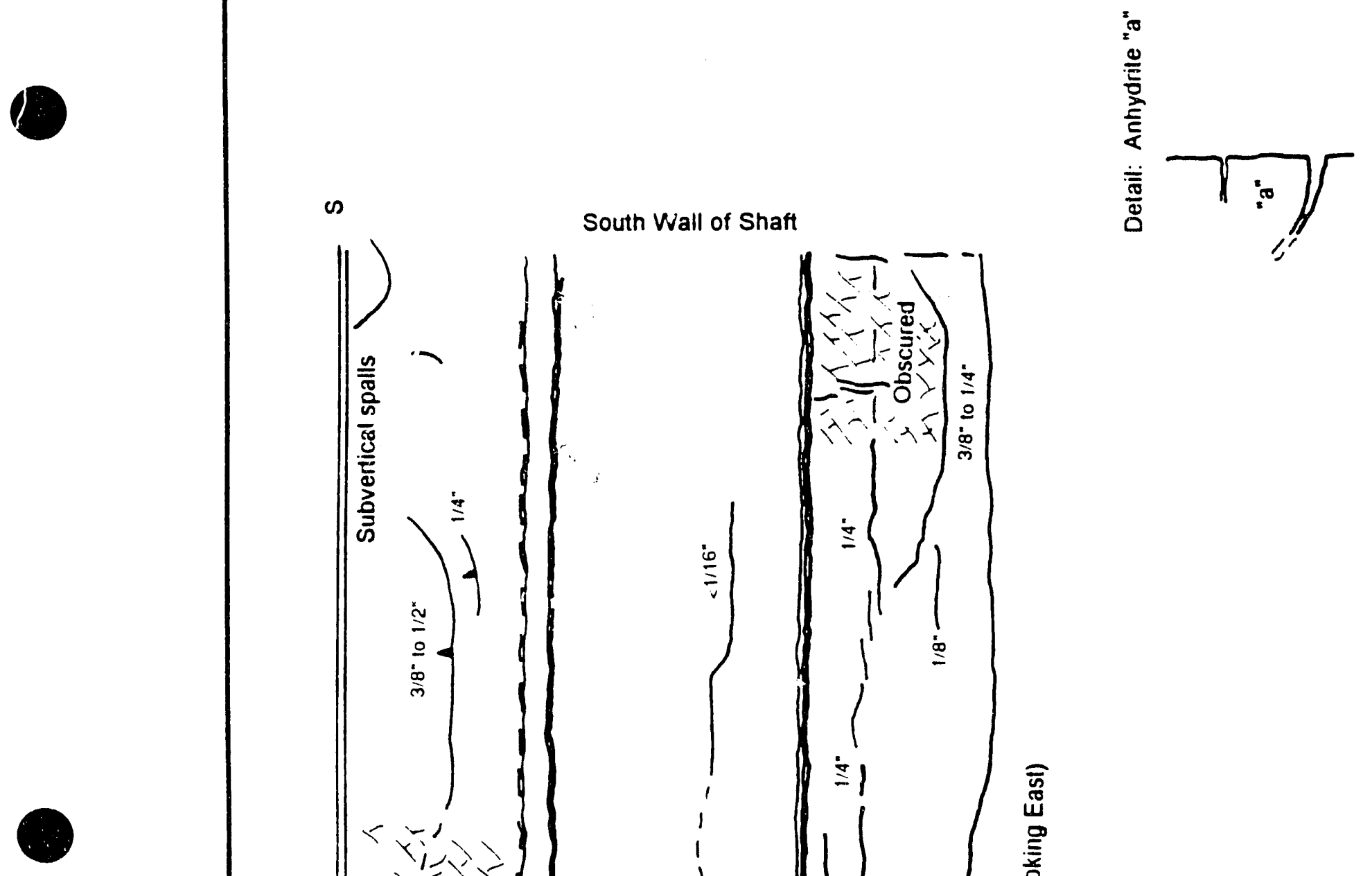

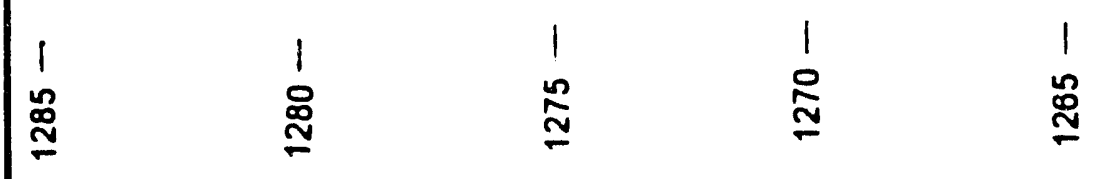


GFDAR

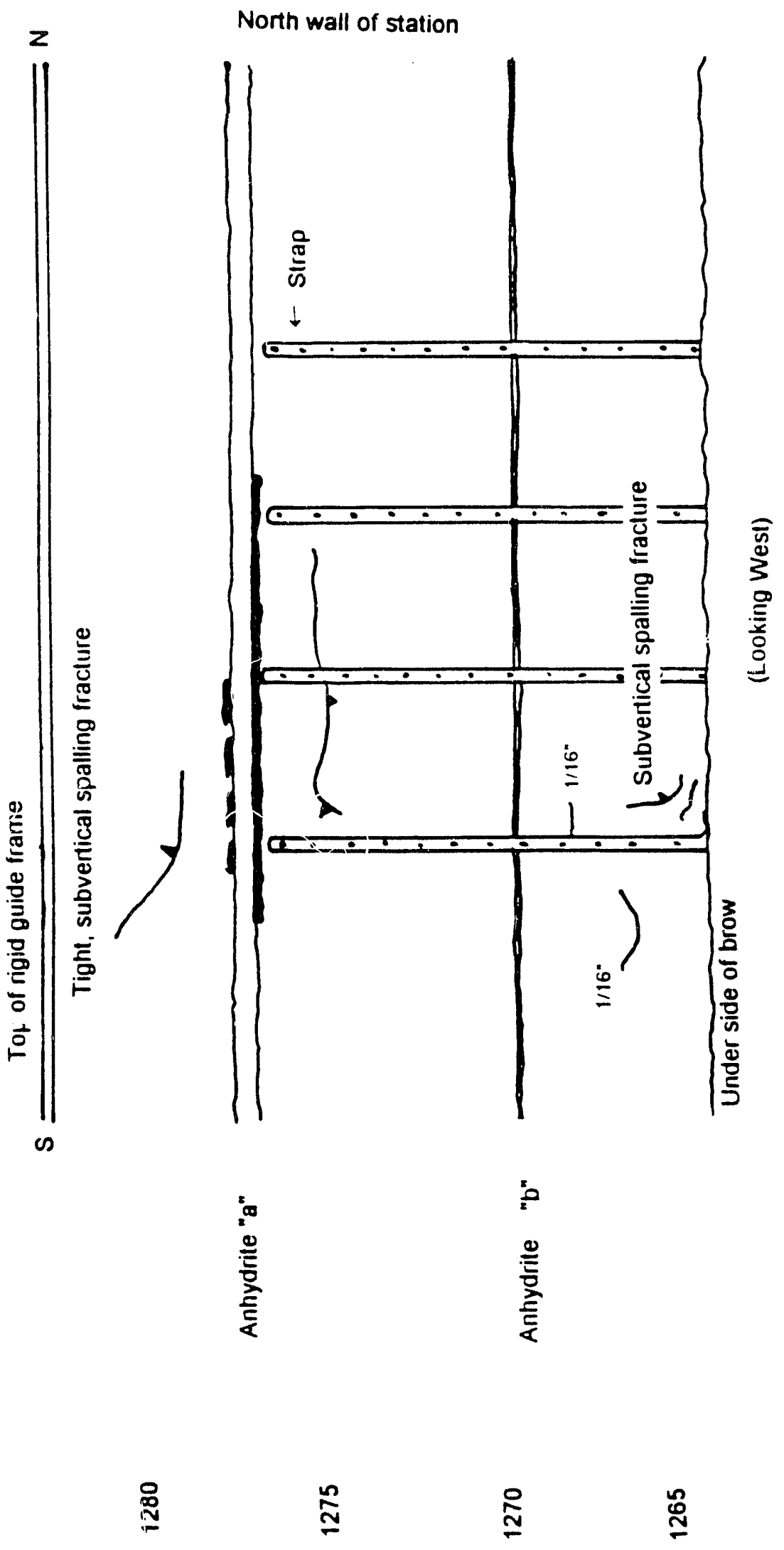

FIGURE 3.40

Waste Shatt West Brow Face 
face. Low-angled fractures originating at the sides of the face intersect this fracture. outlining a wedge-shaped section of rock.

\section{West Brow Face}

Much of the west brow face was obscured by wire mesh encrusted with halite. making observations difficult. The brow exhibited features similar to those of the east 'rivw (Figure 3-40). A spall was found between 4 meters ( 13 feet) and 5 meters (18 feet) up into the shaft. Anhydrite "a" contained a discontinuous separation along the upper contact. with openings less than 0.15 centimeters ( $1 / 16$ inch) wide. A horizontal tracture with a 0.3 cenitmeters ( $1 / 8$ inch) wide opening was found between anhydrite "a" and anhydrite " $b$ ". The depth of the fracture into the rock could not be determined.

Anhydrite " $b$ " exhibited no separation from the overlying halite. However. the lower contact of the anhydrite with the underlying halite consisted of a separation of up to 1.3 centimeters (1/2 inch) wide. The depth of the separation into the rock could not be determined. The lower halite unit is offset toward the shaft by approximately 2.5 centimeters ( 1 inch).

A group of fractures with openings up to 0.15 centimeters (1/16 inch) wide was located on the south side of the face between the base of the brow and approximately 1.2 meters ( 4 feet) up. Orientations of the fractures ranged from horizontal to vertical, with lengths up to approximately four feet.

\section{East Brow Underside}

Vertical fractures were observed in the back within 3 meters (10 feet) of the shaft (Figure 3-41) Openings up to 1 centimeter ( $3 / 8$ inch) wide were observed in the fractures closest to the shatt. Vertical depths of these fractures were not determined.

\section{West Brow Underside}

Vertical fractures up to 4 centimeters $\left(1 \frac{1}{2}\right.$ inches) of surface opening and, with visible depths extending approximately 0.3 meters ( 1 foot) into the back were found on the underside of the west brow (Figure 3-42). One vertical fracture intersects a horizontal fracture lying approximately four inches above the back, forming a shallow slab.

Four steel straps (anchored with rockbolts) are installed on the west brow and extend approximately 3 meters (10 feet) along the underside of the brow and up into the shaft approximately 4 meters ( 12.5 feet). To contain shallow spalling on the underside of the brow. 
GFDAR

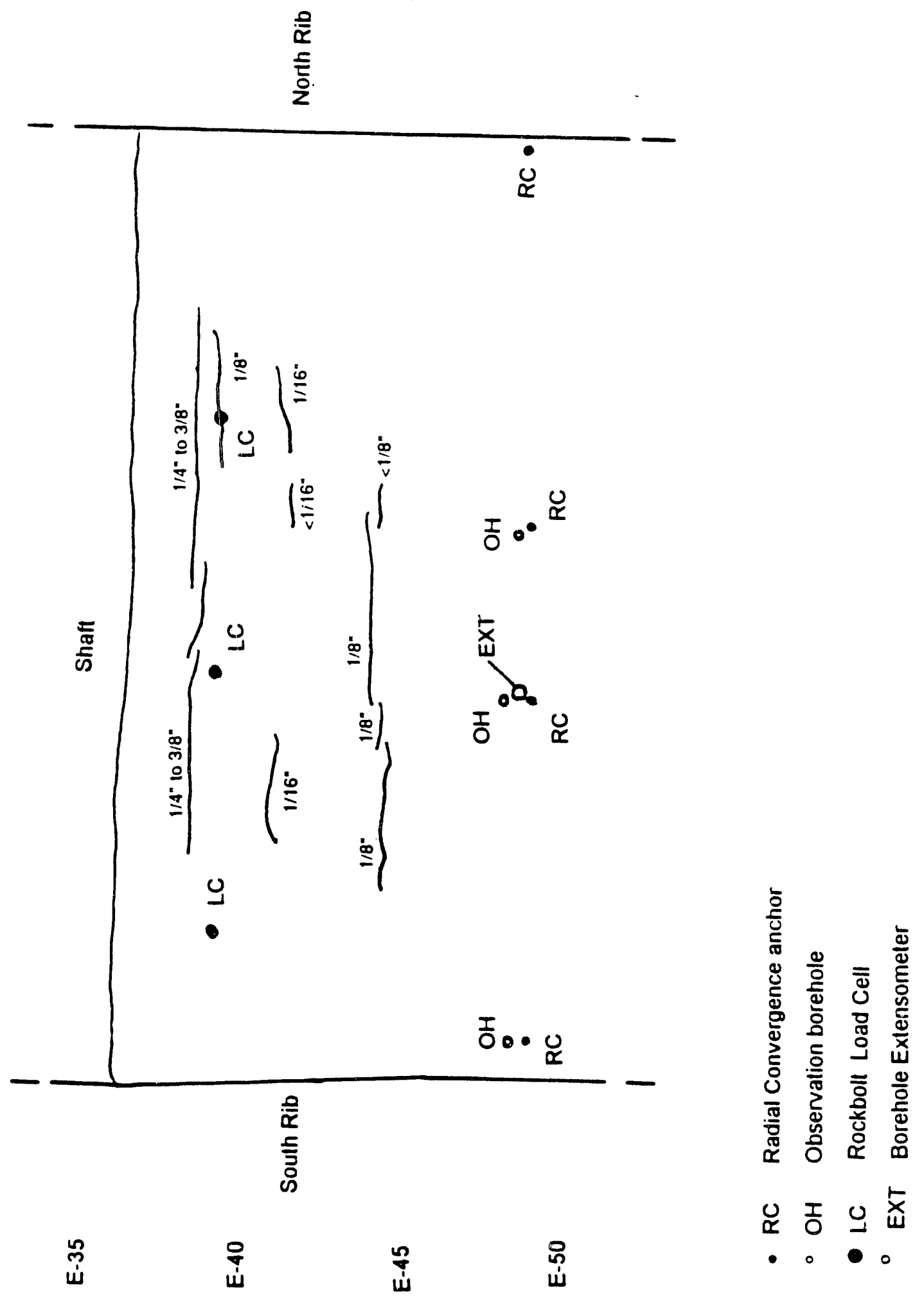

FIGURE 3-41

Waste Shatt East Brow

Station Back 

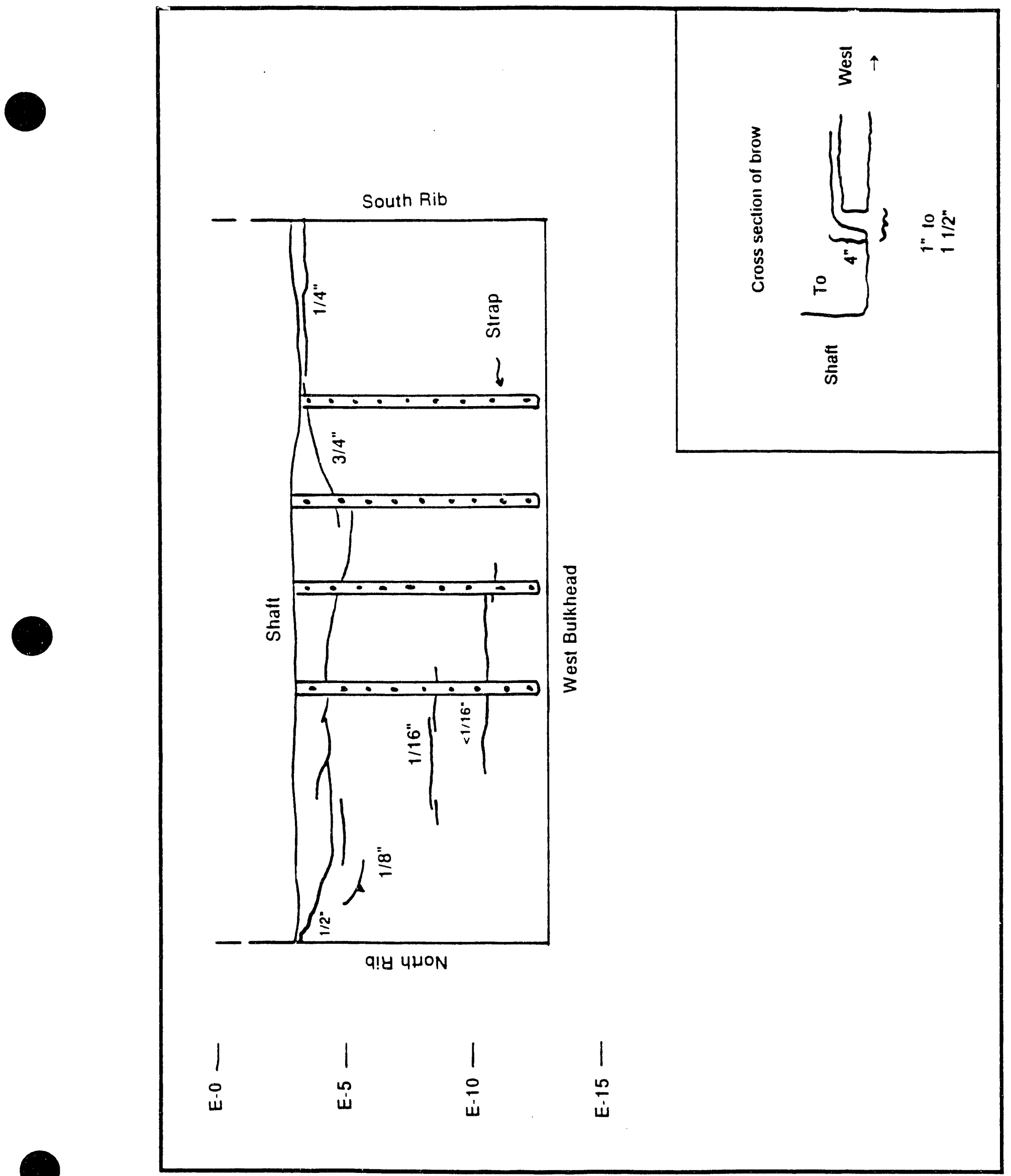

FIGURE 3.42

Waste Shaft West Brow

Station Back 
wire mesh was installed between the straps and the back.

\subsubsection{Panel 1}

\section{Room 7, Panel 1 Back Fractures}

Fractures in the back of Room 7 were mapped in June, 1992. Comparisons with similar maps created in 1991 indicate that the overall lengths of fractures did not increase significantly.

Low-angle fractures continue to appear in the back near the ribs. These fractures are estimated to project at angles less than approximately twenty degrees from horizontal. The depth of fracturing into the rock has been measured up to 0.7 meters $(2.2$ feet) in the past. but generally the openings are not wide enough to allow such measurements to be made. Fracture depths were not estimated or measured during this survey.

The majority of fractures occur along the east side of the room within 2.1 meters ( 7 feet) of the ribs. Although relatively unchanged in length, many of these fractures contained small slabs that were removed. Wire mesh was installed along the east side of the back to contain further spalling.

\section{Room 1, Panel 1 Floor Fractures}

Fractures in the floor of Room 1 were mapped in June 1992. Regularly spaced fractures. averaging approximately 2.1 meters $(6.8$ feet) in length and 2 meters ( 6.5 feet) apart, were found within a 37 meters (120 foot) section along the centerline of the room. Fracture strikes were primarily east-west and dips primarily to the south. A set of fractures approximately 12 meters (40 feet) north of the south bulkhead were found to coincide with a drummy area identified in 1991. A large floor slab was identified 21 to 24 meters (70 to 80 feet) from the south end of the room where existing fractures had extended and intersected forming a rectangular pattern. One continuous fracture parallels the east rib 0.6 to 0.9 meters ( 2 to 3 feet) away and spans eighty percent of the length of the room. Filling with loose salt prevented fracture depth measurements.

\subsection{Observations of Rockbolt Failures}

During this reporting period. each reported rockbolt failure was documented as close to the time of failure as possible and recorded in a database. Figure 3-43 depicts cumulative failures from July 1, 1991, through juine 30, 1992. Some observed failures were noted for inclusion in the database although the actual dates of failure are unknown. Information recorded for each failure include. when possible. the type of failure, location, bolt length and diameter. plate type, and any 
GFDAR

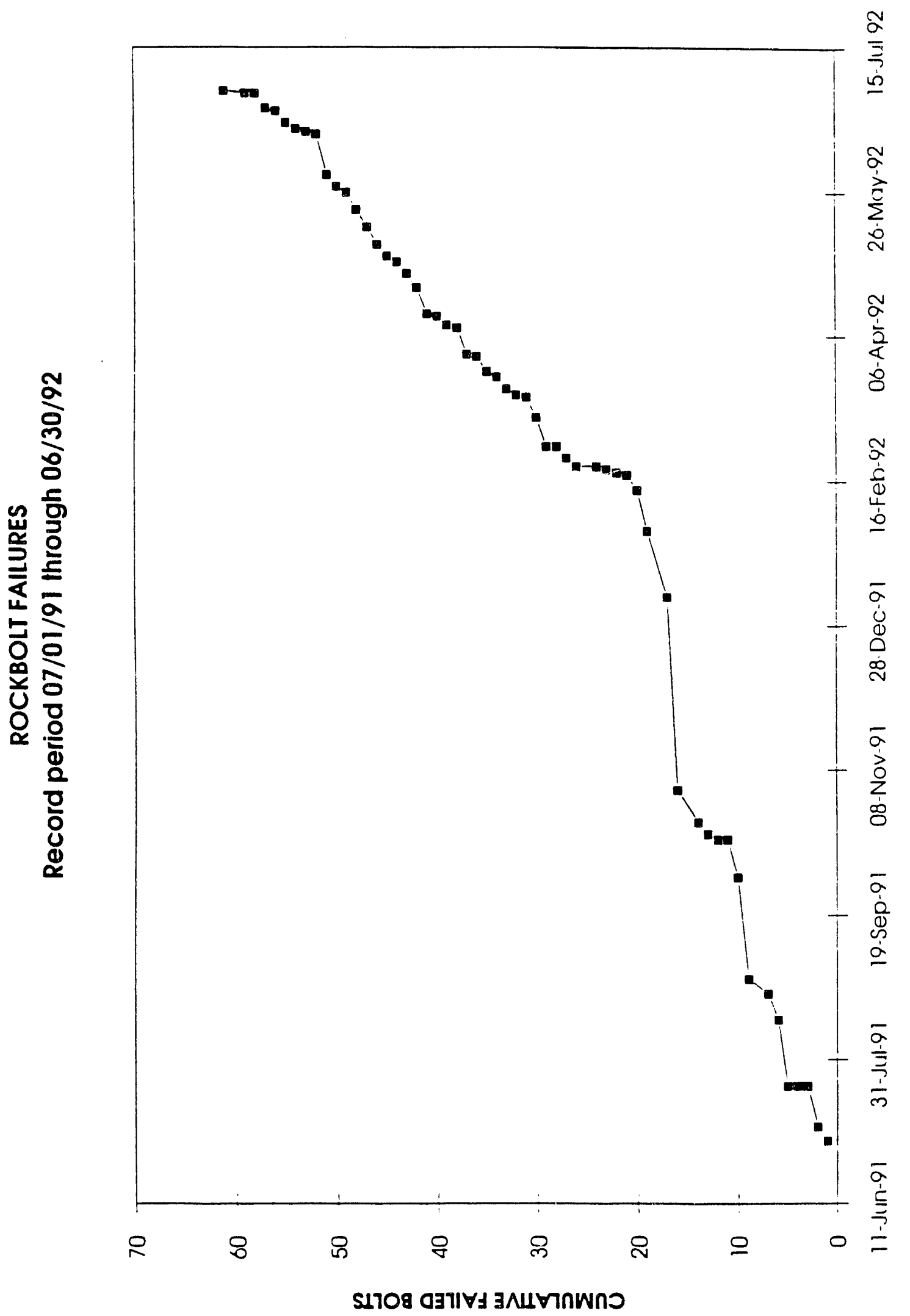

FIGURE 3.43

Plot of Rockbolt Failures in

WIPP Underground Facility 
unusual conditions associated with the installation.

\subsubsection{Failure Mechanisms}

For the purposes of this section, rockbolt failures are divided into ihree categories:

1. Bolt head separating from shaft.

2. Bolt breaking along shaft.

3. Other types of failures, including anchor failures.

Bolt heads fail when the head of the bolt separates from the bolt shaft. The bolts usually have not exhibited necking near the breaks. The exact cause of this type of failure remains undetermined, however it may be attributed to one or more of the following: non-vertical bolt installations: bearing plate not installed parallel to the excavation surface, or overtorquing during installation. If a bolt installation is non-vertical, added stress is induced on one side of the bolt head as the load increases (Figure 3-44). As the salt moves down, one side of the bolt head supports more weight than the other side and the bending moment causes the bolt head to break off. Overtorquing may weaken the bolt, contributing to the conditions which lead to failure.

Failures occurring along the bolt shafts are associated with lateral movements within the strata in which they are installed. Inspections of observation boreholes located near many of these failures otten reveal slip-planes (usually clay layers) lying at approximately the same distance from the excavation as the zones of bolt breakage. Bolts that break along the shaft typically exhibit some degree of bending near the broken ends, indicating that lateral forces were exerted on the bolts.

A small number of bolts experienced failure when the anchor assemblies failed or slipped down the bolthole. These faiiures are believed to be associated with the mechanical aspects of installation.

\subsubsection{Failure Locations}

Rockbolt failures were found at various locations throughout the underground facility during this reporting period. Two thirds of these failures occurred at the heads of the bolts. The remainder were primarily shaft failures.

\section{E300 Shop: N1100 to N1420}

Bolt failures at this location primarily occurred along the shafts, and almost all the bolts exhibitect 


\section{NORMAL INSTALLATION}

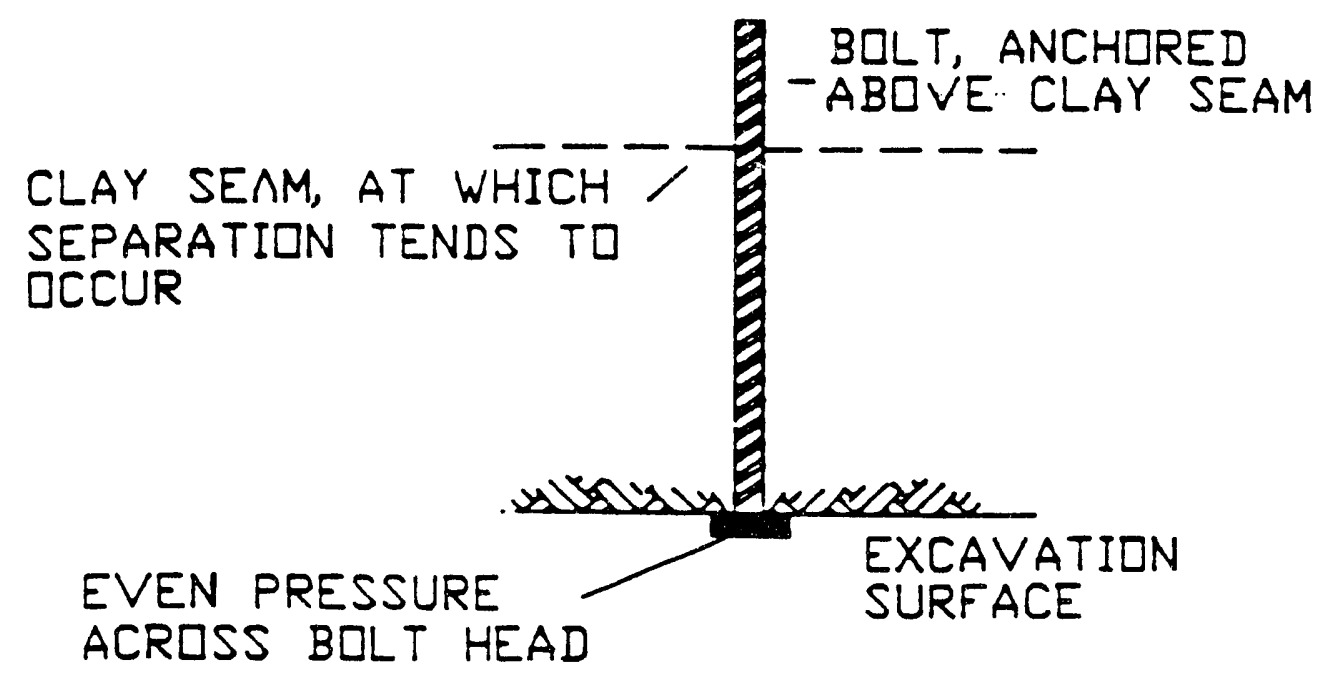

$$
\text { NUN-VERTICAL INSTALLATIDN }
$$

CLAY SEAM, AT WHICH SEPARATION TENDS TO QCCUR

INCREASED PRESSURE

QN SIDE GF BULT HEAD 
some degree of bending at the breaks. These failures are associated with lateral movement at anhydrite "b", which is evident in observation boreholes located in the roof of the shop. Because these bolts were installed almost immediately after excavation, they were affected earlier by the high deformation of the rock immediately after excavation, whereas most bolts in other areas of the facility were installed years after excavation. This may explain the high concentration of bolt failures in this area.

\section{Panel 1}

All boli failures rec ided through June 30, 1992. in Panel 1 were head failures. Many of these failures are locaied in the $\mathbf{S 1 6 0 0}$ and S:950 access drifts. Bolts iristalled in these drifts (and in Room 7) are six feet long and do not penetrate the first major clay layer (clay G). Failure of these bolts is probably due to non-vertical installation. Bolts installed in Storage Rooms 1 through 6 are ten feet long and do penetrate the clay layer. Bolt shaft failures, similar to those in the E300 Shop, are expected to occur in the storage rooms as lateral movement progresses along the clay, although silicon sealant present in these installations may prevent some broken bolts from falling out of the holes.

\section{E140 Drift: $S 1300$ to $\mathbf{S 2 0 6 5}$}

Failures documented for this area during this reporting period included both head and shaft failures. Many of these occurred at approximately $S 1450$ (see Table 3-1). Observation boreholes were drilled in this section of E140 to provide for inspection of the roof to aid in monitoring of fracturing and lateral movement along clay $G$.

\section{General}

Other areas experiencing several rockbolt failures included the west end of the $\$ 1300$ Shop (especially the north and south alcoves), the Salt Shaft station, and Room L4. Failures in these areas are primarily head failures and are variously attributed to non-vertical installations or installations at rib-back corners, which cause eccentric bolt-head loading, or to installation closely following excavation. The database of rockbolt failures is being updated as bolts continue to fail. More investigations will be conducted into the causes and impacts of rockbolt failures in the underground as additional data are collected.

\subsection{Summary of Excavation Effects Program}

Fracture development in the roof is primarily due to the concentration of compressive stresses in the roof beam, and is influenced by the shape of the excavation and stratigraphy in the immediate vicinity of the opening. The buildup of stress with time causes differential movements along 
stratigraphic boundaries. Large strains associated with lateral movements in the roof can induce fracturing in the roof that is frequently seen near the ribs. The presence of horizontal offsetting confirms lateral movements in the roof beam. The results of borehole observations indicate that fracturing continues to increase as the excavations age.

Observations of excavation effects continue to monitor the increased fracturing as the excavations age. These observations are used to provide information for assessing the geotechnical performance of the excavations and installed support systems. 


\subsection{Summary}

During this reporting period a yielding roof support system was installed in Rcom 1. Panel 1 to extend the life of the room through the test phase. In addition to the support system. additional instrumentation was installed for monitoring purposes. The data accumulated since the installation indicate that the system has performed within design specifications over this reporting period.

Rockbolt load cells installed in Room 1. Panel 1 have proven to be useful in determining when to detension the supfort system to provide a yielding system. Monitoring of all Room 1. Panel 1. instrumentation and evaluation of the data collected will continue on a weekly basis.

Due to the observed fracturing in E140 drift between $S 1300$ and $S 1600$ drifts, a supplementary roof support system was installed temporarily until a permanent suppon system is designed. Also, roof extensometers and additional convergence points were installed to monitor bed separation and closure in the vicinity of the roof support system. Unlike the support system in Rciori, 1, Panel 1, the E140 support system is not a detensioning support system.

Fracture development in the roof is primarily caused by the concentration of compressive stresses in the roof beam and is influenced by the shape of the excavation and the stratigraphy in the immediate vicinity of the opening. The buildup of stress with time causes differential movements along stratigraphic boundaries. Large strains associated with lateral movements in the roof can induce fracturing in the roof which is frequently seen near the ribs. The presence of horizontal offsetting confirms that lateral movements occur in the roof beam. The results of excavation effects borehole observations indicate that fracturing continues to increase as the excavations age.

Numerous failed rockbolts were recorded in the E300 Shop during this reporting period. In the interest of satety, wire mesh was installed to prevent any failed rockbolts or debris from falling onto personnel in this highly used area. Most of the rockbolt failures occurred along the rockbolt shafts. and virtually all of the bolts have exhibited some degree of bending at the breaks. These failures are associated with lateral movement at clay $G$. which is evident in observation boreholes located in the roof of the shop. Due to the fact that these bolts were installed almost immediately after excavation, they were affected earlier by the high deformation of the rock immediately after excavation. whereas most bolts in other areas of the facility were installed years after excavation. 
To provide a better understanding of the mechanisms acting in and around the excavations and to evaluate future room conditions. modeling was conducted using FLAC and VISCOT. FLAC was compared to the Sandia Second Benchmark models and was found to predict displacements as well as the Second Benchmark models. In addition. models with varying stratigraphic and rockbolting conditions of the underground were calculated out using FLAC.

In addition to FLAC, the Munson-Dawson constitutive creep law was implemented into VISCOT. Several different cases of the underground were modeled. including a general WIPP storage room. The results were comparable to actual measured convergence data from SPDV Rooms 1. 2. and 4

Modeling has proven to be a useful tool in determining the future conditions of the excavations, and it provides a better understanding of ground conditions. Modeling of underground excavations in various other conditions and configurations will continue. 


\subsection{REFERENCES}

Borns. D.J. and J.C. Stormont. 1988. An interim Report on Excavation-Effects Studies at the Waste Isolation Dilot Plant. The Delineation of the Disturbed Rock Zone. SAND 87-1355. Sandia National Laboratories. Albuquerque, New Mexico.

Callahan. G.D., K.L. DeVries, 1991. Analysis of Backfilled Transuranic Waste Disposal Roems. SAN91-7052. Sandia National Laboratories. Albuquerque. New Mexico.

DOE - See U.S. Department of Energy

Holt. R.M.. and D.W. Powers. 1990. Geologic Maoping of the Air Intake Shaft at the Waste Isolation Pilot Plant, DOE/WIPP 90-051, Waste isolation Pilot Plant. Carlsbad. New Mexico.

INTERA Environmental Consultants. Inc.. 1983. VISCOT. A Two-Dimensional and Axisymmetric Nonlinear Transient Thermoviscoelastic and Thermoviscoplastic Finite-Element Code tor Modeling Time-Dependent Viscous Mechanical Behavior of a Rock Mass, prepared for Battelle Project Management Division, Office of Nuclear Waste Isolation, ONWI-437, Houston. Texas.

Itasca Consulting Group. Inc.. 1988. Thermal-Mechanical Benchmark Testing of FLAC " prepared tor U.S. Nuclear Regulatory Commission Division of Waste Management, NRC-02-85-002. Minneapolis. Minnesota.

Itasca Consulting Group. Inc., 1991, ELAC User's Manual, Minneapolis, Minnesota.

Krieg. R.D., 1984, Reference Stratigraphy and Rock Propenties for the Waste Isolation Pilot Plant (WIPP) Project, SAND 83-1908, Sandia National Laboratories. Albuquerque. New Mexico.

Krieg, R.D., H.S. Morgan, and T.O. Hunter, 1980. Second Benchmark Problem for WIPP Structural Computation, SAND 80-1331, Sandia National Laboratories. Albuquerque. New Mexico.

Morgan. H.S., R.D. Krieg, and R.V. Matalucci, 1981, Comparative Analysis of Nine Structural Codes Used in the Second WIPP Benchmark Problem, SAND81-1389. Sandia National Laboratories. Albuquerque, New Mexico.

Munson. D.E., and P.R. Dawson, 1979. Constitutive Medel for the Low Temperature Creep of Salt (with Application to WIPP), SAND79-1853, Sandia National Laboratories. Albuquerque. New Mexico.

Munson. D.E. and P.R. Dawson, 1982. A Transient Creep Model for Salt During Stress Leading and Unloading, SAND82-0962. Sandia National Laboratories, Albuquerque. New Mexico.

Munson. D.E., A.F. Fossum, and P.E. Senseny, 1989. Advances in Resolution of Discrepancies Between Predicted and Measured in Situ WIPP Room Closure. SAND88-2948. Sandia National Laboratories. Albuquerque. New Mexico.

Sjaardema. G.D.. and R.D. Krieg, 1987. A Constitutive Model for the Consolidation of WIPD Crushed Salt and its Use in Analyses of Backfilled Shatt and Drift Contigurations. SAND87-1977. UC-TO. Sandia National Laboratories. Albuquerque. New Mexico.

Statistical Graphics Corporation, 1990. Statgraphics (Version 4.0).

U.S. Department of Energy, 1983. Summary of the Results of the Evaluation of the WIPP Site and Preliminary Desion Validation Program. WIPP-DOE-161; Waste Isolation Pilot Plant. CarIsbad. New Mexico. 
U.S. Department of Energy, 1984. Design Criteria. Waste Isolation Pilot Plant (WIPP) Revised Mission Concedt-1lA. WIPP-DOE-071; Waste Isolation Pilot Plant, Carisbad, New Mexico.

U.S. Department of Energy, 1985, Quarterly Geotechnical Field Data Report, DOE-WIPP-221; Waste Isolation Pilot Plant, Carlsbad. New Mexico.

U.S. Department of Energy, 1986a, Interim Geotechnical Field Data Report, DOE-WIPP-86-012, Waste Isolation Pilot Plant, Carlsbad, New Mexico.

U.S. Department of Energy. 1986b, Design Validation Final Repon, October 1986, DOE-WIPP-86010; Waste Isolation Pilot Plant. Carlsbad. New Mexico.

U.S. Department of Energy, 1989. Geotechnical Field Data and Analysis Report, July 1987-June 1988 Volume I of II," DOE/WIPP 89-009, Waste Isolation Pilot Plant, Carlsbad, New Mexico.

U.S. Department of Energy, 1989. Waste Retrieval Plan, DOE/WIPP 89-022. Waste Isolation Pilot Plant, Carlsbad, New Mexico.

U.S. Department of Energy, 1990, Geotechnical Field Data and Analysis Reperd, DOE/WIPP 90006. Waste Isolation Pilot Plant, Larlsbad, New Mexico.

U.S. Department of Energy, 1991. Geotechnical Field Data and Analysis Report, DOE.WIPP 91 012. Waste Isolation Pilot Plant. Carlsbad. New Mexico.

U.S. Department of Energy. 1991a. Report of the Geotechnical Panel on the Effective Life of the Rooms in Panel 1, DOE/WIPP 91-023, Waste Isulation Pilot Plant. Carlsbad. New Mexico

U.S. Department of Energy, 1991b. Waste Isolation Pilot Plant Supplementary Roof Support System Underground Storage Area Room 1, Panel 1. DOE/WIPP 91-057, Waste Isolation Pilot Plant. Carisbad. New Mexico.

U.S. Department of Energy 1992a. WIPP Supplementary Roof Support System Room 1 Danel 1 Geotechnical Field Data Analysis Bi-Annual Reoon, DOEiWIPP 92-024, Waste Isolation Pilot Plant. Carlsbad, New Mexico.

U.S. Department of Energy, 1992b, Geotechnical Field Data and Analysis Report, DOE.WIPP 92 010. Waste Isolation Pilot Plant, Carlsbad. New Mexico.

U.S. Department of Energy, 1993, WIPP Supplementary Roof Support System. Room 1, Panel 1 Geotecnnical Field Data Analysis Reoen March 1993. DOE:WIPP 93-012. Waste Isolation Pilot Plant, Carlsbad, New Mexico. 


\section{Appendix A - Munson-Dawson Material Model}

Munson et al. (1989) present a creep model that attempts to resolve the discrepancy between measured and calculated room closure and closure rates. The significant improvements of the model involve a more accurate representation of the transient strain potential curve using a quadratic function that replaces the earlier linear function. Although the steady-state portion of the model formulation remains as initially presented by Munson and Dawson (1979 and 1982). minor improvement has been made 10 it.

Furthermore. the model now uses a Tresca creep flow potential in place of the previously used von Mises flow potential. A brief description of the formulation is presented here. The details can be found in Munson et al. (1989) and Callahan and DeVries (1991).

The modified Munson-Dawson material model defines the inelastic creep strain as follows:

$$
\dot{\varepsilon}_{e}^{c}=F \dot{\varepsilon}_{s}
$$

where $\dot{\varepsilon}_{e}^{c}$ is the invariant inelastic strain-rate measure and $\dot{\varepsilon}$, is the steady-state strain rate.

The transient creep is incorporated through the function $F$. which consists of three branches

$$
F=\left\{\begin{array}{cc}
\exp \left[\Delta\left(1-\frac{\zeta}{\varepsilon_{i}^{f}}\right)^{2}\right] & \zeta<\varepsilon_{i}^{\prime} \\
1 & \zeta=\varepsilon_{!}^{\prime} \\
\exp \left[-\delta\left(1-\frac{\zeta}{\varepsilon_{i}^{\prime}}\right)^{2}\right] & \zeta>\varepsilon_{t}^{\prime}
\end{array}\right.
$$

where $\Delta$ and $\delta$ are the work hardening and recovery parameters. respectively. The internal variable $\zeta$ is governed by the evolutionary equation

$$
\dot{\zeta}=(F-1) \dot{\varepsilon}_{s}
$$

and the transient strain-rate limit $\varepsilon_{t}^{f}$ is given by

$$
\varepsilon_{t}^{\prime}=K_{0} e^{c T}\left(\frac{\sigma_{e}}{\mu}\right)^{m}
$$


where $K_{o}, c, m$, and $\mu$ are material parameters: $T$ is temperature: and $\sigma_{e}$ is an invariant stress measure.

The steady-state strain rate is taken as the sum of the individual strain rates $\left(\dot{\varepsilon}_{s t}\right)$ for the various creep mechanisms acting in parallel to give:

$$
\dot{r}_{s}=\sum_{i=1}^{2} \dot{\varepsilon}_{s t}
$$

where

$$
\begin{aligned}
& \dot{\varepsilon}_{s_{5}}=A_{1}\left(\frac{\sigma_{p}}{\mu}\right)^{n_{3}} \exp \left(-\frac{Q_{1}}{R T}\right) \\
& \dot{\varepsilon}_{s_{2}}=A_{2}\left(\frac{\sigma_{e}}{\mu}\right)^{n_{2}} \exp \left(-\frac{Q_{2}}{R T}\right) \text {, and } \\
& \dot{\varepsilon}_{s_{3}}=\left(\hat{B}_{1} e^{-b / R T}+\hat{B}_{2} e^{-\sigma_{s} / R T}\right) \sinh \left[q\left(\frac{\sigma_{c}-\sigma_{o}}{\mu}\right)\right] H\left(\sigma_{e}-\sigma_{o}\right)
\end{aligned}
$$

in which

$$
\begin{aligned}
\mu & =\text { Normalizing parameter (MPa) } \\
q & =\text { Activation Volume } \\
A_{1}, A_{2}, \hat{B}_{1}, \hat{B}_{2}, & \\
n_{1}, n_{2}, Q_{1}, Q_{2}, \sigma_{o}, & =\text { Experimental constants } \\
R & =1.987 . \text { universal gas constant }\left(\frac{\text { cal }}{\mathrm{mol}-\mathrm{K}}\right) \\
H(.) & =\text { Heaviside step function. }
\end{aligned}
$$

In order to generalize the Munson-Dawson model to three-dimensional states of stress.

Callahan and DeVries (1991) expressed the inelastic tensorial strain-rate $\left(\dot{\varepsilon}_{i j}^{c}\right)$ components as follows:

$$
\dot{\varepsilon}_{i j}^{c}=\dot{\varepsilon}_{e}^{c} \frac{\partial \sigma_{e}^{f}}{\partial \sigma_{\imath}}
$$

where the inelastic strain-rate measure $\left(\dot{\varepsilon}_{e}\right)$ is 


$$
\dot{\varepsilon}_{e}^{i}=\dot{\varepsilon}_{e}^{c}\left(T, \sigma_{e}, \varepsilon_{e}^{i}\right)
$$

and the two invariant stress measures $\left(\sigma_{e}^{\prime}, \sigma_{0}\right)$ are:

$$
\begin{aligned}
& \sigma_{e}^{\prime}=\sigma_{e}^{j}\left(\sigma_{m}, J_{2}, J_{3}\right) \\
& \sigma_{a}=\sigma_{e}\left(\sigma_{m}, J_{2}, J_{3}\right)
\end{aligned}
$$

In these equations. the mean stress $\left(\sigma_{n}\right)$, the second invariant of the deviator stress $\left(J_{2}\right)$, and the third invariant of the deviator stress $\left(J_{3}\right)$ are given by

$$
\begin{aligned}
& \sigma_{m}=\frac{\sigma_{l k}}{3} \\
& J_{z}=\div S_{u s} S_{n} \\
& J_{2}=\div S_{i !} S_{i k} S_{k}
\end{aligned}
$$

where $S_{i f}$ represents the deviatoric stress tensor and repeated indices indicates summation (tensor notation).

The Lode angle $(\Psi)$, which is a convenient alternative to $J_{3}$, is given by

$$
\Psi=\frac{1}{3} \sin ^{-1}\left[\frac{-3 \sqrt{3} J_{2}}{2 J_{2}^{x}}\right], \quad\left(-\frac{\pi}{6} \leq \Psi \leq \frac{\pi}{6}\right)
$$

The partial derivative given earlier is determined using the chain rule

$$
\frac{\partial \sigma_{e}^{f}}{\partial \sigma_{i j}}=\frac{\partial \sigma^{\prime}}{\partial \sigma_{m}} \frac{\partial \sigma_{m}}{\partial \sigma_{i j}}+\frac{\partial \sigma_{0}^{\prime}}{\partial J_{2}} \frac{\partial J_{2}}{\partial \sigma_{i j}}+\frac{\partial \sigma^{\prime}}{\partial \Psi} \frac{\partial \Psi}{\partial J_{3}} \frac{\partial J_{2}}{\partial \sigma_{i \jmath}}
$$



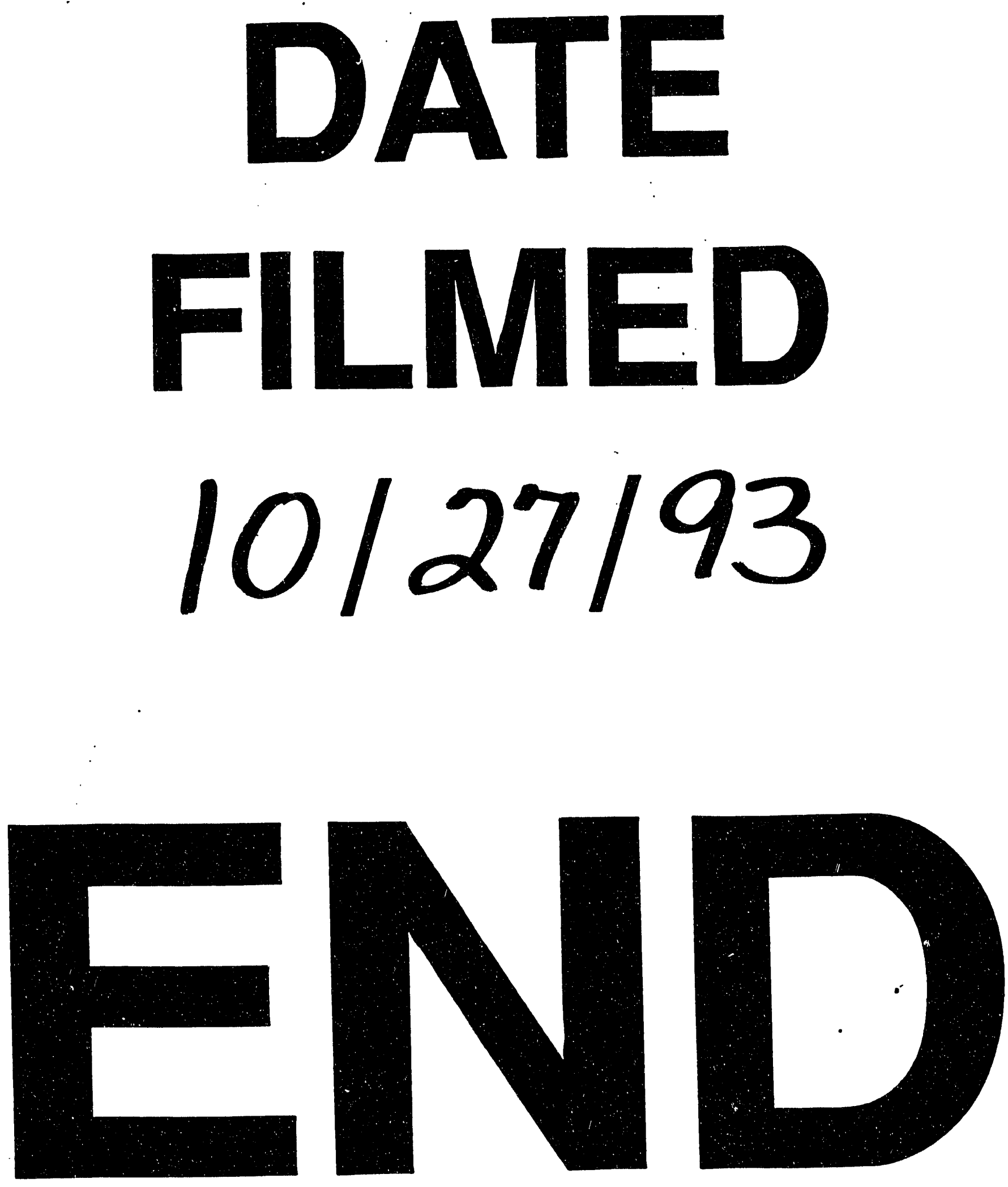
